UNIVERSIDADE DE SÃO PAULO

INSTITUTO DE ASTRONOMIA, GEOFÍSICA E CIÊNCIAS ATMOSFÉRICAS

DEPARTAMENTO DE CIÊNCIAS ATMOSFÉRICAS

\title{
Simulação numérica da influência dos fluxos de superfície em ciclones na costa leste do sul do Brasil
}

\author{
Luiz Felippe Gozzo
}

\author{
Dissertação de Mestrado \\ Orientadora \\ Prof ${ }^{\text {a }}$ Dra. Rosmerí Porfírio da Rocha
}

São Paulo, Abril de 2010 



\title{
LUIZ FELIPPE GOZZO
}

\author{
Simulação numérica da influência dos fluxos de \\ superfície em ciclones na costa leste do sul do Brasil
}

Tese apresentada ao Instituto de Astronomia, Geofísica e Ciências Atmosféricas da Universidade de São Paulo para obtenção do título de Mestre em Meteorologia

Orientadora: Prof ${ }^{\mathrm{a}}$. Doutora

Rosmeri Porfírio da Rocha

São Paulo 

Dedico este trabalho aos meus pais, José Roberto Gozzo e Vera Lucia Gozzo, os maiores incentivadores do meu sonho. 



\section{AGRADECIMENTOS}

- À minha orientadora, Dra. Rosmeri Porfírio da Rocha, pela orientação, conhecimentos transmitidos e enorme paciência. Sem o seu impulso desde a graduação, eu talvez não chegasse até aqui;

- Ao CNPq e à CAPES, pelo apoio financeiro;

- À minha família, meus pais José Roberto e Vera Lucia, tia Maria Aparecida e vó Letícia, que sempre me apoiaram incondicionalmente e me ensinaram a ser a pessoa de bem que eu tento ser;

- A todos os professores do IAG que contribuíram para a minha formação;

- Aos funcionários da seção de Informática, biblioteca e gráfica do IAG, sempre muito atenciosos;

- À amiga Clara Miho Narukawa Iwabe, que sempre me apoiou, fez sugestões construtivas a este trabalho, e sempre me recebia com toda a paciência quando eu chegava e dizia "Clara, posso fazer só uma perguntinha?". E à amiga Michelle Simões Reboita, que avaliou a primeira versão do texto desta dissertação;

- À amiga e colega de sala Angélica Tavares Ferreira, pela amizade, companheirismo e paciência durante estes dois anos. Ninguém suportou mais minhas oscilações de humor durante este período, sempre me encorajando e me ajudando;

- A todos os meus amigos, que graças a Deus são muitos para citar nesse pequeno espaço. Os amigos da hora do café da tarde, os colegas do mestrado, os amigos das festas e "coizzz", os que sempre me colocam pra cima - às vezes aos pontapés -, os que suportam minha ansiedade e aqueles que estão longe, mas sempre entendem os meus "desaparecimentos" quando preciso me dedicar à faculdade. E à pessoa especial de quem eu sempre vou me lembrar quando olhar para essa dissertação. 

"É como se tivesse sido apenas um menino brincando na praia, divertindo-se de vez em quando ao encontrar um seixo mais arredondado ou uma concha mais bonita do que o normal, enquanto o grande oceano da verdade permanecia totalmente inexplorado diante de mim."

Sir Isaac Newton 



\section{RESUMO}

\section{GOZZO, L. F. Simulação numérica da influência dos fluxos de superfície em ciclones na}

costa leste do sul do Brasil. 121 p. Dissertação (Mestrado) - Institudo de Astronomia, Geofísica e Ciências Atmosféricas (IAG), Universidade de São Paulo, 2010.

O papel dos fluxos de superfície de calor sensível e latente (FCSL) em dois ciclones extratropicais com desenvolvimento distinto na costa do sul do Brasil foi avaliado a partir de simulações numéricas utilizando o modelo de área limitada WRF versão 2.2. Em um dos ciclones, a circulação se originou em baixos níveis e propagou-se para a média troposfera (ciclone 1). No outro ciclone (ciclone 2) a circulação originou-se em níveis médios e propagou-se até a superfície. Foram realizadas simulações numéricas com e sem FCSL para cada um dos ciclones. A trajetória do ciclone 1 foi fortemente alterada na ausência de FCSL, exibindo deslocamento incorreto (para nordeste) e menor tempo de vida. Este comportamento esteve associado às mudanças no padrão de advecção de temperatura em baixos níveis e à diminuição da convergência de massa induzida pelo calor sensível, na ausência de FCSL. No experimento sem FCSL, ocorre também desacoplamento entre o ciclone em superfície e a onda em níveis médios e altos, com consequente enfraquecimento do sistema. $\mathrm{O}$ aumento da estabilidade estática e o mecanismo de convergência de Ekman são responsáveis por menor convergência nas regiões frontais na ausência de FCSL. A relação de fase entre os campos de altura geopotencial e temperatura em baixos níveis e o perfil vertical de aquecimento diabático também mostram condições mais favoráveis ao desenvolvimento do ciclone na presença dos FCSL. O ciclone 2 não teve a trajetória alterada entre as duas simulações. A advecção de temperatura e a convergência em baixos níveis devido ao calor sensível foram semelhantes, explicando a similaridade na trajetória nos experimentos com e sem FCSL. A convergência de Ekman diferenciou-se entre as duas simulações, especialmente no final do ciclo de vida do ciclone, mostrando que este processo também altera a intensidade de ciclones fracos. A influência dos FCSL mostrou-se dependente do mecanismo dominante de formação dos ciclones. O ciclone 1, com forçante dinâmica menos intensa, sofreu grandes variações em trajetória e tempo de vida na ausência de FCSL. Já o ciclone 2, sob forçante dinâmica mais definida e intensa, mostrou-se menos dependente dos processos de superfície para o seu deslocamento. Os mecanismos de aprofundamento foram mais intensos no ciclone 1.

Palavras-chave: Ciclone extratropical. Interação oceano-atmosfera. 



\begin{abstract}
GOZZO, L. F. Numerical simulation of the role of surface heat and moisture fluxes in cyclones at the southeastern coast of Brasil. 121 p. Dissertação (Mestrado) - Institudo de Astronomia, Geofísica e Ciências Atmosféricas (IAG), Universidade de São Paulo, 2010.
\end{abstract}

The role of latent and sensible heat fluxes (LSHF) between ocean and atmosphere during the development of two extratropical cyclones over the southwestern Atlantic Ocean is analyzed using the WRF (Weather Range and Forecast) Mesoscale Model, version 2.2. In cyclone 1, the circulation has originated in low levels and propagated to the middle troposphere; the cyclone 2's circulation has originated in middle levels propagating towards the surface during its life cycle. The trajectory of cyclone 1 was strongly influenced by the surface heat fluxes, showing an incorrect displacement and a shorter lifetime in the absence of these fluxes. This behavior is associated with changes in low level temperature advection and the reduction of low level mass convergence is induced by sensible heat fluxes from surface. In the absence of LSHF there is also a decoupling of the surface low and the upper level wave, causing the weakening of the system. Without surface fluxes, the higher static stability and the weaker Ekman convergence mechanism are responsible for less convergence in the frontal regions of the cyclone. The lagging of the geopotential wave and the temperature wave in low levels, and the diabatic heating profile in the troposphere also show more favorable conditions to the cyclone deepening in the presence of surface fluxes. The trajectory of cyclone 2 showed no significant modification in the absence of LSHF. The temperature advection field is similar and the low level convergence related to sensible heat fluxes didn't has an impact on the displacement of this system. The Ekman convergence had smaller magnitude in the no-LSHF simulation, especially in the final stages of the cyclone life cycle, indicating that this mechanism can be important also for the deepening of weak systems and not only for explosive systems, as considered in previous studies. This work shows that the role of the LSHF seems to be dependent on the cyclone development main mechanisms. In cyclone 1, where the dynamic forcings are less intense, the absence of surface fluxes had a great impact on the trajectory, intensity and duration of the system. In cyclone 2, with more intense dynamic forcings, the displacement was less influenced by surface processes. The deepening mechanisms had greater impact on the cyclone 1.

Keywords: Extatropical cyclogenesis. Air-sea interaction. 



\section{LISTA DE FIGURAS}

Figura 2.1: Esquema do desenvolvimento de um ciclone extratropical no Hemisfério Sul (Adaptado de CARLSON (1998), por IWABE (2008)). As linhas contínuas representam a altura geopotencial em $500 \mathrm{hPa}$, as linhas tracejadas são os contornos de vorticidade relativa em $500 \mathrm{hPa}$. Os sistemas frontais em superfície estão marcados com a simbologia habitual, e L representa a posição da baixa pressão em superfície. A seta indica a região de máxima velocidade do vento geostrófico.

Figura 2.2: Ciclo de vida de um ciclone do tipo Shapiro-Keyser, no hemisfério Sul. Acima: pressão ao nível do mar (linhas sólidas) e regiões frontais; abaixo: temperatura do ar (linhas sólidas) e correntes fria (seta sólida) e quente (seta tracejada) (Adaptado de Neiman e Shapiro, 1993) .23

Figura 2.3: (a) Esquema mostrando o processo de enfraquecimento da circulação ciclônica pelo bombeamento de Ekman (BOUTLE, 2009). (b) Circulação secundária forçada pelo atrito em uma atmosfera baroclínica (HOLTON, 2004). "De" indica a profundidade da camada de Ekman .25

Figura 2.4: Esquema da circulação geral de grande escala na superfície do oceano Atlântico Sul (PETERSON e STRAMMA, 1991) 30

Figura 2.5: Média dos fluxos de (a) calor sensível e (b) calor latente sobre os oceanos, em W $\mathrm{m}^{-2}$, no período de 1958 a 2008. Fonte: Objectively Analyzed Air-Sea Fluxes Project, WHOI,

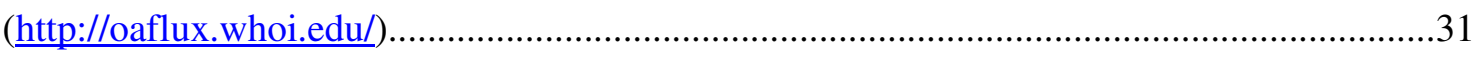

Figura 3.1: Coordenada vertical $\eta$ as superfícies $p_{h s}$ e $p_{h t}$ (SKAMAROCK et al., 2005)......34

Figura 3.2: Grades horizontal e vertical do ARW (adaptado de SKAMAROCK et al., 2005) .38

Figura 3.3: Zonas especificada e de relaxação para uma grade com uma coluna de zona especificada e quatro pontos para a zona de relaxação (valores típicos utilizados para uma simulação a partir de dados reais). 
Figura 4.1: (a) PNMM (linha contínua, em hPa) e temperatura do ar (linha tracejada, em K) em $925 \mathrm{hPa}$; (b) altura geopotencial (linha contínua, em m) e temperatura do ar (sombreado, em K) em $500 \mathrm{hPa}$. (c) geopotencial (linha contínua, em m) e advecção de vorticidade relativa em $250 \mathrm{hPa}$ (sombreado, em x10 ${ }^{-9} \mathrm{~s}^{-2}$ ); (d) advecção de temperatura em $850 \mathrm{hPa}\left(\mathrm{Kdia}^{-1}\right)$, para 1200 UTC de 27 de maio de 1997.

Figura 4.2: Idem à figura 4.1, válida para 1200 UTC de 28 de maio de 1997. .57

Figura 4.3: Idem à figura 4.1, válido para 1200 UTC de 29 de maio de 1997. .58

Figura. 4.4: (a) Temperatura potencial equivalente (K) e vetor vento horizontal $\left(\mathrm{ms}^{-1}\right)$ em 925 $\mathrm{hPa}$, (b) Divergência (linhas tracejadas, em $\times 10^{-5} \mathrm{~s}^{-1}$, apenas valores negativos) e vorticidade relativa ciclônica (sombreada, em $\times 10^{-5} \mathrm{~s}^{-1}$ ) do vento horizontal e (c) imagem do satélite GOES-8 no canal infravermelho, para o dia 29 de maio de 1997 às 0000 UTC. .59

Figura 4.5: (a) Advecção de temperatura em $850 \mathrm{hPa}\left(\mathrm{K} \mathrm{dia}^{-1}\right)$ e (b) altura geopotencial (linha contínua, em m) e temperatura do ar em $500 \mathrm{hPa}$ (sombreado, em K) para 30 de maio de 1997, às 0000 UTC. 59

Figura 4.6: Idem à figura 4.1, válido para 0000 UTC de 31 de maio de 1997. .60

Figura 4.7: Perfil vertical de vorticidade relativa ciclônica $\left(\times 10^{-4} \mathrm{~s}^{-1}\right)$ na latitude do centro do ciclone em (a) 28 de maio, (b) 29 de maio, (b) 30 de maio e (d) 31 de maio de 1997, 0000 UTC......

Figura 4.8: (a) Temperatura potencial equivalente $(\mathrm{K})$ e vetor vento horizontal $\left(\mathrm{ms}^{-1}\right)$, e (b) vorticidade relativa (sombreado, em $\times 10^{-5} \mathrm{~s}^{-1}$ ) e divergência (linha tracejada, em $\times 10^{-5} \mathrm{~s}^{-1}$, apenas valores negativos) do vento horizontal em $925 \mathrm{hPa}$, para 1200 UTC de 31 de maio de 1997, segundo a reanálise Era-Interim.

Figura 4.9: PNMM (linha contínua, em hPa) e temperatura do ar em $925 \mathrm{hPa}$ (linha traceada, em K), da reanálise Era-Interim para os dias (a) 29, (c) 30, (e) 31 de maio e (g) 04 de junho, 0000 UTC; e EXPCOM97 para os dias (b) 29, (d) 30 e (f) 31 de maio e (h) 04 de junho, 0000 UTC.

Figura 4.10: Altura geopotencial (linha contínua, em m) e temperatura do ar (sombreado, em K) segundo a reanálise Era-Interim para os dias (a) 30 de maio às 0000 UTC, (c) 31 de maio 
às 1200 UTC e (e) 01 de junho às 0000 UTC, e segundo o EXPCOM97 para os dias (b) 30 de maio às 0000 UTC, (d) 31 de maio às 1200 UTC e (f) 01 de junho às 0000 UTC .65

Figura 4.11: Temperatura potencial equivalente $(\mathrm{K})$ e vetor vento em $925 \mathrm{hPa}$ para (a) a reanálise Era-Interim e (b) EXPCOM97; vorticidade relativa ciclônica (sombreado, $\times 10^{-5} \mathrm{~s}^{-1}$ ) e divergência (linha tracejada, $\times 10^{-5} \mathrm{~s}^{-1}$, apenas valores negativos) do vento horizontal em 925 hPa para (c) a reanálise Era-Interim e (d) EXPCOM97, para o dia 31 de maio de 1997 às 0000 UTC. .66

Figura 4.12: PNMM (linha contínua, em hPa) segundo a reanálise Era-Interim e fluxo de calor sensível (sombreado, em $\mathrm{Wm}^{-2}$ ) segundo a reanálise WHOI para os dias (a) 28, (c) 29, (e) 30 e (g) 31 de maio de 1997, e segundo o EXPCOM97 para os dias (b) 28, (d) 29, (f) 30 e (h) 31 de maio de 1997 .68

Figura 4.13: PNMM (linha contínua, em $\mathrm{hPa}$ ) segundo a reanálise Era-Interim e fluxo de calor latente (sombreado, em $\mathrm{Wm}^{-2}$ ) segundo a reanálise WHOI para os dias (a) 28, (b) 29, (c) 30 e (d) 31 de maio de 1997 e segundo o EXPCOM97 para os dias (b) 28, (d) 29, (f) 30 e (h) 31 de maio de 1997 (b, d, f, h).

Figura. 4.14: (a) Altura geopotencial (sombreado, em m) e temperatura do ar (linha tracejada, em K) em $500 \mathrm{hPa}$; (b) Vorticidade potencial isobárica (sombreado, em UVP) em $350 \mathrm{hPa}$ e altura geopotencial (linha contínua, em m) em $500 \mathrm{hPa}$, para as 1200 UTC de 12 de abril de 2000 70

Figura 4.15: (a) PNMM (hPa) e temperatura do ar em $925 \mathrm{hPa}$; (b) altura geopotencial (m) e temperatura do ar (K) em $500 \mathrm{hPa}$. (c) geopotencial (m) e advecção de vorticidade relativa em $250 \mathrm{hPa}\left(\mathrm{x} 10^{-9} \mathrm{~s}^{-2}\right)$; advecção de temperatura em $850 \mathrm{hPa}\left(\mathrm{Kdia}^{-1}\right)$, para 13 de abril de 2000 às 0000 UTC .72

Figura 4.16: Idem à figura 4.15, válido para 13 de abril de 2000 às 1200 UTC .73

Figura 4.17: Idem à figura 4.15, válido para 14 de abril de 2000 às 1200 UTC. .74

Figura 4.18: (a) Temperatura potencial equivalente (K) e vetor vento horizontal em $925 \mathrm{hPa}$; (b) Vorticidade relativa ciclônica (sombreado, $\times 10^{-5} \mathrm{~s}^{-1}$ ) e divergência do vento horizontal 
(linha tracejada, $\times 10^{-5} \mathrm{~s}^{-1}$, apenas valores negativos) em $925 \mathrm{hPa}$, para o dia 14 de abril de 2000 às 1200 UTC.

Figura 4.19: (a) PNMM (linha contínua, em hPa) e temperatura do ar (linha tracejada, em K) em $925 \mathrm{hPa}$ e (b) altura geopotencial (linha contínua, em m) e temperatura do ar (sombreado, em K) em $500 \mathrm{hPa}$, para o dia 15 de abril de 2000, 0000 UTC

Figura 4.20: Pressão ao nível do mar (linha contínua, em hPa) e temperatura do ar (linha tracejada, em K) em 925 hPa para (a) 15 de abril de 2000, 1200 UTC e (b) 16 de abril de 2000, 0000 UTC 75

Figura 4.21: Perfil vertical de vorticidade relativa ciclônica $\left(\times 10^{-4} \mathrm{~s}^{-1}\right)$ na latitude do centro do ciclone em (a) 13 de abril de 2000 às 0000 UTC; (b) 14 de abril de 2000 às 0000 UTC; (c) 15 de abril de 2000 às 0000 UTC.

Figura 4.22: PNMM (linha contínua, em m) e temperatura do ar (linha tracejada, em K) para os dias 13, 14 e 15 de abril de 2000, 0000 UTC, para (a, c, e) a reanálise Era-Interim e (b, d, f) a simulação EXPCOM00.

Figura 4.23: Altura geopotencial (linha contínua, em m) e temperatura do ar (linha tracejada, em K) em 500 hPa para os dias 13-16 de abril de 2000 para (a, c, e g) a reanálise Era-Interim e (b, d, f, h) a simulação EXPCOM00. .79

Figura 4.24: PNMM (linha contínua, em hPa) segundo a reanálise Era-Interim e fluxo de calor sensível (sombreado, em $\mathrm{Wm}^{-2}$ ) segundo a reanálise WHOI para os dias (a) 13, (c) $14 \mathrm{e}$ (e) 15 de abril de 2000, e segundo o EXPCOM00 para os dias (b) 13, (d) 14 e (f) 15 de abril de 2000. .80

Figura 4.25: PNMM (linha contínua, em hPa) e fluxo de calor latente (sombreado, em $\mathrm{Wm}^{-2}$ ) no dia 14 de abril de 2000. (a) WHOI (b) EXPCOM00.

Figura 4.26: Temperatura do ar a $2 \mathrm{~m}(\mathrm{~K})$ e umidade específica a $2 \mathrm{~m}\left(\mathrm{gkg}^{-1}\right)$ médios no dia 14 de abril de 2000. para (a, c) a reanálise WHOI e (b, d) EXPCOM00. 82

Figura 4.27: Trajetória do ciclone segundo a reanálise Era-Interim (linha preta), EXPCOM (linha vermelha) e EXPSEM (linha azul). As três trajetórias se iniciam às 0000 UTC do dia 28 de maio de 1997 e os pontos estão marcados a cada 12 horas. .83 
Figura 4.28: Advecção de temperatura em $850 \mathrm{hPa}\left(\mathrm{Kdia}^{-1}\right)$ no (a) EXPCOM97 e no (b) EXPSEM97 (c); diferença da divergência do vento a $10 \mathrm{~m}$ (valores negativos indicam maior convergência na simulação EXPCOM). Altura geopotencial (linha contínua, em m) e advecção de vorticidade relativa (sombreado, em x $10^{-9} \mathrm{~s}^{-2}$ ) em $250 \mathrm{hPa}$ no (d) EXPCOM e (d) EXPSEM, para o dia 28 de maio de 1997 às 1200 UTC. O círculo preto indica a posição da baixa em superfície

Figura. 4.29: Advecção de temperatura em $850 \mathrm{hPa}\left(\mathrm{Kdia}^{-1}\right)$ e vento horizontal e temperatura do ar (K) em $850 \mathrm{hPa}$, para 29 de maio de 1997 às 0000 UTC, para o EXPCOM97 (a,b) e o EXPSEM97 (c,d). O círculo preto indica a posição da baixa em superfície .86

Figura 4.30: Altura geopotencial (linha sólida, em m) e advecção de vorticidade relativa (sombreado, em x $10^{-9} \mathrm{~s}^{-2}$ ) em $250 \mathrm{hPa}$ para o (a) EXPCOM e o (b) EXPSEM, para $29 \mathrm{de}$ maio de 1997, 0000 UTC. O círculo preto indica a posição da baixa em superfície. .87

Figura 4.31: Altura geopotencial (linha sólida, em $\mathrm{m}$ ) e advecção de vorticidade relativa (sombreado, em x $10^{-9} \mathrm{~s}^{-2}$ ) em $250 \mathrm{hPa}$ no (a) EXPCOM97 e no (b) EXPSEM97, para o dia 30 de maio de 1997 às 1200UTC. O círculo preto indica a posição da baixa em superfície .88

Figura 4.32: PNMM (linha sólida, em hPa) e pseudo velocidade vertical (sombreado, em Pas $^{-1}$ ) em 700 hPa para o dia 30 de maio de 1997 às 0000 UTC, para o (a) EXPCOM97 e o (b) EXPSEM97.

Figura 4.33: PNMM(linha sólida, em hPa) e precipitação convectiva acumulada em $24 \mathrm{~h}$ (sombreado, em mm) para o dia 30 de maio de 1997, no (a) EXPCOM97, no (b) EXPSEM97, e na (c) análise GPCP .89

Figura 4.34: Altura geopotencial (linha sólida, em m) e temperatura potencial (sombreado, em K) em $500 \mathrm{hPa}$, para os dias 30 e 31 de maio de 1997. (a), (c) EXPCOM97 e (b), (d) EXPSEM97. O círculo preto indica a posição da baixa em superfície 
Figura 4.35: Trajetória do ciclone segundo a reanálise Era-Interim (linha preta), EXPCOM (linha vermelha) e EXPSEM (linha azul). As três trajetórias se iniciam às 0000 UTC do dia 13 de abril de 2000 e os pontos estão marcados a cada 12 horas. .91

Figura 4.36: Advecção de temperatura em $850 \mathrm{hPa}\left(\mathrm{Kdia}^{-1}\right)$ para os dias 13 e 14 de abril de 2000 às 0000 UTC, para o $(a, c)$ EXPCOM00 e para o $(b, d)$ EXPSEM00.

Figura 4.37: (a) Imagem do satélite GOES-8, canal infravermelho; (b) PNMM (linha contínua, em hPa) e diferença da quantidade de água de nuvem + água de chuva (sombreado, em kgkg-1) no nível de 500 hPa entre o EXPCOM00 e o EXPSEM00, altura geopotencial (linha contínua, em m) e temperatura do ar (sombreado, em K) para o (c) EXPCOM00 e o (d) EXPSEM00, para o dia 14 de abril de 2000 às 0000 UTC .93

Figura 4.38: Altura geopotencial (linha sólida, em m) e temperatura do ar (sombreado, em K) em $500 \mathrm{hPa}$ para o (a) EXPCOM00 e o (b) EXPSEM00, para o dia 15 de abril de 2000 às 0000 UTC. .94

Figura 4.39: Evolução temporal de pressão central para o (a) ciclone 1 e (b) ciclone 2. A linha preta representa a reanálise ERA-Interim, a linha vermelha a simulação EXPCOM e a linha azul a simulação EXPSEM. .96

Figura. 4.40: Vorticidade relativa (sombreado, $\times 10^{-5} \mathrm{~s}^{-1}$ ) e divergência (linha tracejada, em $\mathrm{x} 10^{-5} \mathrm{~s}^{-1}$, apenas valores negativos) do vento horizontal em $925 \mathrm{hPa}$, para o dia 31 de maio de 1997 às 0000 UTC, para o (a) EXPCOM97 e o (b) EXPSEM97. 97

Figura 4.41: Distribuição horizontal de estabilidade estática $\left(\mathrm{m}^{2} \mathrm{~s}^{-2} \mathrm{~Pa}^{-2}\right)$ para o dia 30 de maio de 1997, 0000 UTC, no (a) EXPCOM e (b) EXPSEM. .98

Figura 4.42: Distribuição horizontal de estabilidade estática $\left(\mathrm{m}^{2} \mathrm{~s}^{-2} \mathrm{~Pa}^{-2}\right)$ para o dia 30 de maio de 1997, 0000 UTC, no (a) EXPCOM97 e (b) EXPSEM97 . .98

Figura 4.43: Rotacional da tensão do vento $\left(\mathrm{em} \mathrm{cm} \mathrm{s}^{-1}\right.$ ) em $925 \mathrm{hPa}$, em 30 de maio de 1997 às 0000 UTC, para o (a) EXPCOM97 e (b) EXPSEM97. . .99

Figura 4.44: Rotacional da tensão do vento $\left(\mathrm{em} \mathrm{cm} \mathrm{s}^{-1}\right)$ em $925 \mathrm{hPa}$, para o EXPCOM00 nos dias (a) 13, (c) 14 e (e) 15 de abril de 2000 e para o EXPSEM00 nos dias (b) 13, (d) 14 e (f) 15 de abril de 2000, às 0000UTC 101 
Figura 4.45: Altura geopotencial (linha contínua, em m) e temperatura do ar (sombreado, em K) em $850 \mathrm{hPa}$, para o (a),(c),(e) EXPCOM97 e (b),(d),(f) EXPSEM97, para os dias 29, 30 e 31 de maio de 1997 às 0000 UTC. 103

Figura 4.46: Altura geopotencial (linha contínua, em m) e temperatura do ar (sombreado, em K) em $850 \mathrm{hPa}$, para o (a),(c),(e) EXPCOM00 e (b),(d),(f) EXPSEM00, para os dias 29, 30 e 31 de maio de 1997 às 0000 UTC 105

Figura 4.47: Perfis médios na área de aquecimento diabático $\left(\mathrm{Kh}^{-1}\right)$ (a) para o dia 29 de maio de 1997 às $1200 \mathrm{UTC}$, entre $48^{\circ} \mathrm{W}-35^{\circ} \mathrm{W}$ e $32^{\circ} \mathrm{S}-25^{\circ} \mathrm{S}$ no caso EXPCOM97 (linha contínua) e entre $50^{\circ} \mathrm{W}-40^{\circ} \mathrm{W}$ e $30^{\circ} \mathrm{S}-22^{\circ} \mathrm{S}$ no EXPSEM97 (linha tracejada) e (b) para o dia 13 de abril de $2000,1200 \mathrm{UTC}$, entre $51^{\circ} \mathrm{W}$ e $41^{\circ} \mathrm{W}$ e $33^{\circ} \mathrm{S}$ e $26^{\circ} \mathrm{S}$ para o EXPCOM00 e o EXPSEM00...106 



\section{LISTA DE TABELAS}

Tabela 3.1. Características das simulações do ciclone 1 .......................................................51

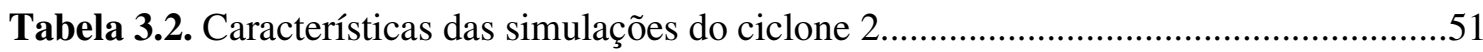





\section{SUMÁRIO}

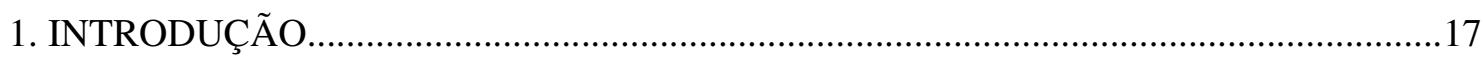

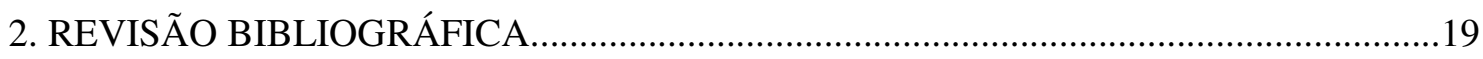

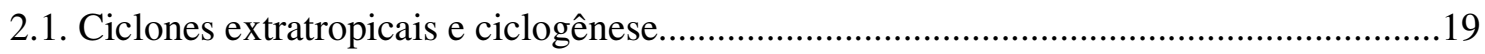

2.1.1. Ciclogênese e desenvolvimento clássico.................................................................19

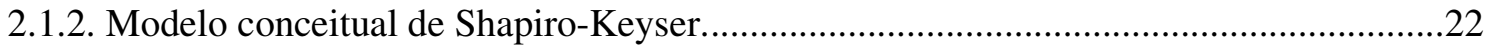

2.1.3. Processos na média-alta troposfera influenciando a ciclogênese extratropical..............23

2.1.4. Processos de camada limite planetária influenciando a ciclogênese extratropical.........24

2.2. Fluxos de calor e umidade de superfície influenciando a ciclogênese extratropical.........26

2.3. Regiões ciclogenéticas da América do Sul..................................................................29

2.4. Circulação oceânica e FCSL na costa leste do sul do Brasil.............................................30

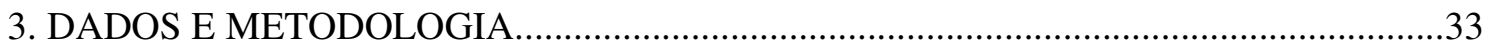

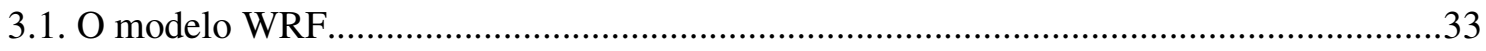

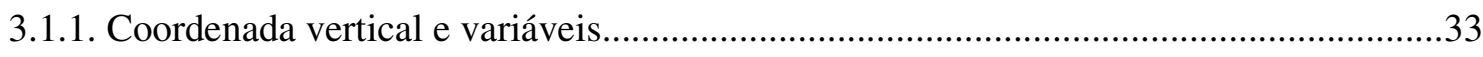

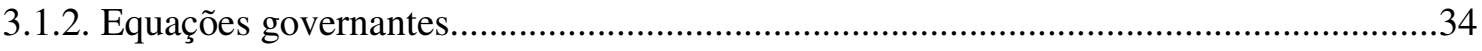

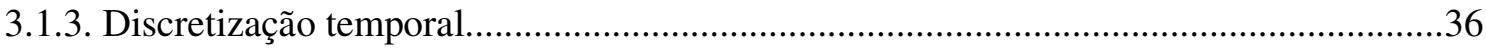

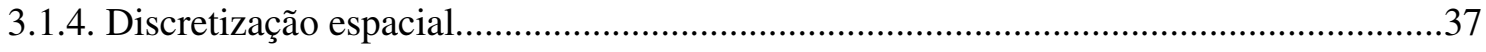

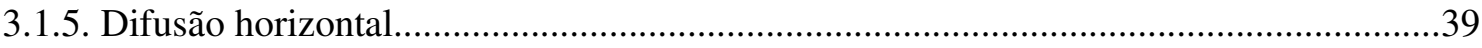

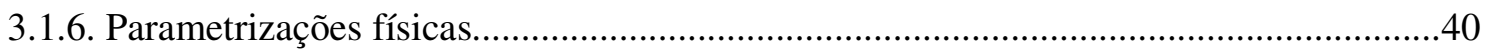

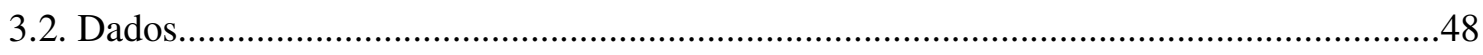

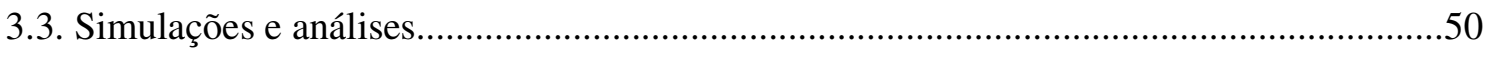

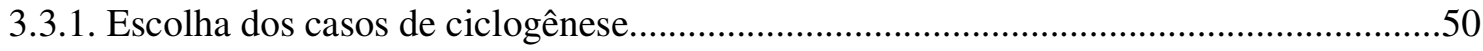




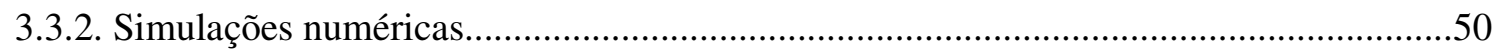

3.3.3. Metodologia de análise das simulações...........................................................................50

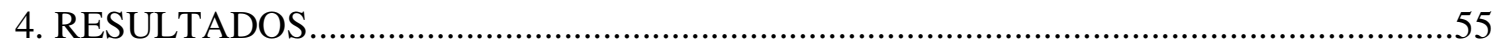

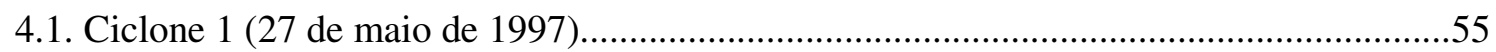

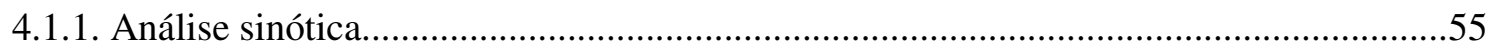

4.1.2. FCSL associados ao ciclone e validação do EXPCOM97 ............................................62

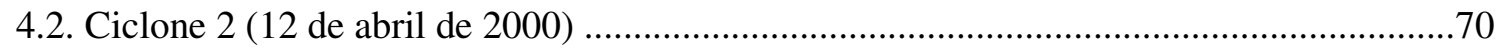

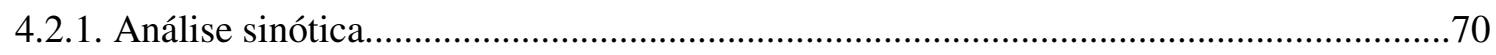

4.2.2. FCSL associados ao ciclone e validação do EXPCOM00 .............................................77

4.3. Influência dos FCSL no deslocamento e estrutura vertical dos sistemas.........................83

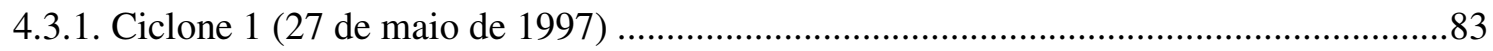

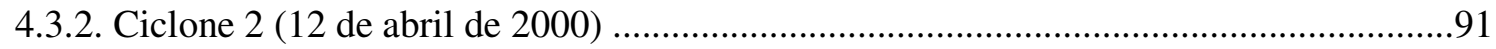

4.4. Outras influências dos FCSL na intensificação dos ciclones..........................................95

4.4.1. Convergência friccional dentro da CLP nas regiões frontais.......................................97

4.4.2. Fase entre as ondas de temperatura e geopotencial em baixos níveis...........................102

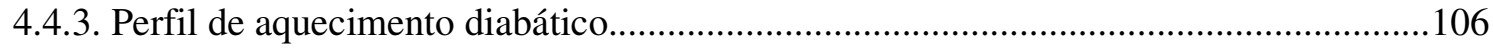

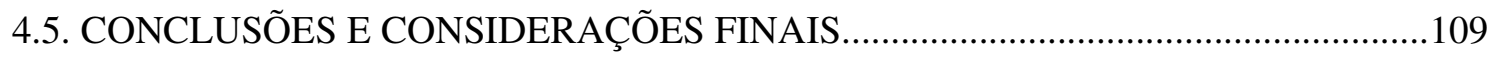

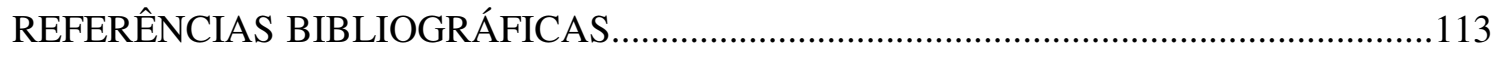




\section{INTRODUÇÃO}

Os ciclones extratropicais são os principais responsáveis pela mudança de tempo no dia-a-dia nas latitudes médias, estando muitas vezes associados a eventos severos. Os mecanismos de gênese e desenvolvimento destes sistemas têm sido amplamente estudados desde os trabalhos pioneiros de Bjerknes, e hoje é bem estabelecido que estes ciclones são formados basicamente por consequência dos gradientes de temperatura meridionais no planeta. Porém, muitas outras forçantes podem influenciar este processo, tais como a topografia da superfície (GAN e RAO, 1994), a liberação de calor latente por convecção (GUTOWSKI e JIANG, 1998), a interação troposfera-estratosfera (HOSKINS, 1985), etc.

Uma importante fonte de energia que influencia o desenvolvimento de ciclones extratropicais são os fluxos de superfície de calor sensível e latente (FCSL), especialmente sobre os oceanos. O real papel destes fluxos, e a maneira como afetam os sistemas atmosféricos é um tópico controverso. Alguns estudos mostram que a presença dos FCSL intensificam as circulações ciclônicas (KUO e LOW-NAM, 1990; CHANG, 1996; DAL PIVA, 2008), aquecendo a baixa troposfera e aumentando a liberação de calor latente por processos convectivos, favorecendo o abaixamento de pressão. Outros estudos mostram que tais fluxos podem enfraquecer certos sistemas (BRANSCOMBE et al., 1989; REED e SIMMONDS, 1991), através da desintensificação de zonas baroclínicas. O efeito dos FCSL no deslocamento dos ciclones também é incerto: alguns estudos indicam que os fluxos não alteram a trajetória (REED e SIMMONDS, 1991, Piva, 2001), porém estudos do impacto da atividade convectiva em ciclones (como DA ROCHA, 1999), mostram que os ciclones se deslocam mais lentamente na ausência de liberação de calor latente. Como esta liberação de calor latente pode estar ligada aos fluxos de superfície, a modificação seria possível.

A interação entre os ciclones extratropicais e os FCSL é um assunto extensivamente estudado. Porém, muitas conclusões são retiradas de ciclones idealizados em experimentos numéricos; e a quase totalidade dos trabalhos observacionais ou simulações de casos reais são focados nos sistemas explosivos, que apresentam aprofundamento anormalmente rápido (nos quais os fluxos de calor têm papel fundamental, principalmente na fase anterior ao rápido aprofundamento, conforme BOSART e LIN, 1984; UCCELINNI et al., 1987; ATLAS, 1987; KUO et al., 1991b, etc). Estudos numéricos da influência dos FCSL em ciclones existem para as regiões do Pacífico (Chen et al., 1983), Atlântico Norte (HOLT e CHANG, 1993; BUSINGER et al., 2005) e Mediterrâneo (LAGOUVARDOS et al., 2007), mas a costa leste 
da América do Sul é uma região onde ainda existem poucos trabalhos a esse respeito (DAL PIVA, 2001; ODA, 2005; REBOITA, 2008).

Dentro deste contexto, o objetivo deste trabalho é avaliar o papel dos fluxos de calor sensível e umidade entre oceano e atmosfera em ciclones extratropicais não intensos que se desenvolveram na costa do sul do Brasil. Estes sistemas, não intensos do ponto de vista de abaixamento de pressão, são muito comuns nesta região (REBOITA, 2008), provocando muitas vezes chuvas fortes e ventos intensos no sul/sudeste do país (REBOITA, 2008; DA ROCHA, 1999; IWABE e DA ROCHA, 2009) e situações de mar agitado (CAMPOS, 1999). Assim, o conhecimento dos processos físicos associados a estes sistemas torna-se importante para uma melhor previsibilidade e possíveis medidas de mitigação dos prejuízos.

Serão investigados a intensificação, o deslocamento e a estrutura vertical de dois sistemas com características distintas, procurando avaliar a extensão dos efeitos dos FCSL. Esta análise será realizada através de simulações numéricas com o modelo WRF versão 2.2.

O trabalho está organizado como se segue: no capítulo 2 apresenta-se uma revisão bibliográfica sobre ciclones extratropicais e os efeitos dos FCSL sobre estes sistemas; o capítulo 3 traz uma descrição do modelo WRF versão 2.2, e a metodologia e os dados utilizados neste trabalho; o capítulo 4 apresenta e discute os resultados, e o capítulo 5 traz as conclusões e considerações finais. 


\section{REVISÃO BIBLIOGRÁFICA}

\subsection{Ciclones extratropicais e ciclogênese}

\subsubsection{Ciclogênese e desenvolvimento clássico}

"Ciclones" são circulações de escala sinótica (ordem de grandeza de milhares de km) associadas a regiões de baixa pressão em superfície. Dependendo da região geográfica e processos de formação, estes sistemas podem ser classificados como tropicais, subtropicais ou extratropicais. Estes últimos se formam em latitudes médias, retirando sua energia primariamente dos gradientes de temperatura próximos à superfície do planeta, e têm um papel climatológico importante no sistema atmosférico, transportando grandes quantidades de calor, umidade e momento das baixas para as altas latitudes (BARRY et al., 2002). Estes sistemas de tempo podem assumir uma grande variedade de formas, dependendo de fatores como o escoamento onde se desenvolvem, a disponibilidade de umidade e características da superfície adjacente.

$\mathrm{O}$ estudo científico dos ciclones extratropicais começou no início do século XX com os trabalhos de BJERKNES (1919) e BJERKNES e SOLBERG (1922). Estes pesquisadores propuseram, a partir de observações de uma densa rede de estações de superfície, o primeiro modelo conceitual do ciclo de vida dos ciclones, que ficou conhecido historicamente como “Teoria da Frente Polar", pois descrevia como estes sistemas se formavam a partir de uma instabilidade na zona frontal que separa as massas de ar polar e tropical. Esta instabilidade é identificada com uma onda de pequena amplitude na interface entre as duas massas de ar, que força o ar frio na direção dos trópicos, abaixo do ar quente. A elevação do ar quente diminui o peso da coluna atmosférica, iniciando um processo de convergência de massa em baixos níveis, e a circulação gera dois sistemas frontais (frio e quente). A frente quente é geralmente mais fraca e a frente fria mais intensa. Esta última circula mais rapidamente em torno da baixa pressão, e eventualmente alcança a frente quente; quando a frente fria ultrapassa a frente quente, tem-se a oclusão.

Apesar da ampla aceitação deste modelo e de sua importância didática e histórica, ele não leva em consideração as forçantes ar superior, cujo papel no processo ciclogenético 
começou a ser estudado nas décadas seguintes. A ondulação do escoamento na alta troposfera gera um padrão de cristas e cavados. O eixo destas ondas são regiões de máxima vorticidade ciclônica (cavados) e anticiclônica (cristas), e nas regiões a leste e oeste ocorre máxima advecção de vorticidade. Esta advecção se relaciona à divergência do campo de vento através da equação da tendência de vorticidade absoluta aproximada para sistemas de escala sinótica (HOLTON, 2004):

$$
\frac{\partial \zeta_{a}}{\partial t}-\vec{V} \cdot \vec{\nabla} \zeta_{a}=-\zeta_{a} \vec{\nabla} \cdot \vec{V}
$$

onde $\zeta_{\mathrm{a}}$ é a vorticidade absoluta e $\vec{V}$ é o vento.

$\mathrm{Na}$ alta troposfera, o termo de variação local de vorticidade pode ser desprezado, ou seja, a advecção de vorticidade ciclônica (anticiclônica) a leste (oeste) dos cavados, indica divergência (convergência), o que, por continuidade de massa, implica em convergência (divergência) em baixos níveis, auxiliando o processo de ciclogênese.

A formação e amplificação de ondas em níveis superiores puderam ser explicadas a partir da instabilidade baroclínica, que descreve como a energia potencial armazenada no escoamento básico, associada aos gradientes horizontais de temperatura, é convertida em energia cinética para as perturbações. Esta teoria indica que a taxa de crescimento das perturbações é proporcional ao gradiente meridional de temperatura, ao comprimento das ondas e à estabilidade estática da atmosfera (HOLTON, 2004).

A teoria atual da gênese e desenvolvimento de ciclones extratropicais é esquematizada na figura 2.1 e descrita em Carlson (1998).
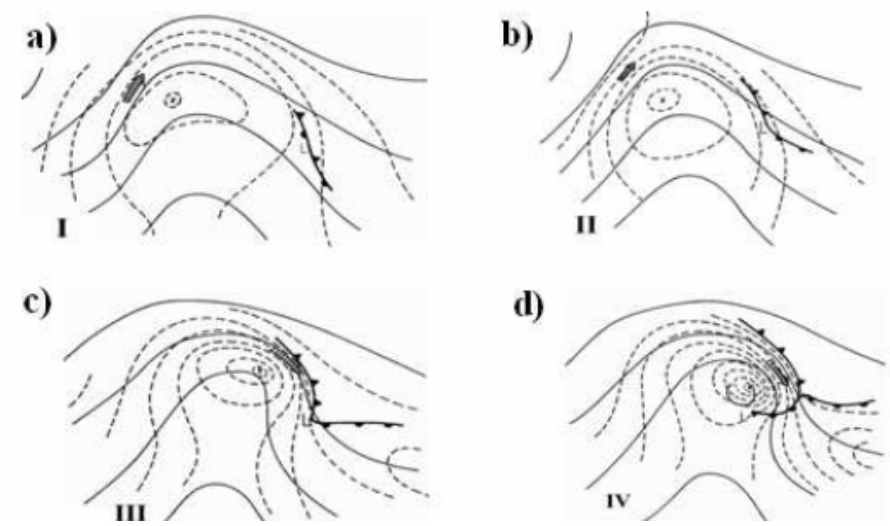

Figura 2.1: Esquema do desenvolvimento de um ciclone extratropical no Hemisfério Sul (Adaptado de CARLSON (1998), por IWABE (2008)). As linhas contínuas representam a altura geopotencial em $500 \mathrm{hPa}$, as linhas tracejadas são os contornos de vorticidade relativa em $500 \mathrm{hPa}$. Os sistemas frontais em superfície estão marcados com a simbologia habitual, e L representa a posição da baixa pressão em superfície. A seta indica a região de máxima velocidade do vento geostrófico. 
No estágio incipiente (I), na figura 2.1a, uma fraca região frontal (ou uma baixa pressão relativa) em superfície está posicionada a leste de um cavado em médios níveis, uma região de movimento vertical ascendente proporcionada pela divergência de massa em altos níveis associada à advecção de vorticidade ciclônica. A intensificação da baixa em superfície resulta desta forçante em altos níveis, levando à formação de uma circulação ciclônica na região da frente em superfície, no estágio (II), na figura 2.1b. O estabelecimento desta circulação em baixos níveis inicia um processo de advecção de temperatura entre 1000 e 500 hPa. A advecção quente a leste da baixa em superfície induz a queda de pressão na região, e o sistema em superfície começa a se deslocar seguindo a máxima advecção térmica positiva. A ideia de que o escoamento em altos níveis "carrega" o ciclone em superfície (unicamente através da advecção de vorticidade) é substituída pela visão termodinâmica de que a baixa pressão se desloca a partir do rearranjo do campo de massa em função da convergência em baixos níveis, que por sua vez se intensifica pela diminuição do peso da coluna atmosférica através da advecção de ar quente (CARLSON, 1998). A advecção fria a oeste do sistema, por sua vez, auxilia no aumento da pressão em superfície na retaguarda do sistema.

A retroalimentação entre os processos de baixos e médios níveis altera o escoamento na média troposfera, e isso torna-se evidente no estágio (III), figura 2.1c, onde se observa aprofundamento do cavado e intensificação do vento geostrófico neste nível (associada ao gradiente de altura geopotencial). Estes dois efeitos ocorrem devido à advecção fria abaixo do cavado.

Até este momento, os processos de baixos e médios níveis interagiram para favorecer o desenvolvimento do ciclone, que atinge agora a sua máxima intensidade e inicia o processo de oclusão. A partir do estágio (IV), figura 2.1d, que representa a fase madura do sistema, o centro da circulação ciclônica se desprende do setor quente em baixos níveis (ou seja, está a oeste da frente fria na figura 2.1d), e o ar frio ocupa todos os níveis da troposfera, desde a superfície até a tropopausa. O eixo de máxima vorticidade em $500 \mathrm{hPa}$ se posiciona exatamente acima da baixa em superfície, e o sistema adquire uma estrutura equivalente barotrópica, onde a direção do vento é praticamente constante com a altura, embora possa ocorrer diferenças na magnitude. O sistema perde a inclinação vertical para oeste, a superposição dos campos de geopotencial e temperatura em todos os níveis tende a cessar a advecção térmica, e o sistema entra em fase de decaimento.

Em meados do século XX, foi formulada a teoria do desenvolvimento dos ciclones extratropicais, ou teoria de Sutcliffe (SUTCLIFFE, 1947; PETTERSSEN, 1956), que busca uma forma de descrever matematicamente o desenvolvimento dos ciclones a partir de 
quantidades físicas básicas associadas à sua formação. Essa teoria propõe que a variação de vorticidade relativa em baixos níveis (usualmente $1000 \mathrm{hPa}$ ) é dada por:

$$
\frac{\partial \zeta_{0}}{\partial t}=-\vec{V}_{500} \cdot \vec{\nabla}_{p}\left(\zeta_{500}+f\right)-\frac{g}{f_{0}}\left\{\nabla_{p}^{2}\left[\left(-\vec{V}_{0} \cdot \vec{\nabla}_{p} h\right)+\bar{S}+\bar{H}\right]\right\}
$$

onde $-\vec{V}_{500} \cdot \vec{\nabla}_{p}\left(\zeta_{500}+f\right)$ é a advecção de vorticidade absoluta no nível de não-

divergência (aproximadamente $500 \mathrm{hPa}$ ) e $-\overline{\vec{V}_{0} \cdot \vec{\nabla}_{p} h}$ é a advecção de espessura média na camada 1000-500 hPa. Pela presença do operador laplaciano neste termo, um máximo de advecção de temperatura (advecção quente) está relacionada a tendência negativa de $\zeta_{0}$, e portanto à ciclogênese. $\mathrm{O}$ termo de estabilidade $\mathrm{S}$ contabiliza os efeitos médios, na camada 1000-500 hPa, de movimento ascendente (descendente), que deve esfriar (aquecer) adiabaticamente as parcelas de ar e assim favorecer a anticiclogênese (ciclogênese). O termo H considera a média na camada 1000-500 hPa das forçantes diabáticas (processos radiativos, liberação de calor latente, fluxos de superfície) no desenvolvimento dos sistemas.

\subsubsection{Modelo conceitual de Shapiro-Keyser}

SHAPIRO e KEYSER (1990), através de experimentos idealizados sugeriram um ciclo de vida alternativo para ciclones frontais, esquematizado na figura 2.2. Estes sistemas possuem quatro fases distintas de desenvolvimento e estrutura marcadamente diferente dos ciclones clássicos da escola norueguesa. No modelo de Shapiro-Keyser os ciclones se formam embebidos num escoamento de grande escala difluente (SCHULTZ et al., 1998), em amplas regiões baroclínicas em baixos níveis (I), que com a intensificação do ciclone se contraem e dão origem às frentes. Enquanto no modelo norueguês a frente fria e a quente circulam em torno da baixa pressão e ocasionalmente se interceptam, no modelo conceitual ShapiroKeyser, a frente fria (que neste caso é menos intensa que a frente quente) se move praticamente perpendicular à frente quente (II e III), formando o padrão conhecido em inglês como "T-bone". Outra característica deste tipo de sistema é uma região de enfraquecimento do gradiente de temperatura na frente fria ("fratura frontal”) próxima ao centro do ciclone, associada a movimentos subsidentes (GODSKE, 1957) e à rotação diferencial (SCHULTZ et 
al., 1998). Além disso, como mostra o estágio III, a região da frente quente se estende a oeste do centro, no setor frio do ciclone. Esta configuração é conhecida, em inglês, como "bentback front”. No estágio maduro (IV), em superfície, a circulação no setor frio (mais rápida) acaba aprisionando a região de ar mais quente, formando a chamada "seclusão quente". Muitos ciclones oceânicos (por exemplo, o famoso QEII Storm, NEIMAN e SHAPIRO, 1993) apresentam um ciclo de vida muito semelhante a este. No Brasil, CAMPOS (1999) estudou os processos de frontogênese em um sistema classificado segundo o modelo conceitual de Shapiro-Keyser, o mesmo que será explorado neste trabalho (ciclone 1).
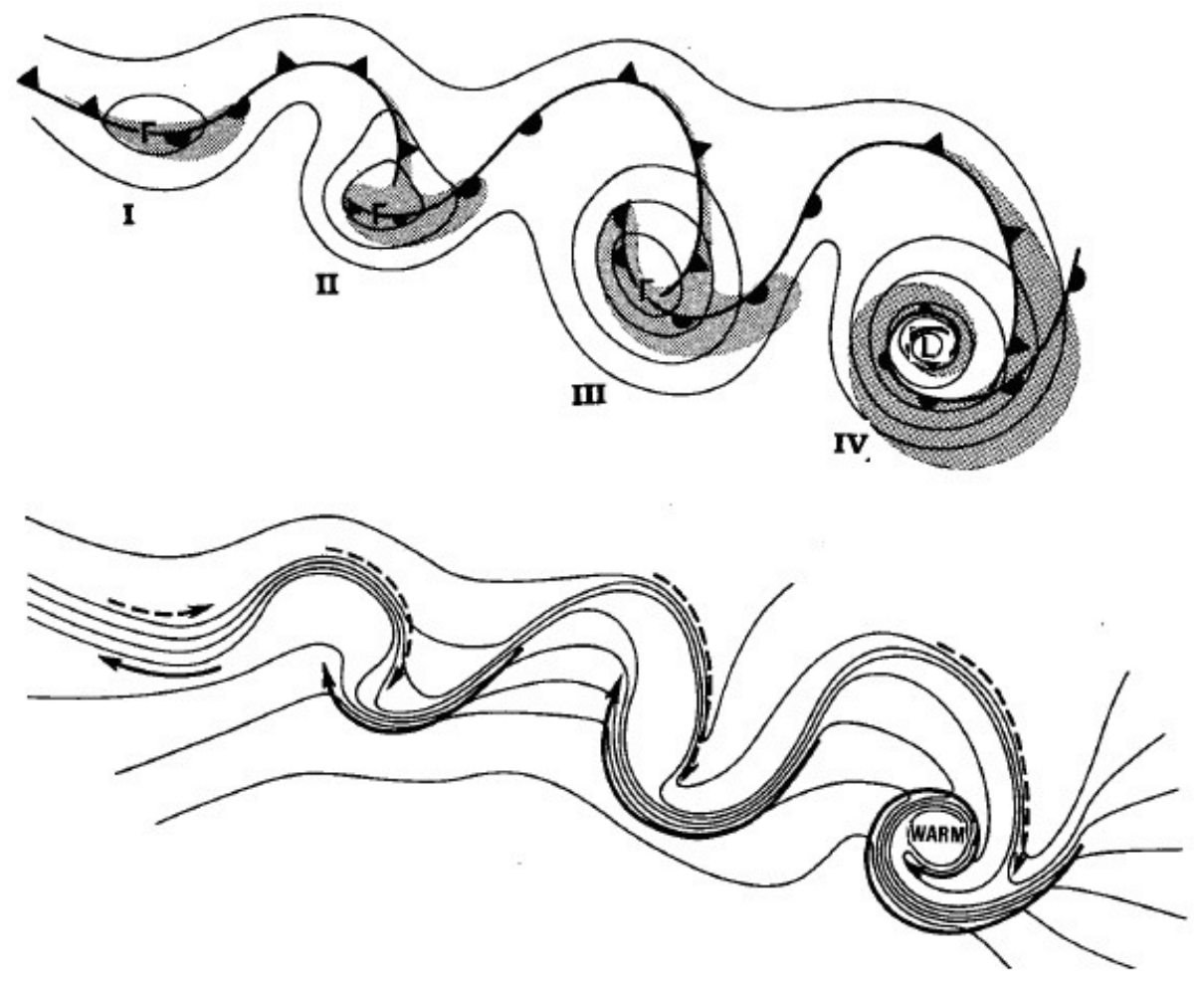

Figura 2.2: Ciclo de vida de um ciclone do tipo Shapiro-Keyser, no hemisfério Sul. Acima: pressão ao nível do mar (linhas sólidas) e regiões frontais; abaixo: temperatura do ar (linhas sólidas) e correntes fria (seta sólida) e quente (seta tracejada) (Adaptado de NEIMAN e SHAPIRO, 1993)

\subsubsection{Processos na média-alta troposfera influenciando a ciclogênese extratropical}

Aos mecanismos básicos descritos nas seções anteriores, podem se somar muitos outros processos no desenvolvimento de ciclones extratropicais. A intrusão de ar estratosférico na alta troposfera, por exemplo, pode infleunciar os processos ciclogenéticos, ou mais ainda, pode ser considerado um aspecto freqüente no desenvolvimento de ciclones 
extratropicais (CARLSON, 1998). A presença de ar estratosférico pode ser diagnosticada pela vorticidade potencial. A partir da conservação desta quantidade (BLUESTEIN, 1993), o ar estratosférico (com alta estabilidade estática) adquire vorticidade ciclônica ao se delocar para a troposfera, uma região de menor estabilidade estática, induzindo circulação ciclônica em baixos níveis (HOSKINS et al., 1985). Além disso, a intrusão estratosférica está associada a uma anomalia quente de temperatura em altos níveis (HIRSCHBERG e FRITSCH, 1991), influenciando a distribuição de tendência de altura geopotencial e consequentemente o desenvolvimento da baixa pressão em superfície.

Anomalias de vorticidade potencial em altos níveis estão frequentemente associadas a baixas desprendidas em médios níveis, ou "cut-off lows" (PALMÉN e NEWTON, 1969). Estes sistemas são circulações ciclônicas fechadas que se destacam do escoamento principal de oeste, e se caracterizam por um núcleo frio. Por isso, a onda de temperatura do ar atrasada em relação à onda de geopotencial, favorecendo forte advecção fria, é uma situação muito favorável ao desenvolvimento das baixas desprendidas (NIETO et al., 2005). Esta circulação pode induzir ciclogênese em baixos níveis, conforme mecanismos discutidos por HOSKINS et al. (1985); de acordo com a climatologia de NIETO et al. (2005), 47,1\% das baixas desprendidas no hemisfério Norte entre 1958-98 formaram baixas pressões em superfície. Ainda segundo este trabalho, a troposfera abaixo de uma baixa desprendida é geralmente instável, podendo levar a eventos convectivos severos dependendo das condições de superfície. GARREAUD e FUENZALIDA (2007) mostraram, através de experimentos numéricos de baixas desprendidas se propagando sobre os Andes, que a dissipação destes sistemas é devida principalmente ao aquecimento da média troposfera devido ao calor latente liberado pela formação de nuvens profundas.

\subsubsection{Processos de camada limite planetária influenciando a ciclogênese extratropical}

A camada limite planetária (CLP) é definida como "a região da troposfera que é diretamente influenciada pela presença da superfícieda Terra e responde às forçantes de superfície em uma escala de tempo de cerca de uma hora ou menos" (STULL, 1989). Usualmente a CLP se estende por 1-2 km de altura durante o dia, e apresenta uma espessura da ordem de 100-200 metros durante a noite, quando cessam os processos turbulentos originados pelo aquecimento da superfície. Dentro desta camada, os efeitos de fricção não 
podem ser desprezados, e são parte fundamental da circulação dos ciclones extratropicais. Em médios e altos níveis o vento sopra quase paralelo às isóbaras, obedecendo ao equilíbrio geostrófico em latitudes médias (balanço o gradiente de pressão e a força de Coriolis). Em baixos níveis, o atrito entre a atmosfera e a superfície desacelera o escoamento, diminuindo a força de Coriolis, e a quebra do equilíbrio geostrófico gera uma circulação que cruza as isóbaras convergindo para as regiões de baixa pressão e divergindo das regiões de alta pressão. A convergência do ar nas regiões de baixa pressão, por continuidade, vai gerar movimento vertical ascendente no topo da CLP conhecido como bombeamento de Ekman ("Ekman pumping"). A maneira como este processo pode enfraquecer um ciclone é mostrado esquematicamente na figura 2.3a. O bombeamento de massa comprime a coluna de fluido atmosférico contra a superfície rígida da tropopausa, e pelo princípio da conservação de vorticidade, o vórtice resultante irá diminuir a rotação $\left(\zeta_{2}<\zeta_{1}\right)$ (BOUTLE, 2009).

(a)

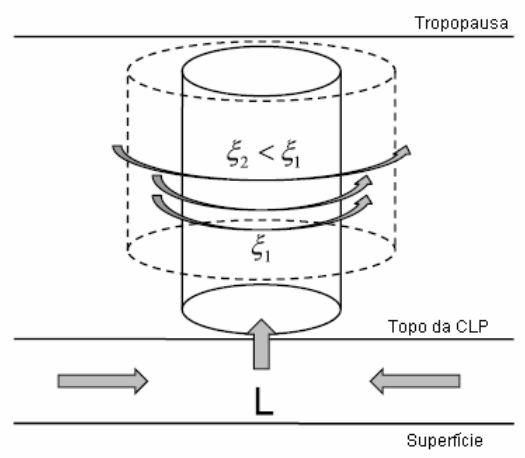

(b)

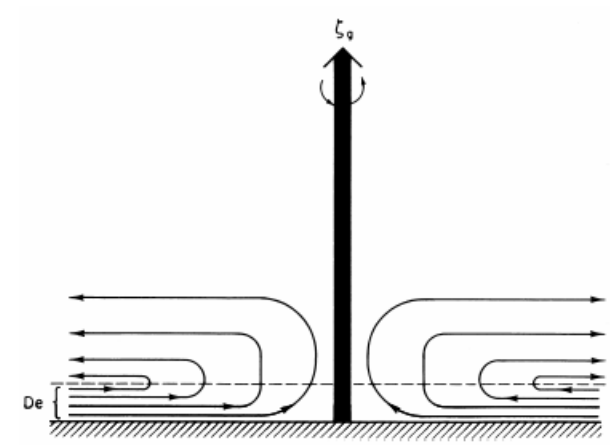

Figura 2.3: (a) Esquema mostrando o processo de enfraquecimento da circulação ciclônica pelo bombeamento de Ekman (BOUTLE, 2009). (b) Circulação secundária forçada pelo atrito em uma atmosfera baroclínica (Holton, 2004). "De" indica a profundidade da camada de Ekman.

O argumento da compressão do tubo de vórtice contra a tropopausa é desenvolvido para vórtices barotrópicos. Em uma atmosfera baroclínica, a circulação secundária que se desenvolve pela presença de atrito, que é radial e dirigida para o centro do ciclone, é compensada por uma circulação radial dirigida para fora do sistema em níveis superiores (fig. 2.3b). Esta circulação para fora é responsável pela ampliação do tubo de vórtice e consequente redução da vorticidade (HOLTON, 2004), o que auxilia o processo de ciclólise.

Os FCSL entre superfície e atmosfera são mais um processo dentro da CLP que influencia a circulação atmosférica. Sendo este o principal foco de estudo deste trabalho, sua 
interação com o desenvolvimento de ciclones, particularmente os ciclones sobre o oceano, é explorada na próxima seção.

\subsection{Fluxos de calor e umidade de superfície influenciando a ciclogênese extratropical}

A influência direta do fluxo de calor sensível sobre a ciclogênese deve-se ao aquecimento/resfriamento da baixa troposfera por estes fluxos. METAXAS (1978) é um dos

primeiros trabalhos a relacionar diretamente o aquecimento por fluxo de calor sensível à modificação da convergência de massa próxima à superfície. Partindo do termo diabático da equação de desenvolvimento de Petterssen, METAXAS (1978) propõe que a divergência se relaciona ao fluxo de calor segundo a equação:

$$
|\vec{\nabla} \bullet \vec{v}|=-K\left|\vec{v}_{o}\right|\left(T_{s}-T_{a}\right) 10^{-7} s^{-1}
$$

onde $\left|\vec{v}_{o}\right|$ é o módulo do vento horizontal em superfície, $\mathrm{T}_{\mathrm{s}}$ é a temperatura da superfície, $\mathrm{T}_{\mathrm{a}}$ é a temperatura do ar a $2 \mathrm{~m}$ e $\mathrm{K}$ é uma constante que depende do tamanho e configuração dos oceanos e costas.

ORLANSKI (1986), a partir de experimentos com um modelo bidimensional, teoriza que a transferência de calor do oceano para a atmosfera pode organizar ciclones explosivos através da redução da estabilidade estática nos primeiros 1000 metros da atmosfera. Isto contribuiria para a maior instabilização das ondas baroclínicas (HOLTON, 2004).

O aquecimento direto da baixa troposfera, porém, pode ter efeitos contrários à intensificação dos sistemas ciclônicos, dependendo da distribuição espacial dos fluxos. HALTINER (1967) encontrou em simulações numéricas de ciclones se desenvolvendo sobre um campo de temperatura da superfície do mar (TSM) médio (temperatura do mar superior à do ar), que as trocas de calor sensível tendem a reduzir a instabilidade de ondas curtas e médias. NUSS e ANTHES (1987) chegaram à mesma conclusão, mas mostraram, através de experimentos numéricos idealizados em um ambiente de baroclinia intensa, que quando a troca de calor entre o oceano e a atmosfera ocorre em fase com a estrutura térmica da camada limite planetária, a ciclogênese é intensificada. Mesmo assim, alguns trabalhos (REED e SIMMONDS, 1991; CHANG et al., 1996) indicam que, nestas condições, pode ocorrer 
desintensificação do sistema através da redução de baroclinia em baixos níveis (enfraquecimento do gradiente horizontal de temperatura através de fluxos positivos no setor frio do ciclone, e negativos no setor quente).

ROEBBER (1989) também enfatiza a importância do posicionamento dos fluxos de calor sensível nos ciclones extratropicais, indicando que a intensificação destes sistemas é dependente da fase entre as ondas de geopotencial e de temperatura do ar em baixos níveis. Utilizando simulações idealizadas em um modelo analítico quase-geostrófico simples, ROEBBER (1989) mostrou que o desenvolvimento adiabático de um ciclone é maximizado quando existe uma defasagem de $1 / 4$ de onda entre estes campos. Na presença de fluxos de calor de superfície, a intensificação do ciclone resultaria da relação de fase entre as ondas atmosféricas de temperatura e geopotencial e da onda de temperatura da superfície. O efeito direto atribuído ao fluxo de calor sensível seria favorecer o desenvolvimento de um sistema localizado no lado frio da onda térmica (através do fornecimento de energia da superfície para a atmosfera), e enfraquecer sistemas localizados no lado quente da onda térmica (pela transferência de calor da atmosfera para a superfície).

NUSS (1989) reforça a idéia de que o efeito dos FCSL depende criticamente do seu posicionamento em relação aos ciclones. Além disso, mostra que o gradiente horizotal destes fluxos pode ter importância fundamental na intensificação dos sistemas, pois induz a variação horizontal do transporte de Ekman (o que gera, por sua vez, convergência de massa, movimento ascendente e atividade convectiva, levando ao abaixamento de pressão).

O perfil de aquecimento diabático da troposfera também tem influência na intensificação dos ciclones. GYAKUM (1983b), SARDIE e WARNER (1985), ROEBBER (1989), entre outros, mostram que a intensificação dos ciclones extratropicais é favorecida quando o máximo aquecimento diabático se localiza em níveis baixos, pois o máximo movimento ascendente por aquecimento ocorrendo neste nível vai intensificar a convergência em superfície. Através de um modelo analítico, MAK (1998) mostrou que a dependência da instabilidade de ondas baroclínicas com o perfil de aquecimento é forte, sendo capaz de induzir modos instáveis em escala sinótica quando o aquecimento diabático aumenta rapidamente com a altura próximo à superfície, mesmo em ciclones rasos e na ausência de forçantes de altos níveis.

A grande maioria dos trabalhos sobre como os FCSL autam em ciclogêneses vem do estudo dos chamados "ciclones-bomba", ou explosivos, onde a taxa de aprofundamento é maior ou igual a $1 \mathrm{hPa} / \mathrm{h}$ durante pelo menos 24 horas, conforme definido por SANDERS e GYAKUM (1980). O estudo dos "ciclones-bomba" mostra que a importância maior dos 
FCSL é preparar o ambiente (instabilizar e saturar a atmosfera) na fase pré-aprofundamento (DANARD e ELLENTON, 1980; FANTINI, 1990, CARRERA et al., 1999). KUO et al. (1991) confirmaram isto realizando simulações numéricas de sete eventos de ciclogênese intensa na costa da América do Norte: os maiores impactos no aprofundamento de ciclones ocorreram quando se suprimiram os fluxos na fase inicial do desenvolvimento. Em simulações numéricas iniciadas próximas ao momento de máxima intensificação dos sistemas, KUO e LOW-NAM (1990) haviam percebido pequena influência destes fluxos. DAL PIVA (2001) estudou o impacto dos fluxos de calor em um caso de ciclogênese intensa na costa leste sul americana, encontrando resultados que também confirmaram a importância dos fluxos no período anterior ao rápido desenvolvimento.

Enquanto a intensificação dos ciclones extratropicais através dos FCSL é um tópico amplamente estudado, o papel destes fluxos no deslocamento e na estrutura vertical dos ciclones extratropicais não recebe a mesma atenção, embora seja também um tópico controverso.

Em trabalhos como DAL PIVA (2001), a ausência dos FCSL não alterou o deslocamento do sistema, durante a fase de maior aprofundamento. Entretanto, trabalhos como Reed et al. (1993), KUO e REED (1988), KUO et al. (1991), LIOU e ELSBERRY (1987), entre outros, através de simulações numéricas de eventos reais de ciclogênese, reportam que a baixa pressão simulada na ausência de atividade convectiva (que é proporcional aos FCSL, conforme LESLIE, 1987) se move mais lentamente que na presença desta. CHEN (1983) sugere que os movimentos verticais mais fracos e a menor disponibilidade de umidade, fatores que limitam a atividade convectiva e mantêm os ciclones mais rasos, seriam responsáveis por este deslocamento mais lento, uma vez que um ciclone mais raso seria menos afetado pelos ventos de oeste em médios e altos níveis. Esta afirmação entra em contradição com os argumentos de CARLSON (1998), segundo os quais o ciclone não é “carregado" pelos altos níveis e sim reconstruído continuamente no campo de pressão. Mas a atividade convectiva ainda parece apresentar grande importância neste processo, pois simulações de DA ROCHA (1999) mostram que na ausência de liberação de calor latente por convecção o ciclone mantém-se atrasado em sua trajetória. 


\subsection{Regiões ciclogenéticas da América do Sul}

Na costa leste da América do Sul, trabalhos como NECCO (1982a) e GAN e RAO (1991) apontam duas regiões ciclogenéticas principais: na costa da Argentina (aproximadamente em $48^{\circ} \mathrm{S}$ ) e próximo à desembocadura do Rio da Prata (cerca de $35^{\circ} \mathrm{S}$ ). $\mathrm{O}$ principal mecanismo de formação de ciclones nestas áreas é a instabilidade baroclínica no escoamento de oeste, devido ao forte gradiente meridional de temperatura. A isso se somam os efeitos orográficos da Cordilheira dos Andes, e no oceano a presença da Corrente do Brasil, transportando águas quentes para sul no leste da América do Sul.

Trabalhos mais recentes (SINCLAIR, 1995; HOSKINS e HODGES, 2005; REBOITA et al., 2008) evidenciam uma terceira região ciclogenética localizada na costa do sul/sudeste do Brasil (entre $30^{\circ}$ e $25^{\circ} \mathrm{S}$ ), onde a instabilidade baroclínica geralmente é menos intensa. REBOITA (2008) encontrou um máximo de ciclogêneses nestas latitudes, utilizando uma metodologia que identifica ciclones de menor intensidade. Este mesmo trabalho mostrou que o impacto dos FCSL é maior nesta região do que nas outras duas anteriormente descritas, visto que os sistemas se formam em um ambiente de mais fraca baroclinia e de águas mais quentes devido às correntes oceânicas.

O transporte de umidade pelo jato de baixos níveis da Amazônia em direção ao Uruguai e sul do Brasil parece ser um dos fatores importantes para a ciclogênese nesta área (SINCLAIR, 1995; REBOITA, 2008).

Apesar da detecção desta região ciclogenética, não se possui atualmente amplo conhecimento dos processos dinâmicos e físicos que influenciam o desenvolvimento destes sistemas. 


\subsection{Circulação oceânica e FCSL na costa leste do sul do Brasil}

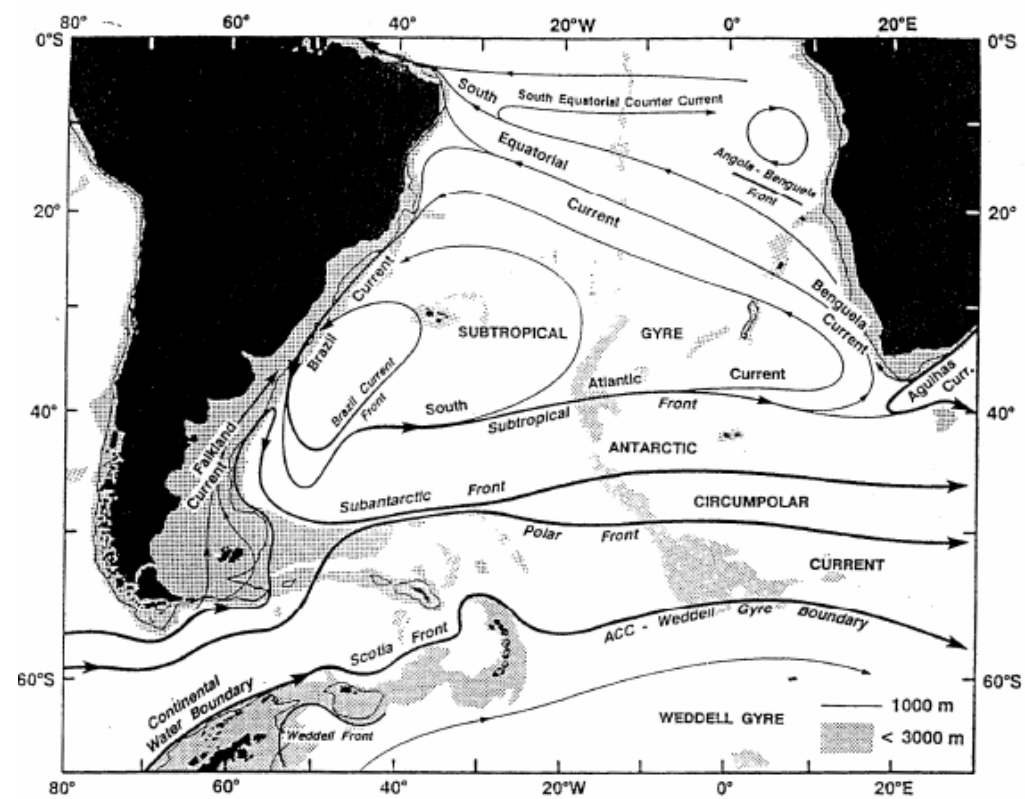

Figura 2.4: Esquema da circulação geral de grande escala na superfície do oceano Atlântico Sul (PETERSON e STRAMMA, 1991).

A circulação geral na superfície do Atlântico Sul (figura 2.4) é dominada pelo Giro Subtropical, induzido pelo anticiclone subtropical semi-permanente do Atlântico sul na atmosfera. O ramo descendente a oeste desta circulação oceânica é conhecido como a corrente do Brasil, que transporta água mais quente e salina das latitudes baixas para as mais altas, até a região de confluência com a corrente fria das Malvinas (próximo à costa do Uruguai, em cerca de $40^{\circ} \mathrm{S}$ ), que se desloca para norte transportando águas frias da Corrente Circumpolar Antártica. Esta região de confluência migra para sul e para norte em escalas sazonal, interanual e possivelmente até mais longas, podendo afetar a distribuição de ciclogêneses na região (WAINER et al., 2003).

Assim como em outras regiões do planeta (costa leste da América do Norte, da Austrália e da Ásia), a costa leste da América do Sul também apresenta fluxos de calor sensível e latente mais elevados próximo ao continente. A figura 2.5 mostra a média de 50 anos dos fluxos de calor sensível e latente sobre os oceanos, obtidos pelo projeto "Objectively Analyzed Air-Sea Fluxes" (OAFLUX) do WHOI (Woods Hole Oceanographic Institute). Embora não tenha a mesma magnitude dos fluxos nas outras regiões de borda oeste dos oceanos, o leste da América do Sul apresenta fluxos médios da ordem de 10-20 $\mathrm{Wm}^{-2}$ (sensível) e $100 \mathrm{Wm}^{-2}$ (latente). Esta intensa transferência de energia entre oceano e atmosfera 
resulta do transporte de ar mais frio e seco do continente, que interage com a corrente de águas quentes vinda de latitudes mais baixas, e parece possuir grande importância no desenvolvimento dos ciclones extratropicais na região (DAL PIVA, 2001; IWABE, 2008).

(a)

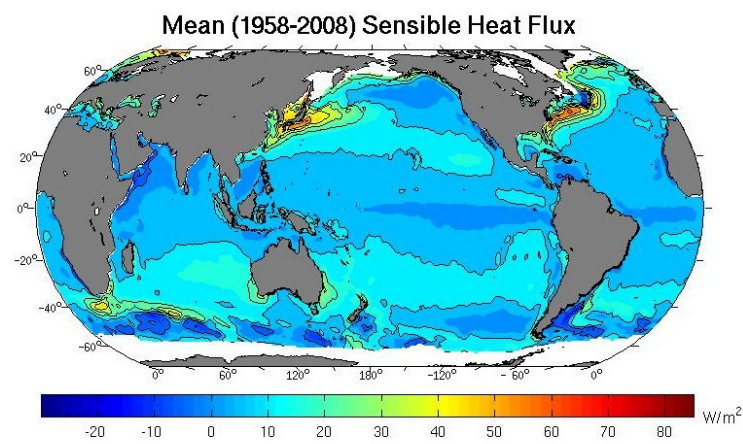

(b)

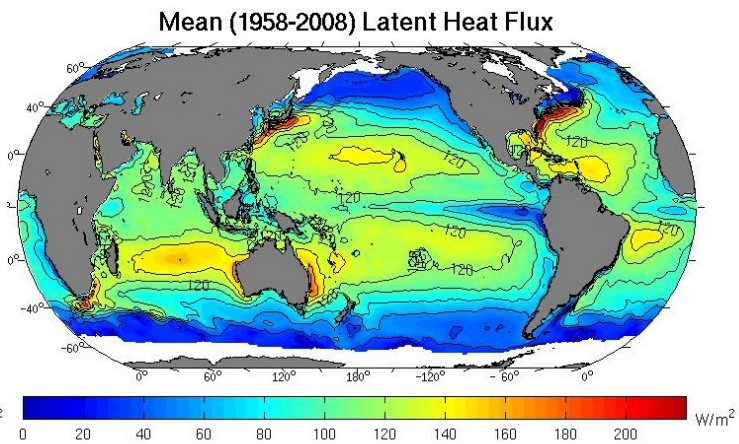

Figura 2.5: Média dos fluxos de (a) calor sensível e (b) calor latente sobre os oceanos, em $\mathrm{W} \mathrm{m}^{-2}$, no período de 1958 a 2008. Fonte: Objectively Analyzed Air-Sea Fluxes Project, WHOI (http://oaflux.whoi.edu/) 


\section{DADOS E METODOLOGIA}

\subsection{O modelo WRF}

O "Weather Research and Forecast" (WRF) é um modelo desenvolvido por várias agências norte-americanas, entre eles o National Center for Atmospheric Research (NCAR) e o National Centers for Environmental Prediction (NCEP), e grupos científicos de diferentes universidades (SKAMAROCK et al., 2005), designado para ser um código portátil e flexível, eficiente em ambiente de processamento paralelo. O WRF apresenta dois núcleos dinâmicos, sendo o núcleo Advanced Research WRF (ARW) utilizado neste trabalho. Este núcleo dinâmico resolve as equações de Euler não-hidrostáticas, numa atmosfera totalmente compressível, em coordenada vertical que segue o terreno e integração no tempo do tipo "time-split". A versão utilizada para este trabalho é o WRF-ARW 2.1.1, lançada em novembro de 2005.

Os próximos sub-itens apresentam as equações governantes resolvidas pelo modelo, sua discretização espacial e o esquema de integração no tempo, e também discute as parametrizações utilizadas neste trabalho para a camada limite superficial, camada limite planetária, interação solo-atmosfera, radiação, convecção e precipitação na escala de grade.

\subsubsection{Coordenada vertical e variáveis}

O ARW utiliza a coordenada vertical denotada por $\eta$ e definida como:

$$
\eta=\frac{p_{h}-p_{h t}}{\mu}, \text { onde } \mu=p_{h s}-p_{h t}
$$




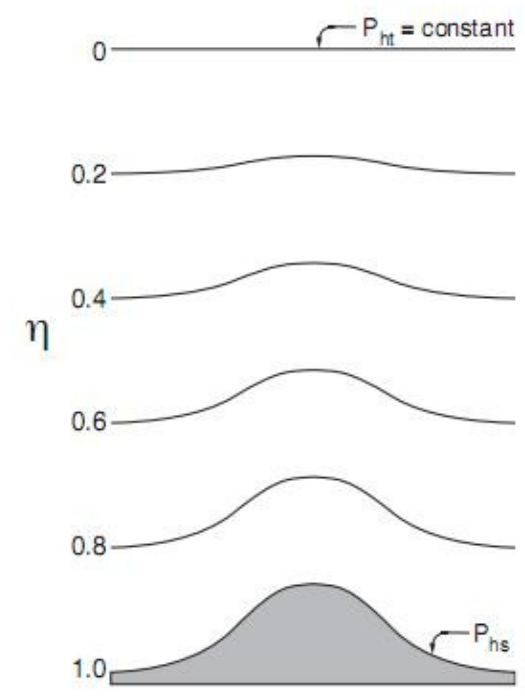

Figura 3.1: Coordenada vertical $\eta$ as superfícies $\mathrm{p}_{\mathrm{hs}}$ e $\mathrm{p}_{\mathrm{ht}}$ (SKAMAROCK et al., 2005)

Esta coordenada é similar à tradicional coordenada $\sigma$ utilizada por vários modelos hidrostáticos. Ela tem valor 1 seguindo a superfície e 0 no topo da camada (figura 3.1).

As variáveis meteorológicas vento tridimensional, pseudo-velocidade vertical e temperatura potencial podem ser reescritas na forma de fluxo como:

$$
\vec{V}=\mu \vec{v}=(U, V, W) \quad \Omega=\mu \dot{\eta} \quad \Theta=\mu \theta
$$

\subsubsection{Equações governantes}

$\mathrm{Na}$ formulação das equações de Euler para uma atmosfera com a presença de vapor de água, o termo $\mu$ é redefinido como $\mu_{\mathrm{d}}$ e a relação diagnóstica de pressão é computada para a pressão total (ar seco mais vapor).

Para a integração, as equações são escritas para variáveis perturbadas (ou seja, as variáveis são divididas em um termo de referência, para um estado hidrostático dependente apenas da altura, e uma perturbação). Este método permite reduzir erros de truncamento e arredondamento nos cálculos de gradientes de pressão e de empuxo.

Após estas considerações, as equações do fluido atmosférico na forma como são resolvidas pelo ARW são: 
- momento:

$$
\begin{aligned}
& \frac{\partial U}{\partial t}+m\left(\frac{\partial U u}{\partial x}+\frac{\partial V v}{\partial y}\right)+\frac{\partial \Omega u}{\partial \eta}+\left(\mu_{d} \alpha \frac{\partial p^{\prime}}{\partial x}+\mu_{d} \alpha^{\prime} \frac{\partial \bar{p}}{\partial x}\right)+\left(\frac{\alpha}{\alpha_{d}}\right)\left(\mu_{d} \frac{\partial \phi^{\prime}}{\partial x}+\frac{\partial \eta}{\partial p^{\prime}} \frac{\partial \phi}{\partial x}-\mu_{d}^{\prime} \frac{\partial \phi}{\partial x}\right)=F_{U} \\
& \frac{\partial V}{\partial t}+m\left(\frac{\partial U u}{\partial x}+\frac{\partial V v}{\partial y}\right)+\frac{\partial \Omega v}{\partial \eta}+\left(\mu_{d} \alpha \frac{\partial p^{\prime}}{\partial y}+\mu_{d} \alpha^{\prime} \frac{\partial \bar{p}}{\partial y}\right)+\left(\frac{\alpha}{\alpha_{d}}\right)\left(\mu_{d} \frac{\partial \phi^{\prime}}{\partial y}+\frac{\partial \eta}{\partial p^{\prime}} \frac{\partial \phi}{\partial y}-\mu_{d}^{\prime} \frac{\partial \phi}{\partial y}\right)=F_{V} \\
& \frac{\partial W}{\partial t}+m\left(\frac{\partial U w}{\partial x}+\frac{\partial V w}{\partial y}\right)+\frac{\partial \Omega w}{\partial \eta}-\frac{1}{m g}\left(\frac{\alpha}{\alpha_{d}}\right)\left[\frac{\partial p^{\prime}}{\partial \eta}-\bar{\mu}_{d}\left(q_{v}+q_{c}+q_{r}\right)\right]+\frac{\mu_{d} g}{m}=F_{W}
\end{aligned}
$$

- conservação de massa:

$$
\frac{\partial \mu_{d}^{\prime}}{\partial t}+m^{2}\left(\frac{\partial U}{\partial x}+\frac{\partial V}{\partial y}\right)+m \frac{\partial \Omega}{\partial \eta}=0
$$

- tendência de geopotencial:

$$
\frac{\partial \phi^{\prime}}{\partial t}+\frac{1}{\mu_{d}}\left[m^{2}\left(U \frac{\partial \phi}{\partial x}+V \frac{\partial \phi}{\partial y}\right)+m \Omega \frac{\partial \phi}{\partial \eta}-g W\right]=0
$$

- conservação de temperatura potencial e outros campos escalares $\left(\mathrm{Q}_{\mathrm{m}}\right)$ :

$$
\begin{gathered}
\frac{\partial \Theta}{\partial t}+m^{2}\left(\frac{\partial U \theta}{\partial x}+\frac{\partial V \theta}{\partial y}\right)+m \frac{\partial \Omega \theta}{\partial \eta}=F_{\Theta} \\
\frac{\partial Q_{m}}{\partial t}+m^{2}\left(\frac{\partial U q_{m}}{\partial x}+\frac{\partial V q_{m}}{\partial y}\right)+m \frac{\partial \Omega q_{m}}{\partial \eta}=F_{Q m}
\end{gathered}
$$

- relação hidrostática:

$$
\frac{\partial \phi^{\prime}}{\partial \eta}=-\bar{\mu}_{d} \alpha_{d}^{\prime}-\alpha_{d} \mu_{d}^{\prime}
$$


- expressão diagnóstica para a pressão total (ar seco mais vapor de água):

$$
p=p_{0}\left(\frac{R_{d} \theta_{m}}{p_{0} \alpha_{d}}\right)^{\gamma}
$$

Os termos do lado direito das relações (6), (7) e (8) contêm as parametrizações físicas, além dos termos de Coriolis e curvatura.

A variável "m" nas equações acima se refere ao fator de mapa (razão entre a distância computacional e a distância correspondente sobre a superfície da Terra). $\alpha_{d}$ é o inverso da densidade do ar seco, $\Phi$ é a altura geopotencial, $R_{d}$ é a constante dos gases para o ar seco (287 $\left.\mathrm{Jkg}^{-1} \mathrm{~K}^{-1}\right), \mathrm{Q}_{\mathrm{m}}$ é a soma das razões de mistura para vapor de água $\left(\mathrm{q}_{\mathrm{v}}\right)$, chuva $\left(\mathrm{q}_{\mathrm{r}}\right)$ e gelo $\left(\mathrm{q}_{\mathrm{i}}\right)$.

Maiores detalhes destas equações podem ser encontradas em SKAMAROCK et al. (2005).

\subsubsection{Discretização temporal}

Para integrar no tempo as equações governantes, o ARW utiliza um esquema denominado "time-split", no qual modos de baixa freqüência são integrados utilizando o esquema de Runge-Kutta de terceira ordem, e os modos acústicos (de alta freqüência) são integrados com passo de tempo menor, para manter a estabilidade numérica, através de um esquema "forward-backward" para os modos acústicos que se propagam horizontalmente, e de um esquema implícito para modos acústicos de propagação vertical e oscilações de empuxo.

O método de Runge-Kutta de terceira ordem necessita de três passos para avançar a solução de $\Phi(\mathrm{t})$ a $\Phi(\mathrm{t}+\Delta \mathrm{t})$ :

$$
\begin{gathered}
\Phi^{*}=\Phi(t)+\frac{\Delta t}{3} R\left(\Phi^{t}\right) \\
\Phi^{* *}=\Phi(t)+\frac{\Delta t}{2} R\left(\Phi^{*}\right) \\
\Phi^{t+\Delta t}=\Phi(t)+\Delta t R\left(\Phi^{* *}\right)
\end{gathered}
$$


onde $\Delta \mathrm{t}$ é o passo de tempo das ondas de baixa freqüência. Os termos $\Phi(\mathrm{t})$ são as derivadas em relação ao tempo das variáveis (equações (6) a (13)) e $\mathrm{R}(\Phi)$ são os demais termos nestas equações. Apesar de este esquema ser denominado de terceira ordem, sua precisão é de terceira ordem apenas para termos lineares, sendo de segunda ordem para os termos não-lineares das equações.

A técnica completa de integração consiste em dois "loopings" principais aninhados. No "loop" interno, procede-se a integração dos modos acústicos e se avança as variáveis U, $\mathrm{V}, \mu_{\mathrm{d}}, \Theta, \mathrm{W}$ e $\phi$. No "loop" externo, calcula-se o transporte de campos escalares (usando as médias temporais de $\mathrm{U}, \mathrm{V}$ e $\Omega$ durante todo o passo acústico), e também p' e $\alpha$ ' através de relações prognósticas, e computam-se os processos de precipitação em larga escala. Por fim atualizam-se as variáveis, tudo isso ocorrendo a cada passo de tempo (SKAMAROCK et al, 2005).

\subsubsection{Discretização espacial}

A grade do ARW apresenta comprimentos fixos $\Delta x$ e $\Delta y$ (cuja variação física associada a diferentes projeções na esfera - Mercator, Lambert, etc - é determinada pelo fator de mapa $m$ presente nas equações), e comprimento vertical $\Delta \eta$ especificado no início da simulação.

A discretização espacial é realizada numa grade do tipo C de Arakawa (ARAKAWA e LAMB, 1977), onde as velocidades normais estão escalonadas a meio comprimento de grade das variáveis termodinâmicas, como mostra a figura 2. Apesar de apresentar alguma dificuldade no cálculo dos termos de Coriolis, análises da representação de ondas gravitoinerciais mostram que esta grade apresenta melhores propriedades em relação às grades $\mathrm{B}$ e $\mathrm{E}$ (ADCROFT et al., 1999).

Os termos de advecção são calculados utilizando esquema de Runge Kutta de ordem 2. 


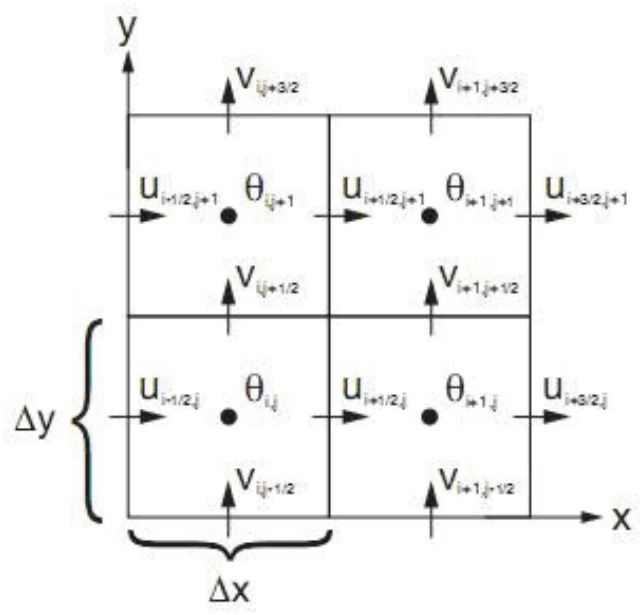

Grade horizontal

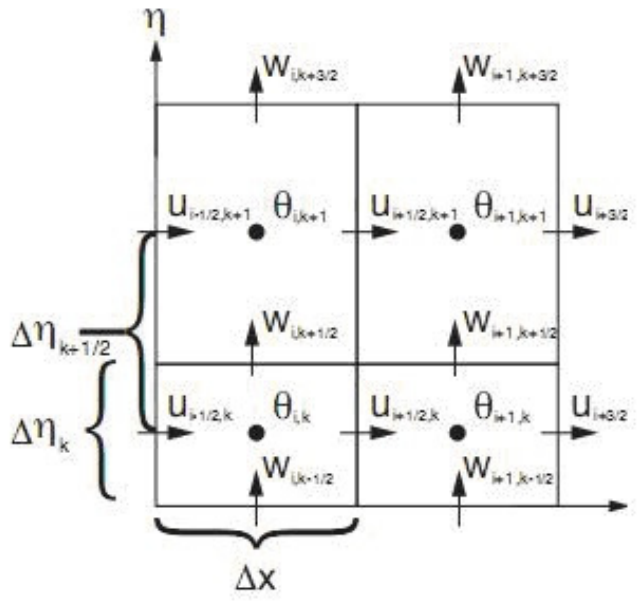

Grade vertical

Figura 3.2: Grades horizontal e vertical do ARW (adaptado de SKAMAROCK et al., 2005)

As condições de fronteira laterais são obtidas de arquivo externo, e o método de relaxação (DAVIES, 1983) é utilizado para forçar a borda do domínio durante todo o período de integração. Este processo ocorre dentro de duas zonas definidas nas fronteiras como "zona especificada" (ZE - que assume o valor das variáveis fornecido pelo arquivo externo, e nas presentes simulações compreende o ponto mais externo do domínio) e "zona de relaxação" (ZR - onde as previsões do modelo são "relaxadas" para os valores do arquivo externo; nas simulações deste trabalho, são os quatro pontos adjacentes à ZE), conforme a figura 3.3.

Dentro da região próxima às bordas, a mudança lucal de uma variável $\psi$ (que pode ser u, v, $\theta, \phi ’ \mu_{\mathrm{d}}$ ' e vapor d'água) é calculada como (DAVIES e TURNER, 1977):

$$
\frac{\partial \psi}{\partial t}=F_{1}\left(\psi_{L S}-\psi\right)-F_{2} \Delta^{2}\left(\psi_{L S}-\psi\right)
$$

Em (16), $\psi_{\text {LS }}$ é o valor da variável obtido por interpolação do arquivo externo e $\Delta^{2}$ é um filtro suavizador aplicado nas superfícies $\eta$ do modelo. As funções-peso $F_{1}$ e $F_{2}$ são dadas por:

$$
F_{1}=\frac{1}{10 \Delta t} \frac{Z E+Z R-n}{Z R-1} \quad \text { e } \quad F_{2}=\frac{1}{50 \Delta t} \frac{Z E+Z R-n}{Z R-1}
$$


onde $\mathrm{n}$ se estende pela $\mathrm{ZR}$. $\mathrm{F}_{1}$ e $\mathrm{F}_{2}$ são funções lineares em forma de rampa com máximo no primeiro ponto da ZR.

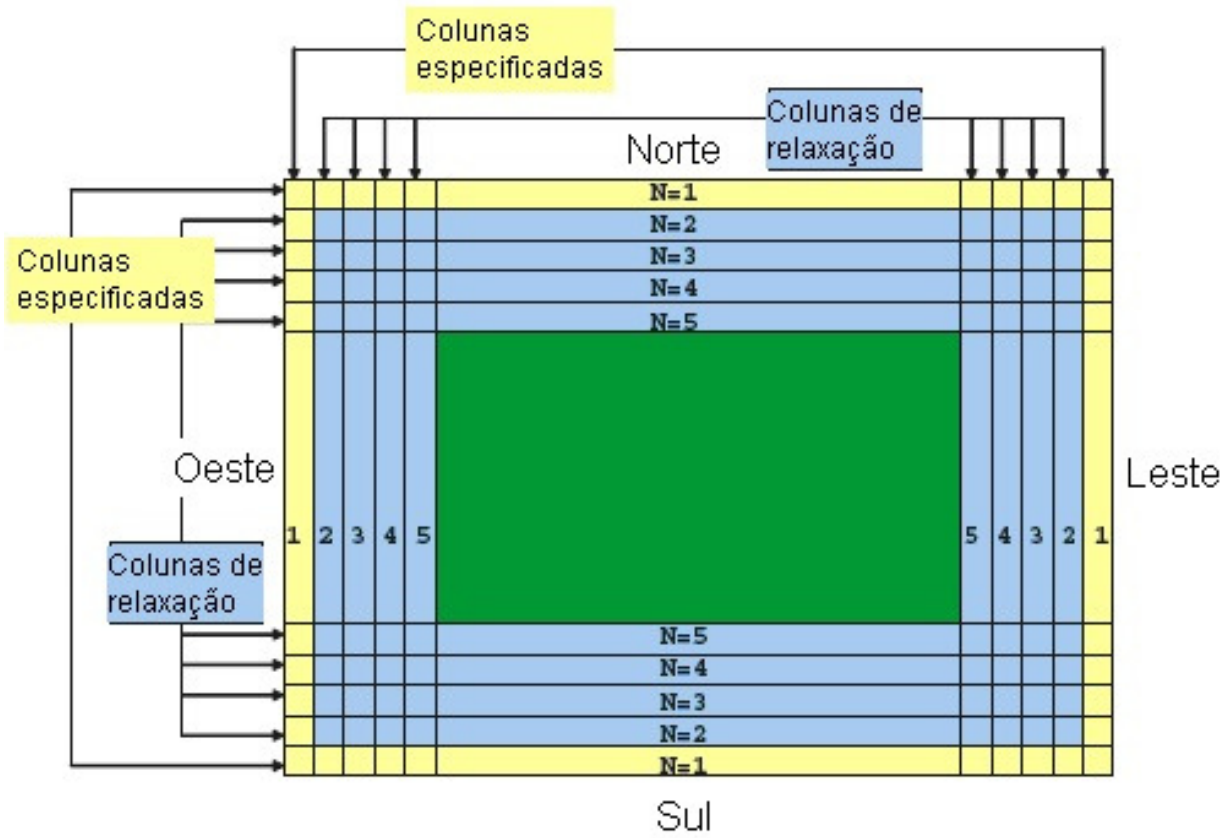

Figura 3.3: Zonas especificada e de relaxação para uma grade com uma coluna de zona especificada e quatro pontos para a zona de relaxação (valores típicos utilizados para uma simulação a partir de dados reais).

\subsubsection{Difusão horizontal}

O ARW possui esquemas de difusão associados à turbulência de sub-grade tanto na direção vertical como horizontal. A difusão vertical neste trabalho foi substituída pela parametrização de camada limite (seção 3.1.6.1) e a difusão horizontal foi calculada até a segunda ordem utilizando coeficientes de viscosidade dos vórtices $\left(\mathrm{K}_{\mathrm{h}}\right)$ computados a partir do valor de Energia Cinética Turbulenta, uma variável prognóstica do modelo. 


\subsubsection{Parametrizações físicas}

\subsubsection{Fluxos turbulentos de superfície (Camada limite superficial)}

Os fluxos de superfície no ARW são calculados de acordo com a teoria da similaridade de Monin-Obukhov (MONIN e OBUKHOV, 1954).

A similaridade é um método no qual variáveis relevantes a certo processo físico dentro da CLP são combinadas entre si em grupos adimensionais, de maneira que seja possível a determinação de relações empíricas "universais" entre esses grupos, ou seja, relações que sejam válidas independentemente do local e do tempo.

Segundo essa teoria, os perfis de vento, temperatura potencial e umidade dentro da camada limite superficial são representados por:

$$
\begin{gathered}
\frac{\partial U}{\partial z}=\frac{u_{*}}{k z} \phi_{M}\left(\frac{z}{L}\right) \\
\frac{\partial \theta}{\partial z}=\frac{\theta_{*}}{k z} \phi_{H}\left(\frac{z}{L}\right) \\
\frac{\partial q}{\partial z}=\frac{q_{*}}{k z} \phi_{W}\left(\frac{z}{L}\right)
\end{gathered}
$$

onde $\mathrm{u} *$ é a escala de velocidade (também chamada de velocidade de fricção), $\theta_{*}$ e $\mathrm{q}_{*}$ são as escalas características de temperatura potencial e umidade, respectivamente; $\mathrm{k}$ é a constante de von Karman (no ARW, $\mathrm{k}=0,4$ ), z é a altura acima da superfície da Terra, e $\phi_{\mathrm{M}}$, $\phi_{\mathrm{H}}$ e $\phi_{\mathrm{W}}$ descrevem respectivamente, o cisalhamento vertical do vento e o gradiente vertical de temperatura e umidade adimensionais. Estes termos são funções do parâmetro z/L, cujo sinal se relaciona com a estabilidade estática da atmosfera $(\mathrm{z} / \mathrm{L}<0$ implica atmosfera estaticamente instável, e z/L > 0 implica estaticamente estável). O comprimento de Obukhov, L, é dado por (STULL, 1989): 


$$
L=-\frac{\bar{\theta}_{v} u_{*}^{3}}{k g\left(w^{\prime} \theta_{v}^{\prime}\right)_{\text {sup }}}
$$

e pode ser fisicamente interpretado como a altura acima da superfície a partir da qual a produção térmica de turbulência domina sobre a produção mecânica (cisalhamento).

O número de Richardson "bulk” é definido como

$$
R i_{b}=\frac{g \Delta \bar{\theta}_{v} \Delta z}{\bar{\theta}_{v} U^{2}}
$$

onde $\bar{\theta}_{v}$ é a temperatura virtual média e o módulo de U é definido como:

$$
|U|=u^{2}+v^{2}+\left(\beta w_{*}\right)^{2}
$$

$\mathrm{O}$ termo $(\beta \mathrm{W} *)^{2}$ representa vento próximo à superfície induzido por grandes vórtices dentro da camada limite (BELJAARS, 1994). A constante $\beta$ é determinada empiricamente e tem valor aproximado de 1,2 conforme experimentos de LES ("Large eddy simulations") realizados por SYKES et al. (1993). O termo $(\beta \mathrm{W} *)^{2}$ está incorporado a U dentro dos cálculos de fluxos no ARW, para contabilizar efeitos da convecção livre, cuja parametrização é crucial para a modelagem do acoplamento oceano-atmosfera (BELJAARS, 1994).

A partir do número de Richardson "bulk" (22), é computado o parâmetro z/L:

$$
\begin{gathered}
\frac{z}{L}=R i_{b} \ln \left(\frac{z}{z_{0}}\right) \quad \text { (condições instáveis) } \\
\frac{z}{L}=R i_{b} \ln \left(\frac{z}{z_{0}}\right)\left(1,1-5 R i_{b}\right)^{-1} \quad \text { (condições estáveis) }
\end{gathered}
$$

Após isolar $\mathbf{u} *$ e integrar a equação (18), determina-se a velocidade de fricção:

$$
u_{*}=\frac{k U}{\ln \left(\frac{z}{z_{0}}\right)-\Psi_{M}\left(\frac{z}{L}\right)}
$$


onde $\mathrm{z}_{0}$ é o comprimento de rugosidade da superfície, definida em função da categoria de solo. Sobre o oceano, o ARW associa $\mathrm{z}_{0}$ à altura das ondas, função da velocidade do vento segundo a relação de Charnock (STULL, 1989):

$$
z_{0}=0,015 \frac{u_{*}^{2}}{g}
$$

O termo $\Psi_{\mathrm{M}}$ é a integral da correção de $\mathrm{u} *$ pela estabilidade atmosférica. Segundo PAULSON (1970), para condições instáveis tem-se:

$$
\Psi_{M}=2 \ln \left(\frac{1+x}{2}\right)+\ln \left(\frac{1+x^{2}}{2}\right)-\frac{2}{\tan (x)}+\frac{\pi}{2}
$$

onde $x=\left(1-16 \frac{z}{L}\right)^{-\frac{1}{4}}$, conforme DYER e HICKS (1970).

Para condições estáveis, este termo é definido como (WEBB, 1970):

$$
\Psi_{M}=-5 \frac{z}{L}
$$

Obtido $\mathrm{u}^{*}$, o fluxo de momento é determinado por

$$
\tau=-\rho u_{*}
$$

A escala de temperatura e o fluxo de calor sensível são:

$$
\theta_{*}=\frac{k\left(\theta-\theta_{0}\right)}{\operatorname{Pr}\left[\ln \left(\frac{z}{z_{0}}\right)-\Psi_{H}\right]} \quad \text { (31) e } \overline{\theta^{\prime} w^{\prime}}=-\theta_{*} u_{*}
$$

onde $\theta_{0}$ é a temperatura potencial na superfície (ou em $\mathrm{z}=\mathrm{z}_{0}$ ). O número de Prandtl turbulento, Pr, definido como a razão entre a taxa de difusão viscosa e a taxa de difusão térmica, tem valor 1 no ARW, seguindo WEBB (1970).

A escala de umidade possui uma formulação diferenciada, para contabilizar também o efeito da difusão vertical molecular de umidade (ZHANG e ANTHES, 1982): 


$$
q_{*}=\frac{M k\left[q-q_{0}\left(\theta_{0}\right)\right]}{\ln \left(\frac{k u_{*} z}{K_{q m}}+\frac{z}{z_{l}}\right)-\Psi_{W}}
$$

onde M é o parâmetro de disponibilidade de umidade (característico da categoria do solo escolhida), $\mathrm{z}_{1}$ é o topo da subcamada molecular, e $\mathrm{K}_{\mathrm{qm}}$ é a difusividade molecular $\left(2,4 \times 10^{-5} \mathrm{~m}^{2} \mathrm{~s}^{-1}\right)$.

O fluxo de umidade é dado por:

$$
\overline{q^{\prime} w^{\prime}}=-q_{*} u_{*}
$$

O ARW considera quatro regimes de estabilidade, seguindo ZHANG e ANTHES (1982). Para cada um destes regimes, as formulações de $\Psi_{\mathrm{H}}$ e $\Psi_{\mathrm{W}}$ são diferentes:

- Convecção livre $\left(\mathrm{Ri}_{\mathrm{b}}<0,\left|\frac{h}{L}\right|>1,5\right)$ :

$$
\Psi_{\mathrm{H}}=\Psi_{\mathrm{W}}=-3,23\left(\frac{z}{L}\right)-1,99\left(\frac{z}{L}\right)^{2}-0,474\left(\frac{z}{L}\right)^{3}
$$

- Convecção forçada $\left(\mathrm{Ri}_{\mathrm{b}}<0,\left|\frac{h}{L}\right| \leq 1,5\right)$ :

$$
\Psi_{\mathrm{H}}=\Psi_{\mathrm{W}}=0
$$

- Turbulência mecanicamente dirigida $\left(0 \leq R i_{b} \leq R i_{c}=0,2\right)$ :

$$
\Psi_{\mathrm{H}}=\Psi_{\mathrm{W}}=-5\left(\frac{R i_{b}}{1,1-5 R i_{b}}\right) \ln \left(\frac{z}{z_{0}}\right)
$$


- Condição estável $\left(\mathrm{Ri}_{\mathrm{b}}>0,2\right)$ :

$$
\Psi_{\mathrm{H}}=\Psi_{\mathrm{W}}=-10 \ln \left(\frac{z}{z_{0}}\right)
$$

Além de fornecer os fluxos de momento, calor e umidade para a CLP, o esquema de camada superficial também interage com os esquemas de radiação (no processo de emissão, absorção e espalhamento de radiação) e com a precipitação oriunda dos esquemas de convecção e microfísica.

\subsubsection{Difusão vertical turbulenta}

Os fluxos de superfície obtidos conforme a seção 3.6.1.1 fornecem a condição de fronteira inferior para os esquemas de camada limite do ARW, que calculam o transporte vertical destes fluxos através da camada de mistura. As simulações deste trabalho foram realizadas utilizando o esquema de camada limite da Yonsei University (YSU-PBL).

O YSU-PBL é baseado na teoria K não-local (TROEN e MAHRT, 1986) que determina os fluxos a partir dos gradientes das propriedades. Em primeiro lugar, define-se a altura h, como o nível no qual ocorre fluxo mínimo dentro da camada de inversão. Esta altura é determinada por:

$$
h=R i_{b c} \frac{\theta_{v 0}|U(h)|^{2}}{g\left\{\theta_{v}(h)-\left[\theta_{v 0}+\theta_{T}\right]\right\}}
$$

onde $\mathrm{Ri}_{\mathrm{bc}}$ é o número de Richardson "bulk" crítico, $\mathrm{U}(\mathrm{h})$ é o vento horizontal no nível $\mathrm{h}, \theta_{\mathrm{v} 0}$ é a temperatura potencial virtual no nível mais baixo do modelo, $\theta_{\mathrm{v}}(\mathrm{h})$ é a temperatura potencial virtual no nível h, e $\theta_{T}=6,8 \frac{\overline{\left(w^{\prime} \theta_{v}^{\prime}\right)_{0}}}{w_{s 0}}$, no qual $\overline{\left(w^{\prime} \theta_{v}^{\prime}\right)_{0}}$ é o fluxo de calor sensível da superfície e $\mathrm{w}_{\mathrm{s} 0}$ é a escala de velocidade vertical para o ar úmido na camada de mistura (calculado, por definição, em z $=0,5 \mathrm{~h}$ ): 


$$
w_{s 0}=\left(u_{*}^{3}+\phi_{m} k w_{* b}^{3} \frac{z}{h}\right)^{\frac{1}{3}}
$$

com $\mathrm{W}_{* \mathrm{~b}}{ }^{3}$ representando a escala de velocidade convectiva para o ar úmido. A função de estabilidade para o fluxo de momento, $\phi_{\mathrm{M}}$ (assim como $\phi_{\mathrm{H}}$ e $\phi_{\mathrm{W}}$ ), é calculada de maneira idêntica à parametrização dos fluxos de superfície (seção 3.1.6.1), para satisfazer a compatibilidade entre o topo da camada limite superficial e a base da camada de mistura.

Computacionalmente, h é primeiro calculado pela equação (39) sem considerar o termo $\theta_{\mathrm{T}}$. Este $\mathrm{h}$ é então utilizado para computar $\phi_{\mathrm{M}} \mathrm{e} \mathrm{w}_{\mathrm{s} 0}$, e h é recalculado utilizando estes termos.

Após a determinação de $\mathrm{h}$, a difusão turbulenta dentro da camada de mistura $(\mathrm{z} \leq \mathrm{h})$ para uma variável prognostica $\mathrm{C}$ (que pode ser $\mathrm{u}, \mathrm{v}, \theta, \mathrm{q}, \mathrm{q}_{\mathrm{c}}, \mathrm{q}_{\mathrm{i}}$ ) é dada por:

$$
\frac{\partial C}{\partial t}=\frac{\partial}{\partial z}\left[K_{c}\left(\frac{\partial C}{\partial z}-\gamma_{c}\right)-\overline{\left(w^{\prime} c^{\prime}\right)_{h}}\left(\frac{z}{h}\right)^{3}\right]
$$

onde

- Kc é o coeficiente de difusividade na camada de mistura. Para o momento, este coeficiente é expresso como:

$$
K_{M}=k w_{s} z\left(1-\frac{z}{h}\right)^{2}
$$

e os coeficientes para difusão de calor e umidade, $\mathrm{K}_{\mathrm{H}}$ e $\mathrm{K}_{\mathrm{W}}$ são computados a partir de $\mathrm{K}_{\mathrm{M}}$ utilizando o número de Prandtl dependente da altura dentro da camada de mistura (NOH et al., 2003) e o número de Prandtl no topo da camada de superfície, $\operatorname{Pr}_{0}$ :

$$
\operatorname{Pr}=1+\left(\operatorname{Pr}_{0}-1\right) e^{\left(-\frac{3(z-0,1 h)^{2}}{h^{2}}\right)}
$$

- $\gamma_{c}$ é a correção ao gradiente local da quantidade C (no ARW, apenas para o momento e a temperatura potencial), incorporando a mistura realizada pelos vórtices de escala maior (não-locais); 
- $-\left(w^{\prime} c^{\prime}\right)_{h}\left(\frac{z}{L}\right)^{3}$ é o termo de tratamento explícito do processo de entranhamento na camada de inversão.

Acima da camada de mistura $(\mathrm{z}>\mathrm{h})$, a difusão na atmosfera livre é obtida aplicandose a teoria K local. O comprimento de mistura turbulenta e fórmulas de estabilidade são baseados em observações (KIM e MAHRT, 1992).

\subsubsection{Interação solo-atmosfera}

O modelo de física do solo utiliza informações atmosféricas da camada limite superficial, radiação e precipitação, junto com informações internas das variáveis de estado e propriedades da superfície, para computar os fluxos de calor e umidade acima do solo e de superfícies de gelo marinho. Essa parametrização não fornece tendências, mas atualiza as variáveis de estado (como temperatura da superfície, perfis de temperatura e umidade do solo, etc) a cada passo de tempo. Não ocorre interação horizontal entre pontos vizinhos.

A parametrização utilizada aqui é a de difusão térmica de cinco camadas, baseada no modelo de cinco camadas do MM5. As camadas têm espessura de 1, 2 4, 8 e $16 \mathrm{~cm}$, e abaixo delas assume-se uma temperatura média. A umidade do solo é fixa de acordo com o uso da terra e o período do ano. Não se contabilizam os efeitos explícitos de vegetação.

\subsubsection{Radiação}

O esquema radiativo calcula o aquecimento atmosférico devido à convergência do fluxo radiativo e balanço de energia radiativa no solo.

Para os processos envolvendo ondas longas, utilizou-se o esquema RRTM (Rapid Radiative Transfer Method) baseado no modelo MM5 (MLAWER et al 1997), que considera 16 bandas espectrais. Este esquema contém tabelas pré-definidas para representar processos radiativos devido a vapor d'água, ozônio, $\mathrm{CO}_{2}$, gases traço e nuvens. 
A radiação de onda curta é tratada em um esquema baseado em DUDHIA (1989), também do MM5, onde a radiação solar descendente é obtida computando os efeitos de espalhamento por gases, absorção por vapor d'água e albedo e absorção por nuvens. Para as propriedades das nuvens, foram utilizadas tabelas retiradas de STEPHENS (1978).

\subsubsection{Convecção}

Os processos de formação e desenvolvimento de nuvens se dão em escalas de dezenas a centenas de metros, muito menores do que a resolução horizontal utilizada por modelos de mesoescala como o WRF. Por isso, estes fenômenos são de escala de subgrade em tais modelos e devem ser parametrizados.

Neste trabalho foi utilizada a parametrização de Grell-Devenyi (GRELL e DEVENYI, 2002), que considera um ensemble de vários esquemas de representação de cumulus do tipo "mass-flux". Nestes esquemas, as nuvens são representadas como duas circulações estacionárias ("updraft" e "downdraft"). O entranhamento de ar na nuvem ocorre de acordo com a hipótese de entranhamento

$$
\mu_{u e}(z, \lambda)-\mu_{u d}(z, \lambda)=\frac{1}{m_{u}(z, \lambda)} \frac{\partial m_{u}(z, \lambda)}{\partial z}
$$

onde $\mu_{\mathrm{ue}}$ é a taxa de entranhamento bruta e $\mu_{\mathrm{ud}}$ é a taxa de "detrainment" (a massa de nuvem se misturando ao ar ambiente e sendo removida). $\mathrm{O}$ símbolo $\lambda$ denota o membro de um conjunto.

O fluxo de massa, $m$, é normalizado pelo fluxo de massa na base da nuvem $\left(\mathrm{m}_{\mathrm{b}}\right)$,

$m_{u}(z, \lambda)=m_{b}(\lambda) \mathrm{N}(z, \lambda)(44)$, com $\mathrm{N}(\mathrm{z}, \lambda)$ sendo o fluxo de massa normalizado.

Dadas diferentes condições iniciais e fechamentos para o entranhamento, e diferentes taxas de desentranhamento, para cada membro do conjunto, as equações (43) e (44) podem ser utilizadas, juntamente com a equação da pluma estacionária,

$$
\frac{\partial \alpha_{u, d}(z, \lambda)}{\partial z}=-\mu_{u e / u d}\left(\bar{\alpha}(z)-\alpha_{u, d}\right)+S
$$


para estimar propriedades das nuvens no modelo, tais como perfis de condensação e evaporação, energia estática úmida, conteúdo de água líquida e fluxo de massa normalizado. O termo a é a variável termodinâmica de interesse, e $\mathrm{S}$ denota fontes ou sorvedouros desta variável. Esta equação serve para movimentos ascendentes (subscrito u) e descendentes (subscrito d).

Os fechamentos de controle dinâmico (ou seja, a modulação da convecção pelas condições do ambiente) são baseados na convergência de umidade e na energia potencial convectiva disponível, CAPE (SKAMAROCK et al, 2005).

\subsubsection{Precipitação na escala de grade (Microfísica)}

A parametrização de microfísica inclui processos de precipitação de grande escala, vapor d'água e nuvens, resolvidos explicitamente. O esquema utilizado nas simulações deste trabalho é o WSM5 que representa vapor de água, chuva, neve, água de nuvem e gelo de nuvem. Estas variáveis são alocadas dentro do modelo em diferentes espaços de memória; isto possbilita, diferentemente de outros esquemas simple-ice (DUDHIA, 1989), a existência de água super-resfriada e o derretimento gradual de neve precipitada.

\subsection{Dados}

A análise sinótica e a validação do modelo WRF foram realizadas, em grande parte, utilizando a reanálise Era-Interim (BERRISFORD et al., 2009), do ECMWF (European Center for Medium-Range Weather Forecasting). Deste conjunto de dados foram utilizadas as variáveis meteorológicas altura geopotencial $(\mathrm{m})$, temperatura do ar $(\mathrm{K})$, vento zonal $\left(\mathrm{ms}^{-1}\right)$, vento meridional $\left(\mathrm{ms}^{-1}\right)$, umidade específica $\left(\mathrm{kgkg}^{-1}\right)$, pressão em superfície (Pa) e pressão ao nível do mar $(\mathrm{Pa})$, com espaçamento de grade horizontal de $1,5^{\circ}$ de longitude por $1,5^{\circ}$ de latitude e 11 níveis verticais (1000, 925, 850, 700, 500, 400, 300, 250, 200, 150, 100 hPa), em quatro horários diários (0000 UTC, 0600 UTC, 1200 UTC, 1800 UTC).

Os campos de precipitação acumulada diária foram obtidos da análise Global Precipitation Climatology Project - GPCP (HUFFMAN et al, 2001), com resolução de $1^{\circ}$ de 
longitude por $1^{\circ}$ de latitude. Este projeto combina dados de radiômetros no infravermelho e microondas a bordo de vários satélites geosíncronos e de órbita polar, para fornecer análises de precipitação com cobertura global.

Para análise dos fluxos de calor sensível e latente sobre o oceano, foram utilizadas as médias diárias do Woods Hole Oceanographic Institution (WHOI) (YU et al., 2008), com cobertura global e resolução horizontal de $1^{\circ}$ de longitude por $1^{\circ}$ de latitude. Os fluxos turbulentos neste conjunto de dados foram parametrizados a partir do algoritmo COARE 3.0 (FAIRALL et al., 1996, 2003), que relaciona tais fluxos aos valores médios das variáveis através de fórmulas derivadas da teoria de similaridade de Monin-Obukhov (LIU et al., 1979). As variáveis meteorológicas para este cálculo são obtidas através da combinação de dados das reanálises do NCEP-2 (KANAMITSU et al., 2002) e ECMWF/ERA40, e de observações de satélite (vento e umidade próximos à superfície). Neste algoritsmo, a TSM foi obtida da análise diária com resolução de 0,25 descrita em REYNOLDS et al. (2007).

Como condições iniciais e de fronteira do WRF foram utilizados dois conjuntos de dados. As simulações do ano de 2000 foram realizadas com a análise do FNL-NCEP, com resolução horizontal de $1^{\circ} \times 1^{\circ}$ de longitude e latitude, 26 níveis verticais e resolução temporal de 6 horas. Como estes dados estão disponíveis apenas a partir de 1999, as simulações para o ciclone de 1997 foram realizadas utilizando-se a análise do FNL-NCEP com resolução horizontal de $2,5^{\circ}$ x $2,5^{\circ}$ de longitude e latitude, 16 níveis verticais e resolução temporal de 12 horas. Ambos os conjuntos de dados são globais, incluem a TSM, e estão disponíveis no site http://dss.ucar.edu, identificados como ds083.2 e ds083.0, respectivamente.

As imagens no canal do infravermelho do satélite GOES-8 foram obtidas da DSA, Divisão de Satélites e Sistemas Ambientais do Centro de Previsão de Tempo e Estudos Climáticos do Instituto Nacional de Pesquisas Espaciais (CPTEC-INPE). 


\subsection{Simulações e análises}

\subsubsection{Escolha dos casos de ciclogênese}

O primeiro critério para escolha dos ciclones estudados neste trabalho foi $o$ aprofundamento: optou-se por escolher ciclones não-explosivos, ou seja, aqueles cujo aprofundamento não ultrapasse $24 \mathrm{hPa} / 24 \mathrm{~h}$.

Em seguida, utlizando-se dados de reanálise, foram separados alguns casos que apresentaram desenvolvimento da circulação a partir dos baixos níveis e outros casos que surgiram associados às forçantes de altos níveis. Destas amostras, foram retirados dois eventos para estudo: o ciclone de 28 de maio de 1997, que se iniciou como uma baixa térmica sobre o continente e propagou-se para o oceano, sempre mantendo a circulação mais intensa em baixos níveis, e denominado neste trabalho de "ciclone 1". Este sistema causou tempo severo e condições oceânicas adversas entre os dias 28 de maio e 01 de junho, nas costas de SP e RJ (CAMPOS, 1999; DA ROCHA, 1999); e o ciclone de 13 de abril de 2000, que se formou associado a processos da média-alta troposfera, tendo duração e intensidade bem menores comparado ao ciclone 1 , e é chamado neste trabalho de "ciclone 2".

\subsubsection{Simulações numéricas}

Para cada um dos ciclones em estudo, foram realizadas duas simulações, uma que inclui os fluxos de calor de superfície e outra onde estes fluxos são removidos, denominadas respectivamente de EXPCOM e EXPSEM. As tabelas 3.1 e 3.2 apresentam as características específicas de cada uma destas simulações. Todos os experimentos foram realizados em projeção Lambert, em um domínio de 200 pontos leste-oeste por 100 pontos norte-sul para o caso de 1997 e em um domínio de 190 pontos leste-oeste por 110 pontos norte-sul para o caso de 2000, com 31 níveis verticais (topo em $50 \mathrm{hPa}$ ). As parametrizações físicas utilizadas estão descritas em detalhes na seção 3.1. 
Tabela 3.1 - Características das simulações do ciclone 1

\begin{tabular}{|c|c|c|c|c|}
\hline Experimento & FCSL & $\begin{array}{c}\text { Período de } \\
\text { integração }\end{array}$ & $\begin{array}{c}\text { Espaçamento } \\
\text { horizontal }(\mathrm{km})\end{array}$ & $\begin{array}{c}\text { Passo de tempo } \\
(\mathrm{s})\end{array}$ \\
\hline EXPCOM97 & $\operatorname{sim}$ & $\begin{array}{c}27 / 05 / 1997 \mathrm{a} \\
07 / 06 / 1997\end{array}$ & 40 & 120 \\
\hline EXPSEM97 & não & & \\
\hline
\end{tabular}

Tabela 3.2 - Características das simulações do ciclone 2

\begin{tabular}{|c|c|c|c|c|}
\hline Experimento & FCSL & $\begin{array}{c}\text { Período de } \\
\text { integração }\end{array}$ & $\begin{array}{c}\text { Espaçamento } \\
\text { horizontal }(\mathrm{km})\end{array}$ & $\begin{array}{c}\text { Passo de tempo } \\
(\mathrm{s})\end{array}$ \\
\cline { 1 - 2 } EXPCOM00 & Sim & $\begin{array}{c}12 / 04 / 2000 \mathrm{a} \\
18 / 04 / 2000\end{array}$ & 30 & 90 \\
\cline { 1 - 3 } EXPSEM00 & Não & & \\
\hline
\end{tabular}

O espaçamento de grade horizontal utilizado nas simulações detalha estruturas de pequena escala, dificultando a comparação com as análises observacionais. Por isso, algumas variáveis simuladas foram interpoladas para a resolução das análises $\left(1^{\circ} \mathrm{x} 1^{\circ}\right.$ para os campos de precipitação e fluxos turbulentos de calor, e $1,5^{\circ}$ x $1,5^{\circ}$ para as demais variáveis), sem comprometer a interpretação dos resultados.

\subsubsection{Metodologia de análise das simulações}

A metodologia consiste na análise sinótica e dinâmica dos campos meteorológicos gerados simulados, e na comparação entre os experimentos EXPCOM e EXPSEM para cada um dos ciclones. Gráficos de diferenças entre as simulações não foram utilizados, pois o posicionamento dos ciclones é diferente em cada simulação numérica (especialmente no ciclone 1), e por isso calcular a diferença na distribuição das variáveis não forneceria informações úteis para análise.

A identificação das regiões frontais foi realizada no nível de $925 \mathrm{hPa}$ através dos campos de vento horizontal, divergência e vorticidade relativa do vento horizontal, e temperatura potencial equivalente. $\mathrm{O}$ campo de vorticidade relativa mostra a mudança na 
direção dos ventos ao longo das frentes; áreas de máxima vorticidade indicam regiões de máximo giro do vento associados aos sistemas frontais (MCINNES et al., 1994). A temperatura potencial equivalente (proporcional à temperatura e à quantidade de vapor d'água do ar) também é uma variável útil na determinação de tais regiões, pois as frentes separam massas de ar com temperatura e umidade distintas.

Para avaliar como o fluxo de calor sensível altera a estabilidade atmosférica, foi calculado o parâmetro de estabilidade em coordenadas isobáricas (HOLTON, 2004):

$$
S_{p}=-\frac{T}{\theta} \frac{\partial \theta}{\partial p}
$$

Variações na estabilidade estática da atmosfera influenciam os fluxos verticais de momento. Neste trabalho, utilizou-se a tensão do vento horizontal em $925 \mathrm{hPa}$ para analisar tal influência, pois esta variável é proporcional ao fluxo vertical de momento dentro da camada limite (NUSS, 1989). A tensão foi calculada como:

$$
\vec{\tau}=-\rho C_{D} \vec{U}^{2}
$$

onde $\vec{U}$ é a velocidade do vento no nível em questão, e utilizou-se o valor de $1,2 \times 10^{-3}$ para o coeficiente de arrasto $C_{D}$ (valor próximo à média global de $C_{D}$ sobre os oceanos conforme BIROL KARA, 2007).

A velocidade vertical (w) em escala sinótica dentro da CLP pode ser calculada através da integração e simplificação da equação da vorticidade (FLEAGLE e NUSS, 1985):

$$
w \approx \frac{1}{\rho f}(\vec{\nabla} \times \vec{\tau}) \cdot \hat{k}
$$

O termo do lado direito da equação (48) é proporcional ao rotacional do campo de tensão do vento, representando a velocidade vertical devido ao bombeamento de Ekman dentro da camada limite. Na integração da equação da vorticidade surgem dois outros termos além deste, mas são de magnitude muito menor, e em muitos estudos (como GUYMER et al., 1983) o termo do bombeamento de Ekman é o único utilizado para este diagnóstico da 
velocidade vertical no topo da CLP. Além disso, esta quantidade pode mensurar a rotação do vento por efeito da fricção, um dos efeitos estudados neste trabalho.

Para avaliar a distribuição vertical de aquecimento diabático, foi realizado o cálculo do balanço de calor em toda a extensão da troposfera, através da equação da termodinâmica (BLUESTEIN, 1993):

$$
\frac{\partial T}{\partial t}=-\vec{V} \cdot \vec{\nabla}_{p} T+\omega \frac{R T}{c_{p} p}-\omega \frac{\partial T}{\partial p}+\frac{1}{c_{p}} \frac{d J}{d t}
$$
A
B
C D E

onde o termo $A$ representa a variação local da temperatura, $B$ advecção horizontal, $C$ é expansão/compressão adiabática, $D$ advecção vertical e por fim, $E$ é o termo diabático, calculado como resíduo da equação. Nesta equação, $\vec{V}$ é o vento horizontal, $\omega$ é a pseudovelocidade vertical, $\mathrm{c}_{\mathrm{p}} \mathrm{o}$ calor específico à pressão constante $\left(1004 \mathrm{Jkg}^{-1} \mathrm{~K}^{-1}\right)$ e $J$ representa a soma dos processos radiativos, liberação de calor latente, calor sensível ou transporte turbulento.

Os termos da equação (49) são calculados como a média em uma área que abrange todo o sistema ciclônico em estudo, para que se tenha uma visão representativa da magnitude de tal termo na área de atuação do ciclone. 


\section{RESULTADOS}

\subsection{Ciclone 1 ( 27 de maio de 1997)}

\subsubsection{Análise sinótica}

A análise da pressão ao nível médio do mar (PNMM) para 1200 UTC de 27 de maio 1997 mostra uma área de baixa pressão relativa sobre o Paraguai, em uma região de baroclinia fraca (fig. 4.1a). Em $500 \mathrm{hPa}$, um cavado no campo de geopotencial se aproxima do Paraguai (fig. 1b). A advecção de vorticidade relativa ciclônica em $250 \mathrm{hPa}$ (fig. 4.1c) e a advecção positiva de temperatura em $850 \mathrm{hPa}$ (fig. 4.1d), a leste do cavado em $500 \mathrm{hPa}$, geram condições favoráveis para o desenvolvimento do ciclone em superfície. Às 0000 UTC de 28 de maio forma-se uma circulação ciclônica entre a Argentina e o sul do Brasil, e no campo de PNMM fecha-se uma isóbara de $1014 \mathrm{hPa}$ a oeste de SC (figura não apresentada).

Em 1200 UTC de 28 de maio, o ciclone, com pressão mínima de 1012 hPa, situa-se no oceano, a leste de SC (fig. 4.2a). Observa-se uma pequena amplificação no cavado em 500 $\mathrm{hPa}$ (fig. 4.2b), mas a onda térmica encontra-se praticamente em fase com a onda no campo de geopotencial, indicando fraca advecção de temperatura neste nível. A advecção de vorticidade em altos níveis, a leste do cavado e sobre a região do ciclone em superfície (costa de SC, fig. 4.2c), se intensifica como resposta à amplificação da onda. Em $850 \mathrm{hPa}$, a advecção de temperatura positiva (negativa) a leste (oeste) do cavado em 500 hPa também é mais intensa devido à intensificação tanto do gradiente de temperatura como da circulação associada ao ciclone (fig. $4.2 \mathrm{~d}$ ). 
(a)

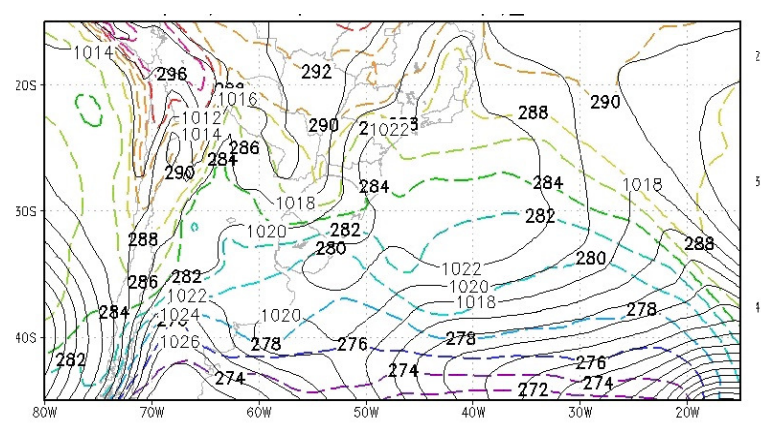

(c)

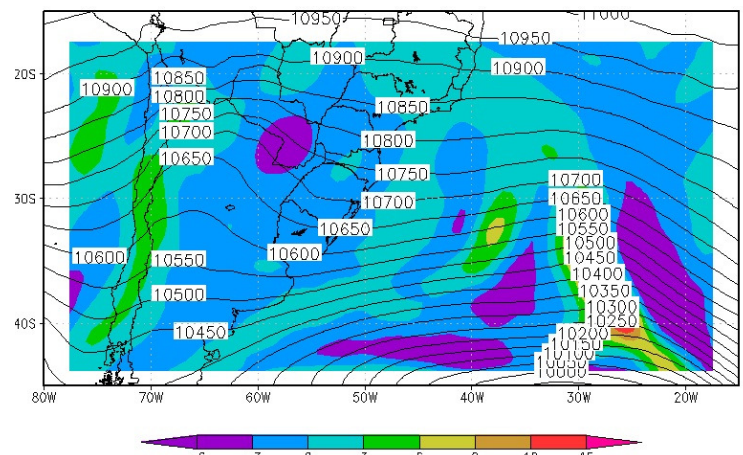

(b)

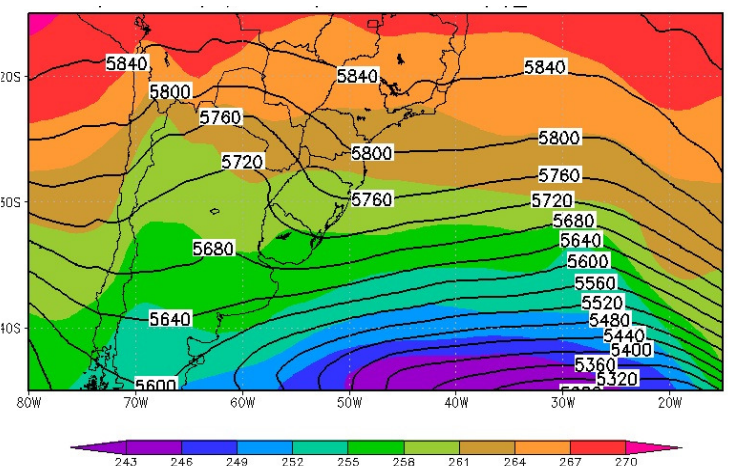

(d)

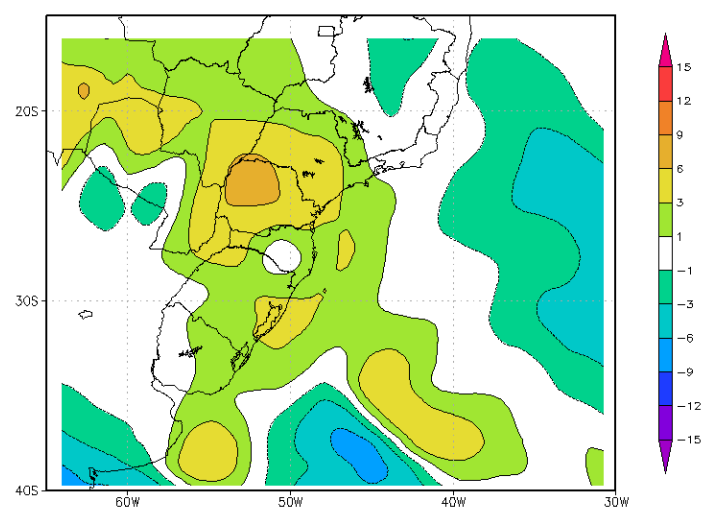

Figura 4.1: (a) PNMM (linha contínua, em hPa) e temperatura do ar (linha tracejada, em K) em 925 hPa; (b) altura geopotencial (linha contínua, em m) e temperatura do ar (sombreado, em K) em $500 \mathrm{hPa}$. (c) geopotencial (linha contínua, em m) e advecção de vorticidade relativa em $250 \mathrm{hPa}$ (sombreado, em x 10 ${ }^{9} \mathrm{~s}^{-2}$ ); (d) advecção de temperatura em $850 \mathrm{hPa}\left(\mathrm{Kdia}^{-1}\right)$, para $1200 \mathrm{UTC}$ de 27 de maio de 1997. 
(a)

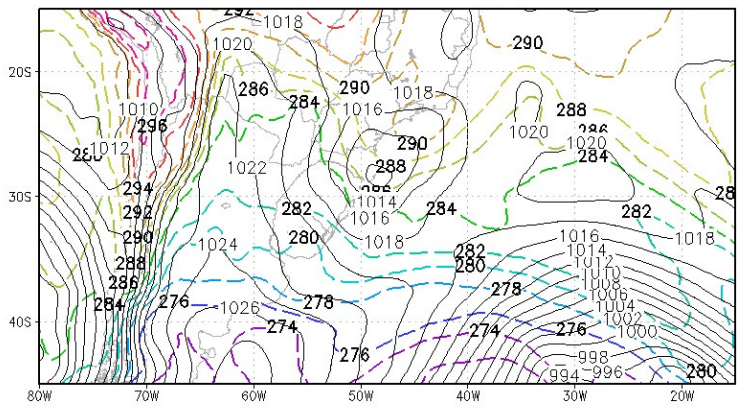

(c)

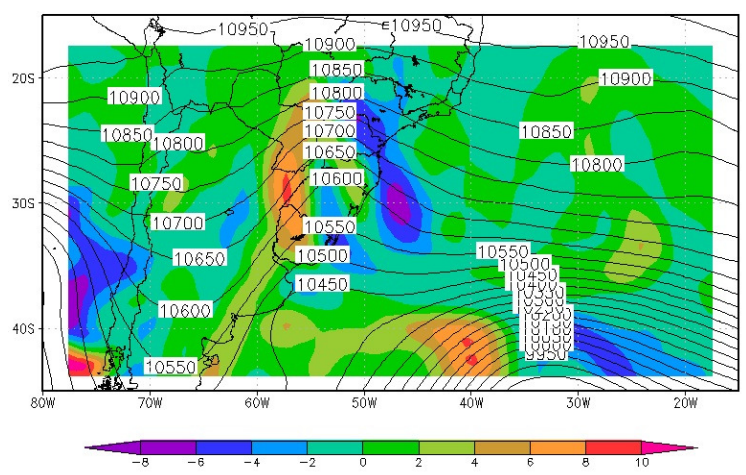

(b)

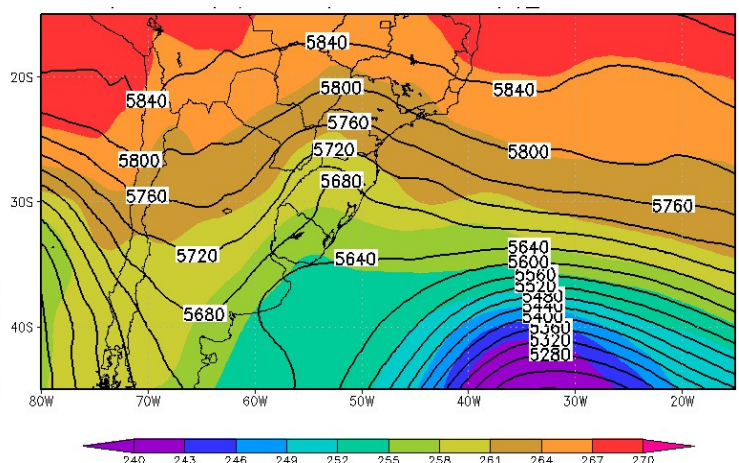

(d)

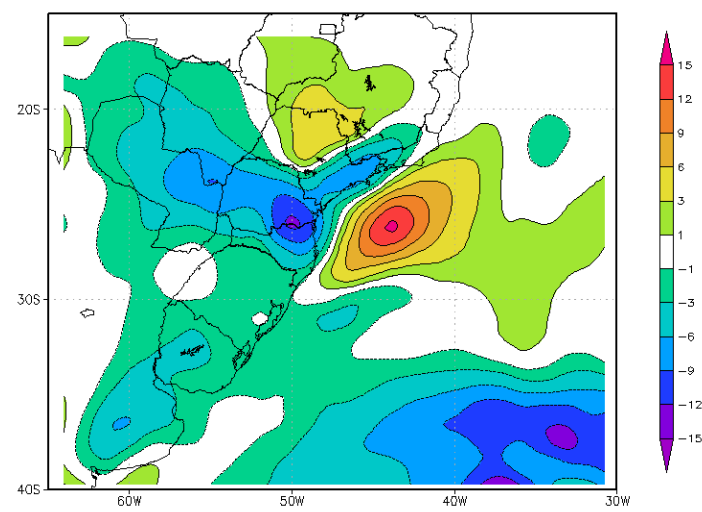

Figura 4.2: Idem à figura 4.1, válida para 1200 UTC de 28 de maio de 1997.

No dia 29 de maio às 0000 UTC, o ciclone em superfície apresenta pressão mínima de $1006 \mathrm{hPa}$ em $44^{\circ} \mathrm{W}-28^{\circ} \mathrm{S}$, (fig. 4.3a). No campo de geopotencial em $500 \mathrm{hPa}$, surge uma baixa fechada em $52^{\circ} \mathrm{W}-35^{\circ} \mathrm{S}$ (fig. 4.3b). A leste do cavado em altos níveis da atmosfera tem-se advecção de vorticidade ciclônica cobrindo uma grande área sobre a baixa em superfície (fig. 4.3c), o que favorece sua intensificação. A advecção de ar frio na retaguarda do ciclone aumenta, amplificando o cavado em níveis médios (fig. 4.3d). 
(a)

(b)
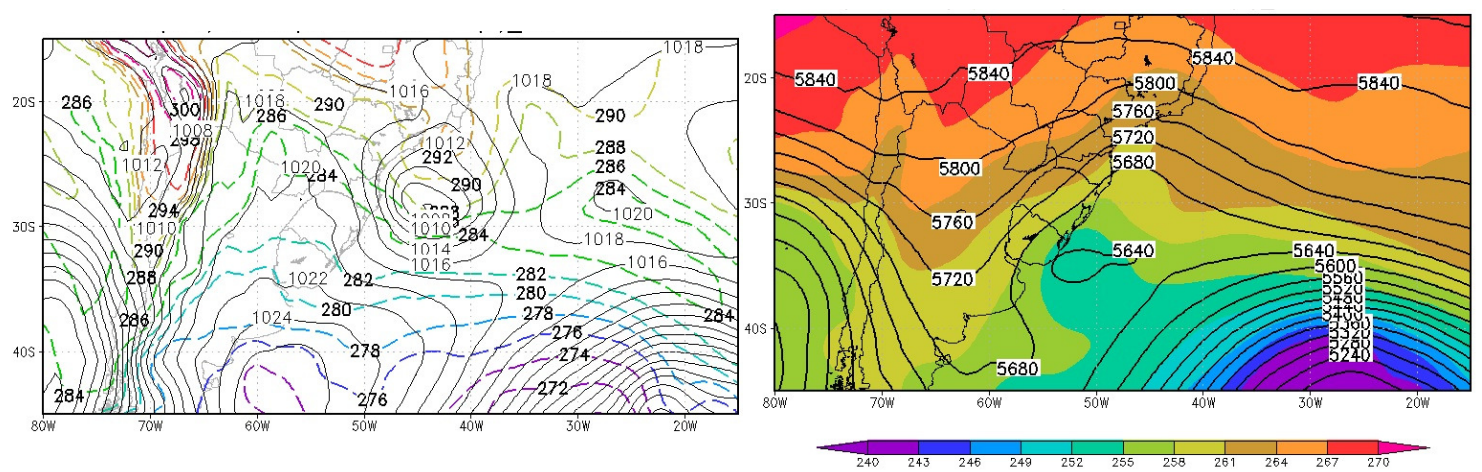

(c)

(d)
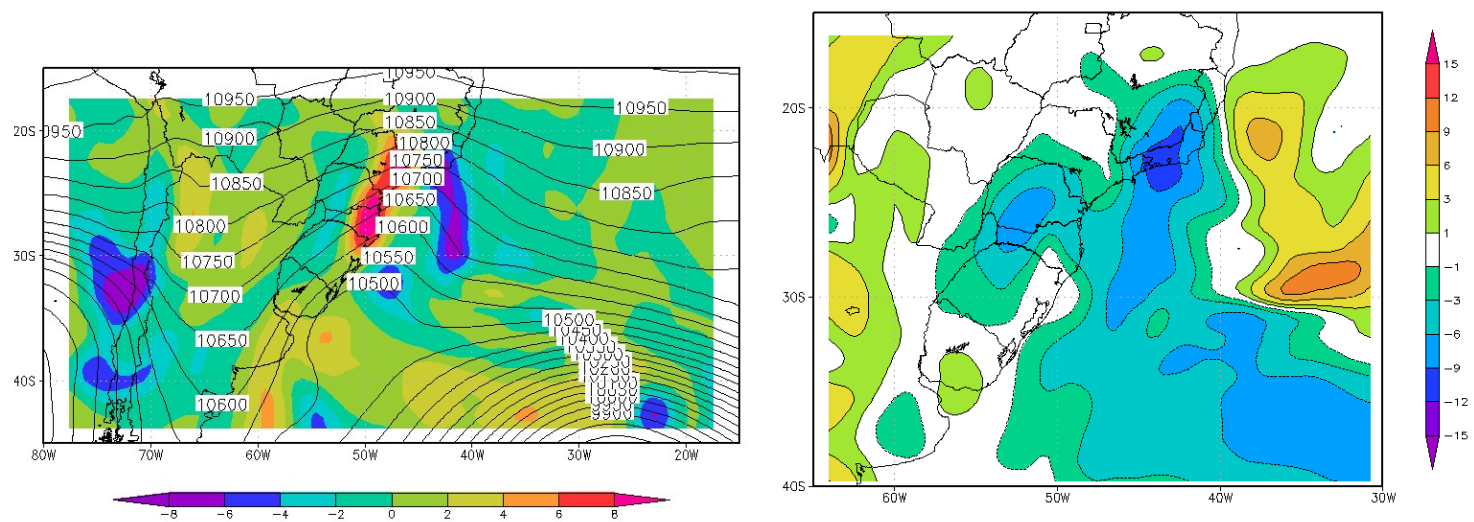

Figura 4.3: Idem à figura 4.1, válido para 1200 UTC de 29 de maio de 1997.

O campo de temperatura potencial equivalente em $925 \mathrm{hPa}$ (fig. 4.4a) exibe gradientes mais intensos próximos de $46^{\circ} \mathrm{W}-24^{\circ} \mathrm{S}$ e $40^{\circ} \mathrm{W}-29^{\circ} \mathrm{S}$ localizando, respectivamente, as frentes fria e quente associadas ao ciclone. Estas regiões frontais, principalmente a frente quente, são evidentes também através da convergência do vento em $925 \mathrm{hPa}$ (fig. 4.4b), que chega a $4 \times 10^{-5} \mathrm{~s}^{-1}\left(\sim 40^{\circ} \mathrm{W}-28^{\circ} \mathrm{S}\right)$. A vorticidade relativa ciclônica (fig. 4.4b) está distribuída uniformemente ao redor do centro do ciclone, não exibindo os padrões frontais. As velocidades máximas do vento em $925 \mathrm{hPa}$, entre 15 e $20 \mathrm{~m} \mathrm{~s}^{-1}$, situam-se a norte-nordeste do centro do sistema (fig. 4.4a). A atividade convectiva organizada pelas frentes pode ser observada na imagem de satélite no infravermelho, como uma banda de nebulosidade se estendendo na direção norte-sul desde o estado do Rio de Janeiro, e outra grande área de nebulosidade na direção leste-oeste, com nuvens de grande desenvolvimento vertical sobre o Atlântico (fig. 4.4c).

No dia 30 de maio, a baixa fechada no campo de geopotencial em $500 \mathrm{hPa}$ amplia sua área de atuação. Na formação desta baixa não se observa aprisionamento de ar frio no centro (fig. 4.5b), não caracterizando, portanto, uma baixa desprendida (PALMÉN e NEWTON, 
1969, NIETO et al., 2005), mas sim um efeito da propagação vertical da circulação do ciclone em superfície. Esta estrutura será melhor discutida na seção 4.3.1.

(a)

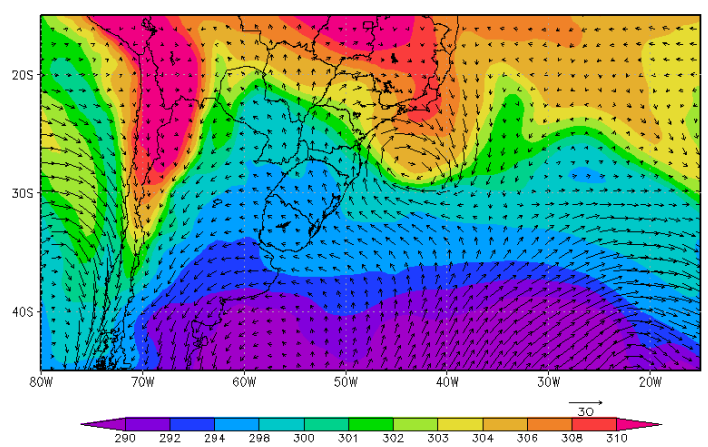

(b)
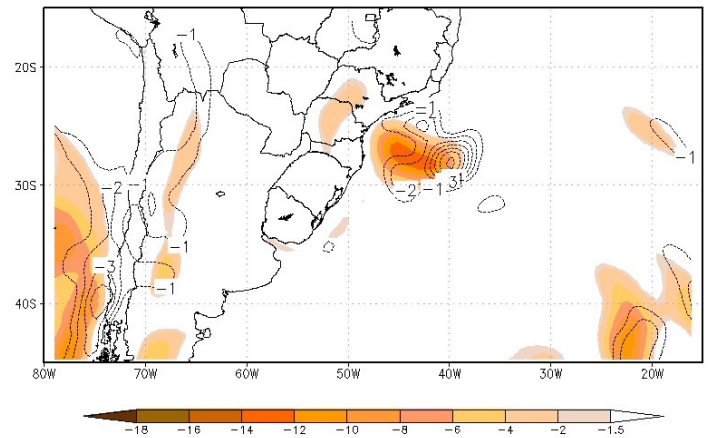

(c)

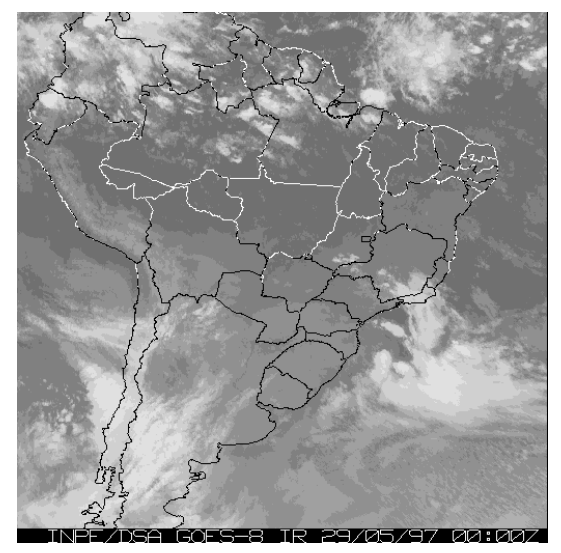

Figura 4.4: (a) Temperatura potencial equivalente $(\mathrm{K})$ e vetor vento horizontal $\left(\mathrm{ms}^{-1}\right)$ em $925 \mathrm{hPa}$, (b) Divergência (linhas tracejadas, em $\times 10^{-5} \mathrm{~s}^{-1}$, apenas valores negativos) e vorticidade relativa ciclônica (sombreada, em $\times 10^{-5} \mathrm{~s}^{-1}$ ) do vento horizontal e (c) imagem do satélite GOES-8 no canal infravermelho, para o dia 29 de maio de 1997 às 0000 UTC.

(a)

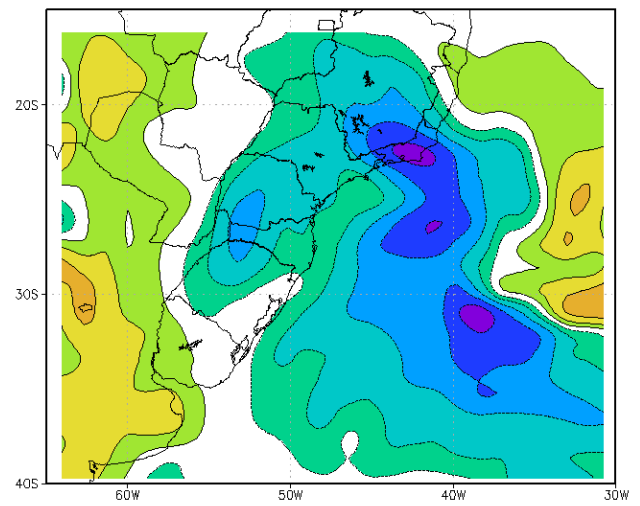

(b)

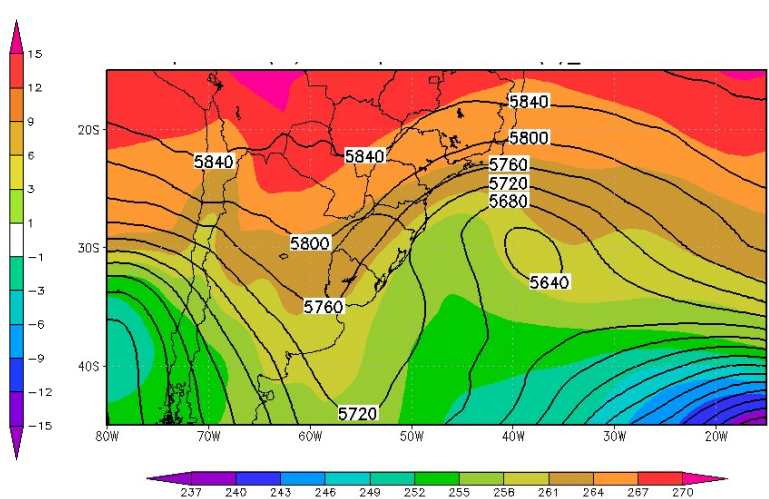

Figura 4.5: (a) Advecção de temperatura em $850 \mathrm{hPa}\left(\mathrm{K} \mathrm{dia}^{-1}\right)$ e (b) altura geopotencial (linha contínua, em m) e temperatura do ar em $500 \mathrm{hPa}$ (sombreado, em K) para 30 de maio de 1997 às 0000 UTC. 
O ciclone segue se intensificando nas 48 horas seguintes, atingindo a menor pressão central até o momento $(998 \mathrm{hPa})$ às 0000 UTC do dia 31 de maio (fig. 4.6a). Neste horário, a distribuição de altura geopotencial em $500 \mathrm{hPa}$ mostra a permanência da baixa fechada (fig. 4.6b), alinhada na vertical com a baixa em superfície, ou seja, o sistema apresenta estrutura barotrópica equivalente. Uma baixa fechada está prestes a se formar também no campo de geopotencial em $250 \mathrm{hPa}$ (fig. 4.6c) e em $850 \mathrm{hPa}$, a advecção de temperatura (fig. 4.6d) atinge $-15 \mathrm{Kdia}^{-1}$ a norte $\mathrm{e}+12 \mathrm{Kdia}^{-1}$ a sul do ciclone.

(a)

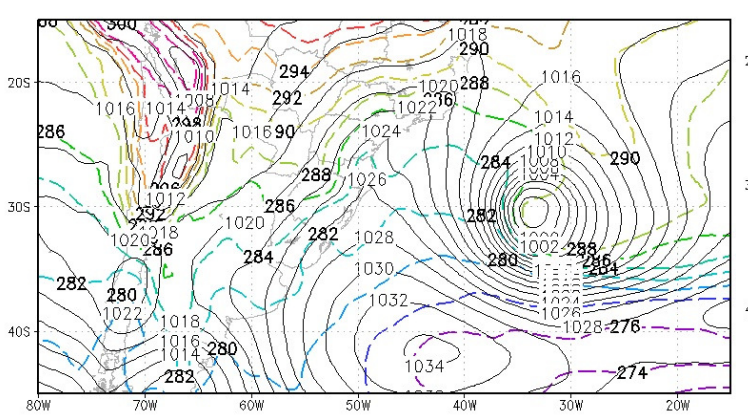

(c)

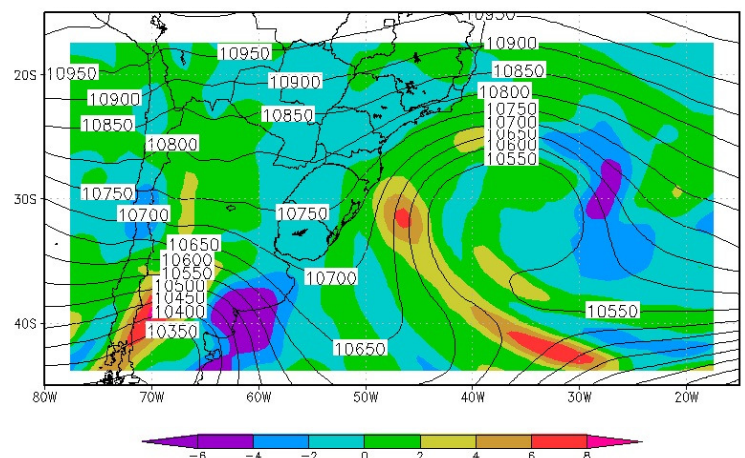

(b)

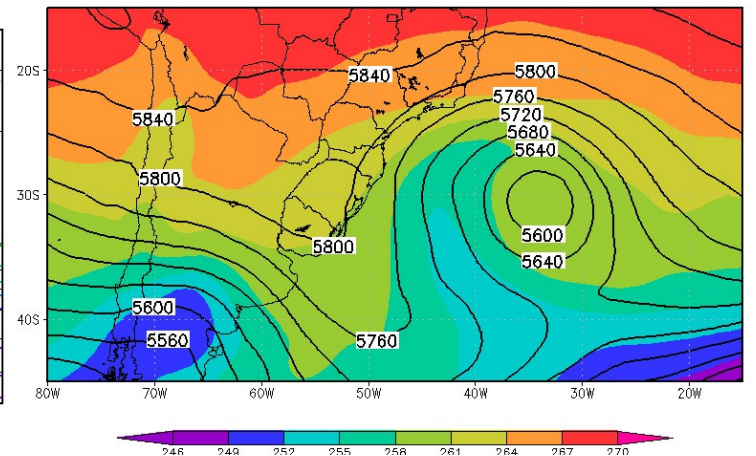

(d)

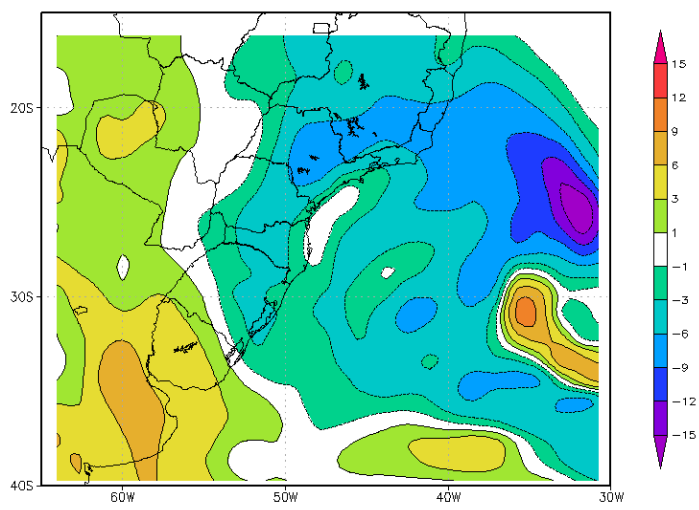

Figura 4.6: Idem à figura 4.1, válido para 0000 UTC de 31 de maio de 1997.

Os perfis de vorticidade relativa no centro deste ciclone mostram que o desenvolvimento da circulação ciclônica iniciou-se em baixos níveis, por volta de $800 \mathrm{hPa}$ (fig. 4.7a). Houve intensificação desta circulação em baixos níveis (fig. 4.7b), e sua posterior propagação na vertical durante os dois dias seguintes. No dia 30 de maio, o sistema exibe uma estrutura equivalente barotrópica, indicando que a baixa fechada no geopotencial de $500 \mathrm{hPa}$ seria devido à propagação vertical da circulação iniciada em baixos níveis. 
(a)

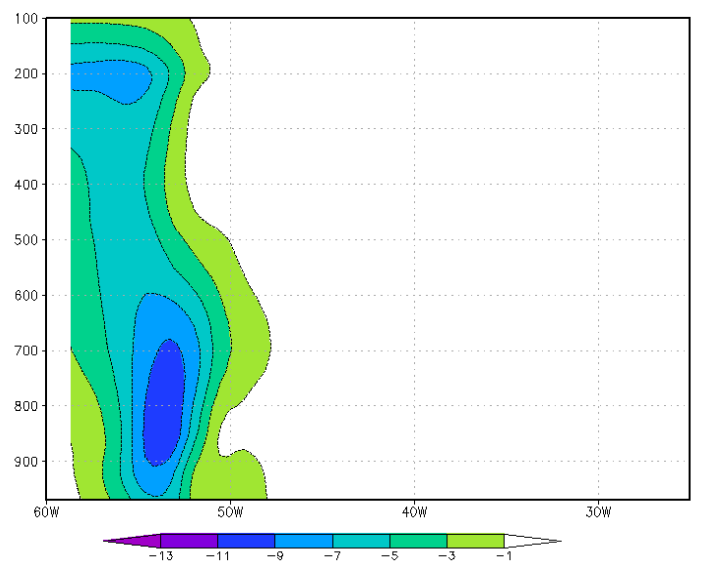

(c)

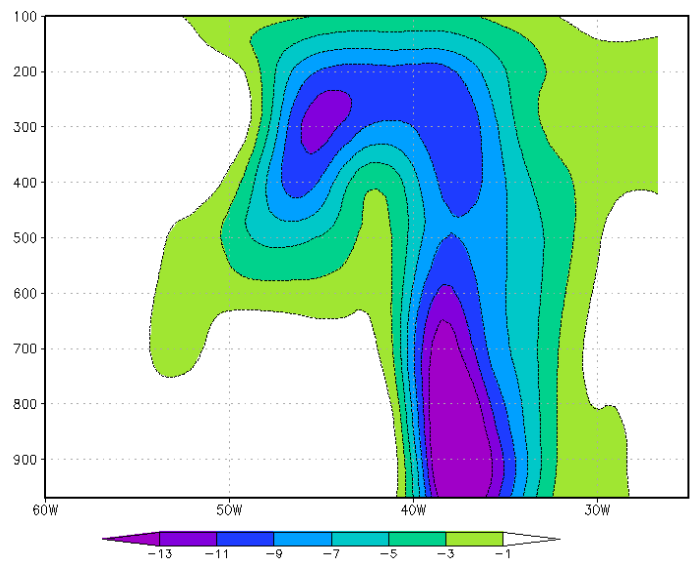

(b)

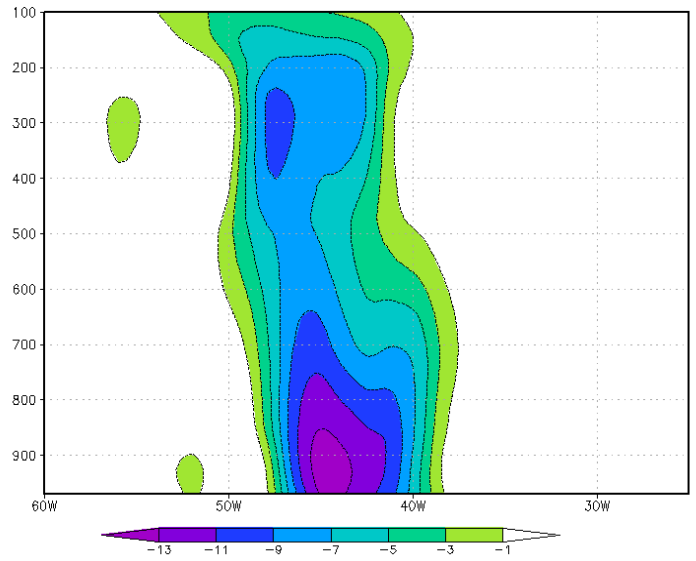

(d)

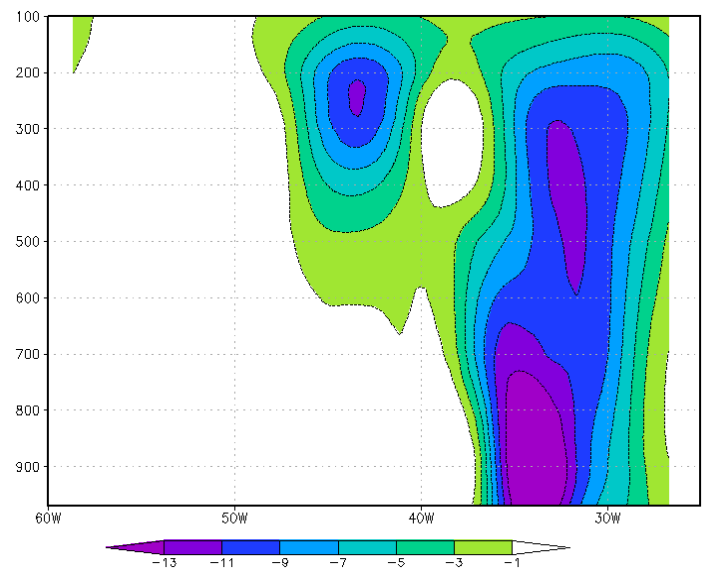

Figura 4.7: Perfil vertical de vorticidade relativa ciclônica $\left(\times 10^{-4} \mathrm{~s}^{-1}\right)$ na latitude do centro do ciclone em (a) 28 de maio, (b) 29 de maio, (b) 30 de maio e (d) 31 de maio de 1997, 0000 UTC.

Em 1200 UTC de 31 de maio, o campo de temperatura potencial equivalente (fig. 4.8a) mostra as frentes fria e quente distintamente separadas, e a formação de uma seclusão quente em $33^{\circ} \mathrm{W}-31^{\circ} \mathrm{S}$, indicativo do processo de decaimento de um ciclone do tipo ShapiroKeyser (SHAPIRO e KEYSER, 1990). As frentes fria e quente, desde as 0000 UTC do dia 30 de maio, exibem o padrão denominado T-bone, onde a frente fria orientada no sentido nortesul intercepta a frente quente orientada no sentido leste-oeste (NEIMAN e SHAPIRO, 1993). Este padrão é melhor observado nos campos de divergência e vorticidade relativa em $925 \mathrm{hPa}$ (fig. 4.8b), nos quais também é possível ver a fratura da frente fria (em aproximadamente $25^{\circ} \mathrm{W}-33^{\circ} \mathrm{S}$ ) e a maior intensidade da região frontal quente, outras duas características deste modelo conceitual. Estas características também foram verificadas, neste ciclone, por CAMPOS (1999). O setor sudoeste do ciclone apresenta os ventos mais intensos (superiores a $25 \mathrm{~ms}^{-1}$ ), devido ao forte gradiente de pressão na região, resultado do aprofundamento do ciclone e da aproximação de um anticiclone de 1034 hPa à sudoeste (fig. 4.6a). 
(a)

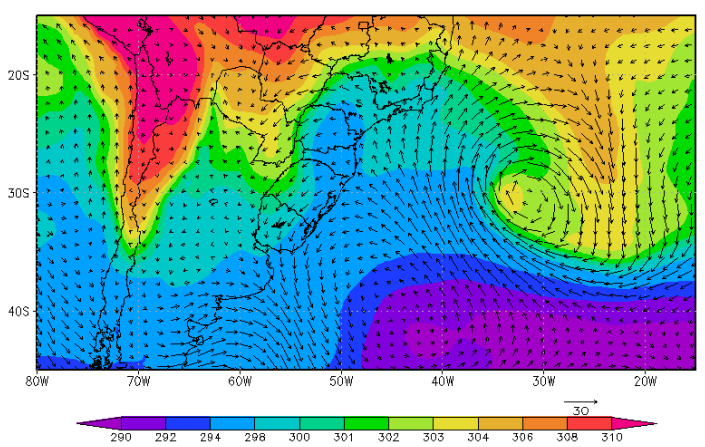

(b)

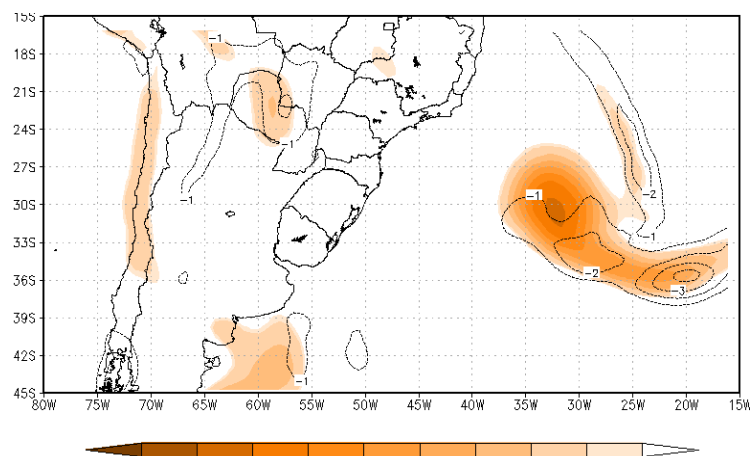

Figura 4.8: (a) Temperatura potencial equivalente $(\mathrm{K})$ e vetor vento horizontal $\left(\mathrm{ms}^{-1}\right)$, e (b) vorticidade relativa (sombreado, em $\times 10^{-5} \mathrm{~s}^{-1}$ ) e divergência (linha tracejada, em $\times 10^{-5} \mathrm{~s}^{-1}$, apenas valores negativos) do vento horizontal em $925 \mathrm{hPa}$, para 1200 UTC de 31 de maio de 1997, segundo a reanálise Era-Interim.

A partir do dia 01 de junho, o sistema começa a enfraquecer e a pressão central sofre um pequeno aumento ( $2 \mathrm{hPa}$ ). O campo de geopotencial em baixos e médios níveis segue mostrando o alinhamento vertical da baixa, e o sistema apresenta estrutura equivalente barotrópica (figura não apresentada). A velocidade de deslocamento do ciclone diminui, e entre 01 de junho e 03 de junho o ciclone registra velocidade média de apenas $2 \mathrm{~ms}^{-1}$. Esta baixa velocidade de deslocamento pode estar associada com a diminuição da advecção de vorticidade em médios e altos níveis provocada pela circulação ciclônica fechada em $500 \mathrm{hPa}$ (IWABE, 2008; REBOITA et al., 2009), que persiste até o dia 02 de junho. Em 04 de junho, a aproximação de um cavado em $250 \mathrm{hPa}$ gera intensa advecção de vorticidade ciclônica sobre o sistema, que ainda situa-se em área com fluxos de calor sensível e latente da ordem de +70 $\mathrm{Wm}^{-2}$ e $+300 \mathrm{Wm}^{-2}$, respectivamente, e o ciclone volta a se intensificar, formando um novo sistema com ciclo de vida independente.

\subsubsection{FCSL associados ao ciclone e validação do EXPCOM97}

O modelo WRF simulou satisfatoriamente o ciclone 1, quando incluídos os fluxos de calor e umidade de superfície. A figura 4.9 mostra a evolução temporal dos campos de pressão ao nível do mar e temperatura em $925 \mathrm{hPa}$ de acordo com a reanálise Era-Interim (a, c, e, g) e com o EXPCOM97 (b, d, f, h). 
(a)

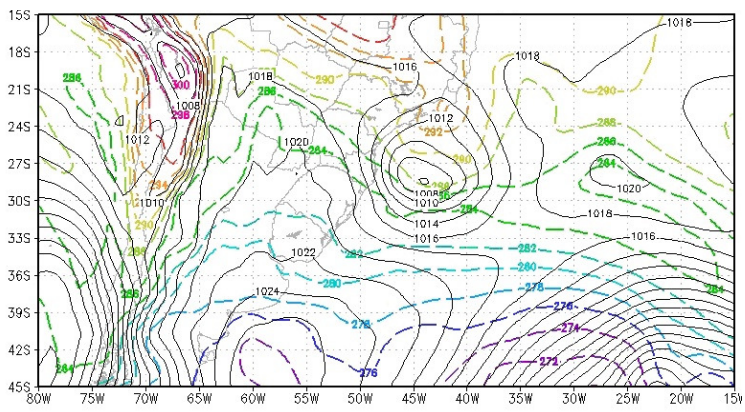

(c)

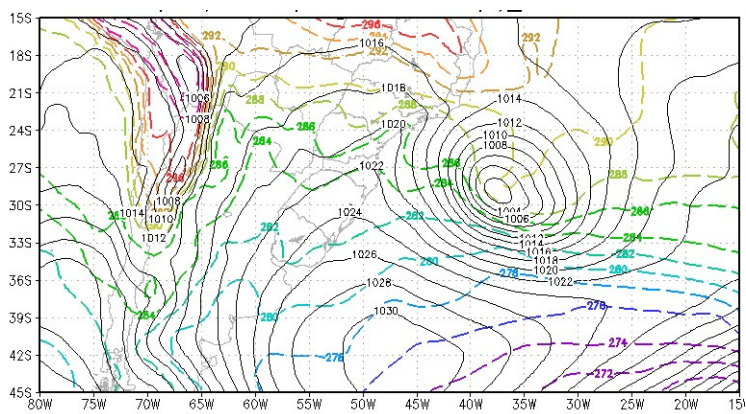

(e)

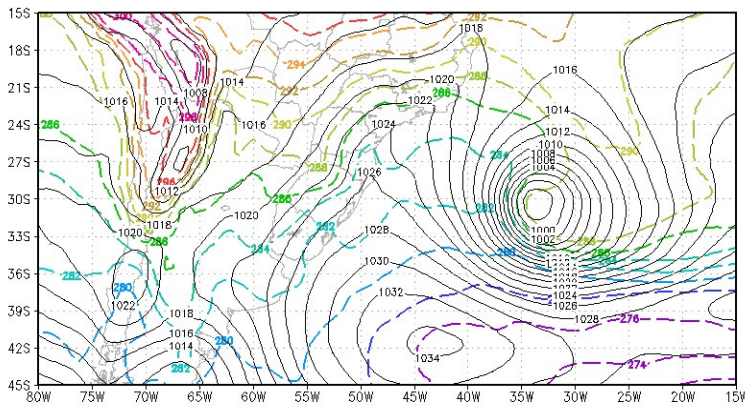

(g)

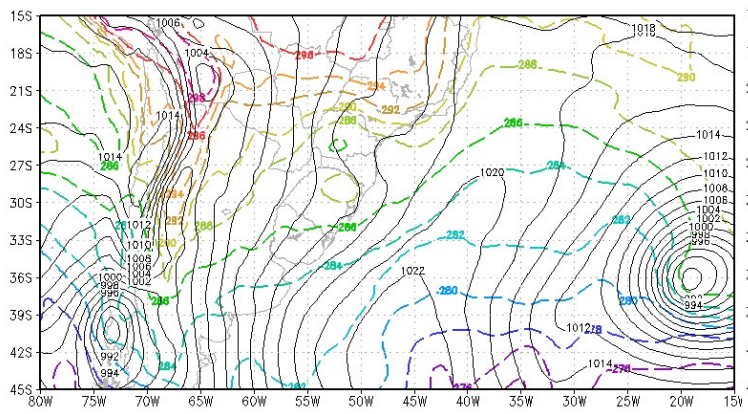

(b)

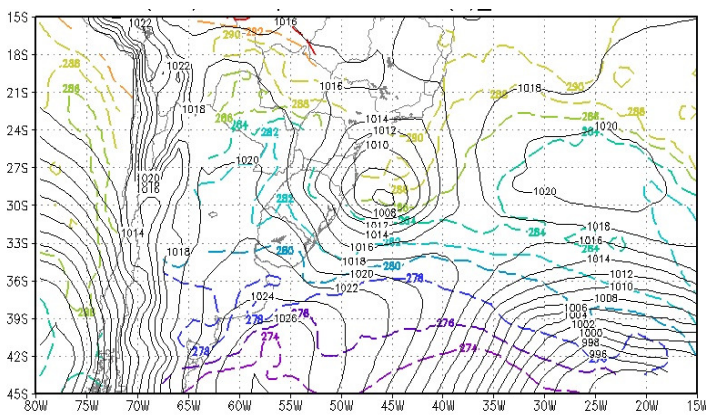

(d)

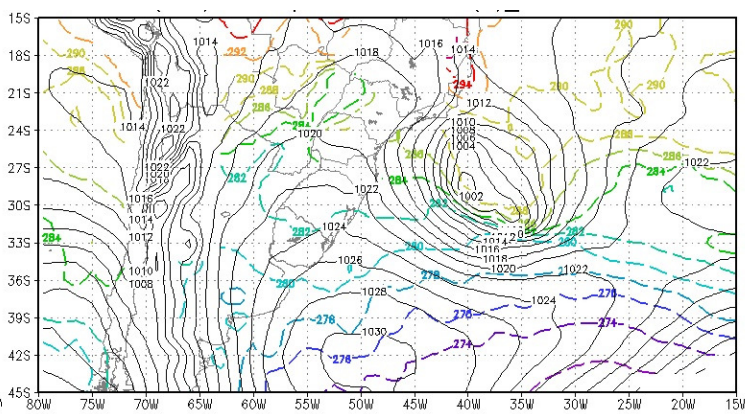

(f)

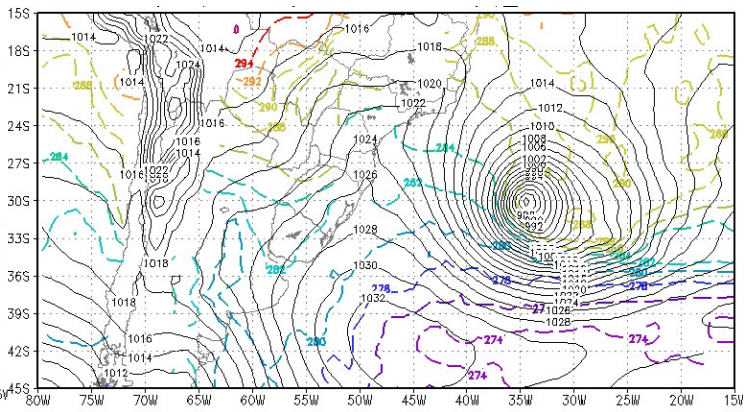

(h)

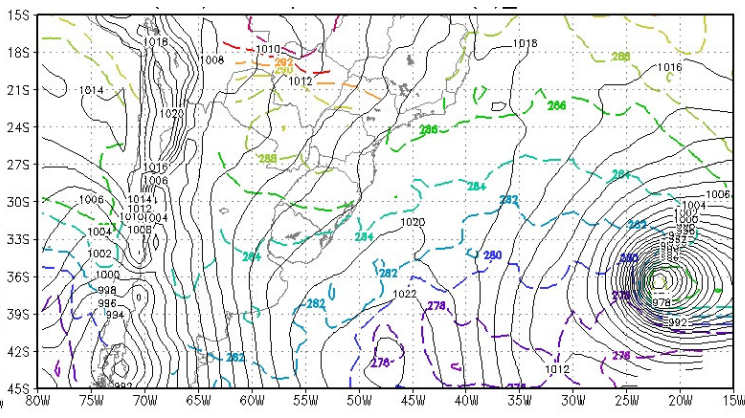

Figura 4.9: PNMM (linha contínua, em hPa) e temperatura do ar em $925 \mathrm{hPa}$ (linha traceada, em K), da reanálise Era-Interim para os dias (a) 29, (c) 30, (e) 31 de maio e (g) 04 de junho, 0000 UTC; e EXPCOM97 para os dias (b) 29, (d) 30 e (f) 31 de maio e (h) 04 de junho, 0000 UTC. 
Na figura 4.9 observa-se que a posição e deslocamento do ciclone foram bem simulados pelo EXPCOM97, assim como a distribuição espacial de temperatura em baixos níveis. O período em que o sistema apresentou pouco deslocamento, entre 01 de junho e 03 de junho, foi também capturado pelo EXPCOM97 e no dia 04 de junho (figs. $4.9 \mathrm{~g}$ e $4.9 \mathrm{~h}$ ) o ciclone encontra-se em posição semelhante na análise e na simulação. No entanto, o EXPCOM97 apresenta um ciclone mais profundo, com diferença de pressão central entre simulação e reanálise de $12 \mathrm{hPa}$ no dia 31 de maio às 0000 UTC (figs 4.9e e 4.9f), e ao final do período de análise (04 de junho) a diferença atinge $20 \mathrm{hPa}$ (figs. 4.9g e 4.9h).

O campo de altura geopotencial em $500 \mathrm{hPa}$ do EXPCOM97 é muito semelhante ao do Era-Interim até o dia 29 de maio (figuras não apresentadas). No dia 30 de maio começa a se fechar uma baixa quente em níveis médios na reanálise (fig. 4.10a), o que não ocorre na simulação (fig. 4.10b). O EXPCOM97 simula este sistema 12 horas depois, em 30 de maio às 1200 UTC. No dia 31 de maio às 1200 UTC, as baixas encontram-se na mesma posição, e o campo de temperatura do ar apresenta um centro mais quente na simulação (figs. 4.10c e 4.10d). Esta baixa se mantém até o dia 02 de junho às 0000 UTC na reanálise, mas o EXPCOM97 ainda simula esta circulação (fig. 4.10f) até o dia 04 de junho (figura não mostrada). O setor oeste da onda de temperatura no EXPCOM97 é mais frio do que na reanálise. 
(a)

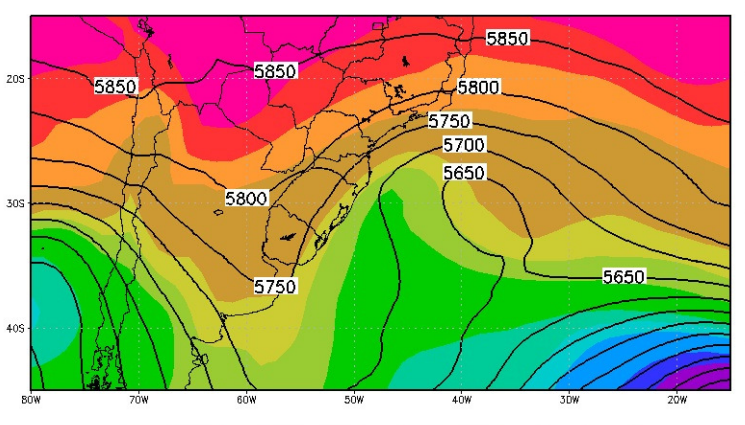

(c)

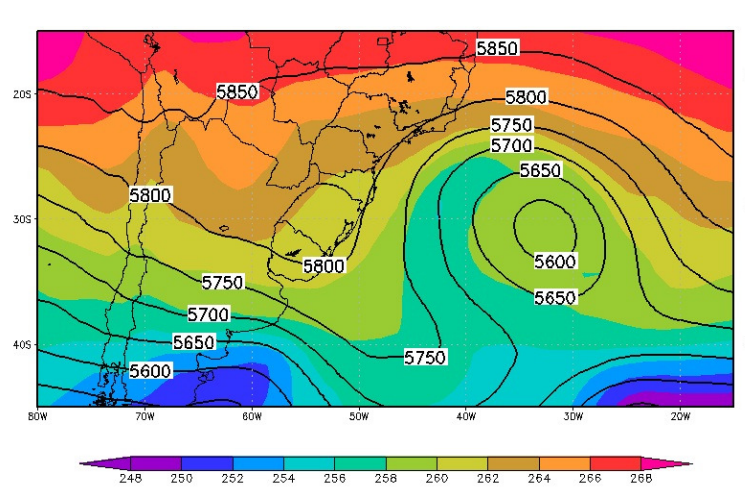

(e)

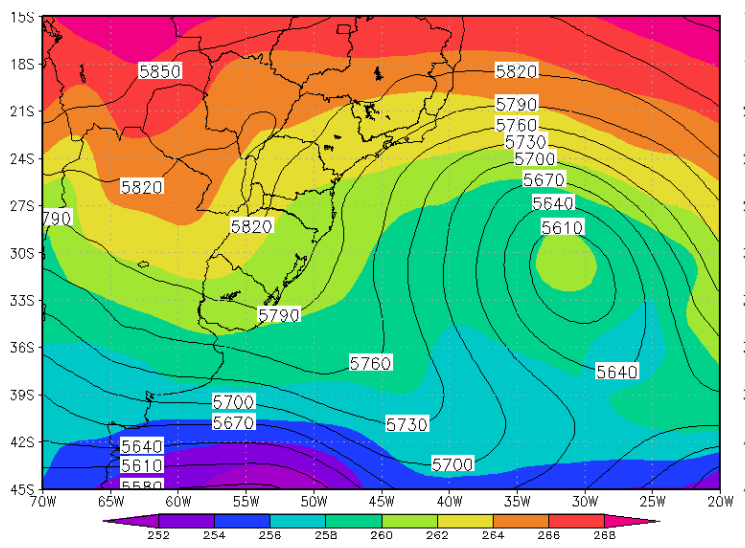

(b)

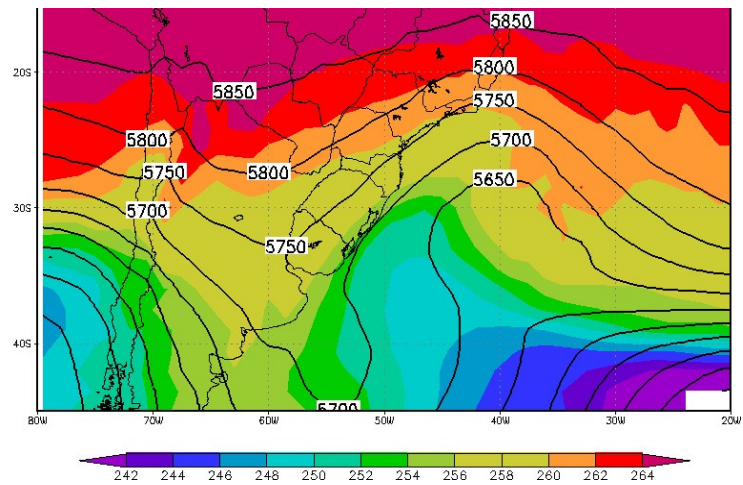

(d)

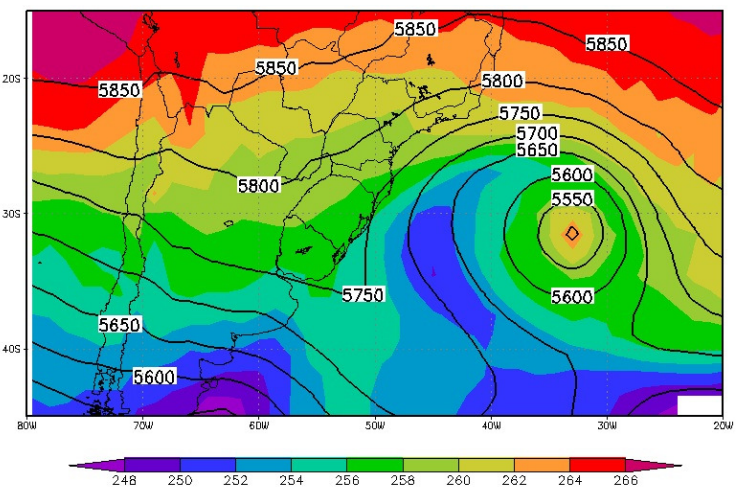

(f)

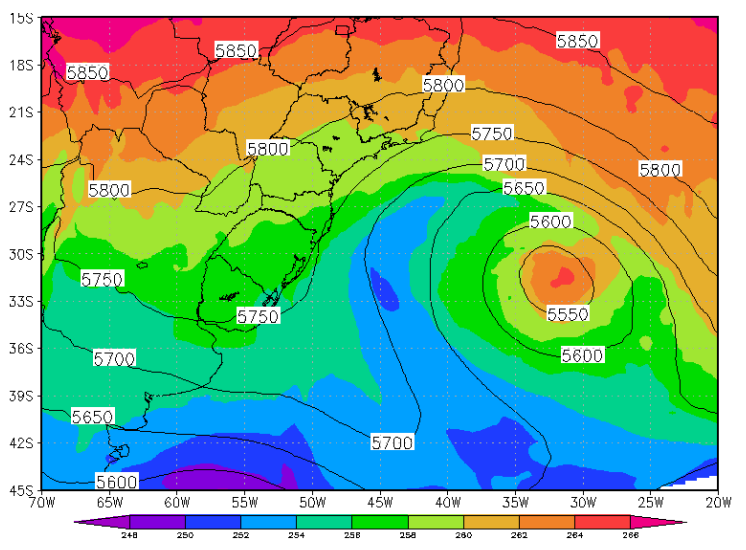

Figura 4.10: Altura geopotencial (linha contínua, em m) e temperatura do ar (sombreado, em $\mathrm{K}$ ) segundo a reanálise Era-Interim para os dias (a) 30 de maio às 0000 UTC, (c) 31 de maio às 1200 UTC e (e) 01 de junho às 0000 UTC, e segundo o EXPCOM97 para os dias (b) 30 de maio às 0000 UTC, (d) 31 de maio às 1200 UTC e (f) 01 de junho às 0000 UTC 
(a)

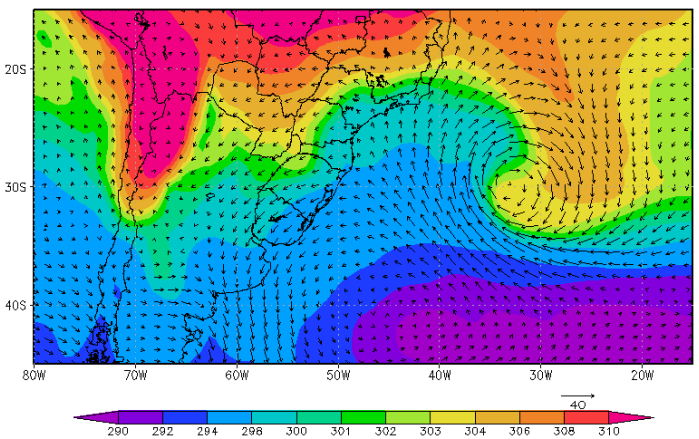

(c)

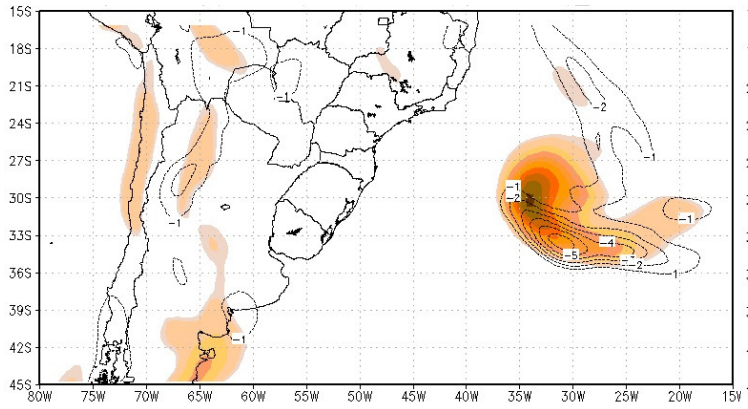

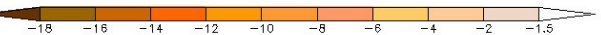

(b)

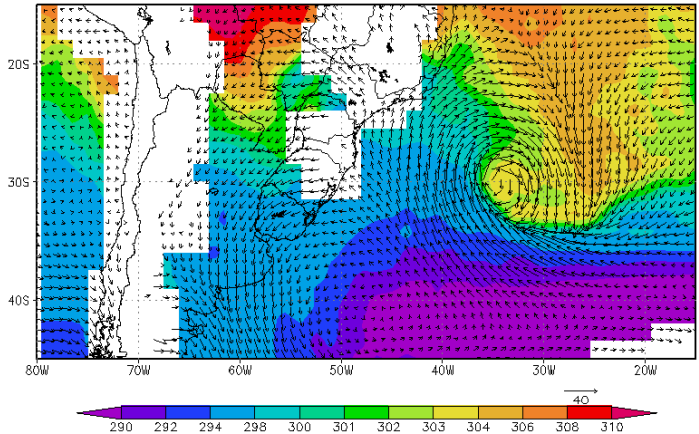

(d)

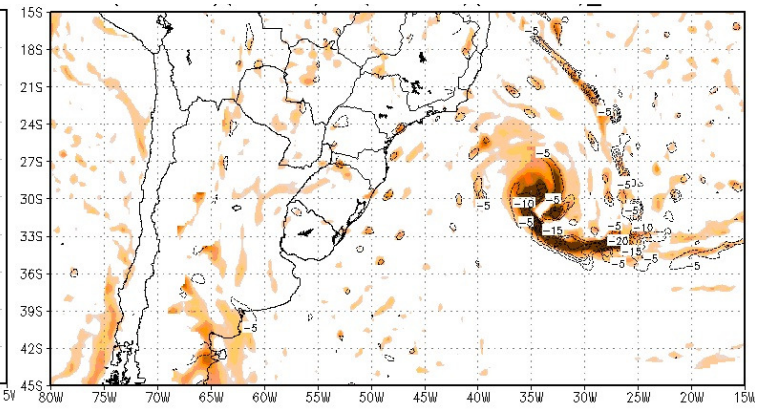

$\begin{array}{llllllllll}-18 & -16 & -14 & -12 & -10 & -8 & -6 & -4 & -2 & -1.5\end{array}$

Figura 4.11: Temperatura potencial equivalente (K) e vetor vento em $925 \mathrm{hPa}$ para (a) a reanálise Era-Interim e (b) EXPCOM97; vorticidade relativa ciclônica (sombreado, $\times 10^{-5} \mathrm{~s}^{-1}$ ) e divergência (linha tracejada, $\times 10^{-5} \mathrm{~s}^{-1}$, apenas valores negativos) do vento horizontal em $925 \mathrm{hPa}$ para (c) a reanálise Era-Interim e (d) EXPCOM97, para o dia 31 de maio de 1997 às 0000 UTC.

Os sistemas frontais no EXPCOM97, conforme mostra a figura 4.11(a-d), encontramse em posição semelhante às da reanálise. Já com relação aos ventos, estes são mais intensos no EXPCOM97, pois o anticiclone centrado em $45^{\circ} \mathrm{W}-42^{\circ} \mathrm{S}$ possui $1030 \mathrm{hPa}$, concordando com a reanálise, mas no ciclone a pressão é menor (com diferença de até $10 \mathrm{hPa}$ ), resultando em maior gradiente de pressão e ventos mais intensos a sudoeste do ciclone. As figuras 4.11c e 4.11d mostram que o EXPCOM97 tende a superestimar a intensidade dos sistemas frontais: a frente quente simulada apresenta valores de vorticidade relativa em $925 \mathrm{hPa}$ de até $20 \times 10^{-5}$ $\mathrm{s}^{-1}$, enquanto a reanálise registra um núcleo máximo de $5 \times 10^{-5} \mathrm{~s}^{-1}$. Isto ocorre durante toda a simulação e deve estar associado à circulação mais intensa simulada pelo EXPCOM97, além de processos da camada limite (discutidos na seção 4.3).

A média diária do fluxo de calor sensível segundo a reanálise WHOI para o dia 28 de maio de 1997 (fig. 4.12a) próxima à região do ciclone (em cerca de $48^{\circ} \mathrm{W}-30^{\circ} \mathrm{S}$ ), apresenta valores superiores a $70 \mathrm{Wm}^{-2}$, quase 5 vezes o valor médio entre 1958-2008 para a região. O 
EXPCOM97 simulou corretamente a distribuição espacial dos fluxos de calor sensível nas proximidades do ciclone (fig. 4.12b).

No dia 29 de maio, fluxos de calor sensível intensos ocorrem a sul do ciclone, posicionado na costa da região Sul, e estes são bem representados pela simulação (figs. 4.12cd). No EXPCOM97, os fluxos continuam mais intensos a norte do ciclone. Em 30 de maio, uma extensa área de fluxos acima de $70 \mathrm{Wm}^{-2}$ se localiza a sul-sudoeste do sistema, e no setor quente (adiante da frente fria e atrás da frente quente) os fluxos são menores e em alguns pontos negativos (fig. 4.12e). Este padrão de distribuição é simulado corretamente no EXPCOM97 (fig. 4.12f). O mesmo ocorre para o dia 31 de maio (figs. 4.12g e 4.12h), embora

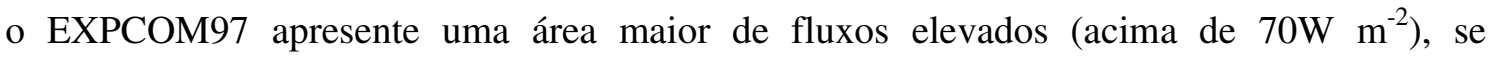
estendendo de $42^{\circ} \mathrm{S}$ a $18^{\circ} \mathrm{S}$. Este comportamento ocorre até o final da simulação.

O fluxo de calor latente (fig. 4.13) apresentou comportamento semelhante ao do calor sensível. Isto era esperado, pois as regiões de advecção fria associadas à circulação do anticiclone a sudoeste e ao ciclone são também regiões de advecção de ar seco, que promove maior evaporação da superfície do oceano. Novamente é interessante observar o núcleo de alto valor de fluxo de calor latente na costa sul do Brasil no início do desenvolvimento do ciclone tanto no WHOI como no EXPCOM97 (fig. 4.13a-b). Além disto, o EXPCOM97 tende a superestimar as áreas de máximo fluxo de calor latente (por exemplo, fig. 4.13h). As diferenças entre os fluxos da reanálise e do EXPCOM97 podem ser devido a uma maior intensificação do ciclone simulado, que com ventos mais intensos contribui para maior transferência de umidade entre oceano e atmosfera.

Durante todo o período mostrado pelas figuras 4.12 e 4.13, tanto o WHOI como o EXPCOM97 mostram que no ciclone 1 a maior transferência de calor sensível e latente ocorre no setor frio, atrás da frente fria e na dianteira da frente quente, regiões de ar mais frio e seco. Este comportamento difere do ciclone intenso estudado por DAL PIVA et al. (2008), onde praticamente toda a transferência de calor e umidade ocorre no setor quente (reforçando a baroclinia do sistema). 
(a)
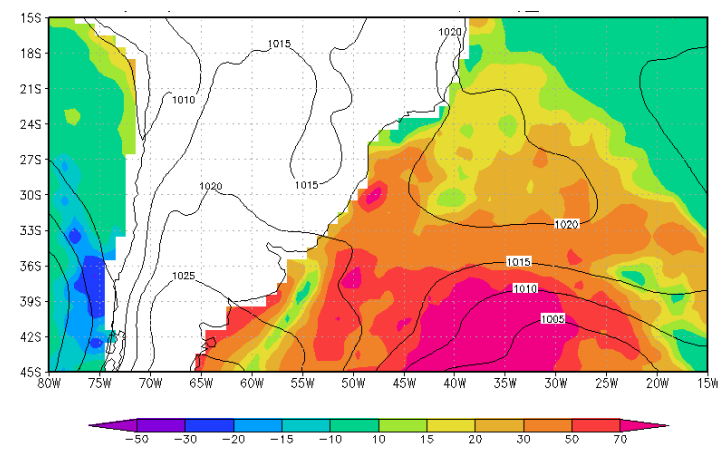

(c)
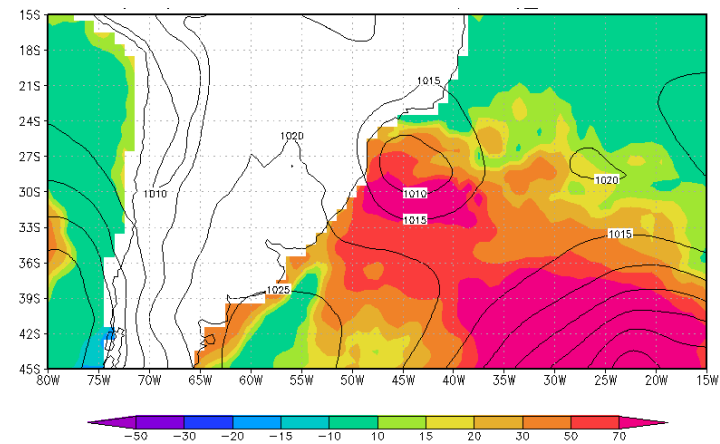

(e)

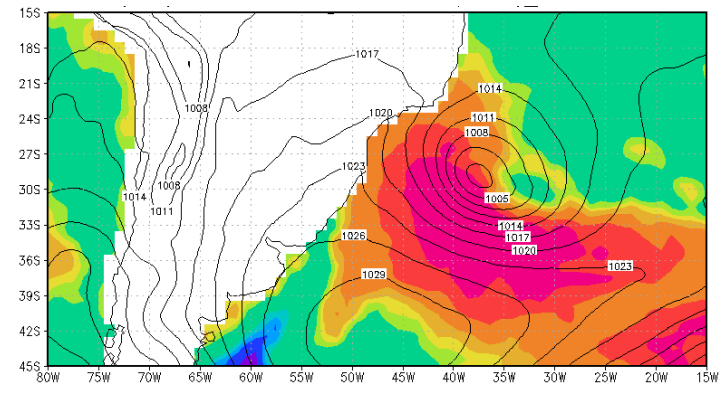

\begin{tabular}{lllllllllllll}
-50 & -30 & -20 & -15 & -10 & 10 & $\frac{1}{15}$ & $\frac{1}{20}$ & $\frac{1}{30}$ & $\frac{1}{50}$ & 70 \\
\hline
\end{tabular}

(g)

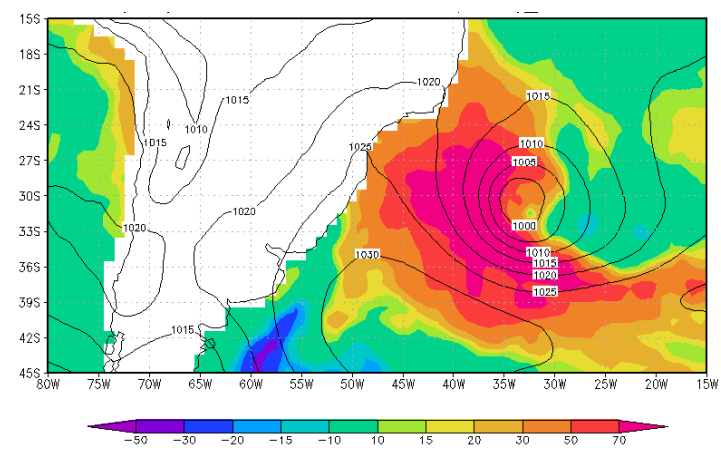

(b)

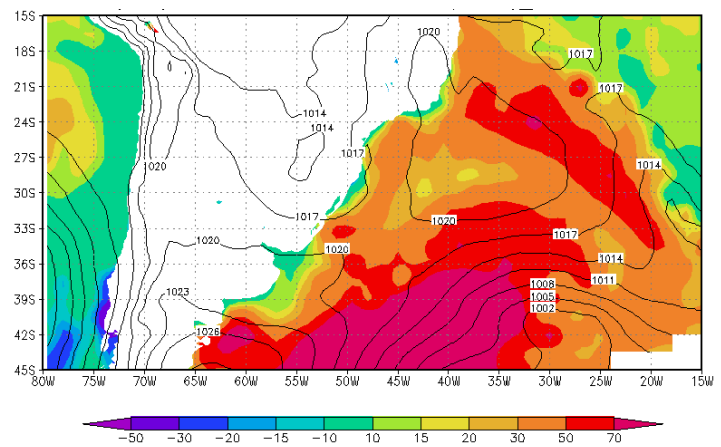

(d)

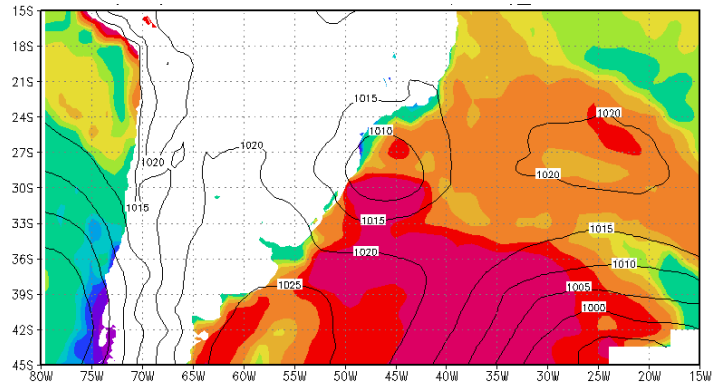

(f)

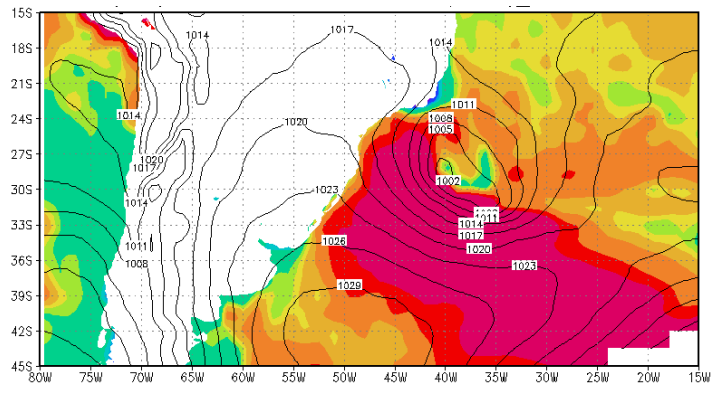

(h)

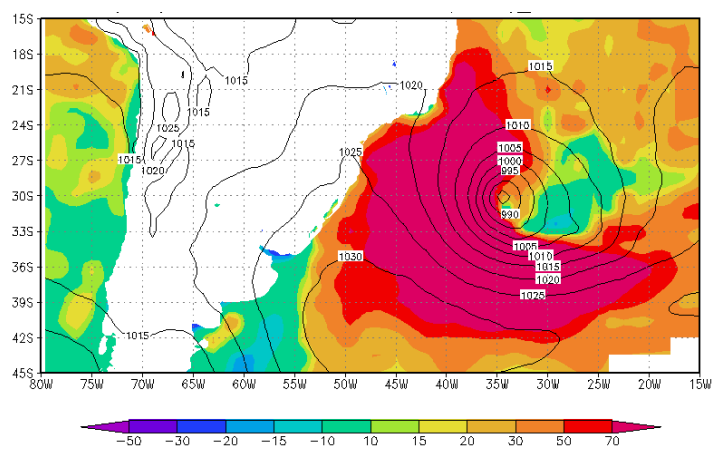

Figura 4.12: PNMM (linha contínua, em hPa) segundo a reanálise Era-Interim e fluxo de calor sensível (sombreado, em $\mathrm{Wm}^{-2}$ ) segundo a reanálise WHOI para os dias (a) 28, (c) 29, (e) 30 e (g) 31 de maio de 1997, e segundo o EXPCOM97 para os dias (b) 28, (d) 29, (f) 30 e (h) 31 de maio de 1997. 
(a)

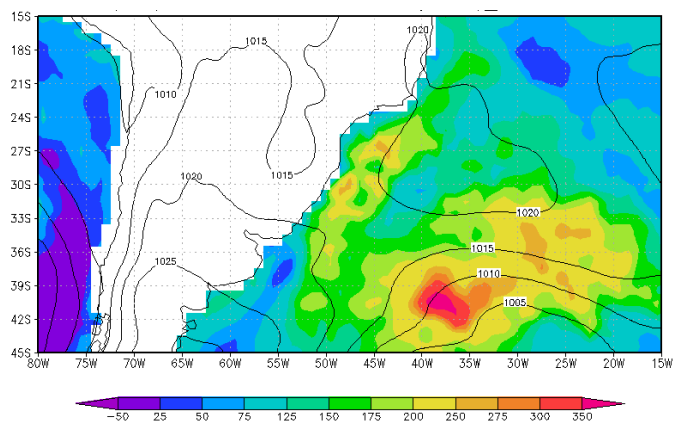

(c)
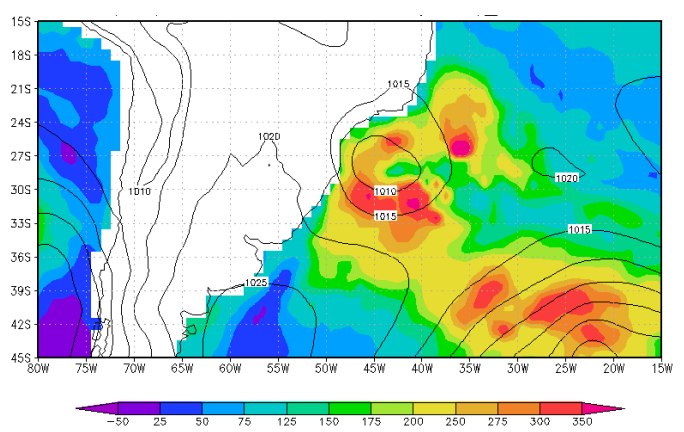

(e)

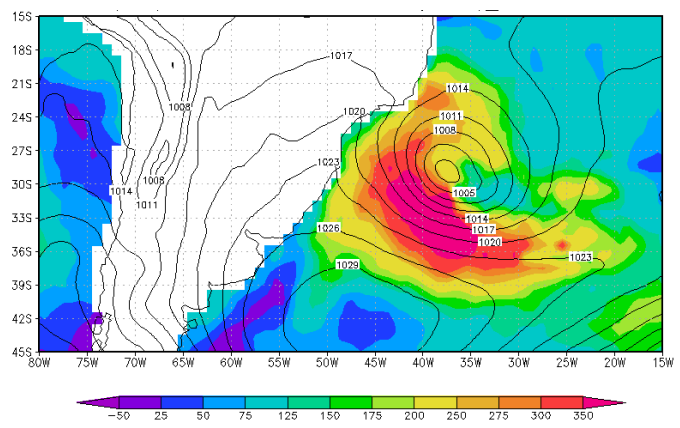

(g)

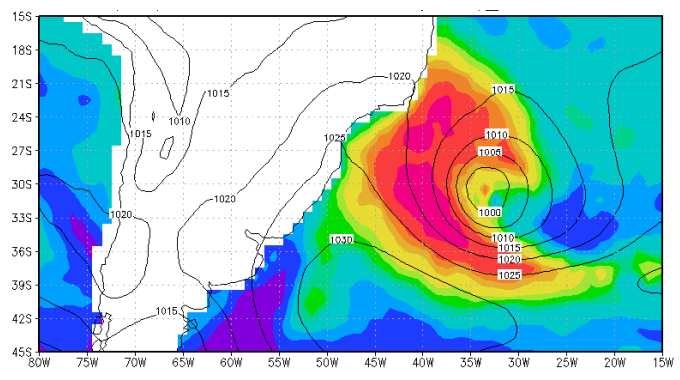

$\begin{array}{lllllllllllll}50 & 25 & 50 & 75 & 125 & 150 & 175 & \frac{1}{200} & \frac{1}{250} & \frac{1}{275} & & & \\ 300 & 350\end{array}$ (b)

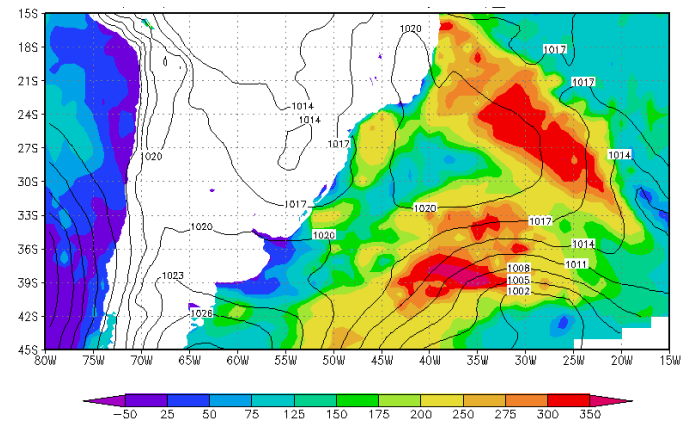

(d)

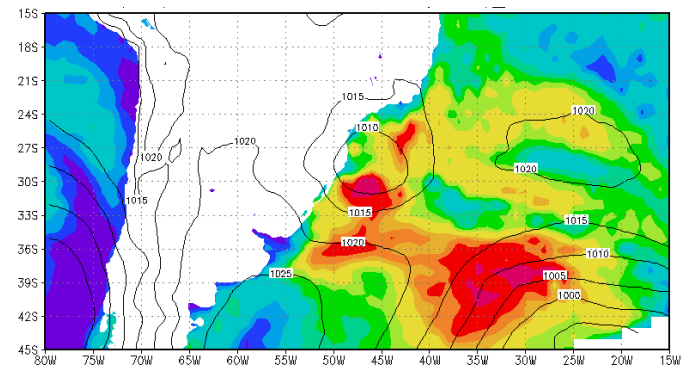

(f)

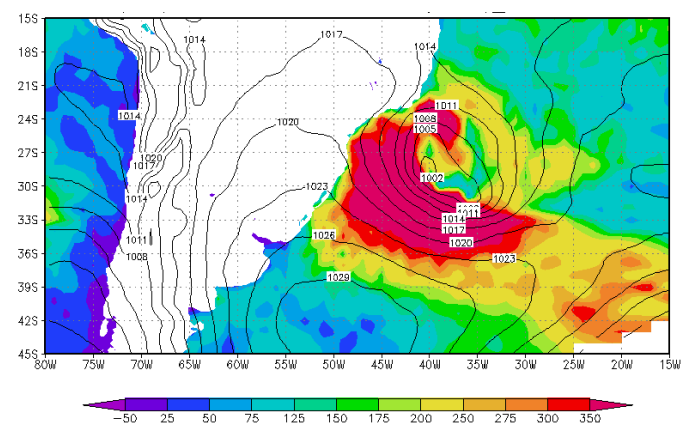

(h)

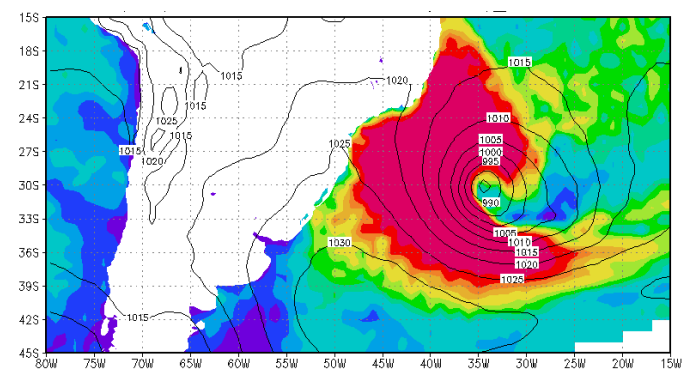

$\begin{array}{llllllllllll}-50 & 25 & 50 & 75 & 125 & 150 & 175 & 200 & 250 & 275 & 300 & 350\end{array}$

Figura 4.13: PNMM (linha contínua, em $\mathrm{hPa}$ ) segundo a reanálise Era-Interim e fluxo de calor latente (sombreado, em $\mathrm{Wm}^{-2}$ ) segundo a reanálise WHOI para os dias (a) 28, (b) 29, (c) 30 e (d) 31 de maio de 1997 e segundo o EXPCOM97 para os dias (b) 28, (d) 29, (f) 30 e (h) 31 de maio de 1997 (b, d, f, h). 


\section{2. Ciclone 2 (12 de abril de 2000)}

\subsubsection{Análise sinótica}

No dia 12 de abril (0000 UTC), um cavado em $500 \mathrm{hPa}$ se aproxima do Uruguai (figura não apresentada). Nas 12 horas seguintes, fecha-se no campo de geopotencial uma baixa desprendida de núcleo frio (fig. 4.14a). O padrão de vorticidade potencial isobárica em $350 \mathrm{hPa}$ (fig. 4.14b), com valores inferiores a $-1,5 \mathrm{UVP}\left(1 \mathrm{UVP}=10^{-6} \mathrm{~m}^{2} \mathrm{~kg}^{-1} \mathrm{~s}^{-1} \mathrm{~K}\right)$, sugere que há incursão horizontal de ar de latitudes mais altas para os subtrópicos. Em outras palavras, o ar estratosférico de altas latitudes está atingindo a troposfera subtropical, favorecendo o desenvolvimento da baixa desprendida que, por sua vez, pode induzir ciclogênese em baixos níveis (HOSKINS et al., 1985).

(a)

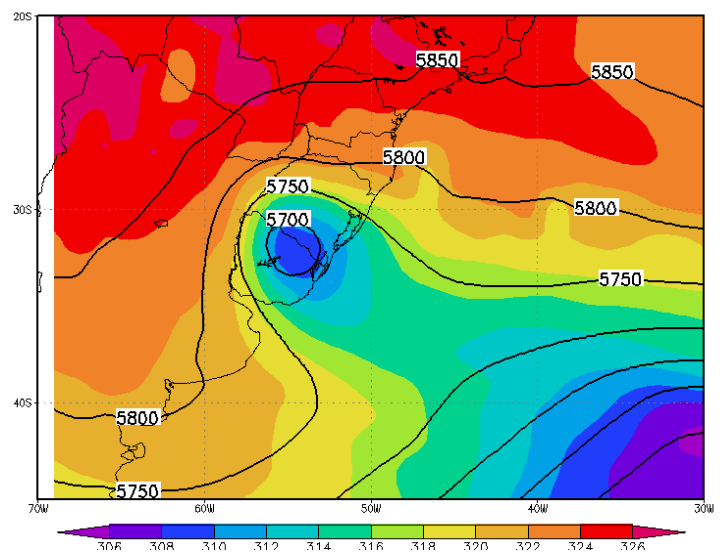

(b)

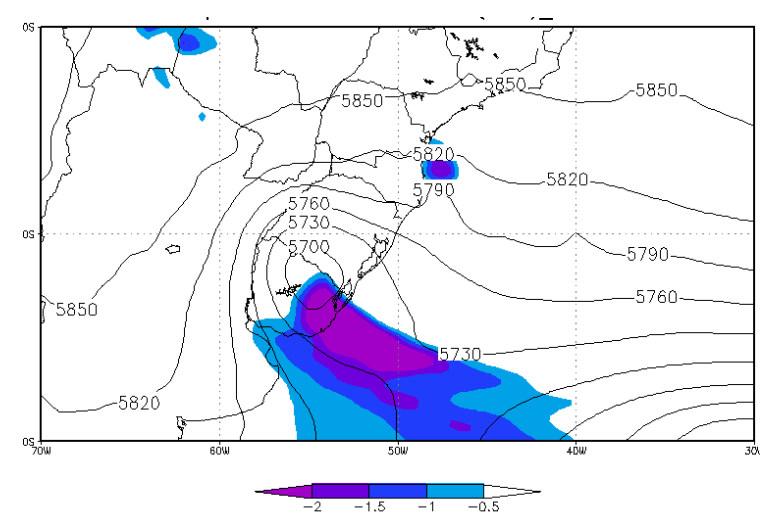

Figura. 4.14: (a) Altura geopotencial (sombreado, em m) e temperatura do ar (linha tracejada, em K) em 500 $\mathrm{hPa}$; (b) Vorticidade potencial isobárica (sombreado, em UVP) em $350 \mathrm{hPa}$ e altura geopotencial (linha contínua, em m) em $500 \mathrm{hPa}$, para as 1200 UTC de 12 de abril de 2000.

Em 13 de abril às 0000 UTC, o campo de PNMM mostra um cavado invertido em superfície na costa de Santa Catarina (fig. 4.15a). Nesta região os fortes gradientes na temperatura do ar em $925 \mathrm{hPa}$ indicam a existência de uma zona baroclínica (cerca de $12 \mathrm{~K} / 600 \mathrm{~km}$ ). Em $500 \mathrm{hPa}$, a baixa desprendida aumenta a sua área de atuação e caracterizase pela presença de núcleo frio (fig. 4.15b). Os campos de temperatura do ar e geopotencial já estão em fase, não apresentando a defasagem ideal para futuro desenvolvimento deste sistema, onde a onda de temperatura atrasada em relação à de altura é importante para 
intensificar a advecção fria (NIETO et al., 2005). Esta baixa desprendida se fecha até o nível de $250 \mathrm{hPa}$, e como apresentado na fig. $4.15 \mathrm{c}$ a região a leste (oeste) apresenta forte advecção de vorticidade ciclônica (anticiclônica).

Em superfície, na costa de Santa Catarina, um núcleo de advecção quente em $850 \mathrm{hPa}$ (fig. 4.15d), gerado a partir da circulação ciclônica induzida pelos níveis médios, se soma ao padrão de altos níveis para induzir o abaixamento de pressão e a formação do sistema nas próxima horas.

A associação entre a baixa desprendida, advecção de vorticidade ciclônica em 250 $\mathrm{hPa}$, advecção quente em $850 \mathrm{hPa}$ e a baroclinia em superfície contribuem para a formação do ciclone em 13 de abril às 1200 UTC, próximo à costa norte do estado do RS (fig. 4.16a). O ciclone se inicia com pressão central de $1006 \mathrm{hPa}$. A baixa desprendida se desloca sem aprofundamento e a onda de temperatura se posiciona adiante da onda de geopotencial (fig. 4.16b). A máxima advecção de vorticidade ciclônica em $250 \mathrm{hPa}$ se localiza à nordeste da baixa em superfície (fig. 4.16c). Em $850 \mathrm{hPa}$, a advecção quente (fria) a leste (oeste) do ciclone se intensifica (fig. 4.16d), respondendo principalmente à intensificação da circulação ciclônica (os gradientes horizontais de temperatura não foram muito alterados nestas 12 horas, na região). 
(a)

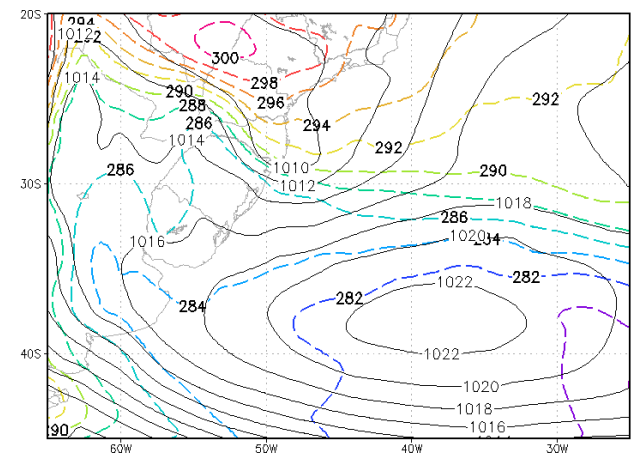

(c)

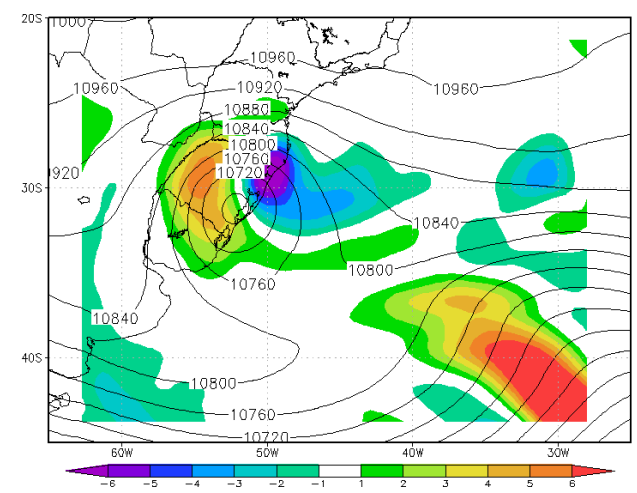

(b)

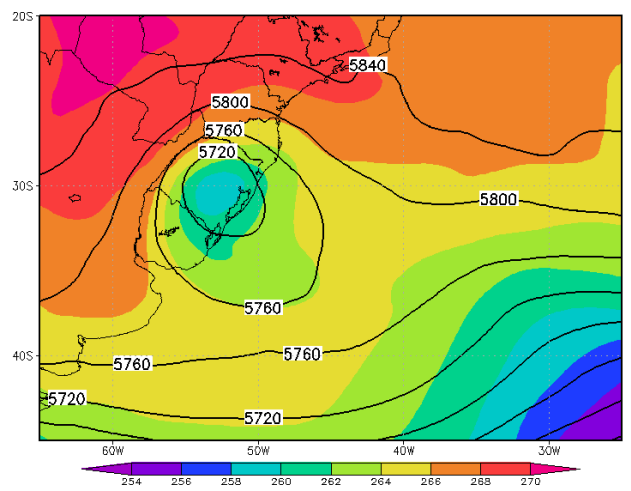

(d)

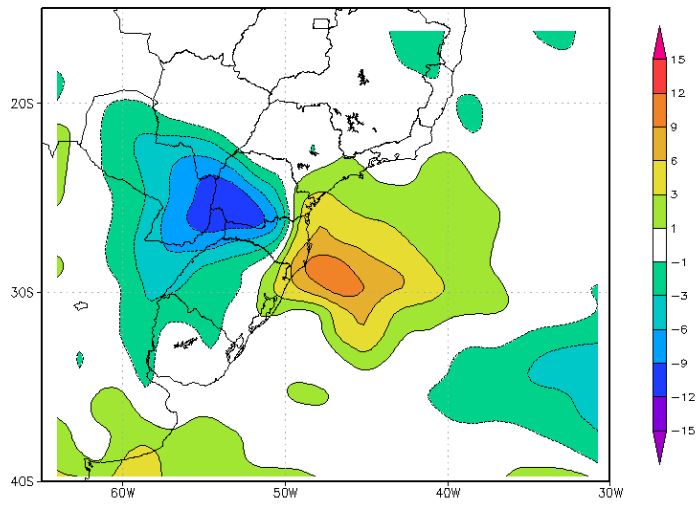

Figura 4.15: (a) PNMM (hPa) e temperatura do ar em $925 \mathrm{hPa}$; (b) altura geopotencial (m) e temperatura do ar (K) em $500 \mathrm{hPa}$. (c) geopotencial (m) e advecção de vorticidade relativa em $250 \mathrm{hPa}$ (x 10 $\left.10^{-9} \mathrm{~s}^{-2}\right)$; advecção de temperatura em $850 \mathrm{hPa}\left(\mathrm{Kdia}^{-1}\right)$, para 13 de abril de 2000 às $0000 \mathrm{UTC}$.

No decorrer do dia 14 de abril, o ciclone em superfície começa a se desintensificar (sua pressão central aumenta para $1008 \mathrm{hPa}$ ) e se alinha à "cut-off low" em $500 \mathrm{hPa}$ (como mostram as figuras 4.17 a e $4.17 \mathrm{~b}$, para as 1200 UTC). Em altos níveis, a baixa desprendida se desconfigura e a advecção de vorticidade ciclônica diminui (fig. 4.17c). A advecção de temperatura quente em baixos níveis se espalha por uma área mais ampla, e a advecção fria enfraquece (fig. 4.17d). 
(a)

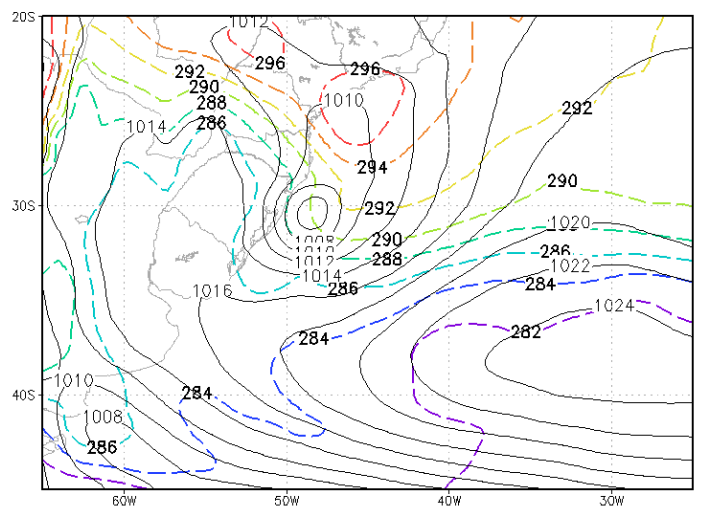

(c)

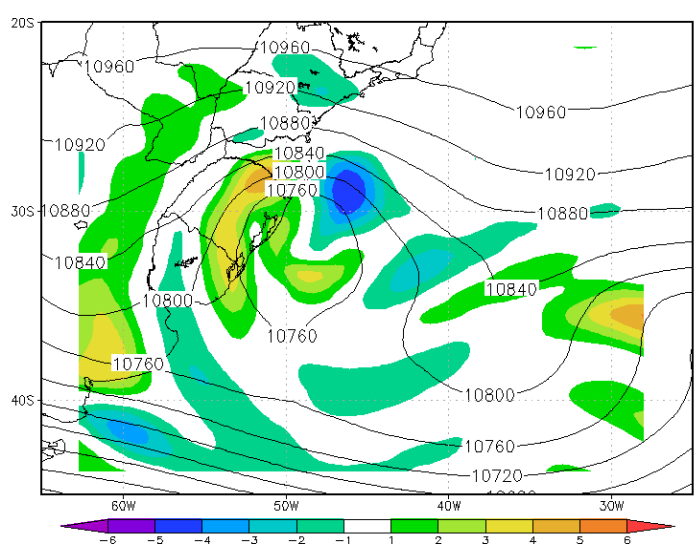

(b)

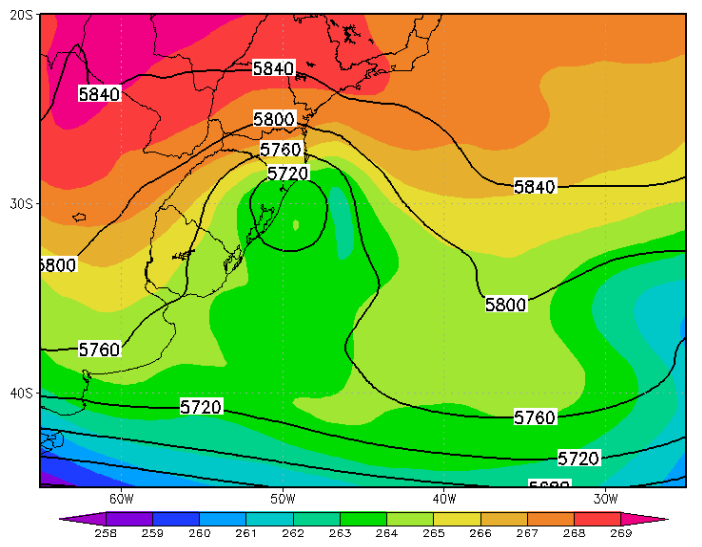

(d)

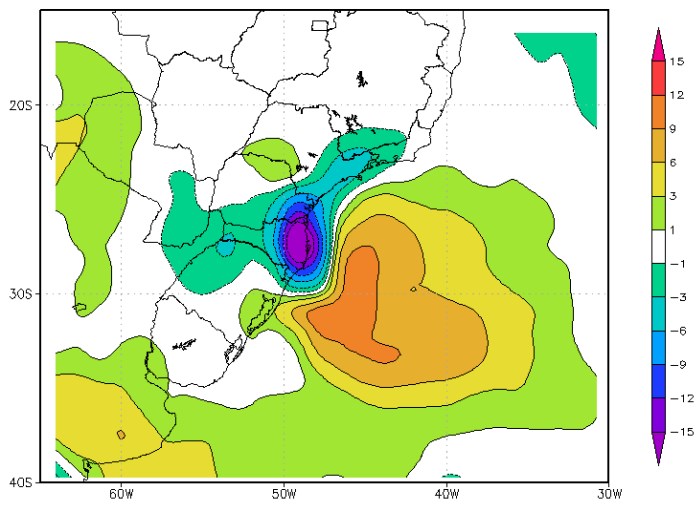

Figura 4.16: Idem à figura 4.15, válido para 13 de abril de 2000 às 1200 UTC.

Uma diferença notável entre o ciclone 1 (seção 4.1.1) e o ciclone 2 é a simetria do segundo caso, como mostra o campo de vento horizontal em $925 \mathrm{hPa}$, para 1200 UTC de 14 de abril de 2000, na figura 4.18a. Os sistemas frontais neste ciclone, apesar de serem aparentes durante o dia 13 de abril e apresentarem considerável gradiente de temperatura, são menos intensos do que no ciclone 1, como é evidente também nos campos de vorticidade e divergência do vento em 925 hPa (fig. 4.18b). Até o dia 16 de abril, quando o ciclone decai totalmente, as frentes vão se enfraquecendo e se afastando do sistema. 
(a)

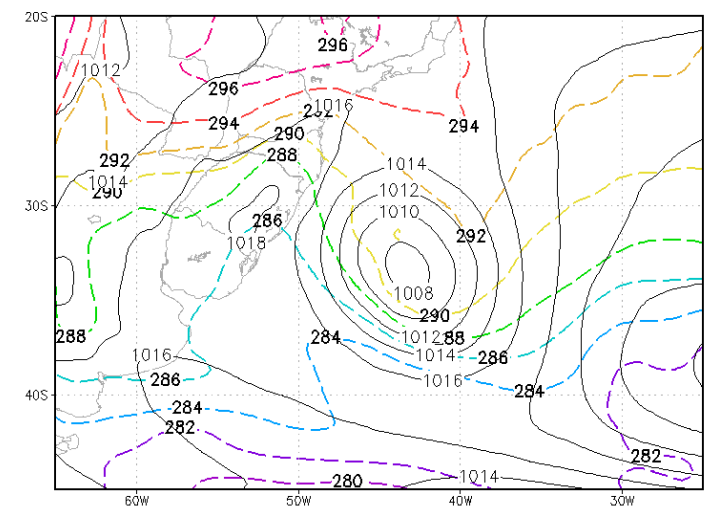

(c)

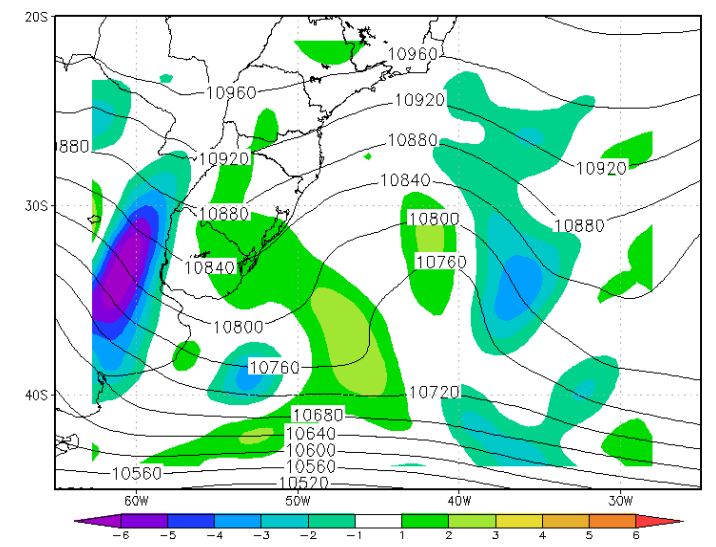

(b)

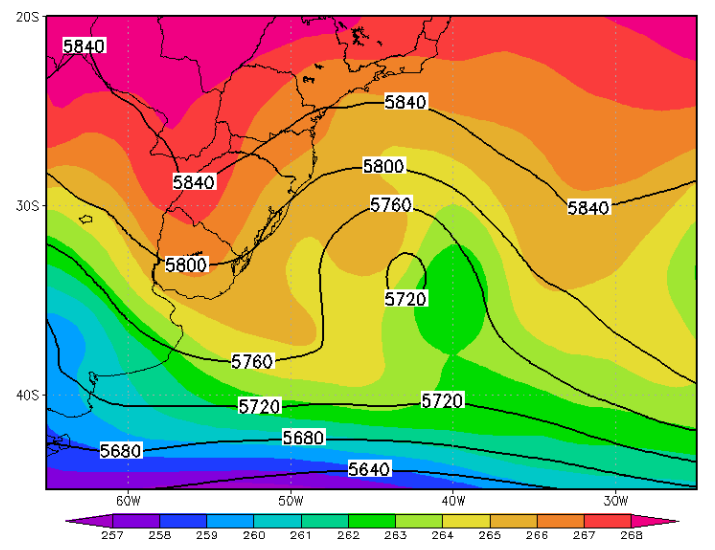

(d)

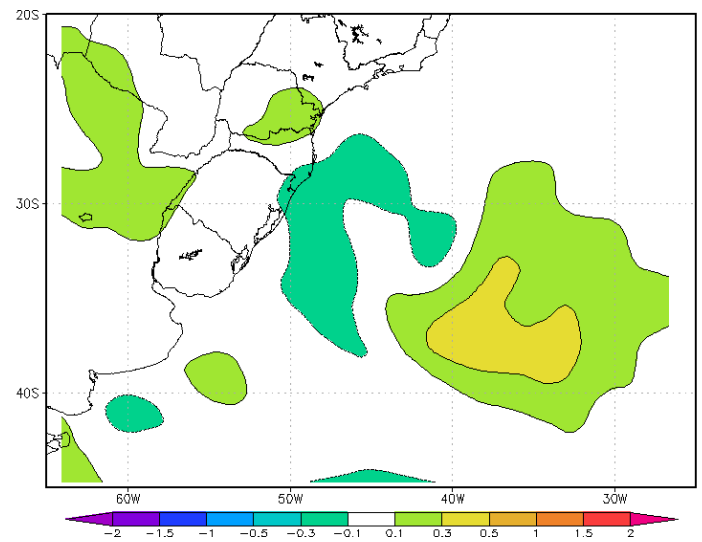

Figura 4.17: Idem à figura 4.15, válido para 14 de abril de 2000 às 1200 UTC.

(a)

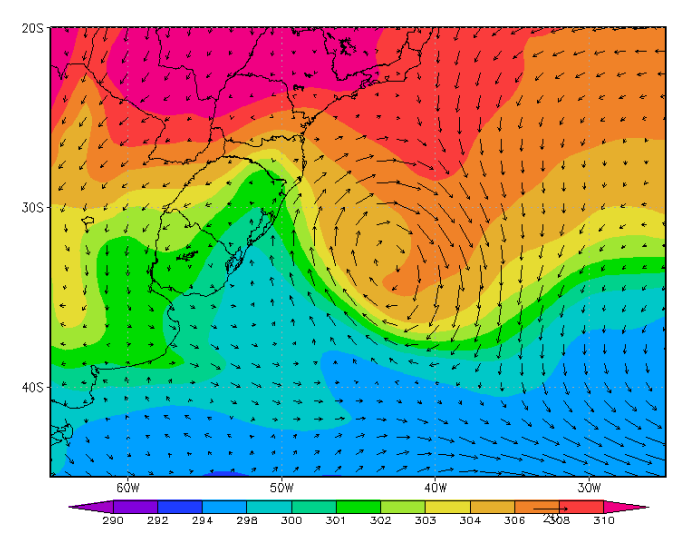

(b)

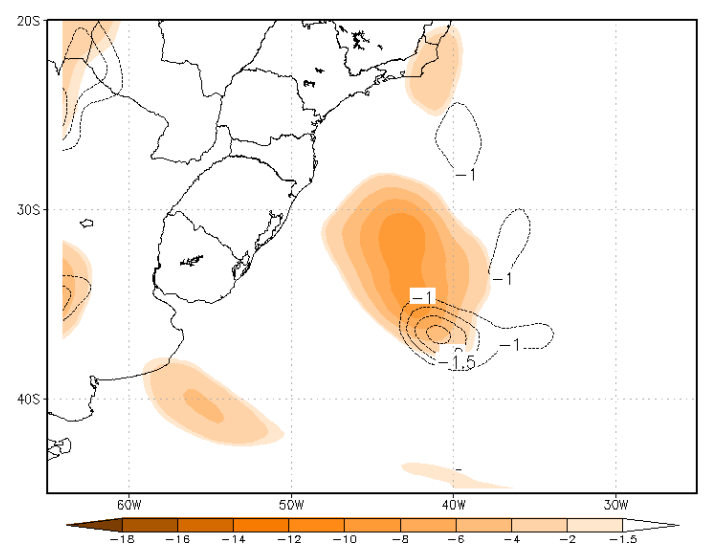

Figura 4.18: (a) Temperatura potencial equivalente (K) e vetor vento horizontal em $925 \mathrm{hPa}$; (b) Vorticidade relativa ciclônica (sombreado, $\times 10^{-5} \mathrm{~s}^{-1}$ ) e divergência do vento horizontal (linha tracejada, $\times 10^{-5} \mathrm{~s}^{-1}$, apenas valores negativos) em $925 \mathrm{hPa}$, para o dia 14 de abril de 2000 às 1200 UTC. 
No dia 15 de abril às 0000 UTC, a baixa em superfície se mantém com pressão mínima de $1008 \mathrm{hPa}$ e alinhada à baixa desprendida em médios níveis, que não exibe mais um núcleo frio fechado no campo de temperatura em 500 hPa (figs. 4.19a e 4.19b). A advecção de vorticidade em altos níveis apresenta magnitude semelhante à de 12 horas antes e a advecção de temperatura em $850 \mathrm{hPa}$ enfraqueceu (figuras não mostradas).

(a)

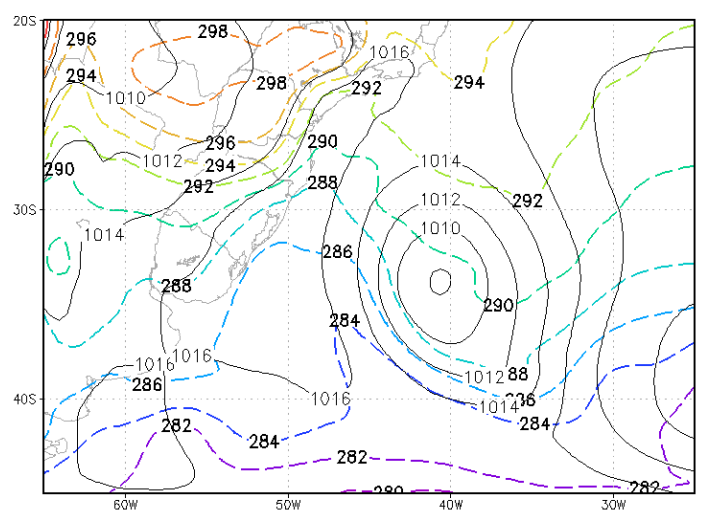

(b)

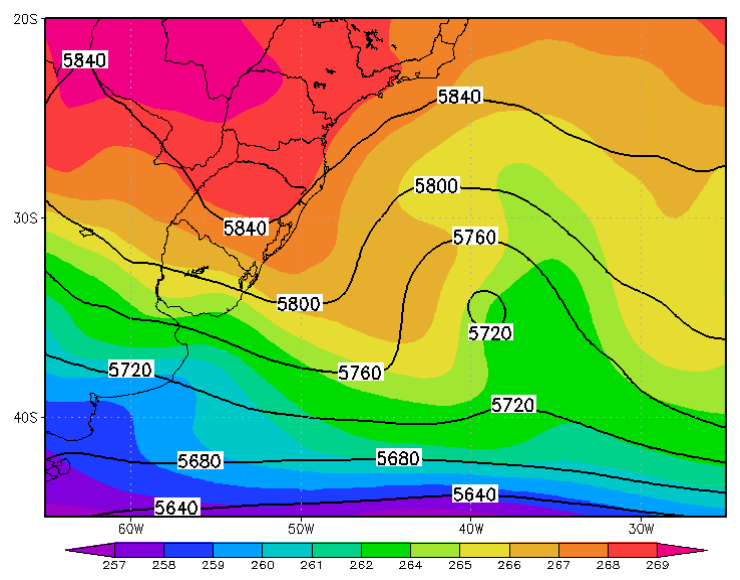

Figura 4.19: (a) PNMM (linha contínua, em hPa) e temperatura do ar (linha tracejada, em K) em 925 hPa e (b) altura geopotencial (linha contínua, em m) e temperatura do ar (sombreado, em K) em $500 \mathrm{hPa}$, para o dia 15 de abril de 2000, 0000 UTC.

(a)

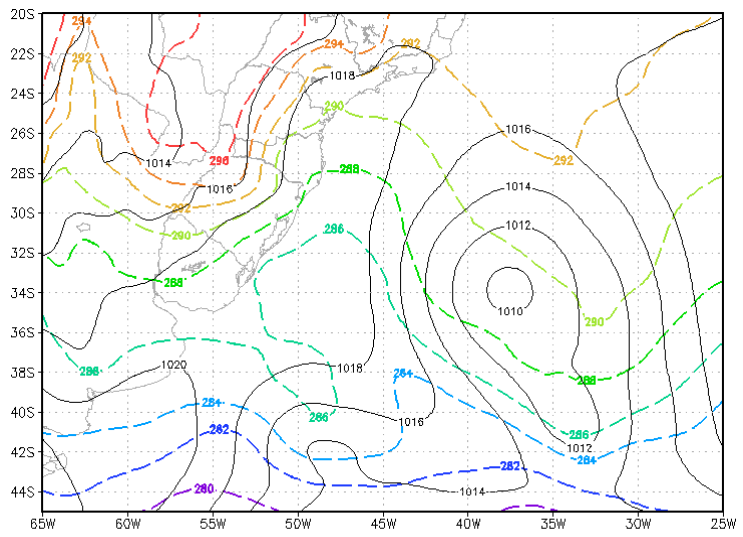

(b)

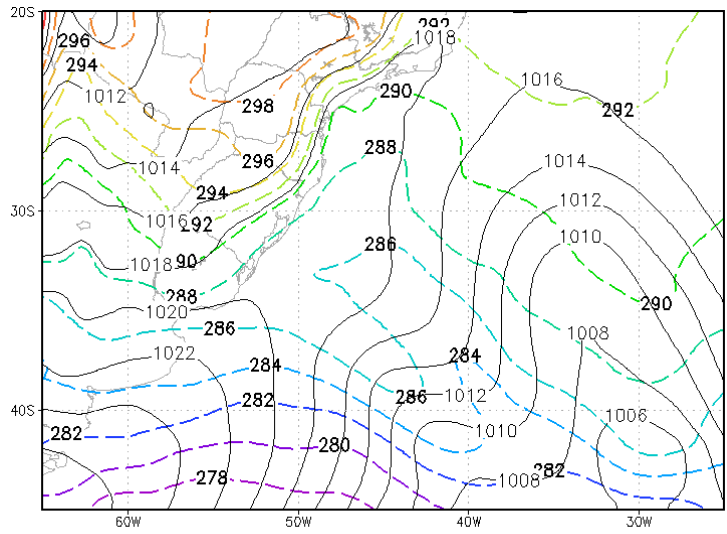

Figura 4.20: Pressão ao nível do mar (linha contínua, em hPa) e temperatura do ar (linha tracejada, em K) em $925 \mathrm{hPa}$ para (a) 15 de abril de 2000, 1200 UTC e (b) 16 de abril de 2000, 0000 UTC.

Em 15 de abril às 1200 UTC, o ciclone em fase de decaimento aumenta a pressão central para $1010 \mathrm{hPa}$, e a isóbara de $1012 \mathrm{hPa}$ se estende para sudeste (fig. 4.20a). Doze horas depois, às 0000 UTC de 16 de abril, o ciclone 2 desaparece, e outro sistema se desenvolveu a sudeste (fig. 4.20b). 
Conforme HOSKINS et al. (1985), a baixa desprendida em médios níveis pode induzir circulação ciclônica em baixos níveis. A propagação do núcleo de vorticidade negativa desde os níveis médios até a baixa troposfera entre os dias 13, 14 e 15 de abril é evidente na figura 4.21. No dia 13, a baixa desprendida é mais intensa entre 500 e $400 \mathrm{hPa}$, e o sistema exibe uma inclinação com a altura para oeste, característico de desenvolvimento baroclínico (fig. 4.21a). Em 14 de abril, a circulação ciclônica se desintensifica na média troposfera (possivelmente devido ao aquecimento do ambiente pela liberação de calor latente no processo convectivo), e o núcleo de máxima vorticidade ciclônica situa-se entre 400 e 200 hPa (fig. 4.21b). O perfil vertical de vorticidade ciclônica se inclina para leste, o que também pode ser visto durante o dia 15 (fig. 4.21c), indicando a fase de decaimento do sistema. A propagação vertical da circulação deste ciclone (de cima para baixo) é oposta à propagação apresentada pelo ciclone 1 (fig. 4.7), o que também pode sugerir que o ciclone 1 seria mais sensível aos processos em superfície (como a transferência de calor e umidade) do que o ciclone 2.

(a)

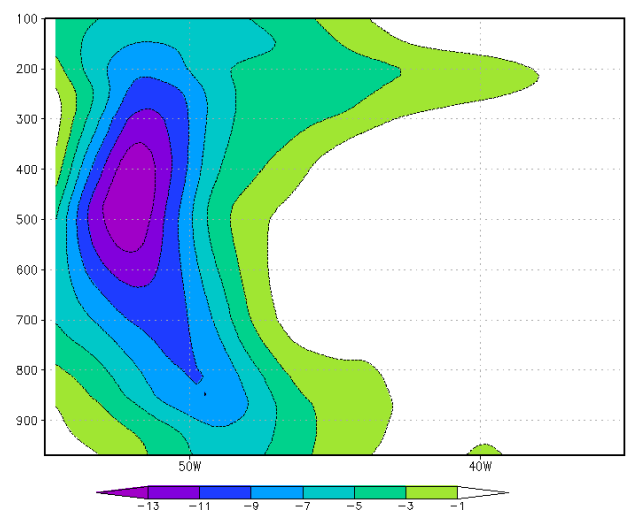

(b)

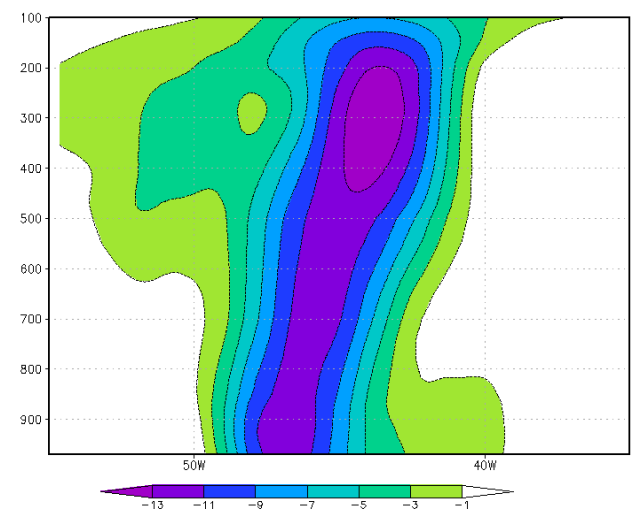

(c)

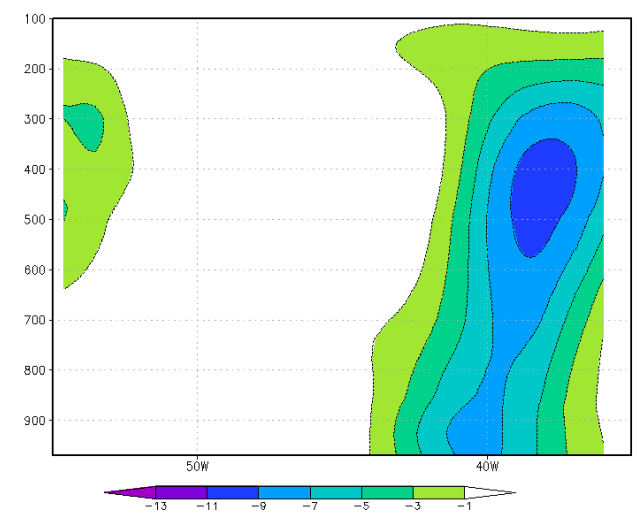

(c)

Figura 4.21: Perfil vertical de vorticidade relativa ciclônica $\left(\times 10^{-4} \mathrm{~s}^{-1}\right)$ na latitude do centro do ciclone em (a) 13 de abril de 2000 às 0000 UTC; (b) 14 de abril de 2000 às 0000 UTC; (c) 15 de abril de 2000 às 0000 UTC. 
A simetria deste ciclone e a baixa latitude em que se formou sugeriram que poderia ser classificado como um ciclone subtropical. A formação associada a uma baixa desprendida em médios níveis (condição não necessária, mas que pode contribuir para a formação de tais sistemas, conforme SIMPSON, 1952 e THORNCROFT, 1993) e a existência de máximos de vento superiores a $17 \mathrm{~m} \mathrm{~s}^{-1}$ em $925 \mathrm{hPa}$, em algum momento do ciclo de vida (requisito na classificação de um ciclone como subtropical conforme GUISHARD, 2006) reforçaram esta idéia. Apesar de o sistema não pode receber esta denominação, pois não foram avaliados outros critérios apresentados em HART (2003), ele parece apresentar características semelhantes a esta classe de ciclones.

\subsubsection{FCSL associados ao ciclone e validação do EXPCOM00}

O EXPCOM00 simulou o ciclone 2 com evolução temporal muito semelhante à EraInterim, mas algumas diferenças também foram notadas.

No dia 13 de abril, enquanto a análise mostra apenas um cavado no campo de pressão em superfície, o EXPCOM00 já apresenta uma baixa fechada (figs. 4.22a e 4.22b). Nos dois dias seguintes, a distribuição espacial do campo de pressão e o deslocamento do sistema simulados continuam muito semelhantes aos da análise (figs. 4.22c a 4.22f), embora o ciclone se apresente mais intenso na simulação do que na reanálise. No dia 16 de abril, o ciclone persiste em superfície na simulação, embora já tenha desaparecido na reanálise e um novo sistema de baixa pressão a sudeste do ciclone em estudo é também capturado pelo EXPCOM00 (figuras não apresentadas).

O EXPCOM00 também simula corretamente a posição, intensidade e desenvolvimento da baixa desprendida em $500 \mathrm{hPa}$ (fig. 4.23). O campo de temperatura em médios níveis mostra um núcleo frio mais intenso na baixa simulada (figs. 4.23a, 4.23b). No dia 14 de abril às 0000 UTC, a região de temperaturas mais baixas na reanálise a leste da baixa desprendida está um pouco mais quente na simulação (figs. 4.23c, 4.23d), e no dia 15 de abril às 0000 UTC, a simulação mostra o cavado a leste, no campo de temperatura, mais distante do centro da baixa do que na reanálise (figs. 4.23e e 4.23f). Para o dia 16 de abril às 0000 UTC, o EXPCOM é próximo à reanálise na localização do cavado de geopotencial e na distribuição de temperatura (figuras não apresentadas). Mesmo com as diferenças apresentadas, a reanálise mostra que a baixa desprendida sofreu aquecimento durante o período, provavelmente associado ao aquecimento convectivo no nível, e isto foi simulado pelo EXPCOM00, embora com maior intensidade. 
(a)

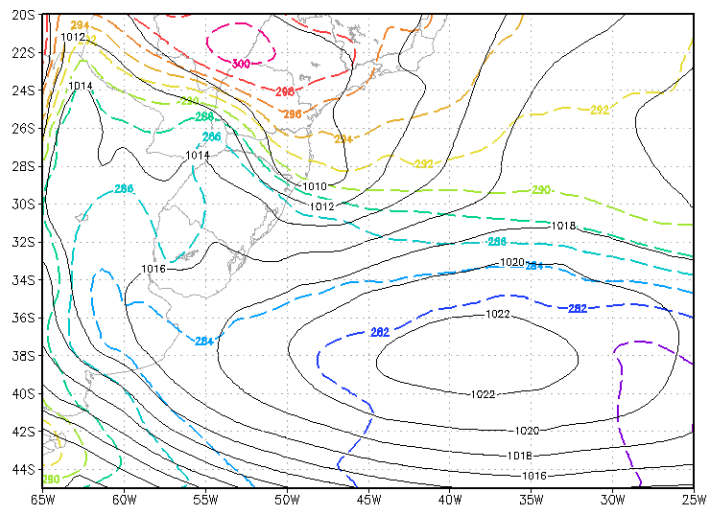

(c)

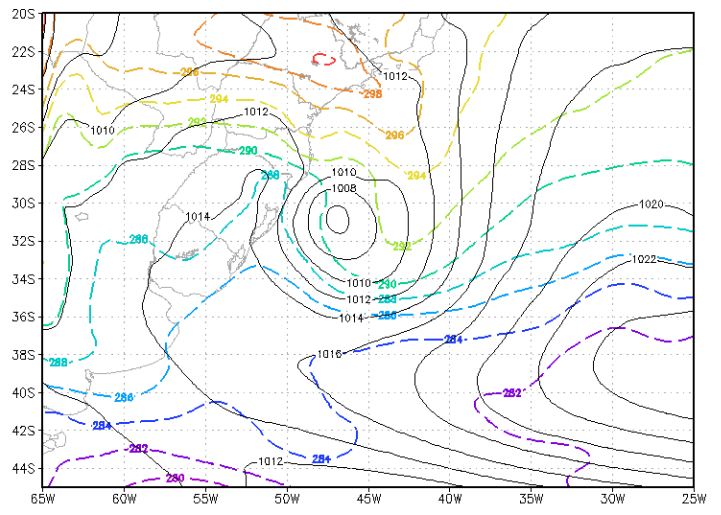

(e)

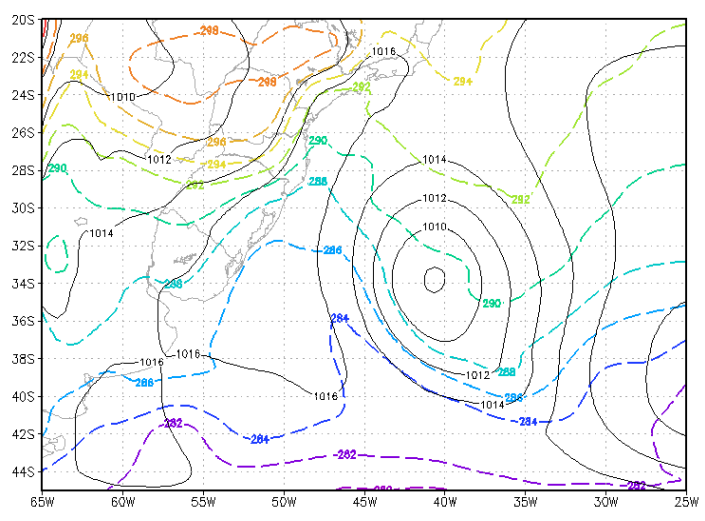

(b)

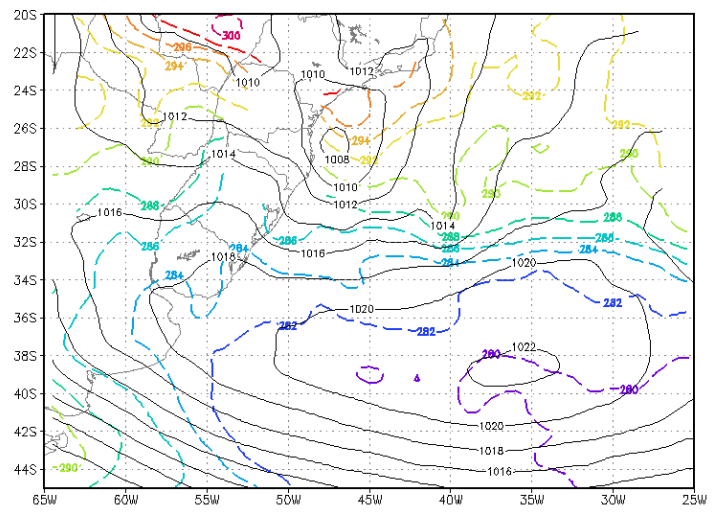

(d)

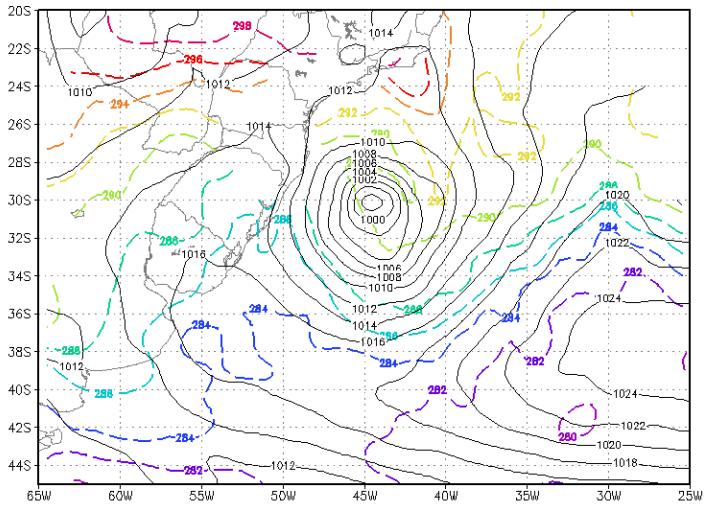

(f)

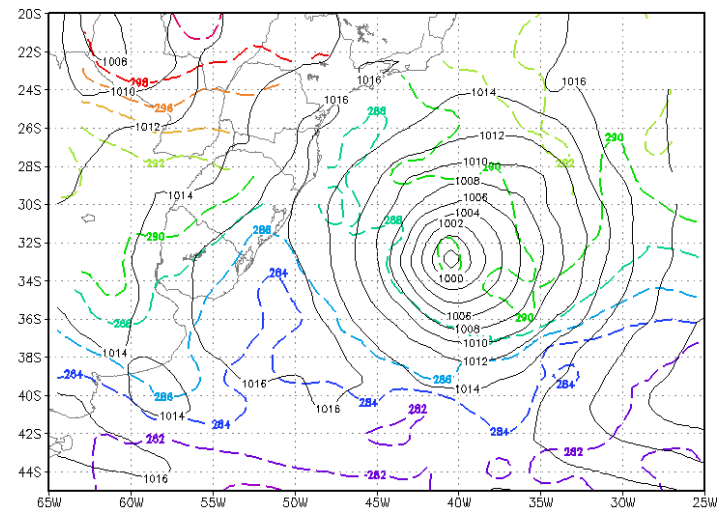

Figura 4.22: PNMM (linha contínua, em m) e temperatura do ar (linha tracejada, em K) para os dias 13, 14 e 15 de abril de 2000, 0000 UTC, para (a, c, e) a reanálise Era-Interim e (b, d, f) a simulação EXPCOM00. 
(a)

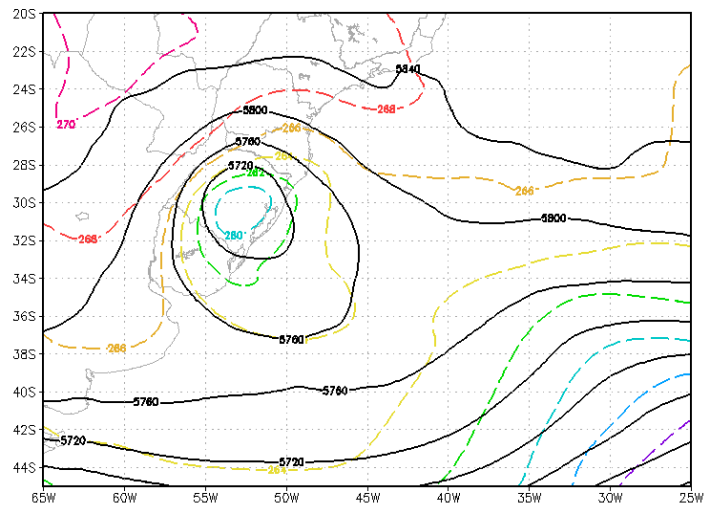

(c)

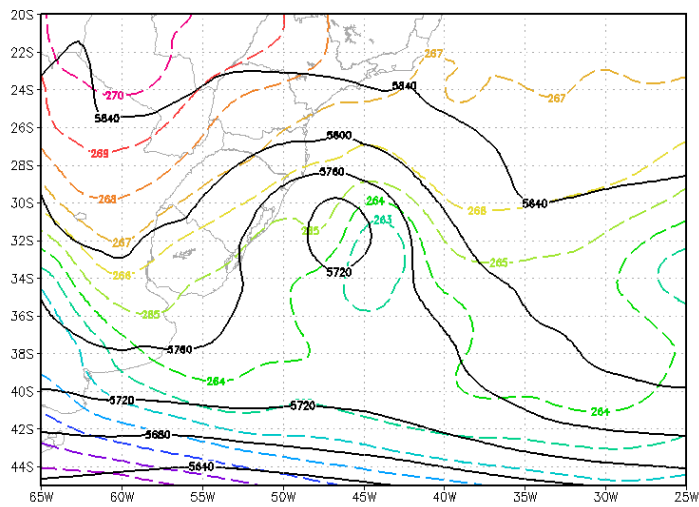

(e)

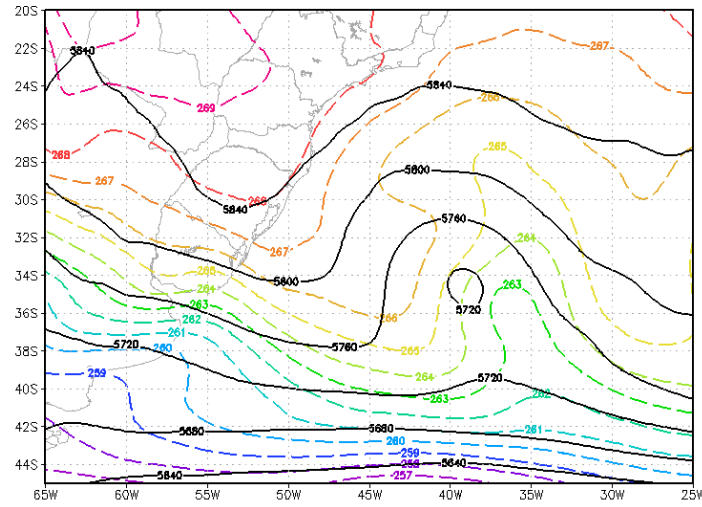

(b)

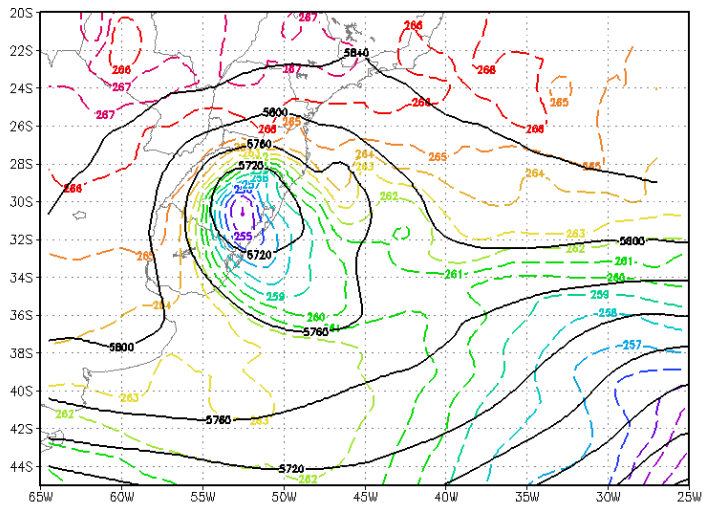

(d)

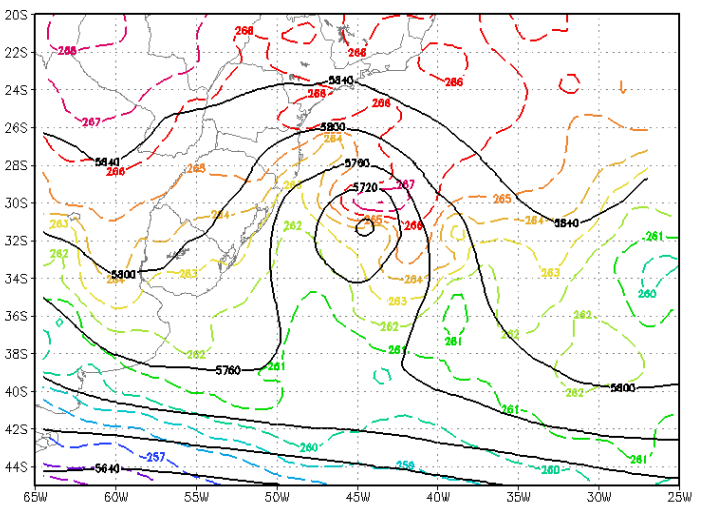

(f)

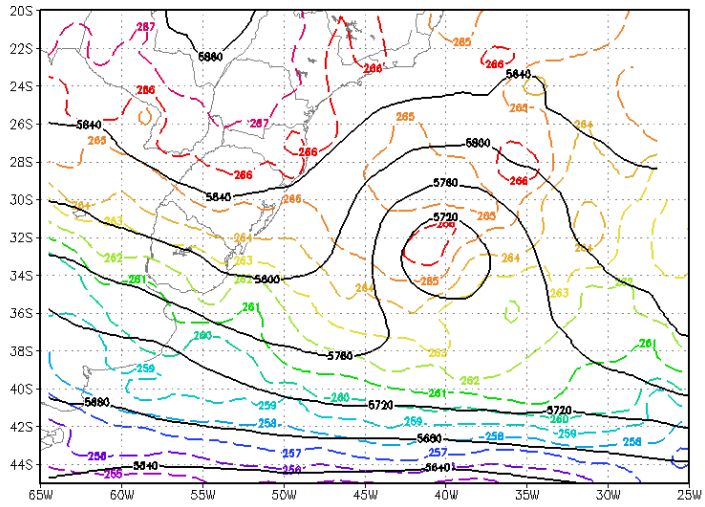

Figura 4.23: Altura geopotencial (linha contínua, em m) e temperatura do ar (linha tracejada, em K) em $500 \mathrm{hPa}$ para os dias 13-16 de abril de 2000 para (a, c, e g) a reanálise Era-Interim e (b, d, f, h) a simulação EXPCOM00.

Os fluxos de calor em superfície médios diários simulados apresentaram boa distribuição espacial e um desenvolvimento semelhante à análise do WHOI no decorrer do ciclo de vida deste ciclone (fig. 4.24). Os fluxos de calor sensível são intensos a sul da baixa pressão em superfície no dia 13 de abril (fig. 4.24a) segundo a reanálise WHOI, e esse posicionamento é semelhante ao simulado, embora a magnitude seja superestimada pelo 
EXPCOM00 (fig. 4.24b). Durante os dias 14 e 15, os maiores fluxos de calor sensível se localizaram, segundo o WHOI, a oeste e sul do sistema, com áreas de intensidade máxima de $50 \mathrm{~W} \mathrm{~m}^{-2}$. No EXPCOM00, as áreas de fluxo de calor sensível intenso são bem maiores, e no dia 14 incluem parte do setor quente do sistema também. Neste horário (fig. 4.24c), ocorrem fluxos de calor sensível entre 50 e $70 \mathrm{Wm}^{-2}$, maiores do que o WHOI a oeste do sistema. No dia 15, a distribuição espacial é mais semelhante ao WHOI, mas a área de fluxo superior a $30 \mathrm{Wm}^{-2}$ é bem maior (figs. 4.24e e 4.24f). Neste sistema os fluxos de calor sensível foram muito menores do que o de 1997, não ultrapassando $70 \mathrm{~W} \mathrm{~m}^{-2}$ em nenhum dia (na reanálise WHOI).

(a)

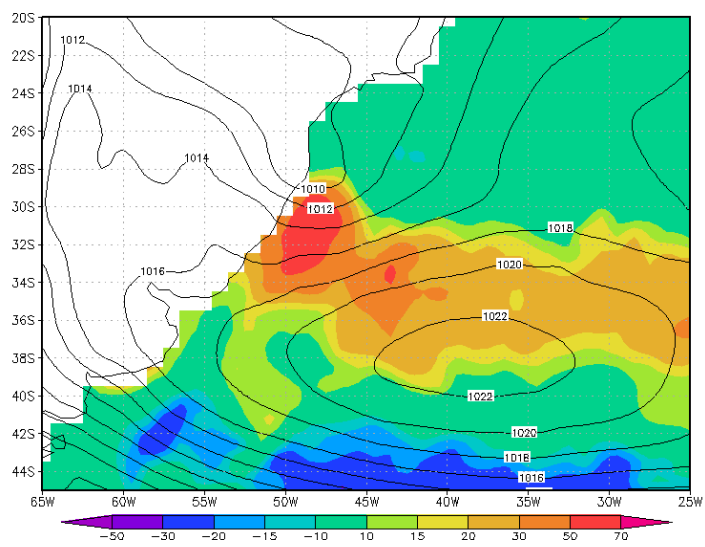

(c)

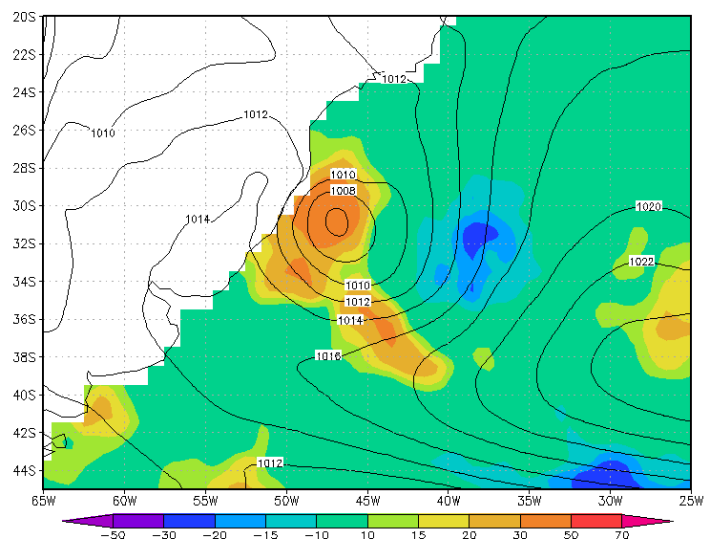

(b)

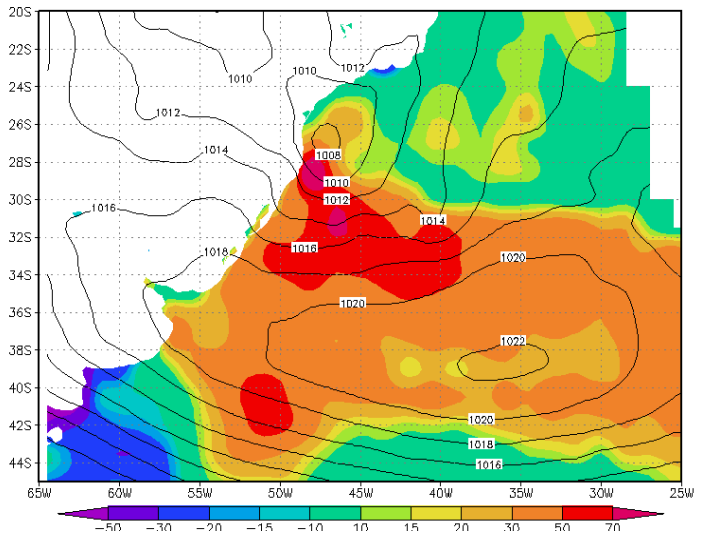

(d)

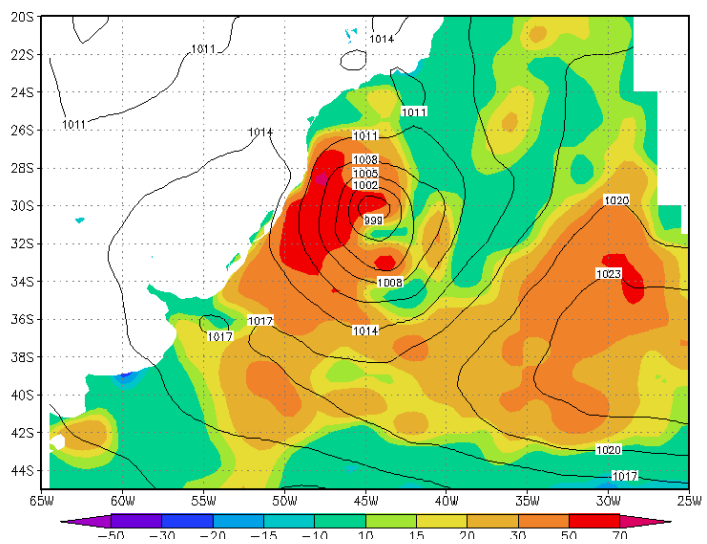

Figura 4.24: PNMM (linha contínua, em hPa) segundo a reanálise Era-Interim e fluxo de calor sensível (sombreado, em $\mathrm{Wm}^{-2}$ ) segundo a reanálise WHOI para os dias (a) 13, (c) 14 e (e) 15 de abril de 2000, e segundo o EXPCOM00 para os dias (b) 13, (d) 14 e (f) 15 de abril de 2000. 
(e)

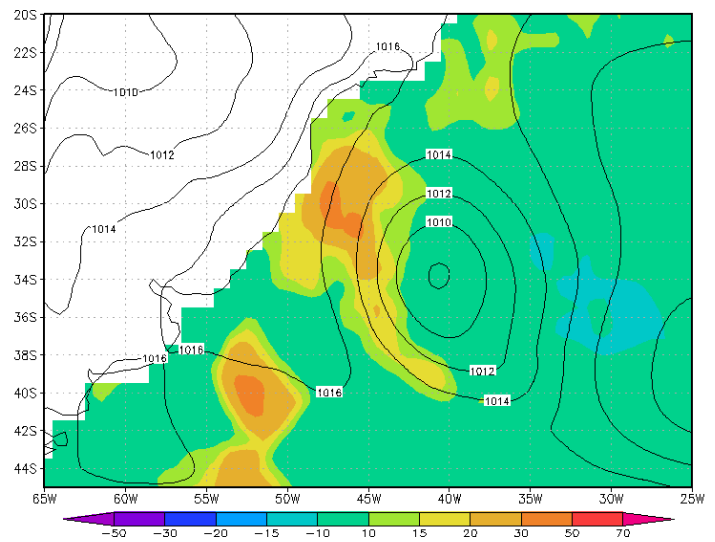

Figura 4.24: Continuação

(a)

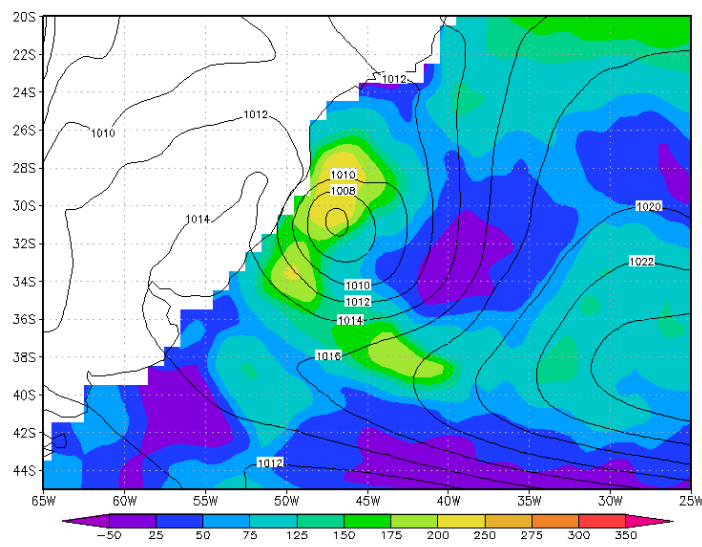

(f)

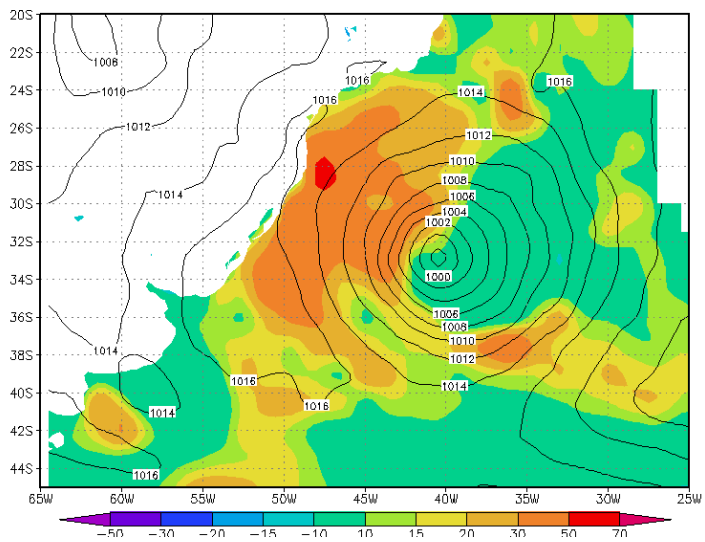

Figura 4.25: PNMM (linha contínua, em hPa) e fluxo de calor latente (sombreado, em $\mathrm{Wm}^{-2}$ ) no dia 14 de abril de 2000. (a) WHOI (b) EXPCOM00.

Os fluxos de calor latente seguem comportamento semelhante aos de calor sensível. Durante toda a simulação, assim como mostra a figura 4.25 para o dia 14 de abril, a região com fluxos de calor latente mais intenso é semelhante na reanálise e na simulação, mas ocorre grande superestimativa pelo EXPCOM00. Durante todo o tempo e por uma grande extensão a oeste do sistema, o EXPCOM00 simula fluxos de calor latente superiores a $350 \mathrm{~W} \mathrm{~m}^{-2}$, valores muito superiores aos do WHOI (fig. 4.25a e 4.25b).

Esta superestimativa dos fluxos de superfície pelo EXPCOM00 pode ter muitas causas: além de imprecisões na parametrização da camada limite superficial, pode resultar de subestimativa da quantidade de vapor de água em baixos níveis, subestimativa da temperatura do ar ou simulação de ventos mais intensos, ou ainda uma combinação destes três fatores.

$\mathrm{Na}$ comparação dos campos de temperatura a 2 metros e umidade específica a 2 metros (médias para o dia 14 de abril) (figura 4.26), não se verifica diferenças muito grandes 
entre o EXPCOM00 e a reanálise WHOI. Na região onde está o ciclone, a temperatura tanto no EXPCOM00 como pelas observações do WHOI está entre 295 e 297 K, e a umidade específica entre 13 e $15 \mathrm{~g} \mathrm{~kg}^{-1}$. A concordância entre o WHOI e o EXPCOM00 para estas variáveis persiste por toda a simulação, indicando que a superestimativa na velocidade do vento (devido à formação de um ciclone mais intenso), e talvez a própria parametrização de camada limite superficial, seriam as causas principais da superestimativa dos fluxos de superfície durante o ciclo de vida deste sistema.

(a)

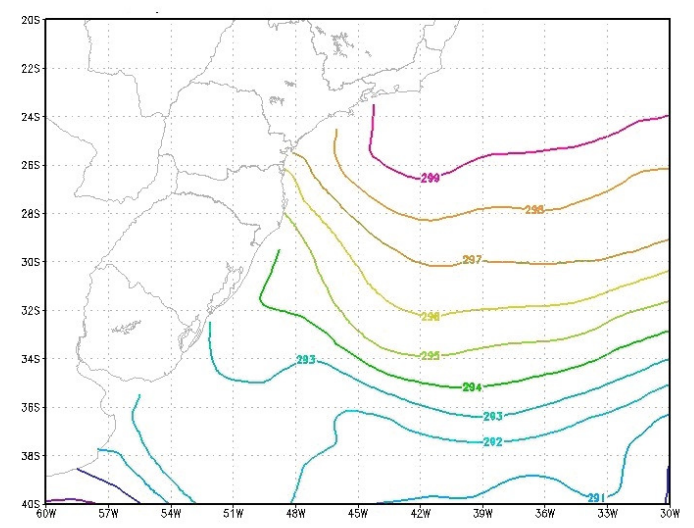

(c)

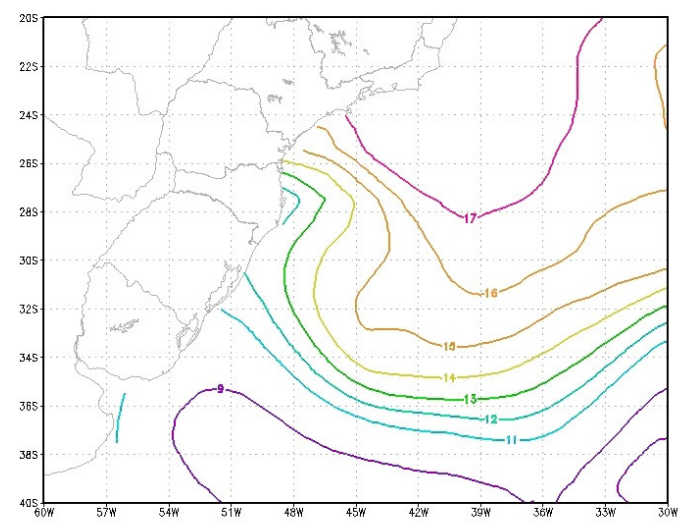

(b)

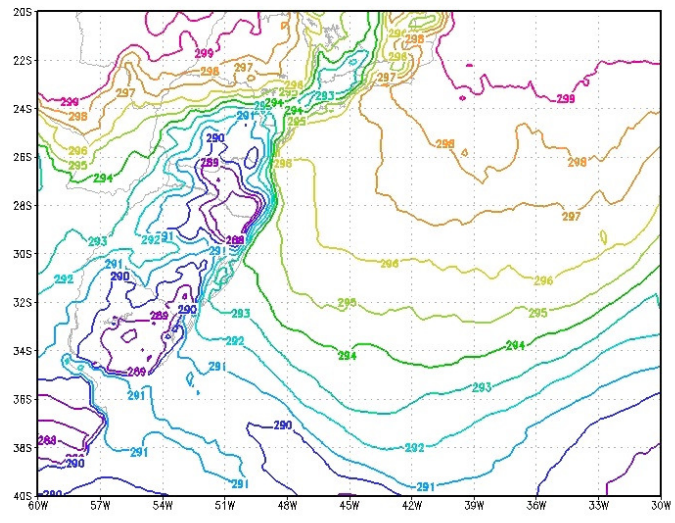

(d)

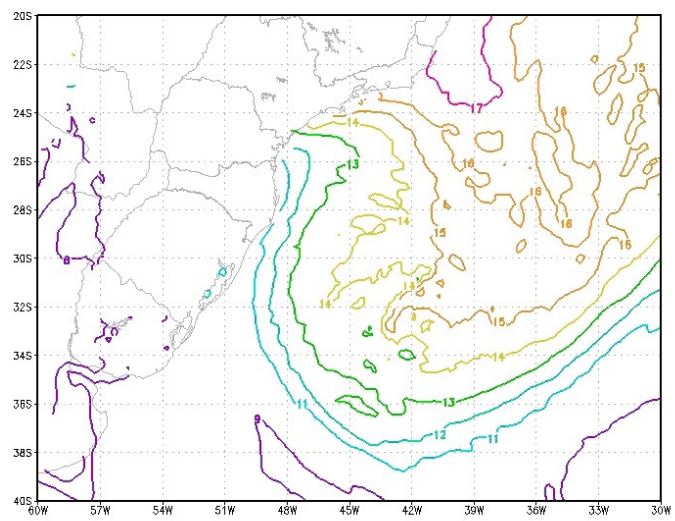

Figura 4.26: Temperatura do ar a $2 \mathrm{~m}(\mathrm{~K})$ e umidade específica a $2 \mathrm{~m}\left(\mathrm{gkg}^{-1}\right)$ médios no dia 14 de abril de 2000. para $(a, c)$ a reanálise WHOI e $(b, d)$ EXPCOM00. 


\subsection{Influência dos fluxos de superfície no deslocamento e estrutura vertical dos ciclones}

\subsubsection{Ciclone 1 ( 27 de maio de 1997)}

A trajetória, tempo de vida e distância percorrida por este sistema sofreram forte influência dos fluxos de superfície, como mostra a figura 4.27. Na fase inicial, enquanto o ciclone se encontra sobre o continente, não se verificam grandes diferenças entre os experimentos EXPCOM97 e EXPSEM97. Após atingir o oceano, entre os dias 28 e 29 de maio, no EXPCOM97 o ciclone se desloca para sudeste por todo o seu ciclo de vida, com trajetória muito semelhante à reanálise ERA-Interim. Na ausência de fluxos, o ciclone se desloca para nordeste, e desaparece do campo de pressão ao nível do mar no dia 01 de junho às 0000 UTC. A menor duração e deslocamento para nordeste do sistema no EXPSEM97 é similar ao comportamento médio climatológico dos ciclones na ausência de fluxos de superfície nesta região como descrito em REBOITA (2008).

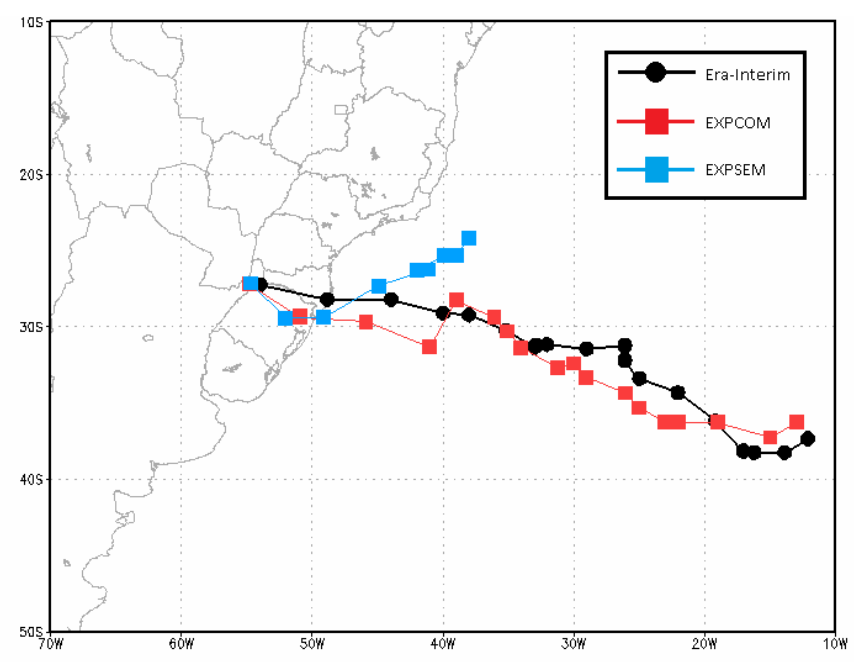

Figura 4.27: Trajetória do ciclone segundo a reanálise Era-Interim (linha preta), EXPCOM (linha vermelha) e EXPSEM (linha azul). As três trajetórias se iniciam às 0000 UTC do dia 28 de maio de 1997 e os pontos estão marcados a cada 12 horas.

Os mecanismos que podem estar contribuindo para a diferença de trajetória são os processos de advecção de temperatura entre os baixos e médios níveis, a convergência induzida pelo aquecimento diabático e a advecção de vorticidade relativa na alta troposfera. 
A trajetória começa a se diferenciar entre os dias 28 e 29 de maio, quando na presença de FCSL o ciclone se desloca para o oceano (centro em $48^{\circ} \mathrm{W}-30^{\circ} \mathrm{S}$ ) e na ausência desta forçante se mantém na costa da região Sul, ainda sobre o continente (fig. 4.27). Considerando que, conforme CARLSON (1998), a baixa pressão em superfície não é “carregada” pelos níveis superiores, e sim reconstruída no campo de movimento tridimensional, espera-se que um processo físico que favoreça movimentos ascendentes na baixa troposfera seja o mecanismo principal de deslocamento. A advecção de temperatura positiva em baixos níveis a leste do ciclone é um destes processos, mas no dia 28 de maio às 1200 UTC as diferenças entre as duas simulações de advecção de temperatura positiva na costa do sul do Brasil são pequenas, em magnitude ou distribuição espacial (figs. 4.28a e 4.28b). Outro mecanismo que pode induzir movimento ascendente é a convergência associada ao aquecimento diabático devido aos fluxos de calor sensível, conforme as ideias apresentadas em METAXAS (1978). Escolhendo um ponto dentro da região para onde o ciclone se deslocará nas próximas horas, no EXPCOM97 (por exemplo, $48^{\circ} \mathrm{W}-30^{\circ} \mathrm{S}$ ), e substituindo na equação 3 (seção 2.2), com $\left|\vec{v}_{o}\right|$ $=12 \mathrm{~ms}^{-1}, \mathrm{~T}_{\mathrm{s}}=294 \mathrm{~K}, \mathrm{~T}_{\mathrm{a}}=292 \mathrm{~K}$, e assumindo $\mathrm{K}=12$, a divergência em baixos níveis chega a $-2,9 \times 10^{-5} \mathrm{~s}^{-1}$. Este valor é superior à convergência associada a sistemas de escala sinótica em latitudes médias $\left(\mathrm{O} \sim 10^{-6}\right)$, mostrando o grande papel dos fluxos de calor sensível na convergência do ar em baixos níveis.

Por influência de intenso fluxo de calor sensível, toda a região da costa de SC apresenta convergência mais intensa no EXPCOM97 (fig. 4.26c), a leste-sudeste do centro do ciclone, o que favorece o deslocamento do sistema para sudeste. Outra forçante importante é a advecção de vorticidade negativa na alta troposfera. A advecção de vorticidade ciclônica no EXPCOM97 apresenta um núcleo intenso em toda a costa da região sul, na longitude $47^{\circ} \mathrm{W}$, que não está presente no EXPSEM97 (figs. 4.28c e 4.28d)

No dia 29 de maio às 0000 UTC, o ciclone já apresenta grande diferença de posicionamento: no EXPCOM97 o centro do sistema encontra-se já sobre o oceano $\left(48^{\circ} \mathrm{W}\right.$ $30^{\circ} \mathrm{S}$ ), mas no EXPSEM97 o ciclone está sobre o continente, na costa de SC (fig. 4.27). 
(a)

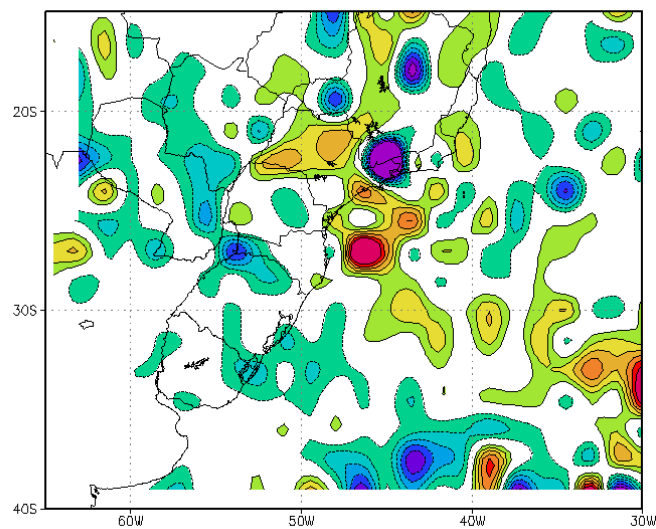

(b)

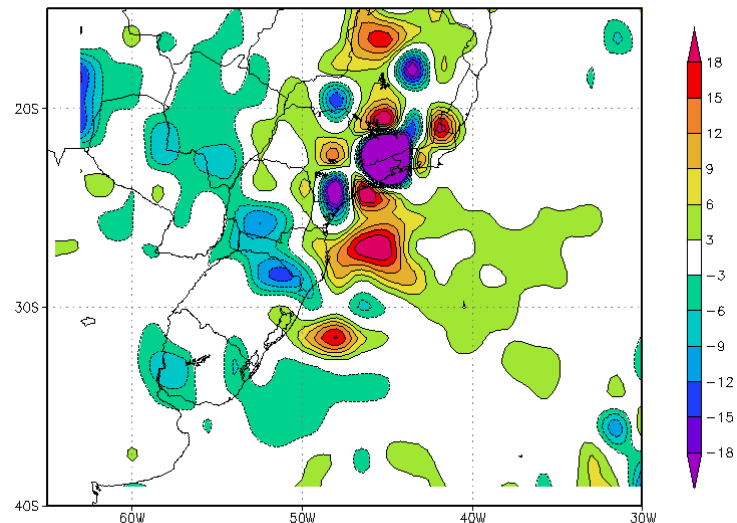

(c)

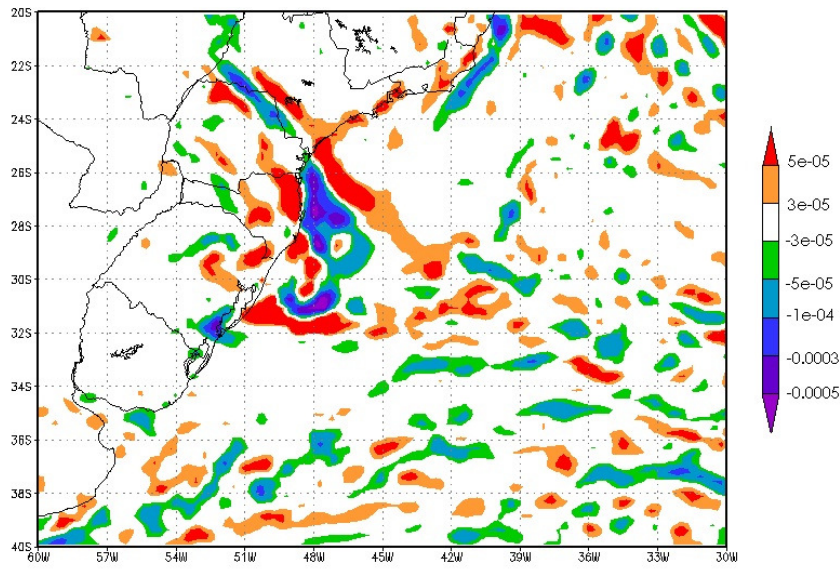

(d)

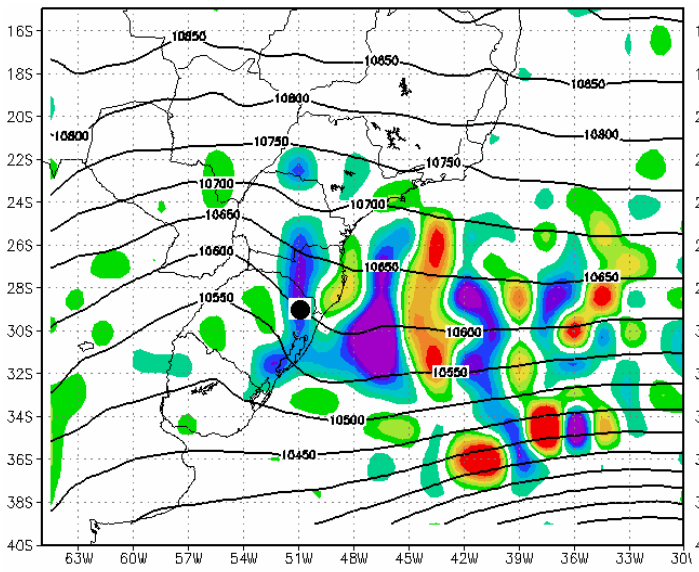

(e)

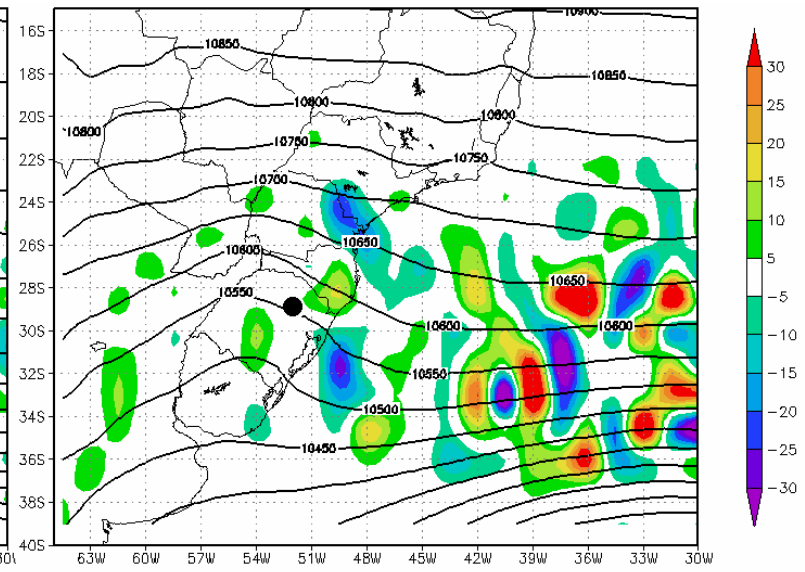

Figura 4.28: Advecção de temperatura em $850 \mathrm{hPa}\left(\mathrm{Kdia}^{-1}\right)$ no (a) EXPCOM97 e no (b) EXPSEM97 (c); diferença da divergência do vento a $10 \mathrm{~m}$ (valores negativos indicam maior convergência na simulação EXPCOM). Altura geopotencial (linha contínua, em m) e advecção de vorticidade relativa (sombreado, em x $10^{-9} \mathrm{~s}^{-2}$ ) em $250 \mathrm{hPa}$ no (d) EXPCOM97 e (d) EXPSEM97, para o dia 28 de maio de 1997 às 1200 UTC. O círculo preto indica a posição da baixa em superfície. 
A partir do dia 29 de maio às 0000 UTC, a advecção de temperatura em baixos níveis se diferencia entre as duas simulações. No EXPCOM97, a advecção quente se encontra praticamente paralela à costa e no setor leste-sudeste do ciclone em superfície (fig. 4.29a), resultado da presença de ar mais quente no continente e ventos de noroeste (fig. 4.29b). No EXPSEM97, porém o continente se aquece menos, os gradientes de temperatura no Atlântico na costa do Sudeste são menores, e a circulação de norte-noroeste é também menos intensa (fig. 4.29d), e todos estes fatores resultam em advecção quente em uma área menor e apenas à nordeste do ciclone (fig. 4.29c). Como o ciclone em superfície tende a se mover seguindo as regiões de advecção quente, esta diferença pode explicar a mudança de trajetória do sistema entre as duas simulações.

(a)

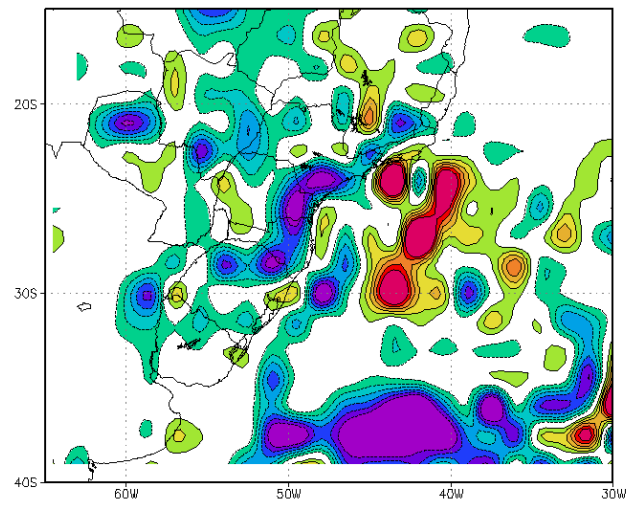

(c)

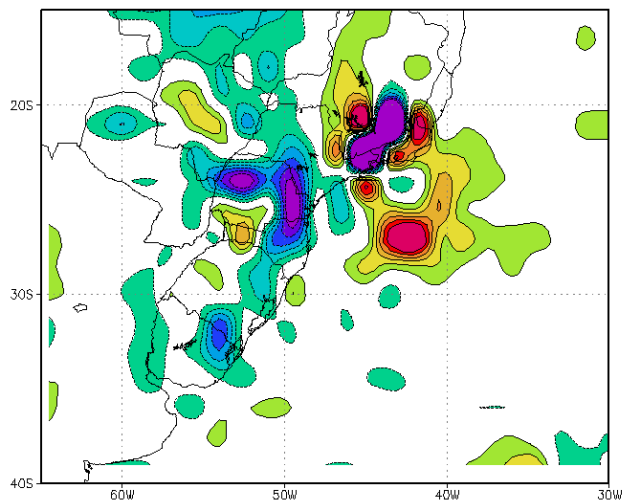

(b)

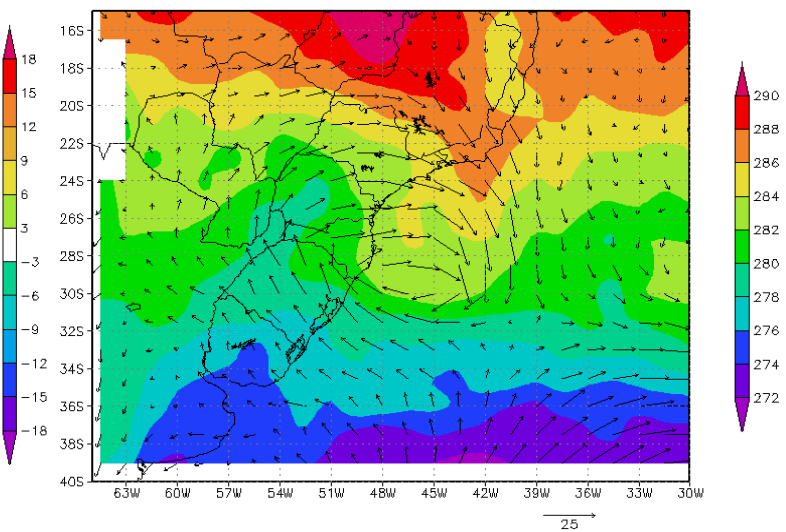

(d)

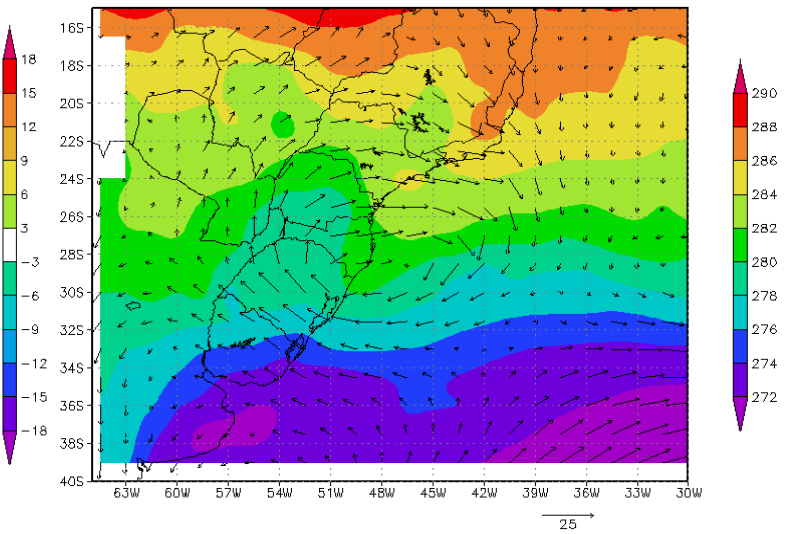

Figura. 4.29: Advecção de temperatura em $850 \mathrm{hPa}\left(\mathrm{Kdia}^{-1}\right)$ e vento horizontal e temperatura do ar (K) em 850 hPa, para 29 de maio de 1997 às 0000 UTC, para o EXPCOM97 (a,b) e o EXPSEM97 (c,d). O círculo preto indica a posição da baixa em superfície. 
A advecção fria mais intensa sobre a costa do sul do Brasil no EXPCOM97 contribuiu para amplificar o cavado em médios e altos níveis na região; associado a isto, maior advecção de vorticidade ciclônica continua ocorrendo a leste do cavado em $250 \mathrm{hPa}$, comparado ao EXPSEM97 (figs. 4.30a e 4.30b). Além disso, está ocorrendo exatamente sobre o sistema em baixos níveis. Este fator favorece ainda mais o deslocamento do ciclone, bem como a sua intensificação através do aumento da convergência em baixos níveis. $\mathrm{O}$ ciclone em superfície no EXPSEM97 (fig. 4.30b) está posicionado sobre o eixo do cavado, onde a advecção de vorticidade fraca e anticiclônica não favorece o seu futuro desenvolvimento.

(a)

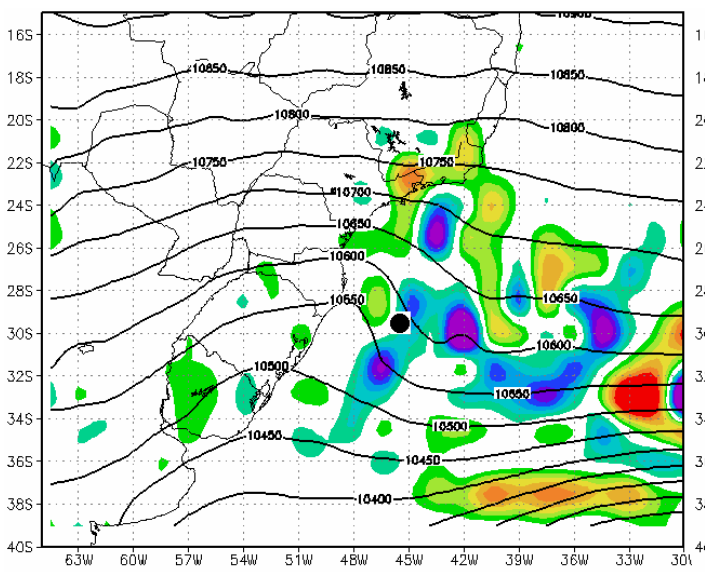

(b)

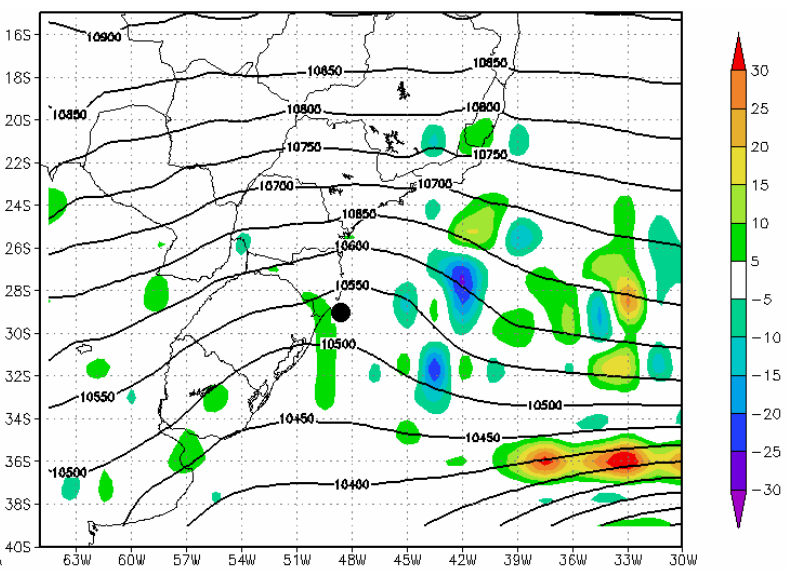

Figura 4.30: Altura geopotencial (linha sólida, em m) e advecção de vorticidade relativa (sombreado, em x $10^{-9}$ $\mathrm{s}^{-2}$ ) em $250 \mathrm{hPa}$ para o (a) EXPCOM97 e o (b) EXPSEM97, para 29 de maio de 1997 às 0000 UTC. O círculo preto indica a posição da baixa em superfície.

Todas as modificações na estrutura e posicionamento do ciclone associadas à ausência de FCSL fazem com que, no decorrer do ciclo de vida, o ciclone em superfície esteja em uma posição favorável ao desenvolvimento no EXPCOM97, e desfavorável no EXPSEM97.

As 1200 UTC de 30 de maio, o ciclone em superfície está numa região de advecção de vorticidade ciclônica (a leste do cavado em altitude) no EXPCOM97 (fig. 4.31a). No EXPSEM97, o deslocamento da onda de geopotencial em $250 \mathrm{hPa}$ foi muito similar ao EXPCOM97, embora o cavado esteja mais profundo e mais intenso na presença de FCSL. O ciclone em superfície, no EXPSEM97, está posicionado numa região de advecção de vorticidade mínima a oeste do eixo do cavado (fig. 4.31b), desfavorecendo sua intensificação. 
(a)

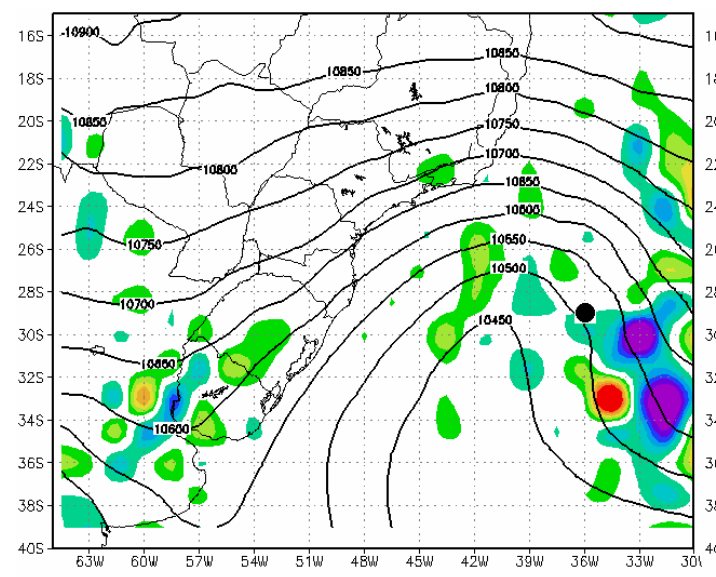

(b)

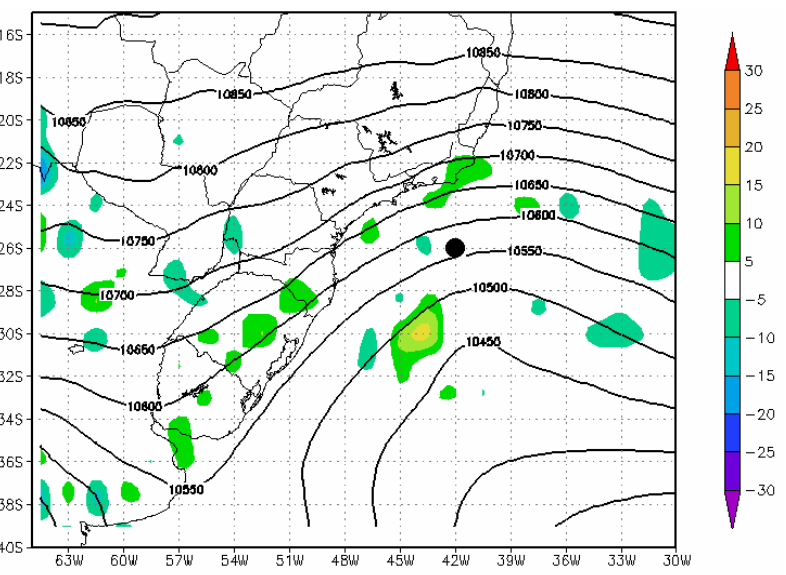

Figura 4.31: Altura geopotencial (linha sólida, em m) e advecção de vorticidade relativa (sombreado, em x $10^{-9}$ $\mathrm{s}^{-2}$ ) em $250 \mathrm{hPa}$ no (a) EXPCOM97 e no (b) EXPSEM97, para o dia 30 de maio de 1997 às $1200 \mathrm{UTC}$. O círculo preto indica a posição da baixa em superfície.

O acoplamento entre a circulação em superfície e os médios níveis da atmosfera pode ocorrer através da liberação de calor latente por convecção. Este processo é alterado pela quantidade de vapor de água na atmosfera e pelos movimentos verticais associados ao ciclone, ambos dependentes dos FCSL. No dia 30 de maio, no EXPCOM97, o movimento vertical ascendente em $700 \mathrm{hPa}$ é máximo na região da frente quente e no setor quente do sistema (fig. 4.32a). Isto resultou em grande volume de precipitação convectiva nestas áreas ao longo do dia (fig. 4.33a), o que é confirmado pela análise do GPCP (fig. 4.33c). No EXPSEM97, a região de movimento ascendente também ocorre a leste do ciclone, porém possui magnitude menor (fig. 4.32b). O movimento ascendente mais fraco, combinado à menor disponibilidade de vapor d'água pela ausência de fluxo de umidade na camada superficial, concentra a fraca precipitação convectiva no setor frontal quente do ciclone no EXPSEM97 (fig. 4.33b). 
(a)

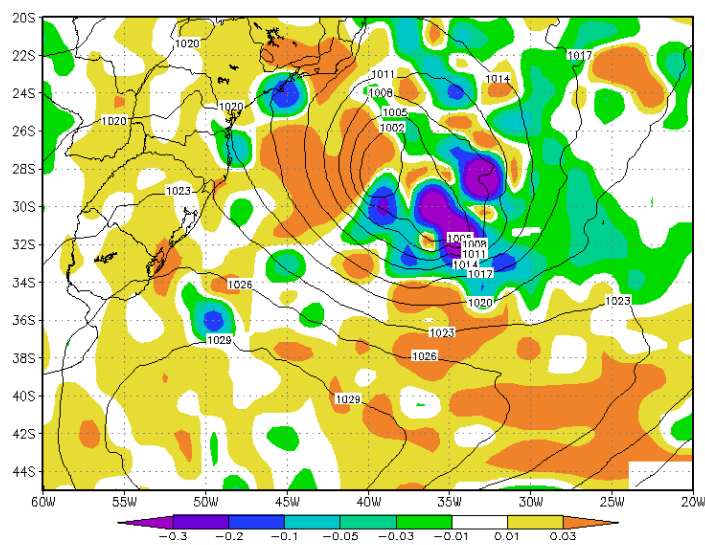

(b)

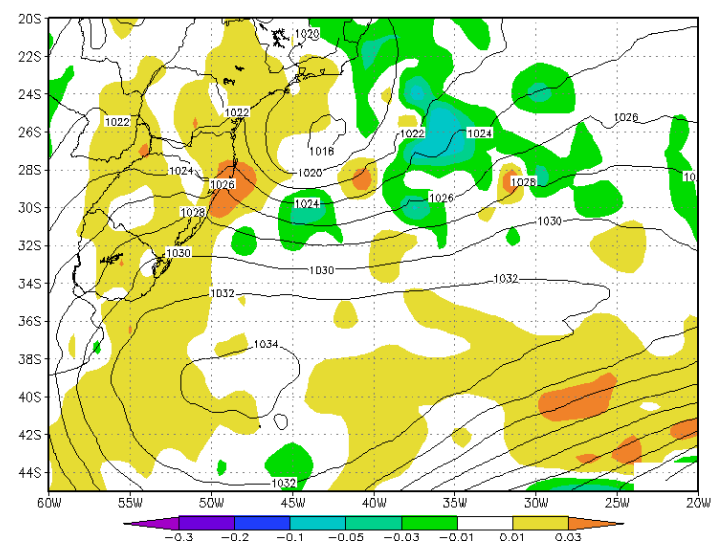

Figura 4.32: PNMM (linha sólida, em hPa) e pseudo velocidade vertical (sombreado, em Pa s-1) em 700 hPa para o dia 30 de maio de 1997 às 0000 UTC, para o (a) EXPCOM97 e o (b) EXPSEM97.

(a)
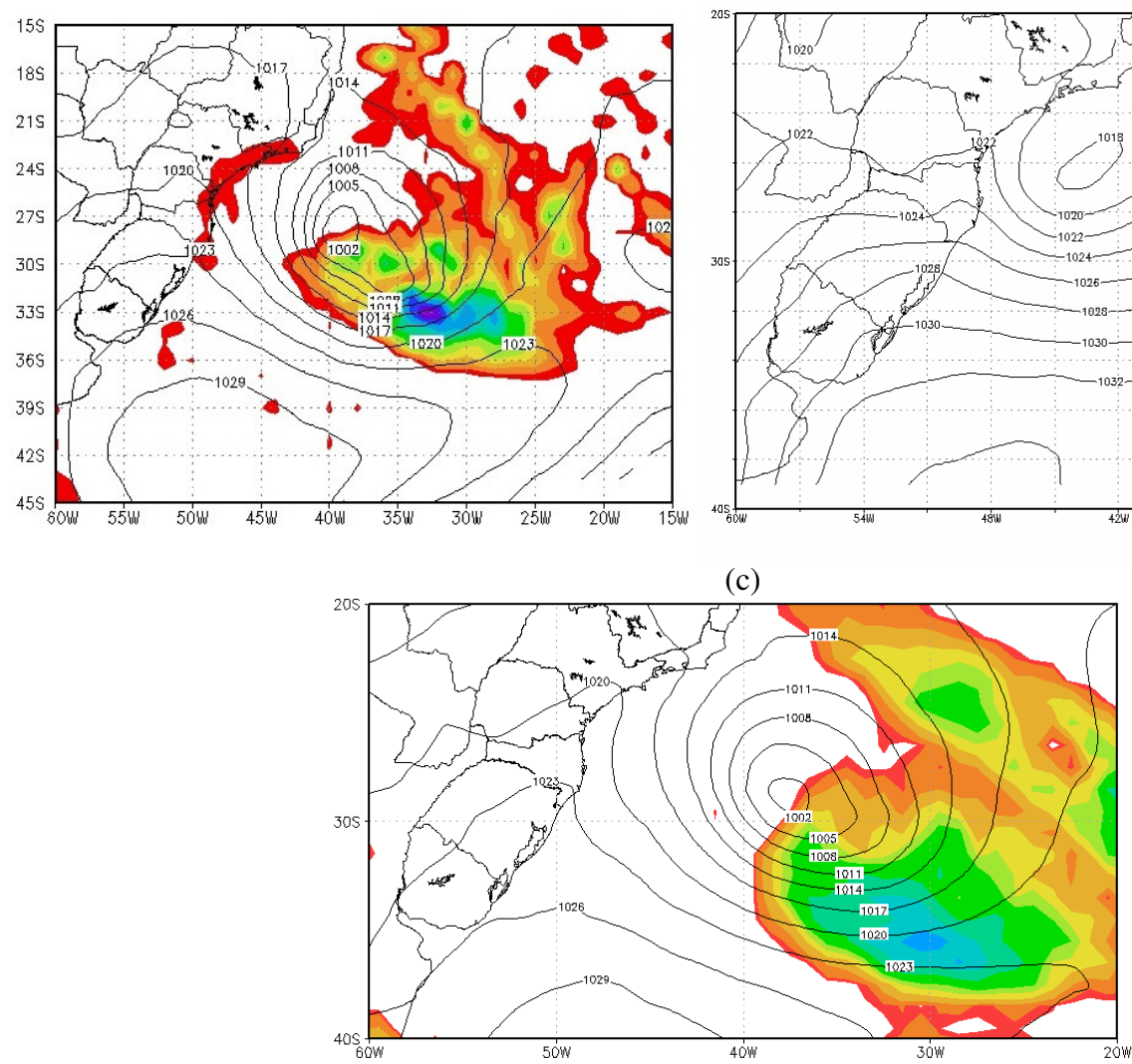

(b)

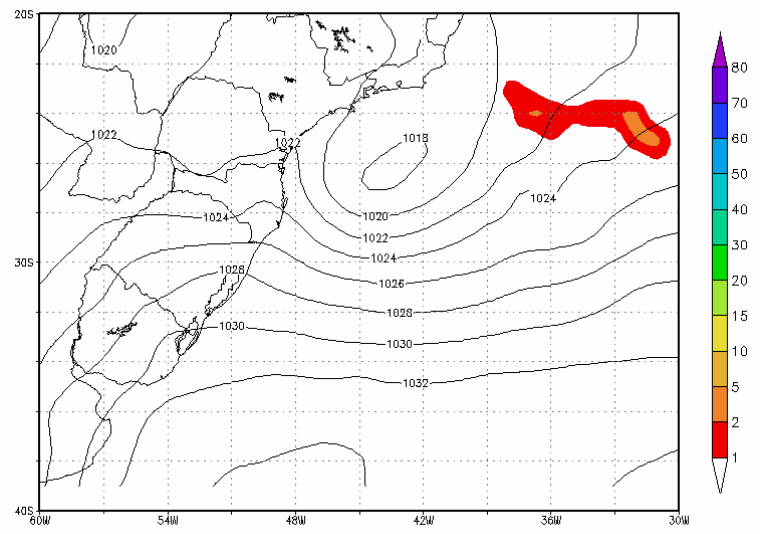

(c) 
isto, no EXPSEM97, o ciclone situou-se sobre o eixo do cavado (fig. 4.34b), configuração menos favorável para o seu futuro desenvolvimento, ou seja, ocorreu um desacoplamento entre o ciclone em superfície e a onda em níveis médios.

(a)

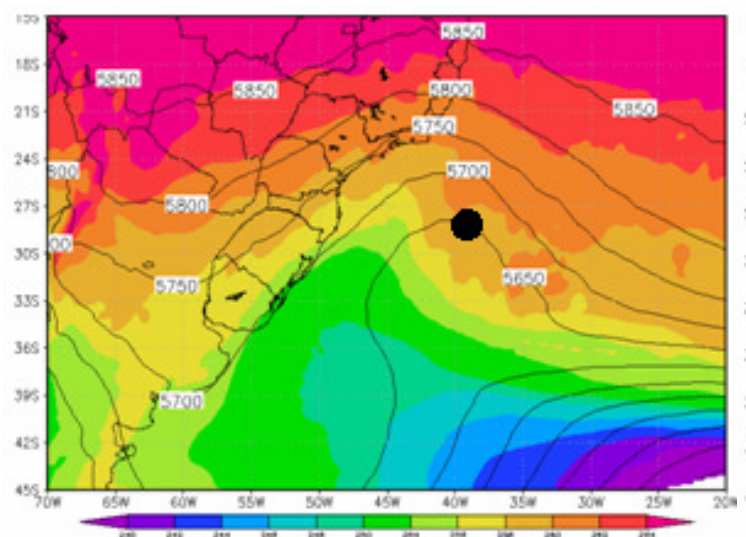

(c)

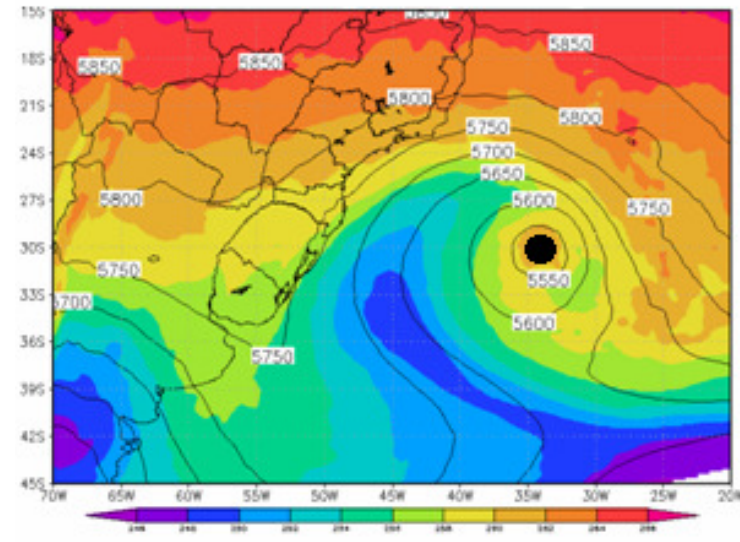

(b)

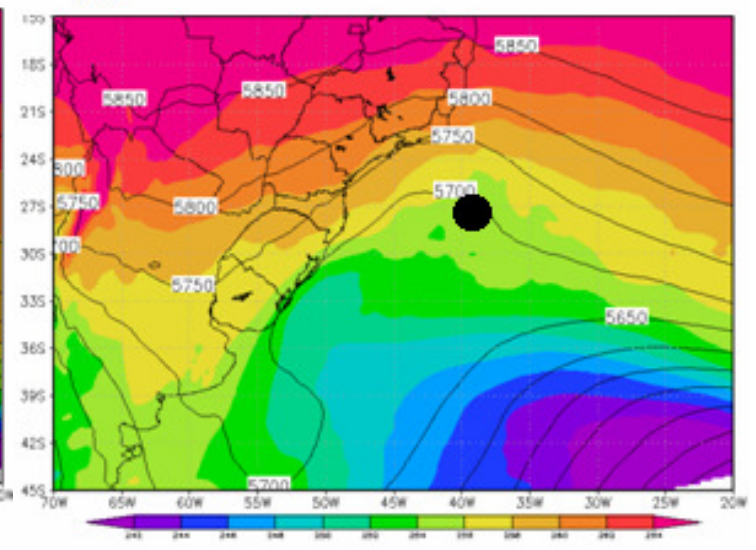

(d)

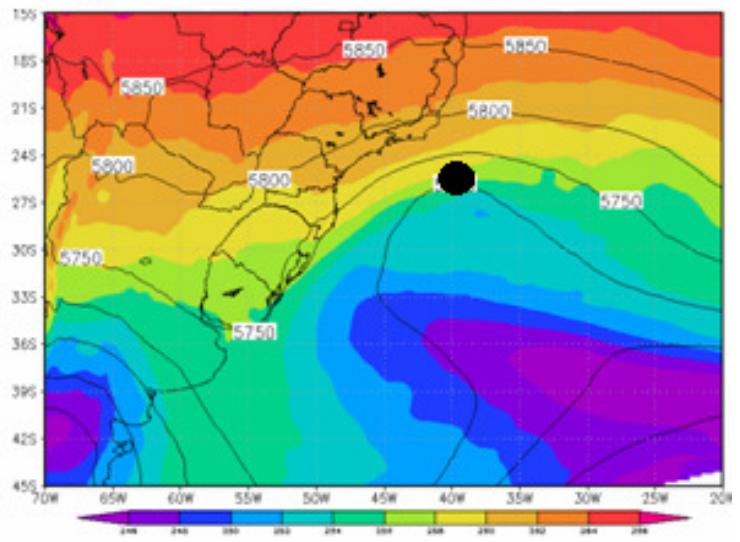

Figura 4.34: Altura geopotencial (linha sólida, em m) e temperatura potencial (sombreado, em K) em $500 \mathrm{hPa}$, para os dias 30 e 31 de maio de 1997. (a), (c) EXPCOM97 e (b), (d) EXPSEM97. O círculo preto indica a posição da baixa em superfície.

Durante os dias 28 e 29 de maio, a configuração dos campos de geopotencial e temperatura em $500 \mathrm{hPa}$ praticamente não sofre alteração entre as duas simulações. No dia 30 de maio, a advecção de temperatura provocada pelo ciclone intensifica a onda térmica no EXPCOM97 (fig. 4.34a). Na região do ciclone no EXPSEM97, não se verifica intensificação da onda térmica neste nível, indicando que o sistema é menos profundo (fig. 4.34b). No dia 31, no EXPCOM97, fecha-se uma baixa no campo de geopotencial em $500 \mathrm{hPa}$, com núcleo quente (fig 4.34c). O sistema atinge o estágio barotrópico equivalente, com a intensidade da circulação diminuindo com a altura neste caso. O abaixamento das isoípsas neste nível está 
associado ao aquecimento por convecção em níveis superiores (seção 4.3), que durante todo o ciclo de vida deste ciclone foi máximo em torno de $300 \mathrm{hPa}$, expandindo a atmosfera neste nível e forçando a altura geopotencial em $500 \mathrm{hPa}$ para baixo. Esta estrutura não ocorre no EXPSEM97 (fig. 4.34d), pois o sistema é mais raso, menos intenso e com menor disponibilidade de vapor d'água, e conseqüente menor aquecimento convectivo na alta atmosfera.

\subsubsection{Ciclone 2 ( 12 de abril de 2000$)$}

O deslocamento do ciclone 2 sofreu influência muito menor dos FCSL, em comparação ao ciclone 1. Na reanálise e nas duas simulações, o sistema iniciou-se na costa de $\mathrm{SC}$ e moveu-se para sudeste (fig. 4.35).

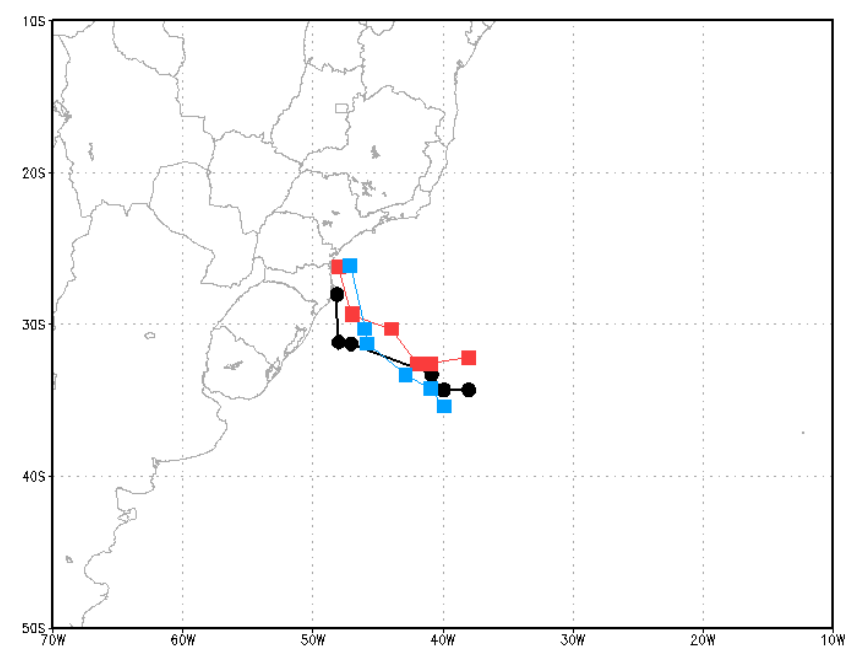

Figura 4.35: Trajetória do ciclone segundo a reanálise Era-Interim (linha preta), EXPCOM (linha vermelha) e EXPSEM (linha azul). As três trajetórias se iniciam às 0000 UTC do dia 13 de abril de 2000 e os pontos estão marcados a cada 12 horas.

A adveção de temperatura associada ao ciclone, no dia 13 de abril às 0000UTC é semelhante nos dois experimentos, com um forte núcleo de advecção positiva na costa da região sul (figs. 4.36a e 4.36b). A partir do dia 14 de abril tornam-se aparentes as diferenças na magnitude, mas ainda a distribuição espacial é bastante semelhante no EXPCOM00 e EXPSEM00 (figs. 4.36c e 4.36d). No dia 15, a advecção de temperatura é fraca e esparsa (fig. não mostrada). Este comportamento entre os dois experimentos, contrasta com as mudanças 
ocorridas no campo de advecção de temperatura no ciclone 1. Neste ciclone, a ausência de FCSL alterou a circulação em baixos níveis, resultando em uma distribuição diferente de advecção de temperatura e conseqüente mudança na trajetória. No ciclone 2 , como a circulação está sendo primeiramente forçada pelos níveis médios, a ausência dos FCSL impactou principalmente a magnitude da advecção de temperatura (modificando o campo de temperatura em baixos níveis), com impacto menor na distribuição espacial, não alterando significativamente o deslocamento deste sistema.

(a)

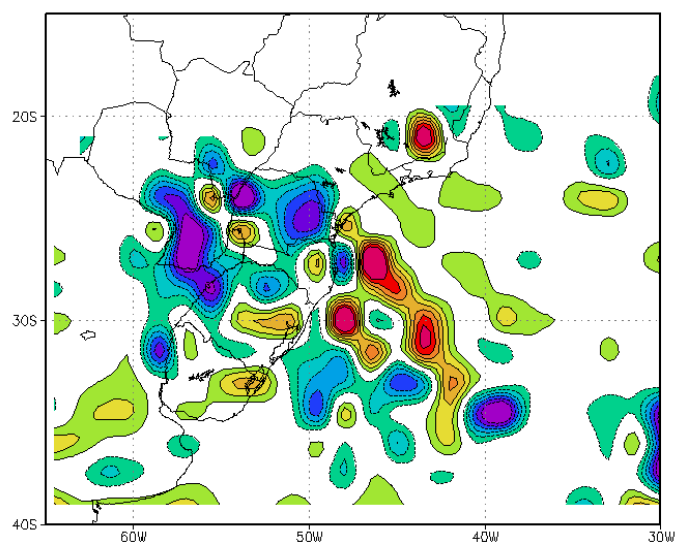

(c)

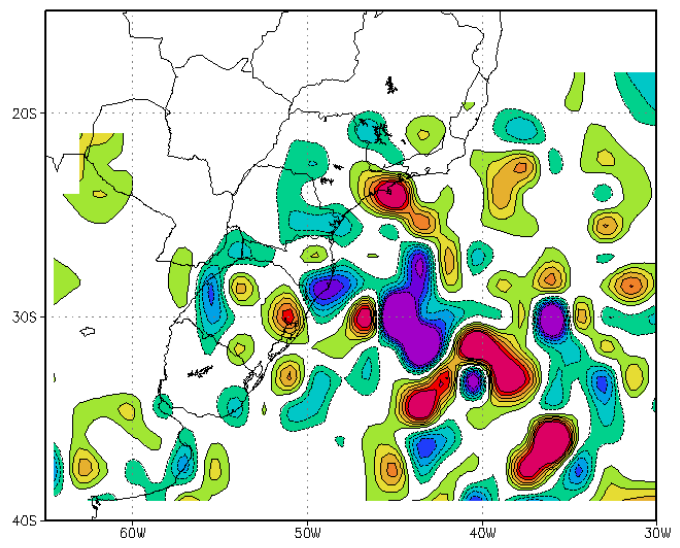

(b)

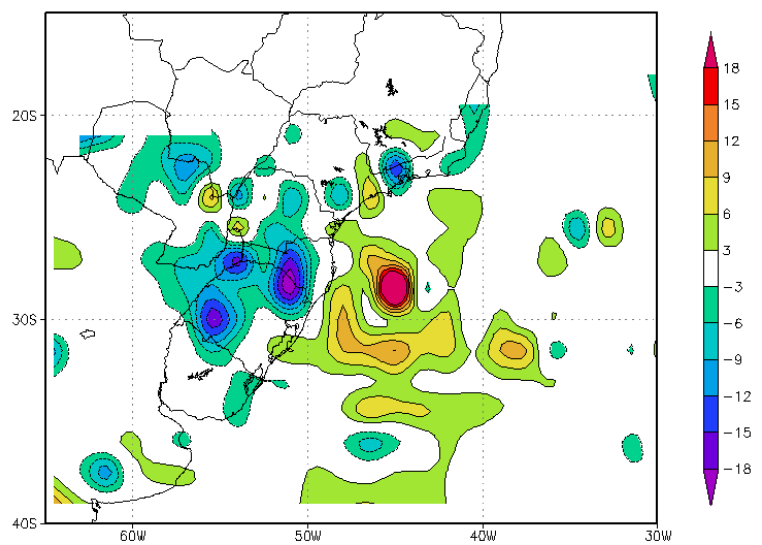

(d)

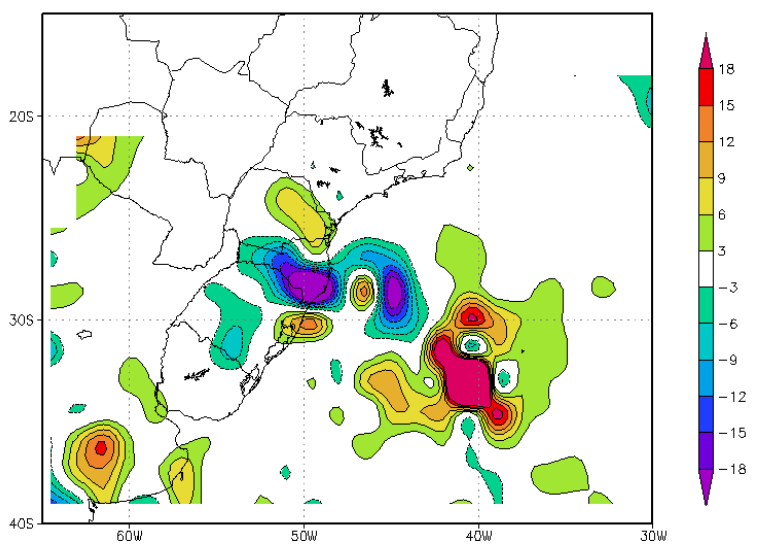

Figura 4.36: Advecção de temperatura em $850 \mathrm{hPa}\left(\mathrm{Kdia}^{-1}\right)$ para os dias 13 e 14 de abril de 2000 às 0000 UTC, para o $(\mathrm{a}, \mathrm{c})$ EXPCOM00 e para o $(\mathrm{b}, \mathrm{d})$ EXPSEM00.

Em 13 de abril às 1200 UTC, o ciclone em superfície, em ambas as simulações, se encontrava sob uma região de advecção de vorticidade ciclônica em $250 \mathrm{hPa}$, favorecendo o desenvolvimento. No dia 14 de abril às 0000 UTC, a baixa desprendida em médios níveis se desintensifica no EXPCOM00, e o ciclone se posiciona sob uma área de advecção positiva de 
vorticidade. No EXPSEM00, a baixa desprendida em $500 \mathrm{hPa}$ mantém-se mais intensa no campo de geopotencial, e o ciclone em superfície se posiciona exatamente abaixo. O maior aprofundamento da baixa desprendida, no EXPSEM00, deve-se à menor liberação de calor latente, uma conseqüência de processos em baixos e médios níveis. A formação de nebulosidade a leste do ciclone e sob a baixa desprendida, como mostra a imagem de satélite no infravermelho (fig. 4.37a), é inibida no EXPSEM00, tanto pela circulação vertical mais fraca como pela ausência de fluxo de umidade do oceano para a atmosfera. A figura 4.37b, diferença de água de nuvem mais água de chuva no nível de $600 \mathrm{hPa}$, mostra uma quantidade maior de hidrometeoros no caso EXPCOM00, e essa diferença atinge até mesmo o nível de $500 \mathrm{hPa}$. Sem esta fonte de calor latente em médios níveis, no EXPSEM00 o ar encontra-se até $10 \mathrm{~K}$ mais frio em $500 \mathrm{hPa}$ em relação ao EXPCOM00 (fig. 4.37c e 4.37d).

(a)

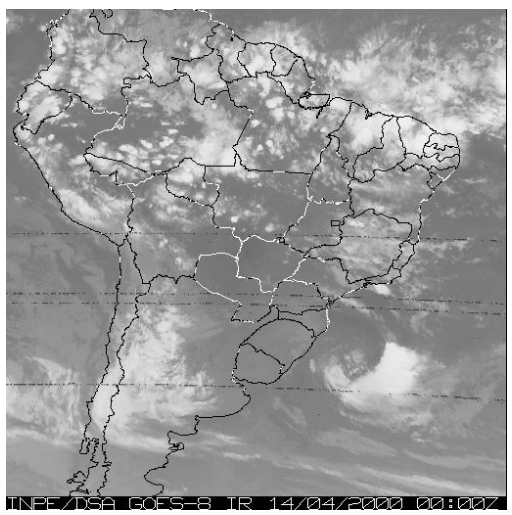

(c)

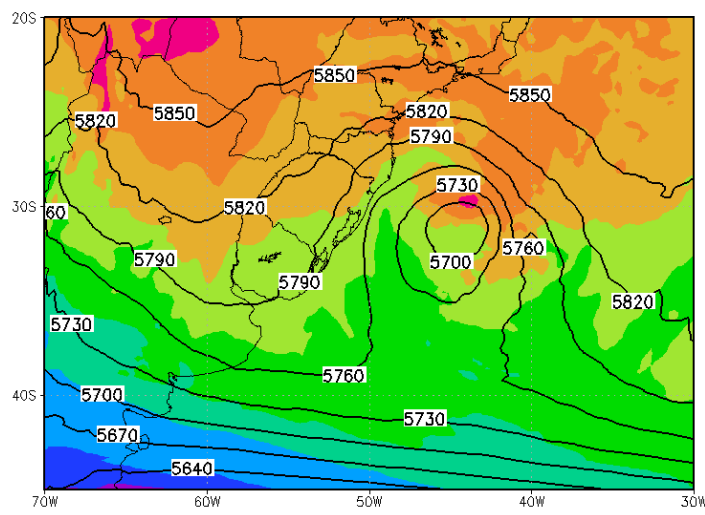

(b)

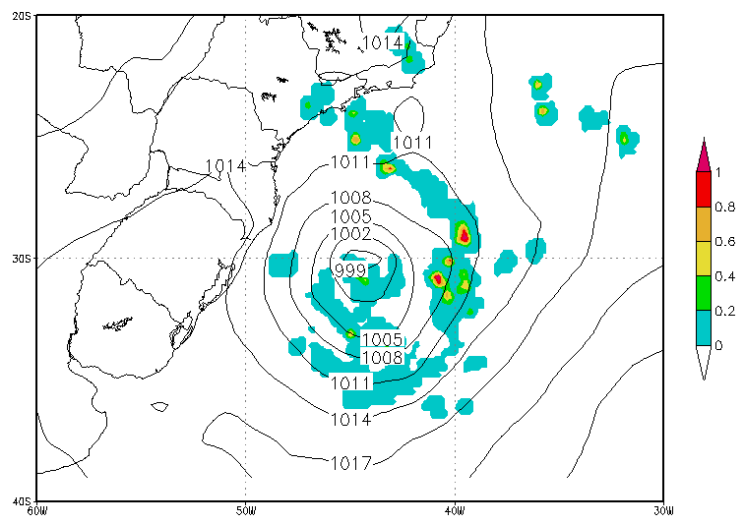

(d)

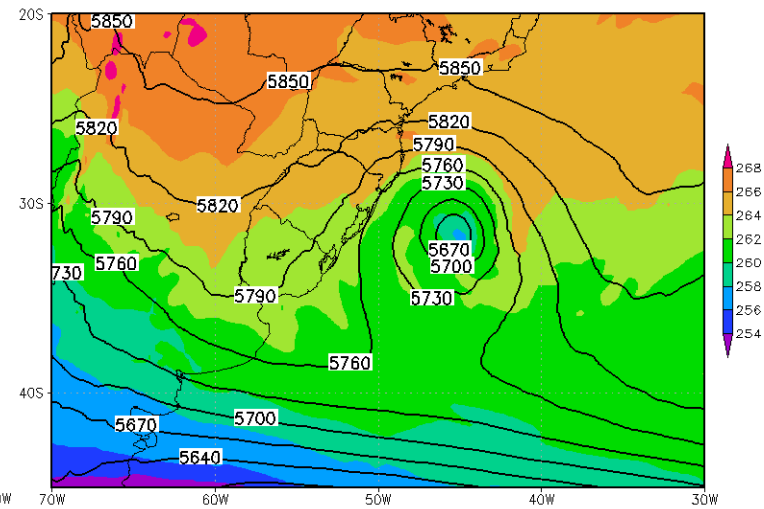

Figura 4.37: (a) Imagem do satélite GOES-8, canal infravermelho; (b) PNMM (linha contínua, em hPa) e diferença da quantidade de água de nuvem + água de chuva (sombreado, em kgkg-1) no nível de $500 \mathrm{hPa}$ entre o EXPCOM00 e o EXPSEM00, altura geopotencial (linha contínua, em m) e temperatura do ar (sombreado, em K) para o (c) EXPCOM00 e o (d) EXPSEM00, para o dia 14 de abril de 2000 às 0000 UTC. 
A figura $4.37 \mathrm{~d}$ mostra o campo de temperatura no EXPSEM00 "fechado" em torno da baixa desprendida no campo de geopotencial, com temperatura de $256 \mathrm{~K}$. No EXPCOM00, a maior atividade convectiva intensificada pelo fornecimento de calor e umidade da superfície oceânica, aquece a atmosfera e enfraquece a baixa desprendida nos níveis médios.

Além do resfriamento da atmosfera na ausência de FCSL, outro mecanismo pode estar associado à intensificação da circulação da baixa desprendida em médios níveis. Segundo STOELINGA (1996) e HOSKINS (1997), acima de um núcleo de liberação de calor latente no hemisfério Norte ocorre anomalia negativa de vorticidade potencial (diminui a circulação ciclônica), e abaixo deste núcleo ocorre anomalia positiva de vorticidade potencial (intensifica a circulação ciclônica). A ausência de FCSL no ciclone 2 minimiza a liberação de calor latente por volta de $600 \mathrm{hPa}$, como já discutido, inibindo a anomalia positiva (no hemisfério Sul) de vorticidade potencial acima (no nível de $500 \mathrm{hPa}$ ), que eventualmente iria diminuir a circulação da baixa desprendida. A ausência da anomalia negativa de vorticidade potencial em baixos níveis, no caso EXPSEM00, contribui para o enfraquecimento do ciclone em superfície, mas seriam necessárias outras análises, fora do escopo deste trabalho, para demonstrar tal afirmação.

GARREAUD e FUENZALIDA (2007), através de simulações numéricas do desenvolvimento de uma baixa desprendida em médios níveis com e sem aquecimento por convecção, também mostraram que esta baixa se aprofunda e persiste por mais tempo na ausência da liberação de calor latente.

(a)

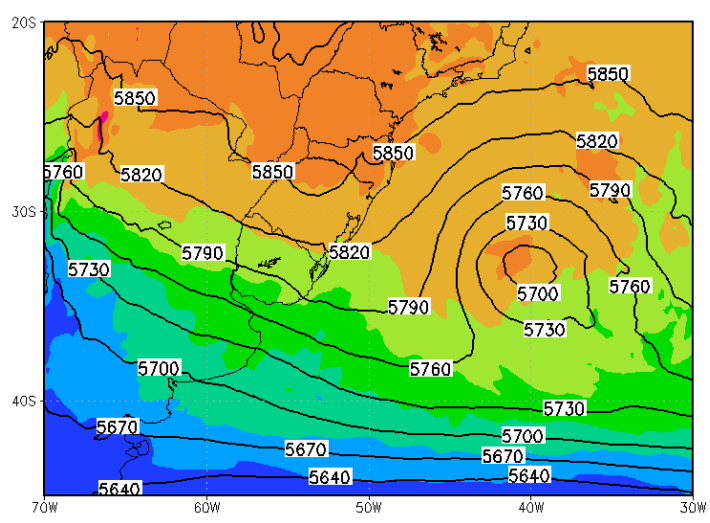

(b)

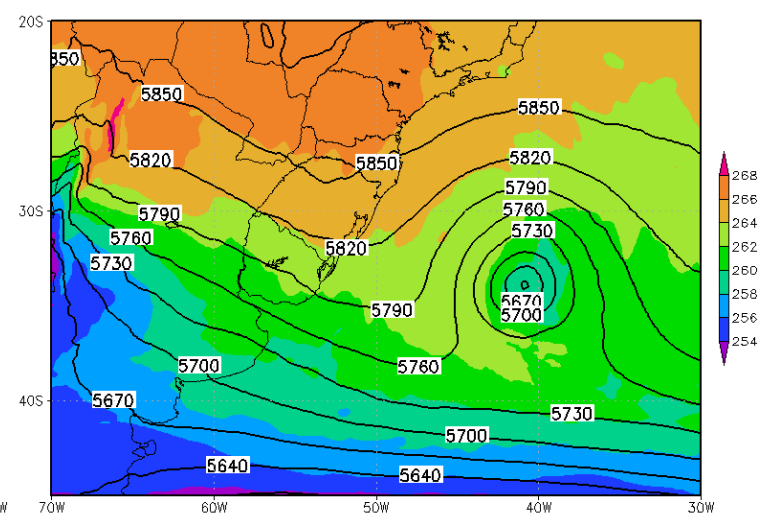

Figura 4.38: Altura geopotencial (linha sólida, em m) e temperatura do ar (sombreado, em K) em 500 hPa para o (a) EXPCOM00 e o (b) EXPSEM00, para o dia 15 de abril de 2000 às 0000 UTC.

Em 14 de abril às 1200 UTC, os ciclones em superfície, em ambas as simulações, encontram-se alinhados com a baixa em médios níveis (figuras não apresentadas). Esta 
situação se mantém por todo o dia 15 de abril (fig. 4.38), quando a baixa desprendida se mantém intensa no EXPSEM00 e continua mais fraca no EXPCOM00.

O ciclone 2 desenvolve em níveis médios e se propaga para a superfície, e apresenta intensidade e movimentos verticais menores do que o ciclone 1, portanto as modificações em níveis superiores devido à ausência de FCSL são menores. A distribuição espacial dos campos é semelhante, e as principais diferenças devem-se à diferença no aquecimento da atmosfera por convecção.

A comparação entre os dois eventos evidencia o papel dos FCSL em superfície na alteração do campo de advecção de temperatura e, consequentemente, no deslocamento dos ciclones. Enquanto o ciclone 1 sofreu grandes mudanças na advecção térmica em baixos níveis, levando-o a uma trajetória diferente na ausência de FCSL, o ciclone 2 teve a sua trajetória praticamente inalterada nas duas simulações, pois a circulação que gera a advecção térmica em baixos níveis foi, neste caso, primariamente dirigida pelos médios níveis. A convergência em baixos níveis, gerada pelo fluxo de calor sensível, também influenciou menos o ciclone 2 (figuras não apresentadas). No dia 13 de abril, praticamente não há diferença no campo de convergência do vento a $10 \mathrm{~m}$, e nos dias 14 e 15, as diferenças (da ordem de $10^{-4} \mathrm{~s}^{-1}$ ) se concentram principalmente na região central do ciclone, e não adiante do sistema, como no caso do ciclone 1. A convergência mais forte estaria mais relacionada à intensidade da circulação, que é maior no EXPCOM00, do que aos fluxos de calor sensível. No caso do ciclone 1 , as diferenças de divergência ocorriam principalmente à sudeste do sistema (região de fortes fluxos de calor sensível, cerca de $70 \mathrm{Wm}^{-2}$ ), influenciando o deslocamento da baixa pressão; no ciclone 2, as áreas a sudeste do sistema possuem fluxos de calor sensível menores, cerca de $20 \mathrm{Wm}^{-2}$, não ocasionando convergência tão intensa. Além disso, o ciclone 2 está sendo mais dirigido por forçantes de níveis médios, com o processo de convergência na CLP devido ao fluxo de calor sensível apresentando impacto secundário.

\subsection{Outras influências dos FCSL na intensificação dos ciclones}

A intensificação dos ciclones sofreu forte influência dos FCSL (fig. 4.39). O ciclone 1, no EXPCOM97, apresentou evolução temporal da pressão central semelhante à reanálise: forte abaixamento de pressão no início, leve desintensificação por volta dos dias 01 e 02 de junho e nova intensificação até o dia 05 de junho. Esta simulação apresentou um 
aprofundamento maior do sistema comparado à reanálise, possivelmente devido aos FCSL mais intensos. No EXPSEM97, o ciclone apresentou queda de pressão mínima nas primeiras 24 horas e a seguir enfraqueceu, aumentando rapidamente a pressão central e desaparecendo no dia 01 de junho.

As simulações do ciclone 2 apresentaram comportamento atípico: a pressão central no EXPSEM00 é mais próxima da reanálise do que no EXPCOM00, onde o ciclone se aprofundou muito mais que a reanálise e manteve sua pressão central constante por todo um dia (fig. 4.39b). Esta evolução deve estar associada aos fluxos de calor e umidade excepcionalmente intensos no EXPCOM00, como já discutido durante a validação do modelo. Além disso, a ausência de observações diretas no oceano Atlântico Sul pode implicar em subestimativa da intensidade dos ciclones nas reanálises. Por exemplo, conforme GAN (2009), a menor pressão central de $1010 \mathrm{hPa}$ obtida em pela reanálise NCEP para o evento Catarina, ocorrido em março de 2004, foi bastante subestimada. No entanto MCTAGGART et al. (2006) chegaram a estimar $972 \mathrm{hPa}$, ou seja, uma diferença de quase $40 \mathrm{hPa}$ em relação à reanálise do NCEP. Portanto, nem toda a diferença de pressão apresentada na figura 4.39 pode ser considerada erro de simulação.

(a)

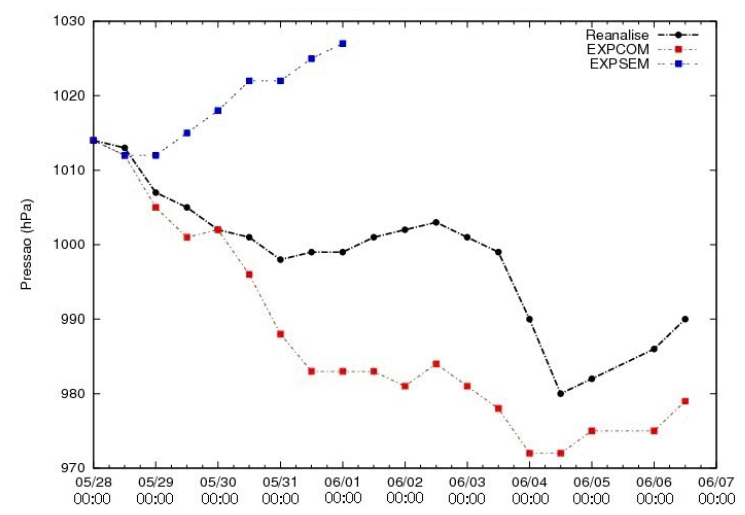

(b)

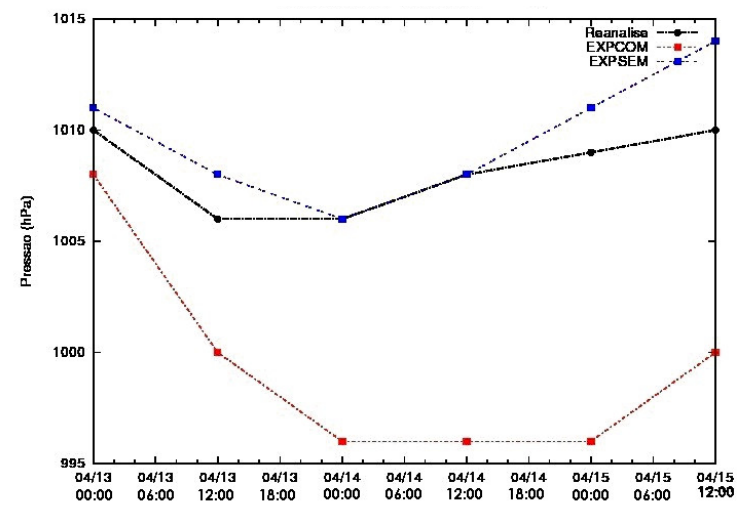

Figura 4.39: Evolução temporal de pressão central para o (a) ciclone 1 e (b) ciclone 2. A linha preta representa a reanálise ERA-Interim, a linha vermelha a simulação EXPCOM e a linha azul a simulação EXPSEM.

O item 4.2 discutiu como os FCSL podem alterar a trajetória dos sistemas ciclônicos e, assim, posicioná-los em relação às forçantes de médios e altos níveis de forma a promover intensificação/desintensificação. Também mostrou que a convergência em baixos níveis pode ser um efeito importante na intensificação dos sistemas. Mas além destas forçantes, outros processos físicos restritos aos baixos níveis da atmofera também podem contribuir para o desenvolvimento do sistema, e serão discutidos a seguir. 


\subsubsection{Convergência friccional dentro da CLP nas regiões frontais}

Os sistemas frontais no ciclone 1 apresentaram intensidade menor no EXPSEM97, como mostra a figura 4.40 para o dia 31 de maio de 1997 às 0000 UTC. Isto ocorre durante todo o ciclo de vida do sistema, mostrando que a convergência (especialmente na região da frente quente e centro do ciclone) está sendo de alguma maneira afetada pelos FCSL de superfície.

(a)

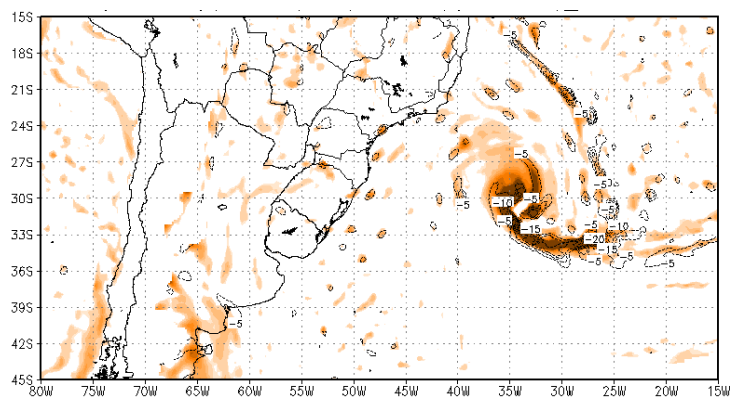

$\begin{array}{llllllllllll}-18 & -16 & -14 & -12 & -10 & -8 & -6 & -4 & -2 & -1.5\end{array}$ (b)
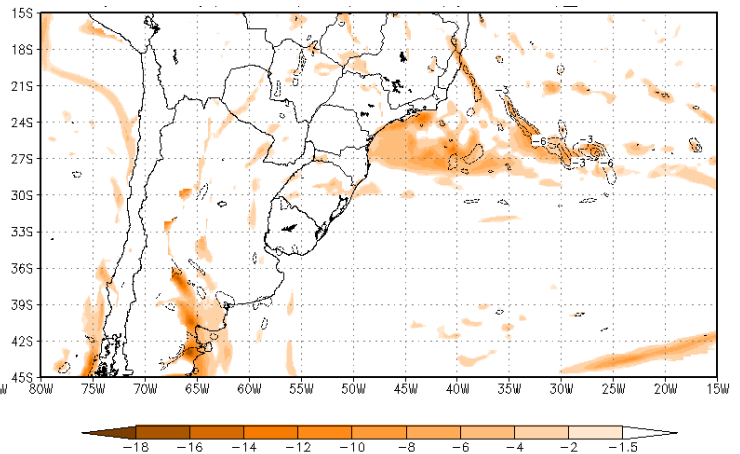

Figura. 4.40: Vorticidade relativa (sombreado, $\times 10^{-5} \mathrm{~s}^{-1}$ ) e divergência (linha tracejada, em $\times 10^{-5} \mathrm{~s}^{-1}$, apenas valores negativos) do vento horizontal em $925 \mathrm{hPa}$, para o dia 31 de maio de 1997 às $0000 \mathrm{UTC}$, para o (a) EXPCOM97 e o (b) EXPSEM97.

Uma das formas dos FCSL influenciarem os sistemas frontais é reduzindo a circulação dos sistemas: em ciclones menos intensos, certamente as regiões frontais serão igualmente menos intensas. Além deste efeito, a desestabilização da baixa troposfera pelos fluxos de calor sensível de superfície pode induzir a convergência de Ekman nas regiões frontais, através de gradientes horizontais de estabilidade estática nestas regiões, conforme sugerido por NUSS (1989) em experimento idealizado. Os campos do dia 30 de maio de 1997 ilustram a atuação deste processo, que ocorre de maneira semelhante entre os dias 29 de maio e 01 de junho de 1997.

A transferência de calor sensível entre oceano e atmosfera, provocou a instabilização da baixa atmosfera até cerca de $900 \mathrm{hPa}$ (profundidade semelhante à encontrada por DAL PIVA, 2001). A distribuição horizontal de estabilidade estática em $925 \mathrm{hPa}$, para as duas simulações, é mostrada na figura 4.41. Todo o domínio apresenta menor estabilidade estática no EXPCOM97. Os maiores valores (ou seja, atmosfera menos instável) estão localizados sobre as regiões frontais fria e quente (fig. 4.41a). Fluxos intensos de calor sensível localizamse a oeste do sistema, no setor frio, e na dianteira da frente quente, fazendo com que a 
instabilidade estática nestas regiões atinja seus valores mínimos (entre -8 e $-10 \mathrm{~m}^{2} \mathrm{~s}^{-2} \mathrm{~Pa}^{-2}$ ). No EXPSEM97, a instabilidade é mais fraca (fig. 4.41b). A maior instabilidade da atmosfera favorece os fluxos verticais, e o fluxo de momento em $925 \mathrm{hPa}$ no EXPCOM97 (representado pela tensão do vento na fig. 4.42a) apresenta valores elevados em todo o setor norte, oeste e sul do ciclone. A região de tensão mais intensa $\left(1,1 \mathrm{Nm}^{-2}\right)$ localiza-se a sul do ciclone, adiante da frente quente (concordando com o experimento de NUSS (1989), que encontrou em ciclone idealizado a mesma região de tensão máxima). No EXPSEM97, a máxima tensão (cerca de $0,3 \mathrm{Nm}^{-2}$ ) ocorre a sul do sistema, na região de ventos mais intensos, e também a oeste (fig. 4.42b).

(a)

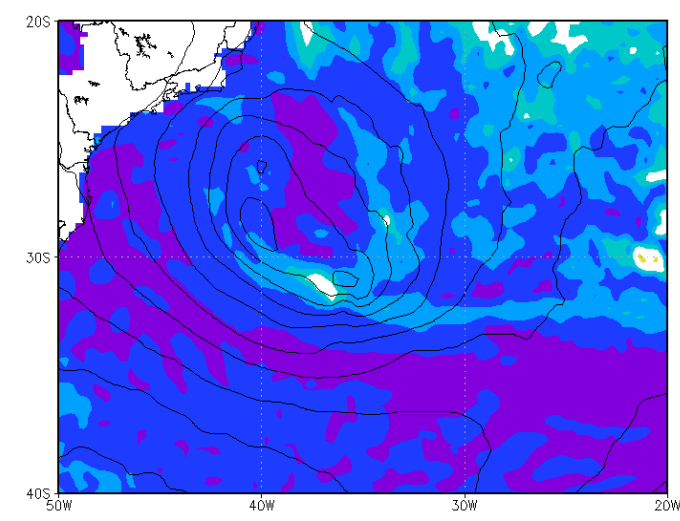

(b)

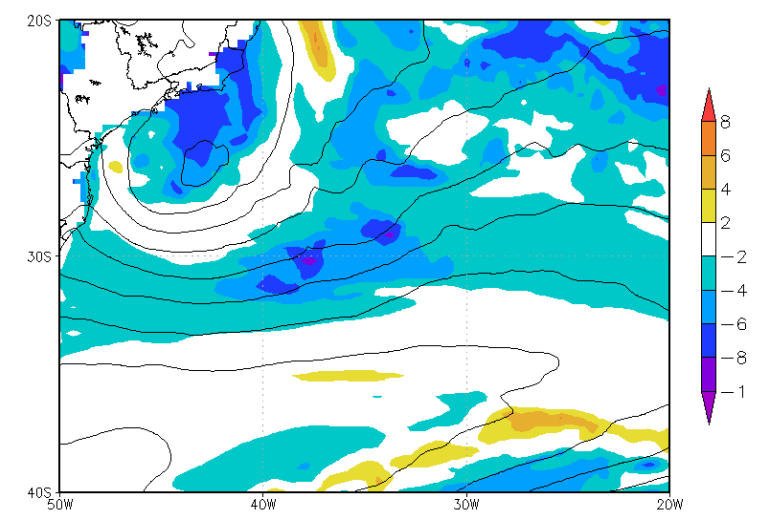

Figura 4.41: Distribuição horizontal de estabilidade estática $\left(\mathrm{m}^{2} \mathrm{~s}^{-2} \mathrm{~Pa}^{-2}\right)$ para o dia 30 de maio de 1997,0000 UTC, no (a) EXPCOM97 e (b) EXPSEM97.

(a)

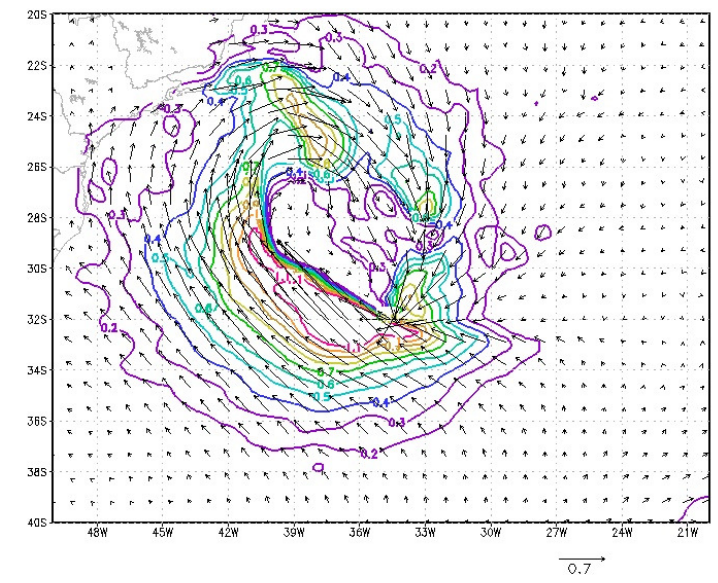

(b)

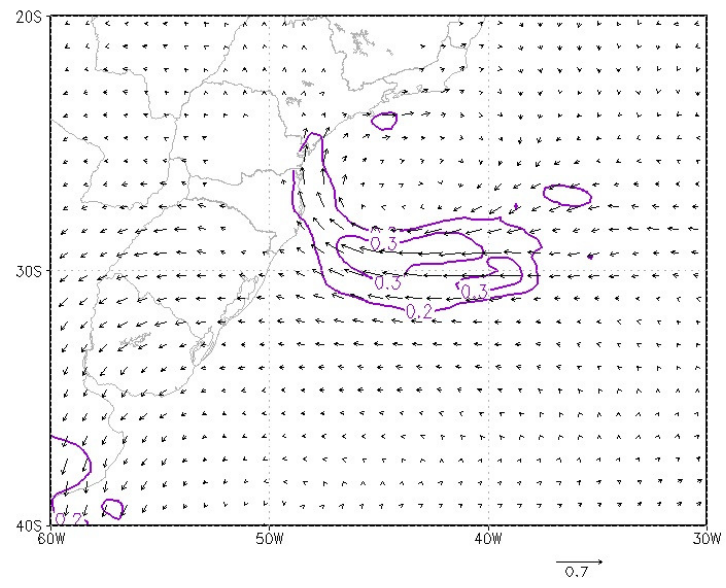

Figura 4.42: Tensão do vento (vetores) e magnitude da tensão do vento (linha contínua, $\mathrm{em} \mathrm{Nm}^{-2}$ ) em $925 \mathrm{hPa}$, para o dia 30 de maio de 1997 às 0000 UTC, no (a) EXPCOM e (b) EXPSEM. 
Conforme MATZNER (2001), a variação horizontal de tensão do vento modifica o transporte de Ekman realizado pelo vento, uma vez que esta quantidade é proporcional à velocidade do escoamento. $\mathrm{O}$ forte gradiente de tensão do vento existente na região da frente quente e próximo ao centro do ciclone proporciona, então, um gradiente intenso de transporte de Ekman em uma região estreita, levando assim a um processo de convergência de massa conhecido como "convergência de Ekman". As regiões onde existe convergência de Ekman podem ser determinadas a partir do rotacional do campo de tensão do vento (apresentado na figura 4.43). Observa-se no EXPCOM97 maior intensidade do movimento vertical ascendente (rotacional negativo, segundo a equação 48) nas regiões de fortes gradientes horizontais de tensão (frente quente, frente fria e a norte-noroeste do ciclone) e movimento vertical ascendente mais fraco induzido pela fricção no EXPSEM97. Este movimento ascendente causa maior transporte de ar quente e úmido para a média troposfera, indicando assim mais um processo pelo qual o ciclone pode se intensificar. No EXPSEM97 (4.43b), os gradientes de tensão são menos intensos e mais localizados, e consequentemente a convergência de Ekman estaria contribuindo menos para diminuir a pressão no ciclone.

(a)

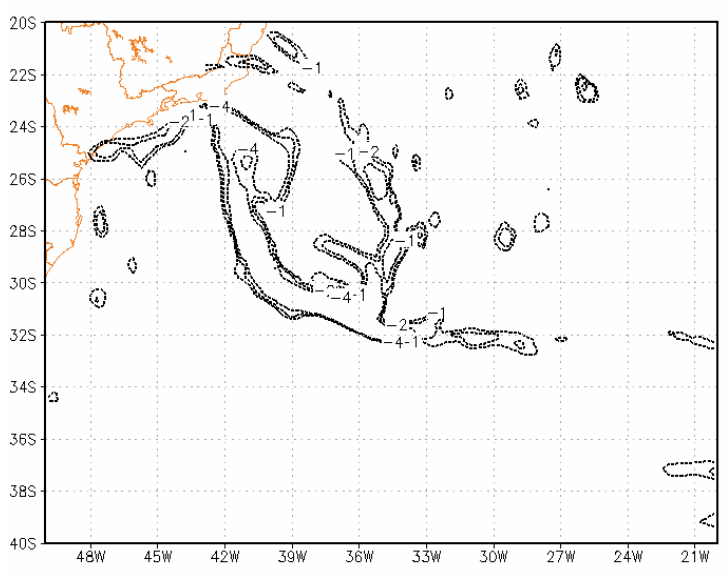

(b)

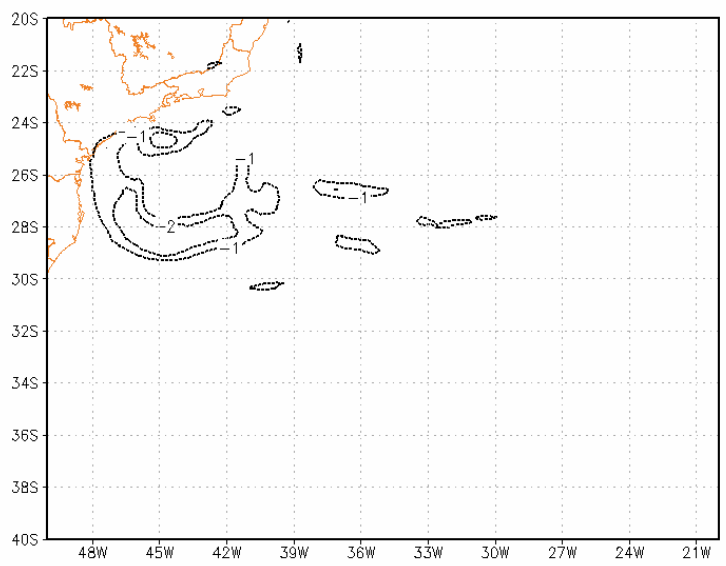

Figura 4.43: Rotacional da tensão do vento $\left(\mathrm{em} \mathrm{cm} \mathrm{s}^{-1}\right.$ ) em $925 \mathrm{hPa}$, em 30 de maio de 1997 às 0000 UTC, para o (a) EXPCOM97 e (b) EXPSEM97.

A intensificação do ciclone 2 parece também receber contribuição deste processo. No dia 13 de abril às 0000 UTC (fig. 4.44a), uma região de convergência friccional mais intensa se forma a oeste da baixa em superfície, onde os fluxos de calor sensível são intensos (fig. 4.24b). No EXPSEM00, esta região apresenta convergência, mas de menor intensidade (fig. 4.44b). Vinte e quatro horas depois, a distribuição espacial das regiões de 
convergência é semelhante entre os dois experimentos, porém apresenta magnitude maior no EXPCOM00 do que no EXPSEM00 (figs. 4.44c, 4.44d). As regiões de maior convergência estão localizadas no centro do ciclone e na região da frente fria (ao longo da longitude de $42^{\circ} \mathrm{W}$ ), onde o gradiente de aquecimento por calor sensível (fig. 4.24d) causa um forte gradiente de tensão do vento e maior convergência de Ekman. No EXPSEM00 esta região também apresenta forte convergência, e isto pode ser explicado pelo fato de que a tensão também é função da velocidade do vento, que é intensa nesta simulação. No dia 15 de abril às 0000 UTC, fluxos de calor sensível da ordem de $30 \mathrm{Wm}^{-2}$ no setor oeste do ciclone (fig. 4.24f) e uma circulação mais intensa no setor leste causam forte tensão do vento ao redor de todo o sistema no EXPCOM00, o que não acontece no EXPSEM00 (figuras não mostradas). Isto resulta em forte convergência friccional ao redor de todo o ciclone no EXPCOM00 (fig. 4.44e), e convergência mais fraca no EXPSEM00 (fig. 4.44f) 
(a)

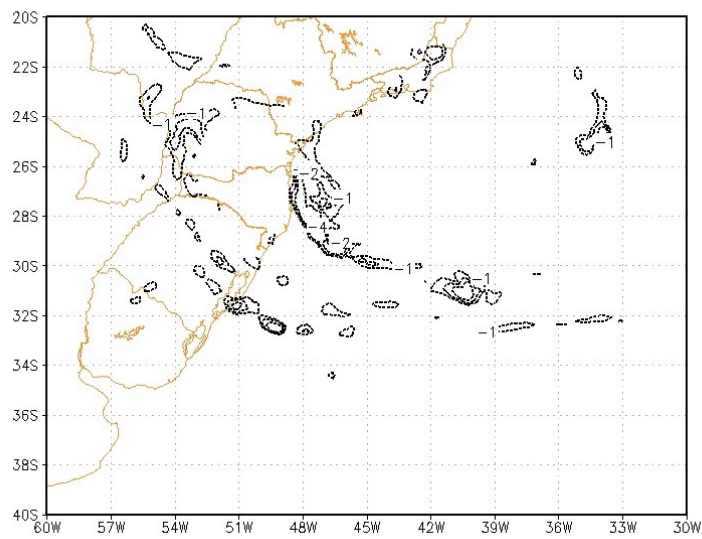

(c)

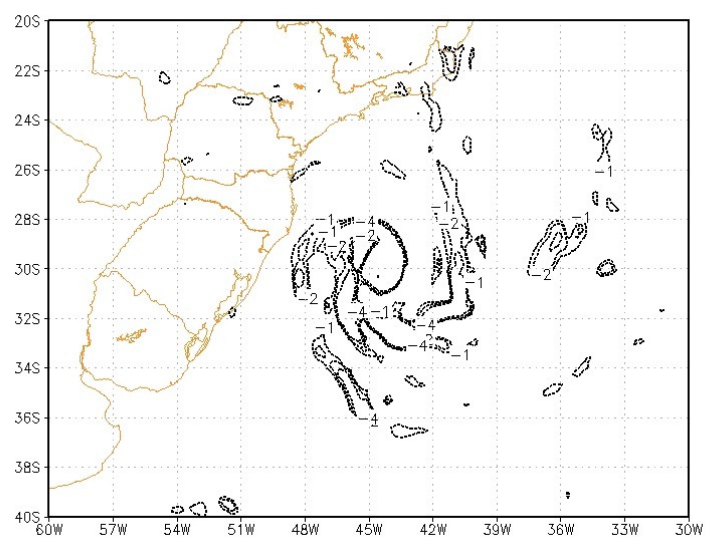

(e)

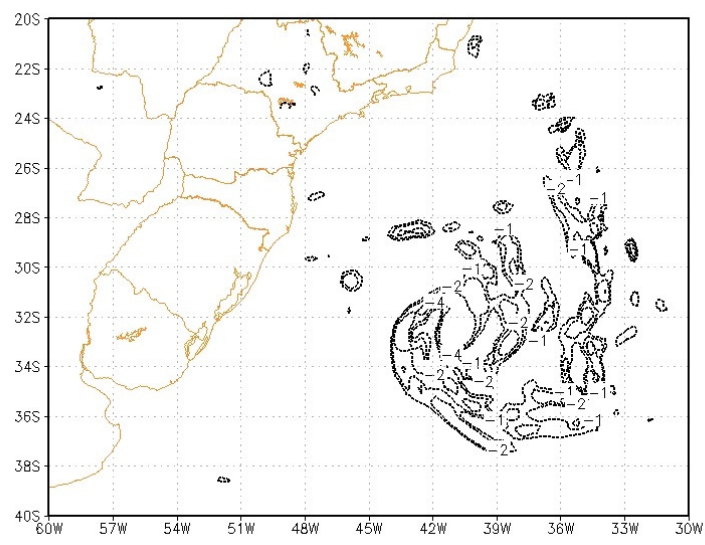

(b)

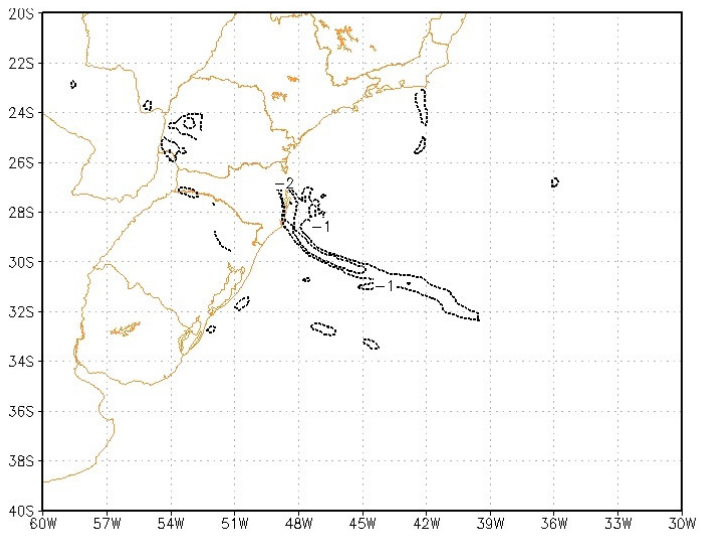

(d)

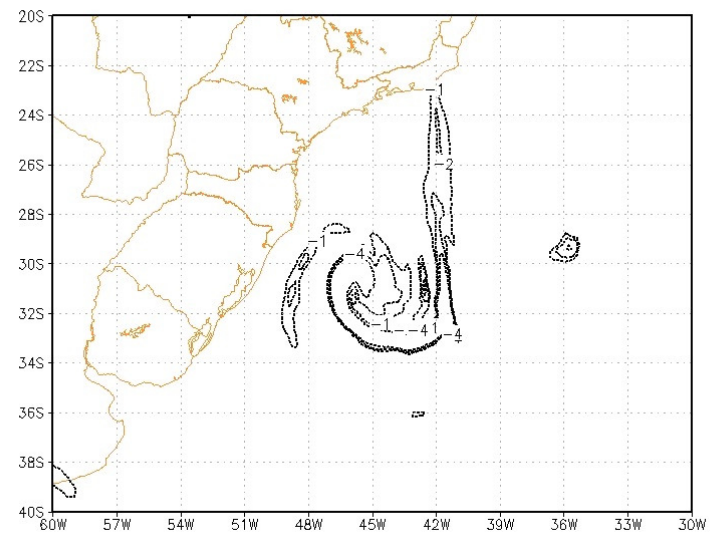

(f)

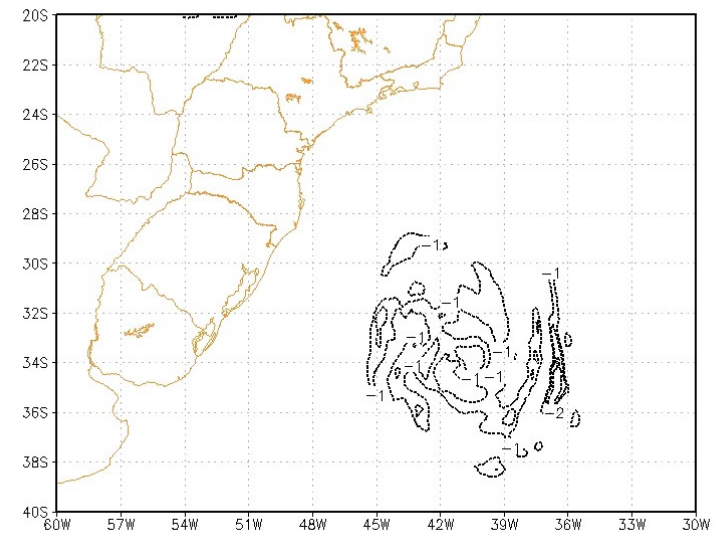

Figura 4.44: Rotacional da tensão do vento $\left(\mathrm{em} \mathrm{cm} \mathrm{s}^{-1}\right.$ ) em $925 \mathrm{hPa}$, para o EXPCOM00 nos dias (a) 13, (c) $14 \mathrm{e}$ (e) 15 de abril de 2000 e para o EXPSEM00 nos dias (b) 13, (d) 14 e (f) 15 de abril de 2000, às 0000UTC. 


\subsubsection{Fase entre as ondas de temperatura e geopotencial em baixos níveis}

Conforme exposto na introdução, o desenvolvimento de ciclones extratropicais é dependente da fase entre as ondas de geopotencial e de temperatura do ar em baixos níveis. Os dois ciclones estudados mostram características distintas de posicionamento.

O ciclone 1 apresenta o campo de geopotencial defasado em 1/2 onda em relação ao campo de temperatura em $850 \mathrm{hPa}$ no dia 29 de maio às 0000 UTC (fig. 4.45a), ou seja, não possui a relação de fase de máxima intensificação adiabática sugerida por ROEBBER (1989). O ciclone se encontra no lado quente da onda de temperatura, e isso é encontrado nas duas simulações (fig. 4.45a e 4.45b). Diferentemente do modelo teórico de Roebber, porém, não está ocorrendo fluxo negativo, isto é, da atmosfera para o oceano, no lado quente da onda, e todo o sistema encontra-se sobre fluxo de calor sensível positivo (fig. 4.12b). Assim, mesmo com esta diferença de fase entre as ondas, o papel direto dos fluxos de calor sensível ainda é intensificar o sistema. No dia 30 de maio às 0000 UTC, os campos de geopotencial e temperatura se deslocaram juntos no EXPCOM97 e o ciclone continua no lado quente e em região de fluxo de calor sensível positivo (fig. 4.45c). Porém, no EXPSEM97, a onda térmica se desloca para nordeste e posiciona o ciclone em uma região mais fria, desfavorável ao desenvolvimento (fig. 4.45d). Vinte e quatro horas depois, fluxos de calor sensível negativos começam a ocorrer no setor quente do sistema (fig. $4.12 \mathrm{~h}$ ), onde o ciclone está posicionado

(fig. 4.45e). No EXPSEM97, a onda térmica se desloca ainda mais para norte e o ciclone está embebido em uma atmosfera ainda mais fria, contribuindo para inibir o desenvolvimento (fig. 4.45f). 
(a)

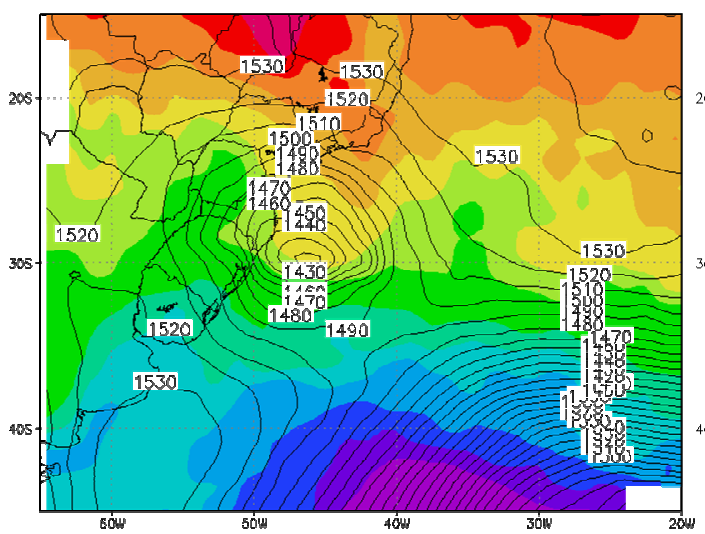

(c)

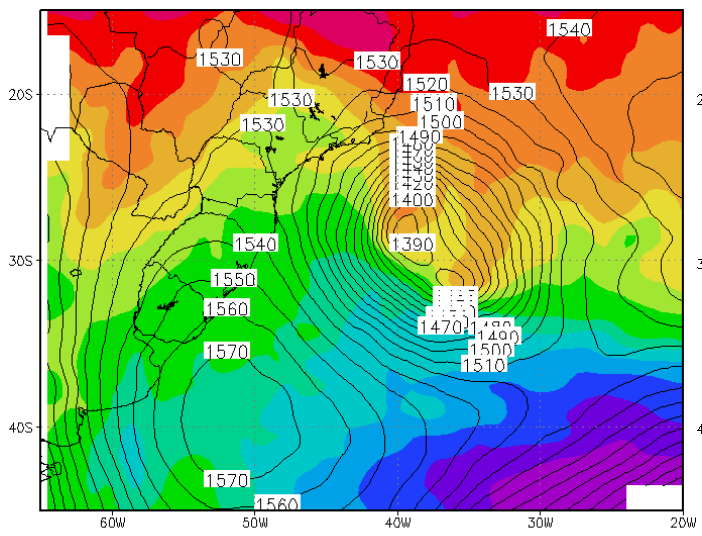

(e)

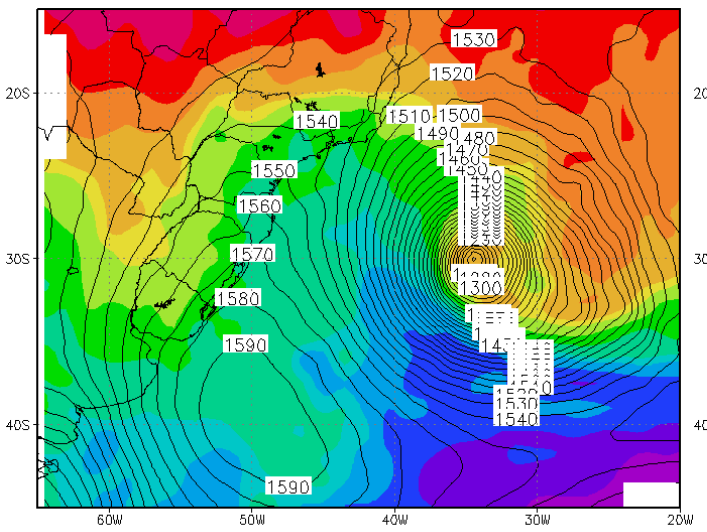

(b)

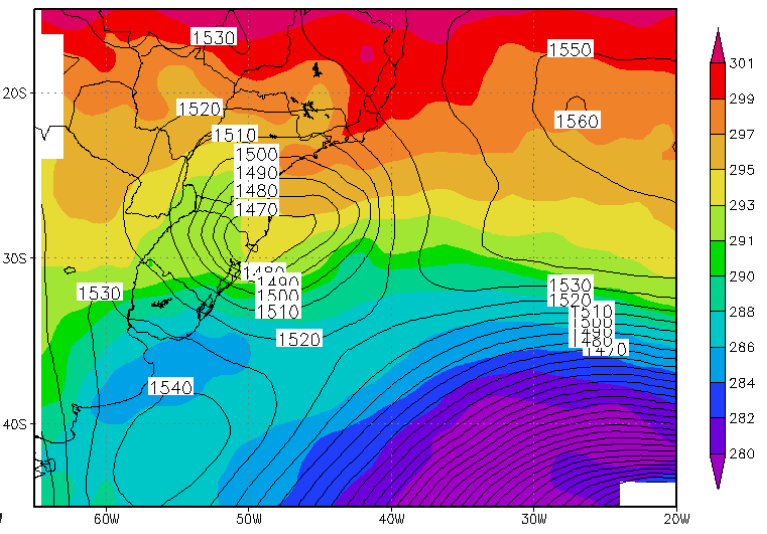

(d)

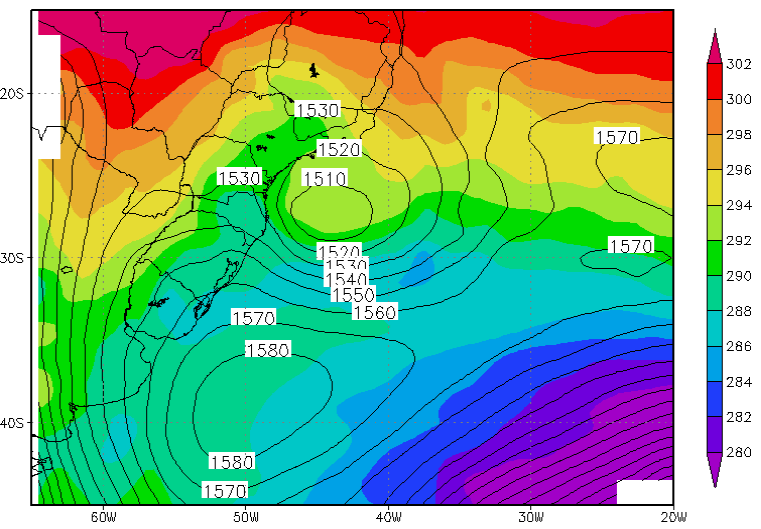

(f)

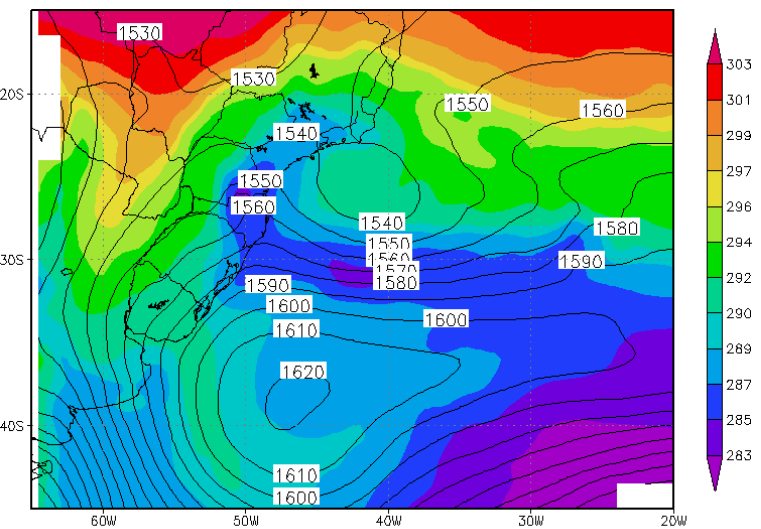

Figura 4.45: Altura geopotencial (linha contínua, em m) e temperatura do ar (sombreado, em K) em $850 \mathrm{hPa}$, para o (a),(c),(e) EXPCOM97 e (b),(d),(f) EXPSEM97, para os dias 29, 30 e 31 de maio de 1997 às 0000 UTC. 
O ciclone 2 se inicia, no dia 13 de abril, com o campo de geopotencial defasado em 1/4 de onda do campo térmico em ambas as simulações (figs. 4.46a e 4.46b). No EXPSEM00, a ausência dos FCSL resulta em maior resfriamento a sul do ciclone e uma região mais baroclínica para o desenvolvimento do sistema. Porém, o sistema se aprofundou mais no EXPCOM00, indicando que provavelmente a convergência friccional, discutida anteriormente, foi mais influente no processo de abaixamento de pressão do que o processo de conversão baroclínica neste sistema. Nos dias subsequentes, no EXPCOM00, os FCSL mantêm a região do ciclone mais aquecida, propiciando o abaixamento de pressão (figs. 4.46c e 4.46e), enquanto no EXPSEM00 a onda de temperatura se move mais rapidamente para leste e o ciclone se posiciona em uma região mais fria, desfavorecendo a intensificação (figs. 4.46d e 4.46f). Nestas figuras nota-se um resfriamento mais intenso no centro do ciclone no EXPSEM00. 
(a)

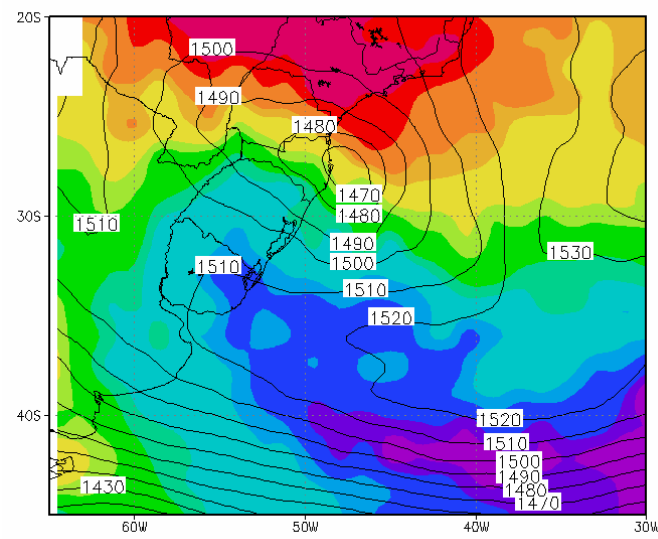

(c)

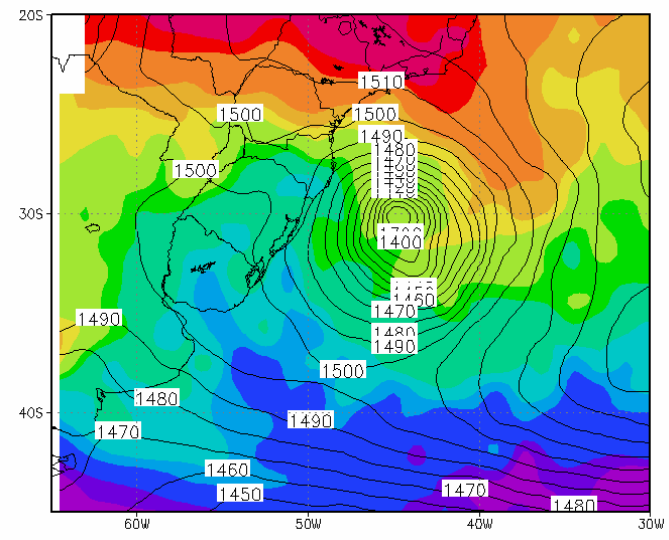

(e)

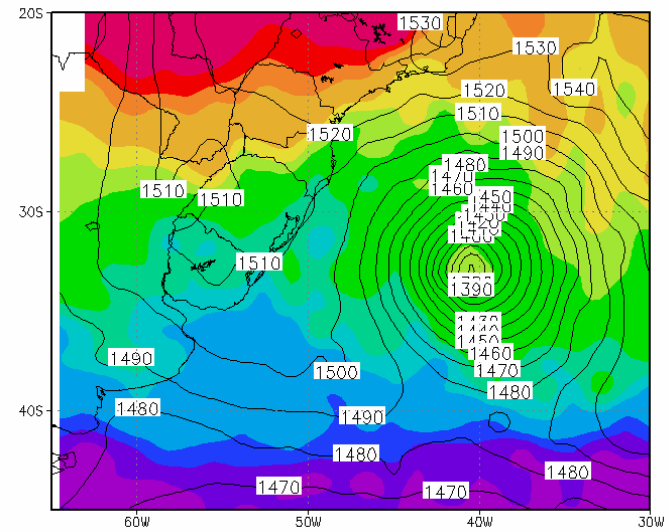

(b)

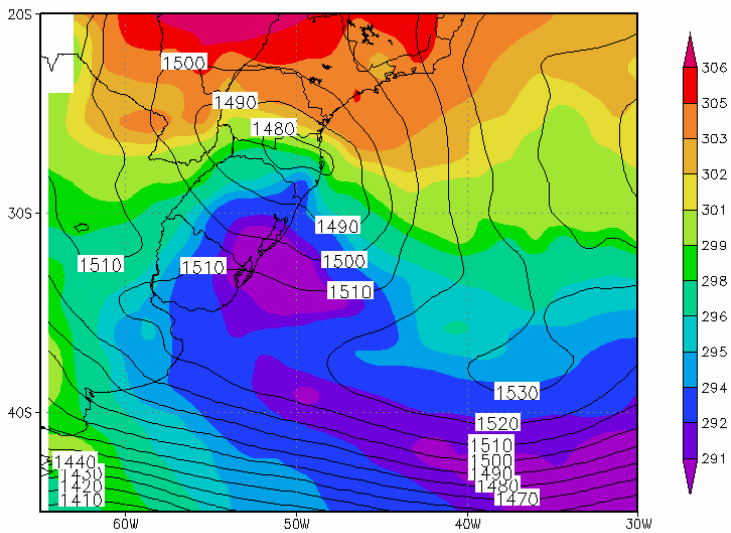

(d)

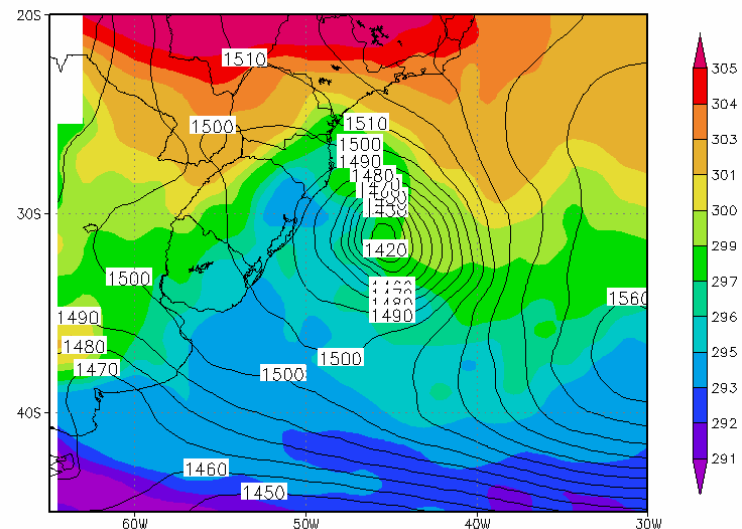

(f)

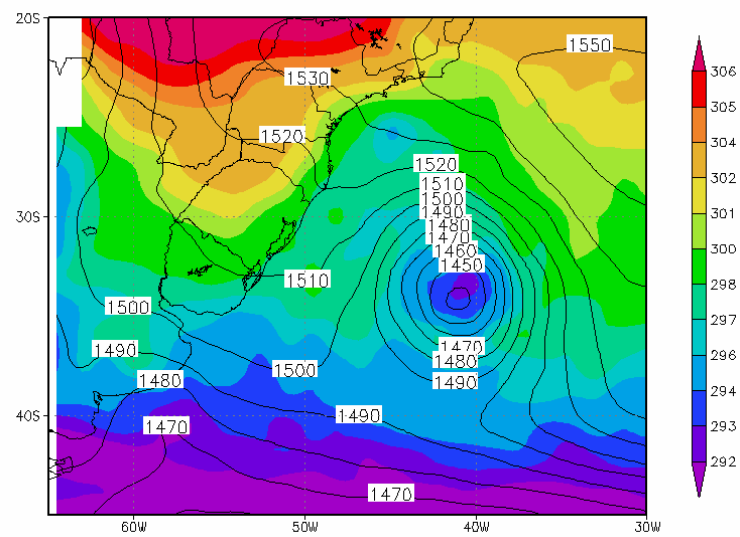

Figura 4.46: Altura geopotencial (linha contínua, em m) e temperatura do ar (sombreado, em K) em $850 \mathrm{hPa}$, para o (a),(c),(e) EXPCOM00 e (b),(d),(f) EXPSEM00, para os dias 29, 30 e 31 de maio de 1997 às 0000 UTC. 


\subsubsection{Perfil de aquecimento diabático}

A figura 4.47a mostra os perfis verticais de aquecimento diabático médio na área que cobre todo o ciclone 1, às 1200 UTC de 29 de maio de 1997, nas duas simulações. A linha contínua, o perfil de aquecimento no EXPCOM97, mostra aquecimento na baixa troposfera (até $800 \mathrm{hPa}$ ) que resulta do fluxo de calor sensível de superfície. Este aquecimento não ocorre no EXPSEM97 (linha tracejada).

(a)

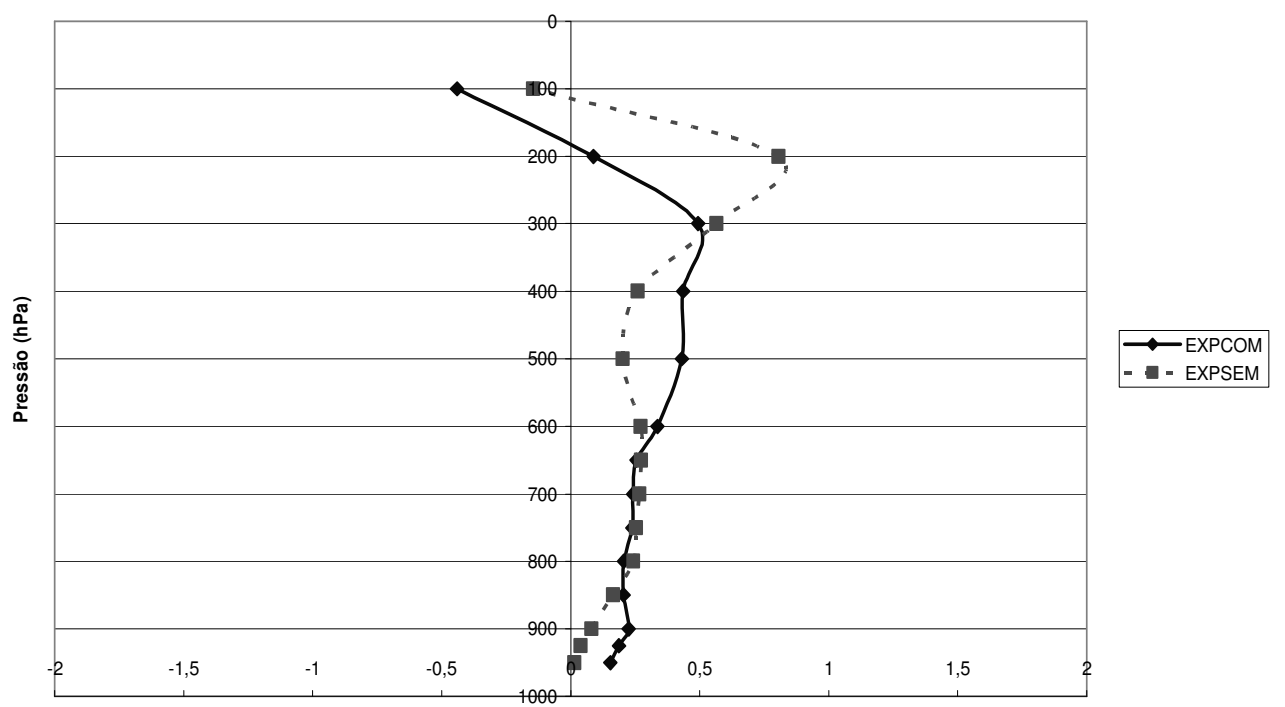

(b)

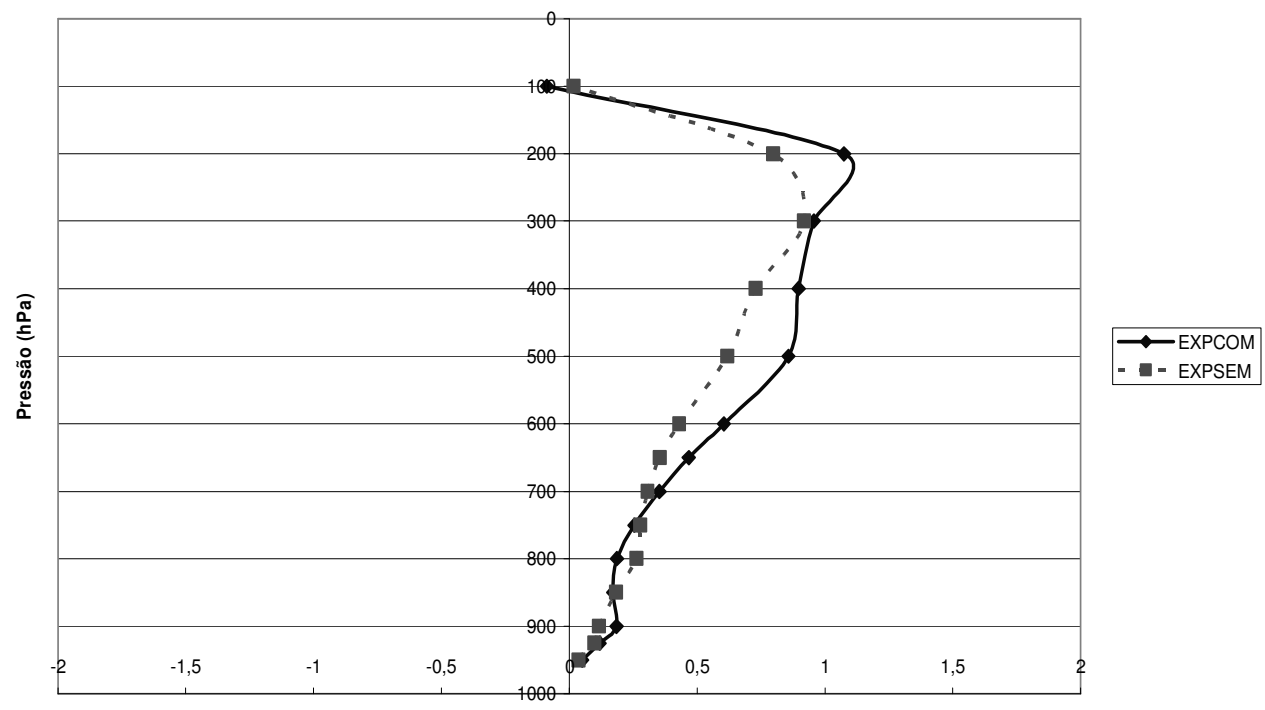

Figura 4.47: Perfis verticais médios na área de aquecimento diabático $\left(\mathrm{Kh}^{-1}\right)$ (a) para o dia 29 de maio de 1997 às $1200 \mathrm{UTC}$, entre $48^{\circ} \mathrm{W}-35^{\circ} \mathrm{W}$ e $32^{\circ} \mathrm{S}-25^{\circ} \mathrm{S}$ no caso EXPCOM97 (linha contínua) e entre $50^{\circ} \mathrm{W}-40^{\circ} \mathrm{W}$ e $30^{\circ} \mathrm{S}-22^{\circ} \mathrm{S}$ no EXPSEM97 (linha tracejada) e (b) para o dia 13 de abril de 2000, $1200 \mathrm{UTC}$, entre $51^{\circ} \mathrm{W}$ e $41^{\circ} \mathrm{W}$ e $33^{\circ} \mathrm{S}$ e $26^{\circ} \mathrm{S}$ para o EXPCOM00 e o EXPSEM00. 
Embora o ciclone 1 não se desenvolva sob condições tão específicas como nos experimentos de MAK (1998), o aquecimento em baixos níveis pode ser um dos processos favoráveis à ciclogênese, conforme mencionado anteriormente. Entre 800 e 600 hPa, não há grande diferença no aquecimento entre as duas simulações, implicando que a convecção rasa na presença e ausência de FCSL foi semelhante. Em médios níveis, entre 600 e 300 hPa, o EXPCOM97 apresenta maior aquecimento, resultante da condensação associada a movimentos verticais mais intensos e maior disponibilidade de vapor d'água. O pico de aquecimento diabático em $200 \mathrm{hPa}$, no EXPSEM97, deve estar associado a processos na alta troposfera, como a ondulação da tropopausa (Hirschberg e Fritsch, 1991), que pode ajudar na formação de frentes em altos níveis.

O perfil vertical de aquecimento diabático para as 1200 UTC do dia 13 de abril de 2000 (fig. 4.47b) mostra diferenças menores entre o EXPCOM00 e o EXPSEM00 próximo à superfície, mais uma vez evidenciando a diferença de impacto dos fluxos nos dois sistemas estudados. O aquecimento é muito semelhante na baixa troposfera, indicando que o efeito direto do fluxo de calor sensível é menor neste caso do que no ciclone 1, e assim a instabilização pela concentração de calor em baixos níveis não, também, alteraria significativamente o desenvolvimento.

Por volta de $800 \mathrm{hPa}$, o maior aquecimento diabático no EXPSEM está ssociado à maior taxa de condensação rasa, enquanto a maior liberação de calor latente por condensação ocorre, no EXPCOM00, na média e alta troposfera (acima de $600 \mathrm{hPa}$ ). 


\subsection{SUMÁRIO, CONCLUSÕES E SUGESTÕES}

Este trabalho estudou o impacto dos fluxos de calor sensível e latente (FCSL) entre oceano e atmosfera no desenvolvimento de dois ciclones sobre o oceano Atlântico, na costa do sul do Brasil. O ciclone 1 desenvolveu-se no dia 27 de maio e se manteve até o dia 07 de junho de 1997, e caracterizou-se por fortes FCSL, desenvolvimento em ambiente de fraca baroclinia e a leste de um cavado em médios níveis pouco profundo. Este ciclone apresentou características de um sistema do tipo Shapiro-Keyser, com as frentes fria e quente orientadas em forma de $\mathrm{T}$ e uma fratura na frente fria, além de uma seclusão quente no final do ciclo de vida. O sistema sofreu forte influência dos processos de superfície, iniciando seu desenvolvimento em baixos níveis e se propagando para níveis superiores. O ciclone 2, que ocorreu entre 13 e 16 de abril de 2000, apresentou intensidade menor que o ciclone 1 e sua formação esteve mais associada a processos dinâmicos e adiabáticos (zona baroclínica mais intensa, baixa desprendida em $500 \mathrm{hPa}$, intrusão de vorticidade potencial em altos níveis), com a circulação ciclônica propagando-se de níveis médios para a superfície. Contou também com FCSL menos intensos do que o ciclone 1.

Foram realizadas duas simulações utilizando o modelo WRF versão 2.2, para cada evento, uma delas com a física completa do modelo e a outra excluindo os FCSL. Através destas simulações, foram comparados trajetória, estrutura vertical e mecanismos de aprofundamento dos sistemas.

Os experimentos incluindo FCSL simularam o deslocamento dos dois ciclones de forma semelhante à reanálise Era-Interim. Porém, a intensidade dos sistemas foi superestimada, assim como os FCSL comparados à reanálise WHOI. Estas duas características devem estar associadas, pois fluxos de calor e umidade mais intensos podem favorecer o aprofundamento de ciclones, intensificando os ventos, e estes por sua vez reforçam ainda mais os fluxos. Comparada à reanálise WHOI, a distribuição espacial dos FCSL foi bem representada durante toda a simulação. Para os dois ciclones, os FCSL foram mais intensos no setor frio, distribuição que difere de DAL PIVA et al. (2008), onde os fluxos mais intensos ocorreram no setor quente do ciclone.

O ciclone 1 apresentou maior intensificação, maior tempo de vida e trajetória mais longa quando incluídos os FCSL. Enquanto na presença de FCSL o ciclone apresentou deslocamento típico para sudeste (mantendo-se a leste do cavado em níveis médios), na ausência desta forçante o ciclone deslocou-se para nordeste. Esta grande diferença na 
trajetória na ausência dos FCSL resultou principalmente de mudanças no padrão de advecção de temperatura em baixos níveis no início do desenvolvimento do sistema, além de diminuição na convergência em baixos níveis sobre o oceano, em toda a região do ciclone. Esta redução poderia ser explicada pela ausência do aquecimento via calor sensível na camada próxima à superfície. O deslocamento diferenciado do ciclone e a ausência de atividade convectiva intensa induziram o desacoplamento entre os baixos e médios níveis da atmosfera, e assim o sistema na ausência de FCSL recebeu menor suporte de escala sinótica para seu aprofundamento. Em baixos níveis, a ausência do fluxo de calor sensível aumentou a estabilidade estática em toda a região do ciclone, enfraquecendo o fluxo vertical de momento e os gradientes horizontais de tensão do vento. Como consequência, diminuiu a convergência de massa devido ao transporte de Ekman nas regiões frontais (especialmente na frente quente), enfraquecendo o aquecimento por convecção na média troposfera e o abaixamento de pressão em superfície, o que concorda com resultados teóricos obtidos por NUSS (1989). O ciclone 1 se desenvolveu no setor quente de uma onda térmica em $850 \mathrm{hPa}$, mas ainda assim fluxos de calor sensível positivos na camada superficial reforçaram o aquecimento. O perfil vertical de aquecimento diabático médio na área do ciclone 1 na presença de FCSL mostrou aquecimento por calor sensível nos baixos níveis da atmosfera (uma situação favorável à ciclogênese, conforme ROEBBER, 1989), e o máximo aquecimento ocorreu na alta troposfera ( 300 hPa) associado à convecção profunda. Na fase madura, o desenvolvimento vertical do ciclone induziu uma circulação ciclônica fechada com núcleo quente em $500 \mathrm{hPa}$, em sua fase barotrópica equivalente. Na simulação sem FCSL, a baixa atmosfera se manteve mais fria e o máximo aquecimento diabático ocorreu em $200 \mathrm{hPa}$, pelo abaixamento da tropopausa.

O ciclone 2 manteve a mesma trajetória na presença ou na ausência de FCSL. A advecção de temperatura em baixos níveis apresentou pequenas diferenças em magnitude entre os dois experimentos. No entanto, a circulação ciclônica não mostrou grande diferença de posicionamento e estrutura, resultando em um padrão espacial de advecção de temperatura em baixos níveis semelhante nas simulações com e sem FCSL. Esta semelhança na circulação seria atribuída ao fato de o ciclone 2 (ao contrário do ciclone 1), se desenvolver sob forte influência dos médios níveis. A convergência de massa devido ao calor sensível foi grande, mas se concentrou na parte central do ciclone, associada à maior intensidade do sistema. Os FCSL apresentaram menor intensidade do que no ciclone 1, e portanto tiveram menor impacto na convergência do vento em baixos níveis. Na ausência dos FCSL, a baixa desprendida em $500 \mathrm{hPa}$ foi mais intensa e duradoura, pois a menor atividade convectiva favoreceu a manutenção da estrutura de núcleo frio e impediu a formação de anomalia de vorticidade 
potencial positiva, que seria responsável pelo enfraquecimento da circulação ciclônica. Embora a ausência dos FCSL altere pouco a trajetória do ciclone 2, a intensidade foi bastante modificada: na presença de FCSL, o sistema se aprofundou mais, a partir dos mecanismos de convergência de Ekman e aquecimento da troposfera pelos fluxos de calor sensível. A convergência de Ekman neste ciclone como proposto por NUSS (1989) para um ciclone idealizado intenso, mostrando que este mecanismo pode ser observado em ciclones reais e também em sistemas com menores taxas de aprofundamento. $\mathrm{O}$ perfil de aquecimento diabático no ciclone 2 mostrou pequenas diferenças em baixos níveis, indicando que a injeção de calor sensível nestes níveis não foi um mecanismo relevante para o abaixamento da pressão. A presença de FCSL gerou uma circulação mais intensa, e assim o aquecimento por convecção que ocorre por volta de $800 \mathrm{hPa}$ (na ausência de FCSL) desloca-se para a média troposfera. Entre 700 e $200 \mathrm{hPa}$, o aquecimento diabático na presença de FCSL foi mais intenso.

A simulação do ciclone 2 onde os FCSL foram eliminados apresentou uma intensificação mais próxima da reanálise Era-Interim do que a simulação com FCSL. Uma explicação para isto é a superestimativa destes fluxos pelo WRF, fornecendo maior energia para o sistema e induzindo maior aprofundamento. Além disso, não se pode descartar a possibilidade de subestimativa da intensidade dos ciclones na reanálise, devido à escassez de dados observados sobre o oceano.

A comparação entre o impacto dos FCSL nos dois ciclones estudados mostra que este ocorre de diferentes formas e intensidades, dependendo das características dos sistemas. Enquanto muitos trabalhos evidenciam o impacto dos FCSL na intensidade e estrutura em baixos níveis (especialmente de ciclones intensos), os ciclones 1 e 2 deste trabalho mostram que a ausência dos FCSL pode alterar a estrutura em níveis médios da troposfera, modificando inclusive a trajetória e o tempo de vida dos sistemas (como o ciclone 1).

Uma sugestão para trabalhos futuros seria a extensão deste estudo para outros ciclones, comparando casos não explosivos entre si e com ciclones explosivos. Além disso, podem ser realizados experimentos numéricos que separem os efeitos devido aos fluxos de calor latente e sensível, e que alterem a temperatura da superfície do mar para estudar o acoplamento entre a temperatura da baixa troposfera e do oceano adjacente. Uma investigação importante seria avaliar como outras parametrizações de FCSL em superfície disponíveis no WRF impactariam os ciclones simulados, além de verificar como outras parametrizações simulariam mais realísticamente a intensidade dos FCSL. 


\section{REFERÊNCIAS BIBLIOGRÁFICAS}

ADCROFT, A.J.; HILL C.N. e MARSHALL, J.C. A New Treatment of the Coriolis Terms in C-Grid Models at Both High and Low Resolutions. Monthly Weather Review, v. 127, p. 1928-1936, 1999.

ARAKAWA, A. e LAMB, V. R. Computational design of the basic dynamical processes of the UCLA general circulation model. Methods Computational Physics, v. 17, p. 173-265, 1997.

ATLAS, R. (1987) The role of oceanic fluxes and initial data in the numerical prediction of an intensive coastal storm. Dynamics of Atmospheres and Oceans, v. 10, p. 359-388, 1987.

BARRY, L.; CRAIG, G. C. e THUBURN, J. Poleward heat transport by the atmospheric heat engine. Nature, v. 415, p. 774-777, 2002.

BERRISFORD, P.; DEE, D.; FIELDING, K.; FUENTES, M.; KALLBERG, P.; KOBAYASHI, S. e UPPALA, S. The ERA-Interim archive, 2009, ERA Report Series, ECMWF, ECMWF Publisher, Shinfield Park, Reading, 2009.

BIROL KARA, A.; WALLCRAFT, A. J.; METZGER, E. J.; HURLBURT, H. E. Wind Stress Drag Coefficient Over the Global Ocean. . Journal of Climate, v. 20, p. 5856-5864, 2007.

BJERKNES, J. On the Structure of Moving Cyclones. Geof. Publ., v. 1(2), p. 1-8, 1919

BJERKNES, J. e SOLBERG H. Life Cycle of Cyclones and the Polar Front Theory of Atmospheric Circulation. Geof. Publ., v. 3 (1), p. 3-18, 1922.

BOSART, L. F. e LIN S. C. A diagnostic analysis of the Presidents' day storm of February 1979. Monthly Weather Review, v. 112, p. 2148-2177, 1984.

BOUTLE, I. A. Boundary-Layer Processes in Mid-latitude Cyclones. Tese (Doutorado em Meteorologia) - University of Reading, 2009.

BLUESTEIN, H. (1993), Synoptic-Dynamic Meteorology in Midlatitudes: Principles of Kinematics and Dynamics, vol. 1, 431 pp., Oxford University Press. New York. 
BRANSCOMBE, L. E.; GUTOWSKI, W. J. e STEWART, D. E. Effect of surface fluxes on the nonlinear development of baroclinic waves. Journal of Atmospheric Sciences, v. 46, p. 460-475, 1989.

BUSINGER, S.; GRAZIANO, T. M.; KAPLAN, M. L.; ROZUMALSKI, R. A. Cold-air cyclogenesis along the Gulf-Stream front: investigation of diabatic impacts on cyclone development, frontal structure, and track, Meteorology and Atmospheric Physics, v. 88, p. 65-90, 2005.

CAMPOS, C. N. Estudo da frontogênese em um ciclone do tipo Shapiro-Keyser. Dissertação (Mestrado em Meteorologia) - Instituto Nacional de Pesquisas Espaciais, São José dos Campos, 1999.

CARLSON, T., Mid-Latitude Weather Systems., Harper Collins, 507 pp, 1998.

CARRERA, M.L., GYAKUM, J.R. e ZHANG, D.L. A Numerical Case Study of Secondary Marine Cyclogenesis Sensitivity to Initial Error and Varying Physical Processes. Monthly Weather Review, v. 127, p. 641-660, 1999.

CHANG, S. W.; HOLT, T. R.; SASHEGYI, K. D. A numerical study of the ERICA IOP 4 marine cyclone. Monthly Weather Review, v. 124, n. 1, p. 27-46, 1996.

CHEN, T.C.; CHANG, C.B. e PERKEY, D.J. Numerical Study of an AMTEX'75 Oceanic Cyclone. Monthly Weather Review, v. 111, p. 1818-1829, 1983.

DA ROCHA, R. P. Impacto de Parametrizações de Convecção em Ciclogênese sobre o Oceano. Tese (Doutorado em Meteorologia) - Instituto Nacional de Pesquisas Espaciais, São José dos Campos, 1999.

DAL PIVA, E. Estudo de caso sobre o papel dos fluxos de calor latente e sensível em superfície em processos de ciclogênese de costa leste ocorrido na costa da América do Sul. Tese (Mestrado em Meteorologia) - Instituto Nacional de Pesquisas Espaciais, São José dos Campos, 2001.

DAL PIVA, E., MOSCATI, M. C.L. e GAN, M. A. Papel dos fluxos de calor latente e sensível em superfície associados a um caso de ciclogênese na costa leste da América do Sul. Revista Brasileira de Meteorologia, v. 23, n. 4, p. 450-476, 2008.

DANARD, M. B. e ELLENTON, G. E., 1980, Physical influences on East coast cyclogenesis, Atmosphere-Ocean, v. 18, p. 65-82, 1980. 
DAVIES, H.C. Limitations of Some Common Lateral Boundary Schemes used in Regional NWP Models. Monthly Weather Review, v. 111, p. 1002-1012, 1983.

DUDHIA, J. Numerical study of convection observed during the winter monsoon experiment using a mesoscale two-dimensional model, Journal of Atmospheric Sciences, v. 46, p. 3077-3107, 1989.

DYER, A. J. e HICKS, B. B. Flux-gradient relationships in the constant flux layer, Quarterly Journal of the Royal Meteorological Society, v. 96, p. 715-721, 1970.

FAIRALL, C. W.; BRADLEY, E. F.; ROGERS, D. P.; EDSON, J. B. e YOUNG, G. S. Bulk parameterization of air-sea fluxes for Tropical Ocean-Global Atmosphere Coupled-Ocean Atmosphere Response Experiment. Journal of Geophysical Research, v. 101, C2, p. 37473764, 1996b

; BRADLEY, E. F.; HARE, J. E.; GRACHEV, A. A. e EDSON, J. B. Bulk parameterization on air-sea fluxes: Updates and verification for the COARE algorithm. Journal of Climate, v. 16, p. 571-591, 2003.

FANTINI, M. The Influence of Heat and Moisture Fluxes from the Ocean on the Development of Baroclinic Waves. Journal of Atmospheric Sciences, v. 47, p. 840-855, 1990.

FLEAGLE, R.G. e NUSS, W.A. The Distribution of Surface Fluxes and Boundary Layer Divergence in Midlatitude Ocean Storms. Journal of Atmospheric Sciences, v. 42, p. 784 $799,1985$.

GAN, M. A. e RAO, B. V. Surface ciclogenesis over South America. Monthly Weather Review, v. 119, p. 293-302, 1991.

GAN, M. A. Ciclone Catarina: análise sinótica. In: III SIMPÓSIO INTERNACIONAL DE CLIMATOLOGIA, Canela - RS, 18 a 21 de outubro de 2009.

GARREAUD, R.D. e FUENZALIDA, H. A. The Influence of the Andes on Cutoff Lows: A Modeling Study. Monthly Weather Review, v. 135, p. 1596-1613, 2007.

GODSKE, C. L.; BERGERON, T.; BJERKNES, J. e BUNDGAARD, R. C. Dynamic Meteorology and Weather Forecasting. Amer. Meteor. Soc., 800 pp, 1957. 
GRELL, G. A., e DÉVÉNYI, D. A generalized approach to parameterizing convection combining ensemble and data assimilation techniques, Geophysics Research. Letters., v. 29(14), p. 1693, 2002.

GUTOWSKI, W.J., e JIANG, W. Surface-Flux Regulation of the Coupling between Cumulus Convection and Baroclinic Waves. Journal of Atmospheric Sciences, v. 55, p. 940-953, 1998.

GUYMER, T. H; BUSINGER, J.A.; KATSAROS, K.B.; SHAW, W.J.; TAYLOR, P.K.; LARGE, W.G. e PAYNE, R.E. Transfer processes at the air-sea interface. Phil. Trans. R. Soc. Lond. A308, p. 253-273, 1983.

GYAKUM, J.R. On the Evolution of the $Q E$ II Storm. II: Dynamic and Thermodynamic Structure. Monthly Weather Review, v. 111, 1156-1173, 1983 b.

HALTINER, G J. The effects of sensible heat exchange on the dynamics of baroclinic waves (Sensible heat transfer influence on dynamic stability of harmonic perturbations superimposed on zonal current, using Lorentz two-level model). Tellus, 19, n. 2, p. 183-198, 1967.

HIRSCHBERG, P. A. e FRITSCH, J. M. Tropopause undulations and the development of extratropical cyclones, Part I: Overview and observations from a cyclone event, Monthly Weather Review, v. 119, p. 496-517, 1991.

HOLT, T. R. e CHANG, S. W. A numerical investigation of the effects of timing of diabatic processes in the coastal cyclogenesis of GALE IOP 2. Monthly Weather Review, v. 121, p. 1007-1029, 1993.

HOLTON, J. R. An Introduction to Dynamic Meteorology, $4^{\mathrm{a}}$ ed., 529 pp., Academic Press, United States of America, 2004.

HOSKINS, B. J.; McINTYRE, M. E. e ROBERTSON, W. On the use and significance of isentropic potential vorticity maps, Quarterly Journal of the Royal Meteoroogical Society, v. 111 (470), p. 877-946, 1985.

HOSKINS, B. J. e HODGES, K. I. A New on Southern Hemisphere Storm Tracks. Journal of Climate, v. 18, p. 4108-4129, 2005.

HUFFMAN, G.J.; ADLER, R.F.; MORRISSEY, M.; BOLVIN, D.T.; CURTIS, S.; JOYCE, R.; McGAVOCK, B.; SUSSKIND, J. Global Precipitation at One-Degree Daily Resolution from Multi-Satellite Observations. Journal of Hydrometeorology, 2, p. 36-50, 2001. 
IWABE, C. M. N., e DA ROCHA, R. P. An event of stratospheric air intrusion and its associated secondary surface cyclogenesis over the South Atlantic Ocean, Journal of Geophysical Research, v. 114, 2009.

KANAMITSU, M., et al 2002: NCEP-DOE AMIP-II Reanalysis (R-2). Bull. Am. Met. Soc., v. 83, p. 1631-1643, 2002.

KIM, J. e MAHRT, L. (1992), Simple formulation of turbulent mixing in the stable free atmosphere and nocturnal boundary layer. Tellus, Stockholm, v. 44, série A, p. 381-394, 1992.

KUO, Y.-H. e REED, R.J. Numerical simulation of an explosively deepening cyclone in the Eastern Pacific. Monthly Weather Review, v. 116, n. 10, p. 2081-2105, 1988.

KUO, Y.H., e LOW-NAM, S. Prediction of Nine Explosive Cyclones over the Western Atlantic Ocean with a Regional Model. Monthly Weather Review, v. 118, p. 3-25, 1990.

KUO, Y. H., REED, R. J.; LOW-NAM, S. Effects of surface energy fluxes during the early development and rapid intensification stages of seven explosive cyclone in the western Atlantic. Monthly Weather Review, v. 119, p. 457-476, $1991 \mathrm{~b}$.

LAGOUVARDOS, K., KOTRONI, V.; DEFER, E. The 21-22 January 2004 explosive cyclogenesis over the Aegean Sea: Observations and model analysis, Quarterly Journal of the Royal Meteorological Society, v. 133, p. 1519-1531, 2007.

LESLIE, L.M.; HOLLAND, G. J. e LYNCH, A. H. Australian East-Coast Cyclones. Part II: Numerical Modeling Study. Monthly Weather Review, v. 115, p. 3037-3054, 1987.

LIOU, C. S. e ELSBERRY, R. L. Heat budgets of analyses and forecasts of an explosively deepening maritime cyclone. Monthly Weather Review, v. 115, n. 9, p. 1809-1824, 1987.

LIU, W. T.; KATSAROS, K. B. e BUSINGER, J. A. Bulk parameterization of air-sea exchanges of heat and water vapor including the molecular constraints at the interface. Journal of Atmospheric Sciences, v. 36, p. 1722-1735, 1979.

MATZNER, R. A. Dictionary of Geophysics, Astrophysics and Astronomy, CRC Press, 524 pp, 2001. 
McINNES, K.L.; McBRIDE, J.L. e LESLIE, L.M. Cold Fronts over Southeastern Australia: Their Representation in an Operational Numerical Weather Prediction Model. Weather and Forecasting, v. 9, p. 384-409, 1994.

METAXAS, D. A. Evidence on the importance of diabatic heating as a divergence factor in the Mediterranean, Meteorology and Atmospheric Physics, v. 27, n. 1, p. 69-80, 1978.

MLAWER, E. J.; TAUMBMAN, S. J.; BROWN, P. D.; IACONO, M. J. e CLOUGH, S. A. Radiative transfer for inhomogeneous atmosphere: RRTM, a validated correlated-k model for the longwave. Journal of Geophysical Research, v. 102 (D14), 1997.

MONIN, A.S. e OBUKHOV, A.M. Basic laws of turbulent mixing in the surface layer of the atmosphere. Contrib. Geophys. Inst. Acad. Sci., USSR, v. 151, p. 163-187, 1954.

NECCO, G. V. Comportamiento de Vortices Ciclonicos En El Area Sudamerica Durante El FGGE: Ciclogenesis. Meteorologica, v. 13 (1), p. 7-19, 1982a.

NEIMAN, P. J., e SHAPIRO, M. A. The life cycle of an extratropical marine cyclone. Part I: Frontal-cyclone evolution and thermodynamic air-sea interaction. Monthly Weather Review, v. 121, p. 2153-2176, 1993.

NIETO, R.; GIMENO, L.; DE LA TORRE, L. ; RIBERA, P.; GALLEGO, D.; GARCIAHERRERA, R.; GARCIA, J.A.; NUÑEZ, M.; REDAÑO, A. e LORENTE, J. Climatological Features of Cutoff Low Systems in the Northern Hemisphere. Journal of Climate, v. 18, p. 3085-3103, 2005.

NOH, Y.; CHEON, W. G; CHONG, S. Y.; RAASCH, S. Improvement of the K-profile Model for the Planetary Boundary Layer based on Large Eddy Simulation Data. Boundary Layer Meteorology, v. 107, n. 2, p. 401-427, 2003.

NUSS, W.A. e ANTHES, R.A. A Numerical Investigation of Low-Level Processes in Rapid Cyclogenesis. Monthly Weather Review, v. 115, p. 2728-2743, 1987.

Air-Sea Interaction Influences on the Structure and intensification of an Idealized Marine Cyclone. Monthly Weather Review, v. 117, p. 351-369, 1989.

ODA, T. O. Efeitos da Distribuição Espaço-Temporal da Temperatura do Mar no Desenvolvimento de Ciclones Extratropicais. Tese (Doutorado em Meteorologia) - UFRJ, Rio de Janeiro, 2005. 
ORLANSKI, I. Localized Baroclinicity: A source for meso-alpha cyclones. Journal of Atmospheric Sciences, v. 43, p. 2857-2885, 1986.

PALMÉN, E. e NEWTON, C. W. (1969), Atmospheric Circulation Systems: Their Structure and Physical Interpretation. New York: Academic Press, 603 p., 1969.

PAULSON, C. A. The mathematical representation of wind speed and temperature profiles in the unstable atmospheric surface layer. Journal of Applied Meteorology, v. 9, p. 857-861, 1970 .

PETERSON, R.G. e STRAMMA, L. Upper-level circulation in the South Atlantic Ocean. Progress in Oceanogr, v. 26, p. 1-73, 1991.

PETTERSSEN, S. Weather Analysis and Forecasting. $2^{\mathrm{a}}$ ed., vol. 1 McGRAW-HILL, New York, 428 p., 1956

REED, R. J. e SIMMONS, A. J. Numerical simulation of an explosively deepening cyclone over the north Atlantic that was unaffected by concurrent surface energy fluxes. Weather and Forcasting, v. 6, n. 1, p. 117-122, 1991.

; GRELL, G. A. e Kuo, Y.-H. The ERICA IOP 5 Storm. Part II: sensitivity tests and further diagnosis based on model output. Monthly Weather Review, v. 121, n. 6, p. 1595$1612,1993$.

REBOITA, M. S. Ciclones Extratropicais sobre o Atlântico Sul: Simulação Climática e Experimentos de Sensibilidade. Tese (Doutorado em Meteorologia) - Instituto de Astronomia, Geofísica e Ciências Atmosféricas - IAG-USP, 2008.

REYNOLDS, R.W.; SMITH, T.M.; LIU, C.; CHELTON, D.B.; CASEY, K.S. e SCHLAX, M.G. Daily High-Resolution-Blended Analyses for Sea Surface Temperature. Journal of Climate, v. 20, p. 5473-5496, 2007.

ROEBBER, P.J. The Role of Surface Heat and Moisture Fluxes Associated with Large-Scale Ocean Current Meanders in Maritime Cyclogenesis. Monthly Weather Review, v. 117, p. 1676-1694, 1989.

SARDIE, J.M e WARNER, T. T. A numerical study of the development mechanisms of polar lows, Tellus, v. 37a(5), 460-477, 1985. 
MAK, M. Influence of Surface Sensible Heat Flux on Incipient Marine Cyclogenesis. Journal of Atmospheric Sciences, v. 55, p. 820-834, 1998.

SANDERS, F. e GYAKUM, J. R. Synoptic-Dynamic Climatology of the Bomb. Monthly Weather Review, v. 108, p. 1589-1606, 1980.

SCHULTZ, D.M., KEYSER, D. e BOSART, L.F. The Effect of Large-Scale Flow on LowLevel Frontal Structure and Evolution in Midlatitude Cyclones. Monthly Weather Review, v. 126, p. 1767-1791, 1998.

SHAPIRO, M.A e KEYSER, D. Fronts, jet streams and the tropopause. Extratropical Cyclones, the Erik Palmén Memorial Volume, Newton C.W. e Holopainen, E., Amer. Met. Soc., p. 167-191, 1990.

SINCLAIR, M. R. A climatology of cyclogenesis for the Southern Hemisphere. Monthly Weather Review, v. 123, p. 1601-1619, 1995.

SKAMAROCK, W.C; KLEMP, J. B.; DUDHIA, J.; GILL, D. O.; BARKER, D. M.; WANG, W.; POWERS, J. G. A Description of the Advanced Research WRF Version 2. NCAR Technical Notes, NCAR/TN-468+STR, 2005.

STEPHENS, G. L. Radiation profiles in extended water clouds. Part II: Parameterization schemes, Journal of Atmospheric Sciences, v. 35, p. 2123-2132, 1978.

STOELINGA, M. A Potential Vorticity-Based Study of the Role of Diabatic Heating and Friction in a Numerically Simulated Baroclinic Cyclone. Monthly Weather Review, v. 124, p. 849-874, 1996.

STULL, R. B. An Introduction to Boundary Layer Meteorology, 1st ed., 663 pp., Kluwer Academic Publishers, The Netherlands, 1989.

TROEN, I. e MAHRT, L. A simple model of the atmospheric boundary layer; sensitivity to surface evaporation. Boundary Layer Meteorology., v. 37, p. 129-148, 1986.

SUTCLIFFE, R. C., 1947: A Contribution to the Problem of Development.Quart. J. Roy. Meteor. Soc., 73, p. 370-383, 1947.

UCCELlinI, L. W.; PETERSEN, R. A.; F.BRILL, K.; KOCIN P. J. E. e TUCCILlO, J. J. (1987), Synergistic interactions between an upper-level jet streak and diabatic processes that 
influence the development of a low-level jet and a secondary coastal cyclone. Monthly Weather Review, v. 115, p. 2227-2261, 1987.

WAINER, I.; TASCHETTO, A.; SOARES, J.; DE OLIVEIRA, A.P.; OTTO-BLIESNER, B. e BRADY, E. Intercomparison of Heat Fluxes in the South Atlantic. Part I: The Seasonal Cycle. Journal of Climate, v. 16, p. 706-714, 2003.

WEBB, E. K. Profile relationships: The log-linear range, and extension to strong stability. Quarterly Journal of the Royal Meteorological Society, v. 96, p. 67-90, 1970.

YU, L.; JIN, X. e WELLER, R. A. Multidecade Global Flux Datasets from the Objectively Analyzed Air-sea Fluxes (OAFlux) Project: Latent and sensible heat fluxes, ocean evaporation, and related surface meteorological variables. Woods Hole Oceanographic Institution, OAFlux Project Technical Report. OA-2008-01, 64pp. Woods Hole. Massachusetts, 2008.

ZHANG, D. L. e ANTHES R. A. A high-resolution model of the planetary boundary layersensitivity tests and comparisons with SESAME-79 data. Journal of Applied Meteorology, v. 21, p. 1594-1609, 1982. 